\title{
Project Management from Simple to Complex
}




\section{Project Management from Simple to Complex}

[Author removed at request of original publisher]

UNIVERSITY OF MINNESOTA LIBRARIES PUBLISHING EDITION, 2016. THIS EDITION ADAPTED FROM A WORK ORIGINALLY PRODUCED IN 2010 BY A PUBLISHER WHO HAS REQUESTED THAT IT NOT RECEIVE ATTRIBUTION.

MINNEAPOLIS, MN 


\section{다 (1) (3) (2)}

Project Management from Simple to Complex by University of Minnesota is licensed under a Creative Commons Attribution-NonCommercial-ShareAlike 4.0 International License, except where otherwise noted.

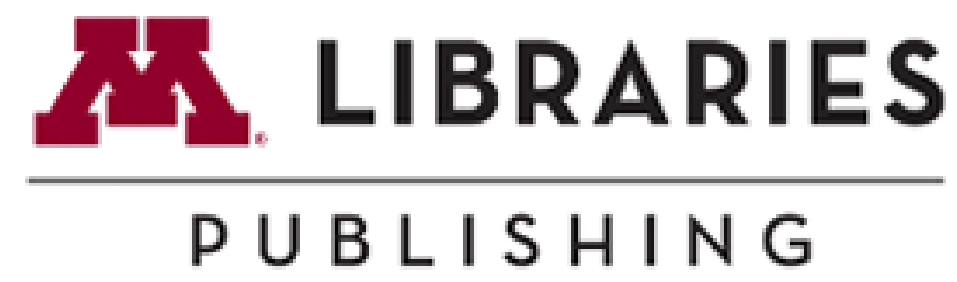

This book was produced using Pressbooks.com, and PDF rendering was done by PrinceXML. 



\section{Contents}

Publisher Information

Chapter 1: Introduction to Project Management

1.1 Project Management Defined

1.2 Project Defined

1.3 Project Context

$\begin{array}{ll}1.4 \text { Key Skills of the Project Manager } & 14\end{array}$

1.5 Introduction to the Project Management Knowledge Areas 17

$\begin{array}{ll}1.6 \text { Exercises } & 27\end{array}$

$\begin{array}{ll}1.7 \text { Web Exercise } & 28\end{array}$

$\begin{array}{lr}1.8 \text { Software and Technology Exercises } & 30\end{array}$

Chapter 2: Project Profiling

2.1 Using a Project Profile $\quad 46$

2.2 Project Profiling Models $\quad 49$

2.3 Complex Systems and the Darnall-Preston Complexity Index 51

2.4 Darnall-Preston Complexity Index Structure 56

$\begin{array}{ll}2.5 \text { Exercises } & 68\end{array}$

2.6 Software and Technology Exercise $\quad 69$

Chapter 3: Project Phases and Organization

$\begin{array}{ll}3.1 \text { Project Phases } & 75\end{array}$

$\begin{array}{ll}3.2 \text { Project Organization } & 79\end{array}$

3.3 Using the Darnall-Preston Complexity Index to Measure Organizational Complexity 91

$\begin{array}{ll}3.4 \text { Exercises } & 95\end{array}$

$\begin{array}{ll}\text { 3.5 Web Exercise } & 97\end{array}$

Chapter 4: Understanding and Meeting Client Expectations

4.1 Including the Client 100

4.2 Understanding Values and Expectations 103

$\begin{array}{ll}4.3 \text { Dealing with Problems } & 107\end{array}$ 
4.4 Nurturing a Feeling of Satisfaction

4.5 Exercises

Chapter 5: Working with People on Projects

5.1 Working with Individuals

5.2 Working with Groups and Teams

5.3 Creating a Project Culture

5.4 Exercises

5.5 Web Exercises

Chapter 6: Communication Technologies

6.1 Types of Communication 163

6.2 Selecting Software 170

6.3 Exercises 187

6.4 Web Exercise 188

6.5 Software and Technology Exercises

Chapter 7: Starting a Project

7.1 Project Selection

7.2 Project Scope

7.3 Project Start-Up

7.4 Alignment Process

7.5 Communications Planning

7.6 Exercises

7.7 Software and Technology Exercise

Chapter 8: Project Time Management

8.1 Types of Schedules

8.2 Elements of Time Management

8.3 Critical Path and Float

8.4 Managing the Schedule

8.5 Project Scheduling Software

8.6 Exercises 
Chapter 9: Estimating and Managing Costs

9.1 Estimating Costs 271

9.2 Managing the Budget $\quad 279$

9.3 Exercises 289

9.4 Software and Technology Exercise 291

Chapter 10: Managing Project Quality

10.1 Quality and Statistics 295

10.2 Development of Quality as a Competitive Advantage 302

10.3 Relevance of Quality Programs to Project Quality 311

10.4 Planning and Controlling Project Quality 315

10.5 Assuring Quality 324

10.6 Exercises 326

10.7 Software and Technology Exercises 327

Chapter 11: Managing Project Risk

11.1 Defining Risk 334

11.2 Risk Management Process 337

11.3 Project Risk by Phases 345

11.4 Project Risk and the Project Complexity Profile 350

11.5 Exercises 353

11.6 Web Exercise $\quad 354$

Chapter 12: Project Procurement and Closure

12.1 Identifying the Need for Resources Outside the Organization 360

12.2 Procurement Plan 363

12.3 Selecting the Type of Contract 368

12.4 Procurement Process 377

$\begin{array}{ll}12.5 \text { Project Closure } & 384\end{array}$

12.6 Exercises 391

12.7 Web Exercises 392

$\begin{array}{ll}\text { Project Management from Simple to Complex } & 400\end{array}$ 


\section{Publisher Information}

Project Management from Simple to Complex is adapted from a work produced and distributed under a Creative Commons license (CC BY-NC-SA) in 2010 by a publisher who has requested that they and the original author not receive attribu-

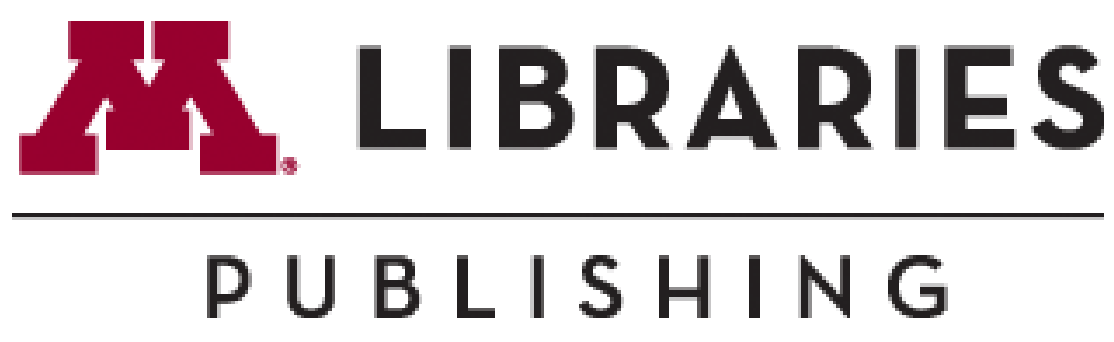
tion. This adapted edition is produced by the University of Minnesota Libraries Publishing through the eLearning Support Initiative.

This adaptation has reformatted the original text, and replaced some images and figures to make the resulting whole more shareable. This adaptation has not significantly altered or updated the original 2010 text. This work is made available under the terms of a Creative Commons Attribution-NonCommercialShareAlike license. 


\section{Chapter 1: Introduction to Project Management}

This chapter provides an overview of project management, defining both projects and project management and exploring the difference between project management and operations management. Advances in technology are driving the speed of innovation and the ability of organizations to shorten the time needed to develop and deliver new products and services that increase an organization's competitive advantage. This drive to develop new and unique products or services creates a perfect environment for the application of project management methodologies and skills. We also provide a brief overview of the knowledge areas of project management and the skills needed to be a successful project manager. 


\subsection{Project Management Defined}

\section{Learning Objectives}

1. Identify the Project Management Institute’s definition of project management.

2. Analyze and evaluate the role of client expectations in a project.

3. Define project scope.

"Project management is the application of knowledge, skills, tools, and techniques to project activities to meet the project requirements” (Project Management Institute, Inc., 2008). This simple definition represents a compromise that resulted from intense discussions within the Project Management Institute (PMI) during the 1980s. One of the priorities of PMI during this time was the development of project management as a profession. Although debate continues on whether project management is a profession with an enforceable code of conduct and other traditional criteria for recognition as a profession, the development of A Guide to the Project Management Body of Knowledge (PMBOK Guide) and the project management certifications that derived from these efforts helped promote the understanding and development of the project management field.

The discussion about what should be in the definition of project management included debates about the purpose of project management. Is the main purpose to meet client expectations or is the main purpose to meet the written specifications and requirements? This discussion around meeting project requirements was not easily settled. If it is assumed that the project client is the one who defines project requirements, then maybe project management is the application of knowledge, skills, tools, and techniques to meet client requirements or client expectations. PMI's definition of project management does provide a good understanding of project management, but it does not help us understand project success. For that, we must include the client.

Jack Meredith and Samuel Mantel (Meredith \& Mantel Jr., 2006) discussed project management in terms of producing project outcomes within the three objectives of cost, schedule, and specifications. Project managers are then expected to develop and execute a project plan that meets cost, schedule, and specification parameters. According to this view, project management is the application of everything a project manager does to meet these parameters. This approach to defining project management shares PMI's focus on the project outcomes in terms of requirements.

Meredith and Mantel added a fourth aspect of project management — the expectations of the client. One client-centered definition of project management is the application of knowledge, skills, tools, and techniques to meet or exceed the expectations of the client. This definition focuses on delivering a product or service to the client that meets expectations rather than project specifications. It is possible to meet all project specifications and not meet client expectations or fail to meet one or more specifications and still meet or exceed a client's expectation (Darnall, 1996). 
Meredith and Mantel discussed a tendency noted by Darnall (Darnall, 1996) that expectations often increase during the life of a project. Meredith and Mantel suggest that this is a form of scope increase. A project scope is a carefully crafted document that reflects the performance specifications of the project deliverables. Defining the project scope and managing scope change is a very different process from developing an understanding of a client's expectations and managing those expectations. Darnall focused on defining and managing client expectations as a critical project management skill that is distinct from scope development and management.

Client expectations encompass an emotional component that includes many client desires that are not easily captured within a specification document. Although closely correlated with project specifications, client expectations are driven by different needs. It is possible for a project team to exceed every project specification and end up with an unsatisfied client.

\section{Highway Project}

The Department of Highways in South Carolina was exploring ways to reduce the road construction costs and developed new contracting processes to allow the road builders to bring new ideas for cutting costs. On one project, the contractor proposed cost-cutting ideas throughout the life of the project. At each phase, the client accepted many of the ideas and then revised the budget. The client promoted the revised cost target of the project as an example of the success of the new process. By the end of the project, the final cost was less than 1 percent over the newest target. Although the total cost of the project was almost 10 percent less than the original cost projections and contract obligations, the success of the project was connected to the new expectations that developed during the life of the project. Even though this project performance exceeded the original goal, the client was disappointed.

The reverse is also true. A project can be late and over budget and the client can be satisfied. Although this may be counterintuitive, the response of a client to the events of a project is complex and goes beyond the data related in project specifications.

\section{Biotech Project}

A biotechnology company developed a new drug that proved to have a large market demand, and the team that developed the drug was assigned to build a new manufacturing facility to produce the drug. The project manager for the construction company that was awarded the contract to build the manufacturing facility managed the project effectively. Every request for a change in scope was approved, and the result was a 20 percent increase to the total cost of the project. On most projects, a 20 percent increase in the project cost would be considered poor performance. For the client's project team, who were accustomed to complex projects with a large number of unknown issues that increase the final cost of the project, a 20 percent overrun in cost was not unusual. Even though the project was 20 percent over budget, the client was happy. Client satisfaction is often tied to expectations about project performance. Identifying and managing those expectations is a primary responsibility of the project manager. 


\section{Key Takeaways}

- According to PMI, project management is the application of knowledge, skills, tools, and techniques to meet project requirements.

- The role of the client is controversial. Some clients include meeting or exceeding their expectations as part of project management.

- Project scope is a document that defines the work required to complete the project successfully.

\section{Exercises}

1. According to PMI, project management is the application of knowledge, tools, and techniques to meet project requirements.

2. According to Meredith and Mantel, a project should (three words) the expectations of the client.

3. If someone had asked you to define project management before you read this section, how would you have defined it? How did your definition differ from the PMI definition?

4. What aspect of project management was omitted from the PMI definition that is included in the definition proposed by Meredith and Mantel? If you were on the PMI decision-making body, would you vote to include it? Explain your choice.

5. What is meant by the statement "The response of the client to the events of the project may be counterintuitive"?

\section{Client Expectations}

Compare and contrast the highway and biotech examples previously described. Suggest an approach that might have prevented client disappointment in the highway project. Include the following in your answer:

- What are the differences between the two projects? Provide a bulleted list.

- Identify the single most important difference between the two projects that affected client satisfaction.

- Suggest an approach to managing client expectations in the highway project that might have resulted in meeting or exceeding expectations rather than disappointment.

\section{References}

Darnall, R. W., The World's Greatest Project (Newtown Square, PA: Project Management Institute, Inc., 1996), 48-54. 
Meredith, J. R. and Samuel J. Mantel, Jr., Project Management: A Managerial Approach (Hoboken, NJ: Wiley, 2006), 8.

Project Management Institute, Inc., A Guide to the Project Management Body of Knowledge (PMBOK Guide), 4th ed. (Newtown Square, PA: Project Management Institute, Inc., 2008), 6. 


\subsection{Project Defined}

\section{Learning Objectives}

1. Describe two defining characteristics of a project.

2. Organize projects within projects.

The Project Management Institute (PMI) defines a project by its two key characteristics. All projects are temporary and undertaken to create a product, service, or result that is unique (Project Management Institute, Inc., 2008). These two simple concepts create a work environment that mandates different management approach from that used by an operations manager, whose work is oriented toward continuous improvement of existing processes over longer periods of time. A project manager needs a different set of skills to both define and successfully execute temporary projects. Because projects are temporary, they have a defined beginning and end. Project managers must manage start-up activities and project closeout activities. The processes for developing teams, organizing work, and establishing priorities require a different set of knowledge and skills because members of the project management team recognize that it is temporary. They seldom report directly to the project manager and the effect of success or failure of the project might not affect their reputations or careers the same way that the success or failure of one of their other job responsibilities would.

The second characteristic of a project, the delivery of a unique product, service, or result, also changes the management approach to the work. A project manager must take time to understand the deliverables of a project, develop a plan for producing the deliverables in the time available, and then execute that plan.

Projects are also defined within the context of larger projects as the following example illustrates.

\section{National Energy Plan}

The National Energy Technology Laboratory laid out a plan for a national energy policy that had a clear and identifiable outcome_-providing reliable, affordable, and environmentally sound energy (National Energy Technology Laboratory, 2001). The details of this plan will be revised and updated, but the general goals are likely to remain unchanged. To accomplish these goals, the project requires the development of new technologies, complex scheduling and cost control, coordination of a large number of subcontractors, and skillful stakeholder management. Development of each of the major components became a project for the winning contractors within the larger project of providing reliable, affordable, and environmentally sound energy. Contractors for cleaner use of fossil fuels, conservation efforts, and development of renewable energy sources 
would manage major projects. Each project has to develop new technologies, manage a large number of subcontractors, and manage the stakeholders at the Department of Energy.

Each subcontractor or work unit becomes a project for that organization. The project is defined by the scope of work. In the energy policy, the scope of work included all activities associated with reducing use of fossil fuels and reliance on imported energy. Using our definition that a project is a temporary endeavor that creates a unique product or service, implementation of the energy policy would be a project that consists of other projects, such as development of the following:

- Wind power

- Solar power

- Electricity transmission

- Electricity storage

- New nuclear reactor design and installation

- Other renewable energy sources

- Biofuels

- Electric vehicles

- Nonpolluting use of coal and natural gas

- Environmental protection

\section{Key Takeaways}

- All projects are temporary and undertaken to create a product, service, or result.

- Projects can contain smaller projects.

\section{Exercises}

1. The project scope is the required to complete the project successfully.

2. According to PMI, all projects are and undertaken to create a product or service that is unique.

3. Projects can contain projects.

4. What are two defining characteristics of a project that distinguish it from a process?

5. If you were planning to move from your current apartment or home to another location, would this qualify as a project? Explain your answer.

Projects within Projects 
Choose a large public works project such as the construction of a new high school. Identify at least five phases to this project that could be treated as projects within a project. Specifically state how each project meets the definition of a project, and describe the product, service, or result of each project and why it is temporary.

\section{References}

National Energy Technology Laboratory, "Reliable, Affordable, and Environmentally Sound Energy for America’s Future,” The Energy Lab, 2001, http:/www.netl.doe.gov/publications/press/2001/nep/ nep.html (accessed June 18, 2009).

Project Management Institute, Inc., A Guide to the Project Management Body of Knowledge (PMBOK Guide), 4th ed. (Newtown Square, PA: Project Management Institute, Inc., 2008), 5. 


\subsection{Project Context}

\section{Learning Objectives}

1. Identify the effect of organization type on time horizons.

2. Compare project management and operations management.

3. Describe the organizational options for managing projects.

The project is affected by the type of organization in which the project is conducted and how the organization is organized to manage projects.

\section{Organizational Priorities}

Organizations fulfill a societal role to meet economic, religious, and governance functions. Local factories, churches, and hospitals are all organizations that provide some social or community need. Factories create wealth and jobs, churches provide spiritual and common social needs for communities, and government organizations provide regulations and services that allow for an orderly society. These organizations have different views of time and each organization develops an operational approach to accomplishing the purpose of the organization over that time horizon. For example, a religious group might begin construction of a cathedral that would take several lifetimes to complete, government performance is reviewed at election time, and a publicly owned company must justify its use of money each year in the annual report.

Organizations operate to effectively and efficiently produce the product or service that achieves the organization's purpose and goals as defined by the key stakeholders - those who have a share or interest. An organization seeks to develop stable and predictable work processes and then improve those work processes over time through increased quality, reduced costs, and shorter delivery times. Total quality management, lean manufacturing, and several other management philosophies and methodologies have focused on providing the tools and processes for increasing the effectiveness and efficiency of the organization. Historically, these methodologies focused on creating incremental and continuous improvement in work processes. More recently, organizations are increasingly focused on step changes that take advantage of new technologies to create a significant improvement in the effectiveness or efficiency of the organization.

Often, these initiatives to increase organizational effectiveness or efficiency are identified as projects. Economic organizations will initiate a project to produce a new product, to introduce or revamp work processes to significantly reduce product costs, or to merge with other organizations to reduce competi- 
tion or lower costs and generate additional profits. A social organization, such as a hospital, may build a new wing, introduce a new service, or design new work processes to reduce costs. A government organization may introduce a new software program that handles public records more efficiently, build a new road to reduce congestion, or combine departments to reduce costs.

Each of the initiatives meets our definition of a project. Each is a temporary endeavor and produces a unique product or service. Managing these projects effectively entails applying project management knowledge, skills, and tools.

\section{Operations Management versus Project Management}

One way to improve understanding of project management is to contrast project management with operations management. Whether in an economic, socioreligious, or government organization, managers are charged with effectively and efficiently achieving the purpose of the organization. Typically, a manager of an economic organization focuses on maximizing profits and stockholder value. Leaders with socioreligious organizations focus on effective and efficient delivery of a service to a community or constituency, and governmental managers are focused on meeting goals established by governmental leaders.

Operations managers focus on the work processes of the operation. More effective work processes will produce a better product or service, and a more efficient work process will reduce costs. Operations managers analyze work processes and explore opportunities to make improvements. Total quality management, continuous process improvement, lean manufacturing, and other aspects of the quality movement provide tools and techniques for examining organizational culture and work processes to create a more effective and efficient organization. Operations managers are process focused, oriented toward capturing and standardizing improvement to work processes and creating an organizational culture focused on the long-term goals of the organization.

Project managers focus on the goals of the project. Project success is connected to achieving the project goals within the project timeline. Project managers are goal directed and time sensitive. Project managers apply project management tools and techniques to clearly define the project goals, develop an execution plan to meet those goals, and meet the milestones and end date of the project.

An operations manager may invest $\$ 10,000$ to improve a work process that saves $\$ 3,000$ a year. Over a five-year period, the operations manager improved the profitability of the operations by $\$ 5,000$ and will continue to save $\$ 3,000$ every year. The project manager of a one-year project could not generate the savings to justify this kind of process improvement and would not invest resources to explore this type of savings.

An operations manager creates a culture to focus on the long-term health of the organization. Operations managers build teams over time that focus on standardizing and improving work processes, that search for and nurture team members who will "fit in," and that contribute to both the effectiveness of the team and the team culture. Project managers create a team that is goal focused and energized around the success of the project. Project team members know that the project assignment is temporary because the project, by definition, is temporary. Project team members are often members of organizational teams 
that have a larger potential to affect long-term advancement potential. Project managers create clear goals and clear expectations for team members and tie project success to the overall success of the organization. Operations managers are long-term focused and process oriented. Project managers are goal directed and milestone oriented.

\section{Organizing to Manage Projects}

Because project management is different from operations management, projects are handled best by people who are trained in project management. This expertise can be obtained by hiring an outside consulting firm that specializes in project management or by developing an in-house group.

Some organizations are designed to execute projects. Often entities contract with engineering and construction companies to design and build their facilities or hire software companies to develop a software solution. The major work processes within these organizations are designed to support the acquisition and execution of projects. Functional departments such as estimating, scheduling, and procurement create and maintain core competencies designed to support projects. The ability of these types of organizations to successfully manage projects becomes a competitive advantage in the marketplace.

Organizations designed to produce products or services also use projects. Major activities outside the normal work of the organization's department or functional units or major activities that cross functional boundaries become a project (a temporary task undertaken to create a product or service that is unique). As economic pressures increase the speed in which organizations must change and adapt to new environmental conditions, leaders are increasingly chartering projects to enable the organization to more quickly adapt. The application of a project management approach increases the likelihood of success as organizations charter a project to facilitate organizational change, to increase the development and introduction of new products or support the merger or divesture of organizational units.

Project management offices (PMOs) have emerged to facilitate development of organizational knowledge, skills, and tools to internally charter and manage projects within the organization. The PMO varies in structure and responsibility depending on the project management approach of the parent organization. On one end of the spectrum, the PMO has complete responsibility for projects within an organization from the criteria and selection of appropriate projects to accountability for project performance. In organizations that make a large investment in the PMO, a large number of new product or process improvement projects are submitted, and the project office develops a portfolio of projects to manage over a given period that maximizes the use of organizational resources and provides the greatest return to the organization.

PMOs can provide various functions for an organization. Some possible functions include the following:

- Project management. Some organizations maintain the project manager within the PMO, assign project managers from other departments, procure contract project managers, or practice a combination of all three.

- Center of excellence. The project office can maintain the organization's project management policies and procedures, maintain a historical database, maintain best practices, and provide training and specialized expertise when needed. 
- Portfolio management. The project office actually supervises the project managers and monitors project performance. Portfolio management also includes prioritizing projects on the basis of value to the organization and maintains an inventory of projects. Portfolio management balances the number and type of projects to create the greatest return from the entire portfolio of projects.

- Functional support. The project office maintains project management expertise to support the project. Estimating, project scheduling, and project cost analysis are examples of functional support.

\section{Key Takeaways}

- The purpose of an organization can affect its view of the time allowed for projects.

- In an organization, project management can be used to make step changes to take advantage of new technologies or make significant improvements in effectiveness or efficiency.

- Operations managers are long-term focused and process oriented. Project managers are goal directed and milestone oriented.

- Projects can be handled by outside contractors or by an internal group in a PMO.

\section{Exercises}

1. The type of organization can influence the frame allowed for projects.

2. Operations managers are focused on while project managers are focused on the goals of the project.

3. If projects are routinely handled internally, the group that manages the projects might be called the (three words).

4. A friend of yours has a forty-five-minute commute to work. She decides to spend some time evaluating the different options she has for routes and possible carpooling to reduce the cost or time it takes to get to work. Is this task an example of something that uses the skills of an operations manager, or does it need the additional skills of a project manager? Explain your answer and refer to the definitions provided.

5. Business managers focus on improving efficiency and effectiveness, but sometimes they use a project management approach to make significant changes. What often prompts them to use the project management approach? What would be an example?

Operations versus Project Management

The manager of a sales department must meet annual sales goals, manage personnel in the department, and develop and deliver product training for clients. How is this type of operations management different from project management? Address each of the following issues in your answer:

- How is the relationship between the operations manager and the sales staff different from the rela- 
tionship between a project manager and the project team members?

- Which of the duties described above is most like project management and might be contracted to an outside firm?

- What is the biggest difference between project management and the sales manager's job? 


\subsection{Key Skills of the Project Manager}

\section{Learning Objectives}

1. Identify necessary operational leadership skills.

2. Identify additional leadership skills required of a project manager.

Every project is unique, and most projects will encounter unexpected technical challenges. Each project management team is a group of individuals who need motivation and coordination. Planning is vital, but the ability to adapt to changes and work with people to overcome challenges is just as necessary. A project manager must master the skills that are necessary to be successful in this environment.

\section{Operational Management Skills}

Often the difference between the project that succeeds and the project that fails is the leadership of the project manager. The leadership skills needed by the successful project manager include all the skills needed by operations managers of organizations. These skills include:

- Good communication

- Team building

- Planning

- Expediting

- Motivating

- Political sensitivity

\section{Project Management Skills}

Because project managers generally operate in a project environment that is more time sensitive and goal driven, the successful project manager requires additional knowledge, skills, and abilities.

Albert Einsiedel (Einsiedel, 1987) discussed leader-sensitive projects and defined five characteristics of an effective project leader. These characteristics were chosen based on some assumptions about projects. These characteristics include the project environment, which is often a matrix organization that results 
in role ambiguity, role conflict, and role erosion. The project environment is often a fluid environment where decisions are made with little information. In this environment, the five characteristics of an effective project leader include the following:

- Credibility

- Creativity as a problem solver

- Tolerance for ambiguity

- Flexibility in management style

- Effectiveness in communicating

Hans Thamhain (Thamhain, 1991) researched the training of project managers and, based on the finding, categorized project management into interpersonal, technical, and administrative skills:

- Interpersonal skills. These skills include providing direction, communicating, assisting with problem solving, and dealing effectively with people without having authority.

- Technical expertise. Technical knowledge gives the project manager the creditability to provide leadership on a technically based project, the ability to understand important aspects of the project, and the ability to communicate in the language of the technicians.

- Administrative skills. These skills include planning, organizing, and controlling the work.

Thamhain's work provides a taxonomy for better understanding the skills needed by project managers.

Traditionally, the project manager has been trained in skills such as developing and managing the project scope, estimating, scheduling, decision making, and team building. Although the level of skills needed by the project manager depends largely on the project profile, increasingly the people skills of the project manager are becoming more important. The skills to build a high-performing team, manage client expectations, and develop a clear vision of project success are the type of skills needed by project managers on more complex projects. "To say Joe is a good project manager except he lacks good people skills is like saying he’s a good electrical engineer but doesn’t really understand electricity” (Darnall, 1997).

\section{Key Takeaways}

- Project managers need the same skills as an operations manager, such as good communications, team building, planning, expediting, motivating, and political sensitivity.

- Project managers need additional skills in establishing credibility, creative problem solving, tolerance for ambiguity, flexible management, and very good people skills. 


\section{Exercises}

1. Project managers need the same skills as an operations manager, including communications, team building, planning, expediting, and sensitivity.

2. In addition to the skills needed by an operations manager, a project manager needs to establish credibility, solve problems creatively, have a tolerance for good people skills. , be flexible, and have

Personal Leadership Inventory

Rate your personal project management skills using the following scale:

- S Strong

- M Moderate

- I Improvement needed

Operational management skills:

1. Good communication

2. Team building

3. Planning

4. Expediting

5. Motivating others

6. Sensitive to the politics of a situation

Additional project management skills:

7. Establish credibility with others

8. Find creative solutions to problems

9. Tolerate ambiguity

10. Use a flexible management style—adapt your management style to changing situations

\section{References}

Darnall, R. W., “The Emerging Role of the Project Manager,” PMI Journal (1997): 64.

Einsiedel, A. A., “Profile of Effective Project Managers,” Project Management Journal 18 (1987): 5.

Thamhain, H. J., “Developing Project Management Skills,” Project Management Journal 22 (1991): 3. 


\subsection{Introduction to the Project Management Knowledge Areas}

\section{Learning Objectives}

1. Identify the tasks performed in a project start-up.

2. Describe the areas of project management knowledge as defined by the Project Management Institute.

Projects are divided into components, and a project manager must be knowledgeable in each area. Each of these areas of knowledge will be explored in more depth in subsequent chapters.

\section{Project Start-Up and Integration}

The start-up of a project is similar to the start-up of a new organization. The project leader develops the project infrastructure used to design and execute the project. The project management team must develop alignment among the major stakeholders - those who have a share or interest — on the project during the early phases or definition phases of the project. The project manager will conduct one or more kickoff meetings or alignment sessions to bring the various parties of the project together and begin the project team building required to operate efficiently during the project.

During project start-up, the project management team refines the scope of work and develops a preliminary schedule and conceptual budget. The project team builds a plan for executing the project based on the project profile. The plan for developing and tracking the detailed schedule, the procurement plan, and the plan for building the budget and estimating and tracking costs are developed during the start-up. The plans for information technology, communication, and tracking client satisfaction are all developed during the start-up phase of the project.

Flowcharts, diagrams, and responsibility matrices are tools to capture the work processes associated with executing the project plan. The first draft of the project procedures manual captures the historic and intuitional knowledge that team members bring to the project. The development and review of these procedures and work processes contribute to the development of the organizational structure of the project.

This is typically an exciting time on a project where all things are possible. The project management team is working many hours developing the initial plan, staffing the project, and building relationships with the client. The project manager sets the tone of the project and sets expectations for each of the project team members. The project start-up phase on complex projects can be chaotic, and until plans are developed, the project manager becomes the source of information and direction. The project manager 
creates an environment that encourages team members to fully engage in the project and encourages innovative approaches to developing the project plan.

\section{Project Scope}

The project scope is a document that defines the parameters-factors that define a system and determine its behavior - of the project, what work is done within the boundaries of the project, and the work that is outside the project boundaries. The scope of work (SOW) is typically a written document that defines what work will be accomplished by the end of the project-the deliverables of the project. The project scope defines what will be done, and the project execution plan defines how the work will be accomplished.

No template works for all projects. Some projects have a very detailed scope of work, and some have a short summary document. The quality of the scope is measured by the ability of the project manager and project stakeholders to develop and maintain a common understanding of what products or services the project will deliver. The size and detail of the project scope is related to the complexity profile of the project. A more complex project often requires a more detailed and comprehensive scope document.

According to the Project Management Institute (Project Management Institute, Inc., 2008), the scope statement should include the following:

- Description of the scope

- Product acceptance criteria

- Project deliverables

- Project exclusions

- Project constraints

- Project assumptions

The scope document is the basis for agreement by all parties. A clear project scope document is also critical to managing change on a project. Since the project scope reflects what work will be accomplished on the project, any change in expectations that is not captured and documented creates the opportunity for confusion. One of the most common trends on projects is the incremental expansion in the project scope. This trend is labeled scope creep. Scope creep threatens the success of a project because the small increases in scope require additional resources that were not in the plan. Increasing the scope of the project is a common occurrence, and adjustments are made to the project budget and schedule to account for these changes. Scope creep occurs when these changes are not recognized or not managed. The ability of a project manager to identify potential changes is often related to the quality of the scope documents.

Events do occur that require the scope of the project to change. Changes in the marketplace may require change in a product design or the timing of the product delivery. Changes in the client's management team or the financial health of the client may also result in changes in the project scope. Changes in the project schedule, budget, or product quality will have an effect on the project plan. Generally, the later in the project the change occurs, the greater the increase to the project costs. Establishing a change man- 
agement system for the project that captures changes to the project scope and assures that these changes are authorized by the appropriate level of management in the client's organization is the responsibility of the project manager. The project manager also analyzes the cost and schedule impact of these changes and adjusts the project plan to reflect the changes authorized by the client. Changes to the scope can cause costs to increase or decrease.

\section{Project Schedule and Time Management}

The definition of project success often includes completing the project on time. The development and management of a project schedule that will complete the project on time is a primary responsibility of the project manager, and completing the project on time requires the development of a realistic plan and the effective management of the plan. On smaller projects, project managers may lead the development of the project plan and build a schedule to meet that plan. On larger and more complex projects, a project controls team that focuses on both costs and schedule planning and controlling functions will assist the project management team in developing the plan and tracking progress against the plan.

To develop the project schedule, the project team does an analysis of the project scope, contract, and other information that helps the team define the project deliverables. Based on this information, the project team develops a milestone schedule. The milestone schedule establishes key dates throughout the life of a project that must be met for the project to finish on time. The key dates are often established to meet contractual obligations or established intervals that will reflect appropriate progress for the project. For less complex projects, a milestone schedule may be sufficient for tracking the progress of the project. For more complex projects, a more detailed schedule is required.

To develop a more detailed schedule, the project team first develops a work breakdown structure (WBS) - a description of tasks arranged in layers of detail. Although the project scope is the primary document for developing the WBS, the WBS incorporates all project deliverables and reflects any documents or information that clarifies the project deliverables. From the WBS, a project plan is developed. The project plan lists the activities that are needed to accomplish the work identified in the WBS. The more detailed the WBS, the more activities that are identified to accomplish the work.

After the project team identifies the activities, the team then sequences the activities according to the order in which the activities are to be accomplished. An outcome from the work process is the project logic diagram. The logic diagram represents the logical sequence of the activities needed to complete the project. The next step in the planning process is to develop an estimation of the time it will take to accomplish each activity or the activity duration. Some activities must be done sequentially, and some activities can be done concurrently. The planning process creates a project schedule by scheduling activities in a way that effectively and efficiently uses project resources and completes the project in the shortest time.

On larger projects, several paths are created that represent a sequence of activities from the beginning to the end of the project. The longest path to the completion of the project is the critical path. If the critical path takes less time than is allowed by the client to complete the project, the project has a positive total float or project slack. If the client's project completion date precedes the calculated critical path 
end date, the project has a negative float. Understanding and managing activities on the critical path is an important project management skill.

To successfully manage a project, the project manager must also know how to accelerate a schedule to compensate for unanticipated events that delay critical activities. Compressing - crashing-the schedule is a term used to describe the techniques used to shorten the project schedule. During the life of the project, scheduling conflicts often occur, and the project manager is responsible for reducing these conflicts while maintaining project quality and meeting cost goals.

\section{Project Costs}

The definition of project success often includes completing the project within budget. Developing and controlling a project budget that will accomplish the project objectives is a critical project management skill. Although clients expect the project to be executed efficiently, cost pressures vary on projects. On some projects, the project completion or end date is the largest contributor to the project complexity. The development of a new drug to address a critical health issue, the production of a new product that will generate critical cash flow for a company, and the competitive advantage for a company to be first in the marketplace with a new technology are examples of projects with schedule pressures that override project costs.

The accuracy of the project budget is related to the amount of information known by the project team. In the early stages of the project, the amount of information needed to develop a detailed budget is often missing. To address the lack of information, the project team develops different levels of project budget estimates. The conceptual estimate (or "ballpark estimate") is developed with the least amount of knowledge. The major input into the conceptual estimate is expert knowledge or past experience. A project manager who has executed a similar project in the past can use those costs to estimate the costs of the current project.

When more information is known, the project team can develop a rough order of magnitude (ROM) estimate. Additional information such as the approximate square feet of a building, the production capacity of a plant, and the approximate number of hours needed to develop a software program can provide a basis for providing a ROM estimate. After a project design is more complete, a project detailed estimate can be developed. When the project team knows the number of rooms, the type of materials, and the building location of a home, the project team can provide a detailed estimate. A detailed estimate is not a bid.

The cost of the project is tracked relative to the progress of the work and the estimate for accomplishing that work. Based on the cost estimate, the cost of the work performed is compared against the cost budgeted for that work. If the cost is significantly higher or lower, the project team explores reasons for the difference between expected costs and actual costs.

Project costs may deviate from the budget because the prices in the marketplace were different from what was expected. For example, the estimated costs for lumber on a housing project may be higher than budgeted or the hourly cost for labor may be lower than budgeted. Project costs may also deviate based on project performance. For example, the project team estimated that the steel design for a bridge over 
the Hudson River would take 800 labor hours, but 846 hours were actually expended. The project team captures the deviation between costs budgeted for work and the actual cost for work, revises the estimate as needed, and takes corrective action if the deviation appears to reflect a trend.

The project manager is responsible for assuring that the project team develops cost estimates based on the best information available and revises those estimates as new or better information becomes available. The project manager is also responsible for tracking costs against the budget and conducting an analysis when project costs deviate significantly from the project estimate. The project manager then takes appropriate corrective action to assure that project performance matches the revised project plan.

\section{Project Quality}

Project quality focuses on the end product or service deliverables that reflect the purpose of the project. The project manager is responsible for developing a project execution approach that provides for a clear understanding of the expected project deliverables and the quality specifications. The project manager of a housing construction project not only needs to understand which rooms in the house will be carpeted but also what grade of carpet is needed. A room with a high volume of traffic will need a high-grade carpet.

The project manager is responsible for developing a project quality plan that defines the quality expectations and assures that the specifications and expectations are met. Developing a good understanding of the project deliverables through documenting specifications and expectations is critical to a good quality plan. The processes for assuring that the specifications and expectations are met are integrated into the project execution plan. Just as the project budget and completion dates may change over the life of a project, the project specifications may also change. Changes in quality specifications are typically managed in the same process as cost or schedule changes. The impact of the changes is analyzed for impact on cost and schedule, and with appropriate approvals, changes are made to the project execution plan.

The Project Management Institute's A Guide to the Project Management Body of Knowledge (PMBOK Guide) has an extensive chapter on project quality management. The material found in this chapter would be similar to material found in a good operational management text. Although any of the quality management techniques designed to make incremental improvement to work processes can be applied to a project work process, the character of a project (unique and relatively short in duration) makes small improvements less attractive on projects.

Rework on projects, as with manufacturing operations, increases the cost of the product or service and often increases the time needed to complete the reworked activities. Because of the duration constraints of a project, the development of the appropriate skills, materials, and work process early in the project is critical to project success. On more complex projects, time is allocated to developing a plan to understand and develop the appropriate levels of skills and work processes.

Project management organizations that execute several similar types of projects may find the process improvement tools useful in identifying and improving the baseline processes used on their projects. Process improvement tools may also be helpful in identifying cost and schedule improvement opportunities. Opportunities for improvement must be found quickly to influence project performance. The 
investment in time and resources to find improvements is greatest during the early stages of the project, when the project is in the planning stages. During later project stages, as pressures to meet project schedule goals increase, the culture of the project is less conducive to making changes in work processes.

Another opportunity for applying process improvement tools is on projects that have repetitive processes. A housing contractor that is building several identical houses may benefit from evaluating work processes in the first few houses to explore the opportunities available to improve the work processes. The investment of $\$ 1,000$ in a work process that saves $\$ 200$ per house is a good investment as long as the contractor is building more than five houses.

\section{Project Team: Human Resources and Communications}

Staffing the project with the right skills, at the right place, and at the right time is an important responsibility of the project management team. The project usually has two types of team members: functional managers and process managers. The functional managers and team focus on the technology of the project. On a construction project, the functional managers would include the engineering manager and construction superintendents. On a training project, the functional manager would include the professional trainers; on an information technology project, the software development managers would be functional managers. The project management team also includes project process managers. The project controls team would include process managers who have expertise in estimating, cost tracking, planning, and scheduling. The project manager needs functional and process expertise to plan and execute a successful project.

Because projects are temporary, the staffing plan for a project typically reflects both the long-term goals of skilled team members needed for the project and short-term commitment that reflects the nature of the project. Exact start and end dates for team members are often negotiated to best meet the needs of individuals and the project. The staffing plan is also determined by the different phases of the project. Team members needed in the early or conceptual phases of the project are often not needed during the later phases or project closeout phases. Team members needed during the execution phase are often not needed during the conceptual or closeout phases. Each phase has staffing requirements, and the staffing of a complex project requires detailed planning to have the right skills, at the right place, at the right time.

Typically a core project management team is dedicated to the project from start-up to closeout. This core team would include members of the project management team: project manager, project controls, project procurement, and key members of the function management or experts in the technology of the project. Although longer projects may experience more team turnover than shorter projects, it is important on all projects to have team members who can provide continuity through the project phases.

For example, on a large commercial building project, the civil engineering team that designs the site work where the building will be constructed would make their largest contribution during the early phases of the design. The civil engineering lead would bring on different civil engineering specialties as they were needed. As the civil engineering work is completed and the structural engineering is well under way, a large portion of the civil engineers would be released from the project. The functional man- 
agers, the engineering manager, and civil engineering lead would provide expertise during the entire length of the project, addressing technical questions that may arise and addressing change requests.

Project team members can be assigned to the project from a number of different sources. The organization that charters the project can assign talented managers and staff from functional units within the organization, contract with individuals or agencies to staff positions on the project, temporarily hire staff for the project, or use any combination of these staffing options. This staffing approach allows the project manager to create the project organizational culture. Some project cultures are more structured and detail oriented, and some are less structured with less formal roles and communication requirements. The type of culture the project manager creates depends greatly on the type of project.

\section{Communications}

Completing a complex project successfully requires teamwork, and teamwork requires good communication among team members. If those team members work in the same building, they can arrange regular meetings, simply stop by each other's office space to get a quick answer, or even discuss a project informally at other office functions. Many complex projects in today's global economy involve team members from widely separated locations, and the types of meetings that work within the same building are not possible. Teams that use electronic methods of communicating without face-to-face meetings are called virtual teams.

Communicating can be divided into two categories: synchronous and asynchronous. If all the parties to the communication are taking part in the exchange at the same time, the communication is synchronous. A telephone conference call is an example of synchronous communication. When the participants are not interacting at the same time, the communication is asynchronous. The letter $a$ at the beginning of the word means not. Communications technologies require a variety of compatible devices, software, and service providers, and communication with a global virtual team can involve many different time zones. Establishing effective communications requires a communications plan.

\section{Project Risk}

Risk exists on all projects. The role of the project management team is to understand the kinds and levels of risks on the project and then to develop and implement plans to mitigate these risks. Risk represents the likelihood that an event will happen during the life of the project that will negatively affect the achievement of project goals. The type and amount of risk varies by industry type, complexity, and phase of the project. The project risk plan will also reflect the risk profile of the project manager and key stakeholders. People have different comfort levels with risk, and some members of the project team will be more risk adverse than others.

The first step in developing a risk management plan involves identifying potential project risks. Some risks are easy to identify, such as the potential for a damaging storm in the Caribbean, and some are less obvious. Many industries or companies have risk checklists developed from past experience. The Construction Industry Institute published a one-hundred-item risk checklist (Construction Industry Institute 
Cost/Schedule Task Force, 1989) that provides examples and areas of project risks. No risk checklist will include all potential risks. The value of a checklist is the stimulation of discussion and thought about the potential risks on a project.

The project team then analyzes the identified risks and estimates the likelihood of the risks occurring. The team then estimates the potential impact of project goals if the event does occur. The outcome from this process is a prioritized list of estimated project risks with a value that represents the likelihood of occurrence and the potential impact on the project.

The project team then develops a risk mitigation plan that reduces the likelihood of an event occurring or reduces the impact on the project if the event does occur. The risk management plan is integrated into the project execution plan, and mitigation activities are assigned to the appropriate project team member. The likelihood that all the potential events identified in the risk analysis would occur is extremely rare. The likelihood that one or more events will happen is high.

The project risk plan reflects the risk profile of the project and balances the investment of the mitigation against the benefit for the project. One of the more common risk mitigation approaches is the use of contingency. Contingency is funds set aside by the project team to address unforeseen events. Projects with a high-risk profile will typically have a large contingency budget. If the team knows which activities have the highest risk, contingency can be allocated to activities with the highest risk. When risks are less identifiable to specific activities, contingency is identified in a separate line item. The plan includes periodic risk plan reviews during the life of the project. The risk review evaluates the effectiveness of the current plan and explores for possible risks not identified in earlier sessions.

\section{Project Procurement}

The procurement effort on projects varies widely and depends on the type of project. Often the client organization will provide procurement services on less complex projects. In this case, the project team identifies the materials, equipment, and supplies needed by the project and provides product specifications and a detailed delivery schedule. When the procurement department of the parent organization provides procurement services, a liaison from the project can help the procurement team better understand the unique requirements of the project and the time-sensitive or critical items of the project schedule.

On larger, more complex projects, personnel are dedicated to procuring and managing the equipment, supplies, and materials needed by the project. Because of the temporary nature of projects, equipment, supplies, and materials are procured as part of the product of the project or for the execution of the pro-

ject. For example, the bricks procured for a construction project would be procured for the product of the project, and the mortar mixer would be equipment procured for the execution of the project work. At the end of the project, equipment bought or rented for the execution of the work of the project are sold, returned to rental organizations, or disposed of some other way.

More complex projects will typically procure through different procurement and management methods. Commodities are common products that are purchased based on the lowest bid. Commodities include items like concrete for building projects, office supplies, or even lab equipment for a research project. The second type of procurement includes products that are specified for the project. Vendors who can 
produce these products bid for a contract. The awarding of a contract can include price, ability to meet the project schedule, the fit for purpose of the product, and other considerations important to the project. Manufacturing a furnace for a new steel mill would be provided by a project vendor. Equipment especially designed and built for a research project is another example. These vendors' performances become important parts of the project, and the project manager assigns resources to coordinate the work and schedule of the vendor. The third procurement approach is the development of one or more partners. A design firm that is awarded the design contract for a major part of the steel mill and a research firm that is conducting critical subparts of the research are examples of potential project partners. A partner contributes to and is integrated into the execution plan. Partners perform best when they share the project vision of success and are emotionally invested in the project. The project management team builds and implements a project procurement plan that recognizes the most efficient and effective procurement approach to support the project schedule and goals.

\section{Key Takeaways}

- During the start-up phase, the project leader develops the project infrastructure used to design and execute the project. A team is formed to create agreement among project stakeholders on the goals, cost, and completion date. Plans for executing the project, managing the schedule and quality, and controlling the budget are created.

- The scope statement establishes project parameters that define what will be done.

- The project schedule begins with a milestone schedule followed by a WBS and a project diagram. The longest path through the project diagram is the critical path, and the difference between the completion of the critical path and the project finish date is the float. Shortening the critical path is called crashing the project.

- Cost estimating begins with a conceptual or ballpark estimate that is followed by a ROM estimate. A project budget is determined from the cost of the tasks in the WBS. Costs are monitored during the project and estimates updated if the costs vary from expectations.

- Project quality begins with the specifications of materials and labor. A quality plan creates a process for assuring the requirements and specifications of the project are met. Quality improvement tools can be applied to projects if the company has several similar projects.

- Team members are selected to manage functions and processes. The staffing plan assigns people as needed. Sources of team members are company employees, contractors, new hires, and partners.

- The risk on a project reflects the number of things that can possibly happen that will have a negative effect on the project and the probability of those events happening.

- The provider of procurement management depends on the size of the project and the organization. Commodities are purchased from the lowest bidder, while specialty items are purchased from bids or from partners. 


\section{Exercises}

1. During the start-up phase, the first estimate of the cost of the project is called the or ballpark estimate.

2. Shortening the schedule to meet the project completion date is called the schedule.

3. Why would it be important to get the stakeholders in a project to actually sign the scope statement?

4. What is the difference between a milestone schedule and a work breakdown schedule?

Areas of Knowledge

Write one or two sentences in which you describe each area of project management knowledge-as defined by the Project Management Institute.

1. Start-up

2. Scope

3. Time

4. Cost

5. Quality

6. Team selection (human resources)

7. Communications

8. Risk

9. Procurement

\section{References}

Construction Industry Institute Cost/Schedule Task Force, Management of Project Risks and Uncertainties (Austin, TX: Construction Industry Institute, 1989).

Project Management Institute, Inc., A Guide to the Project Management Body of Knowledge (PMBOK Guide), 4th ed. (Newtown Square, PA: Project Management Institute, Inc., 2008), 115-16. 


\subsection{Exercises}

Exercises at the end of the chapter are designed to strengthen your understanding and retention of the information recently acquired in the chapter.

\section{Essay Questions}

Write several paragraphs to provide more in-depth analysis and consideration when answering the following questions.

1. If you were planning to change the landscaping around the location where you or a friend lives and decided to approach it like a project, describe the start-up activities you would use. Refer to the elements of a project start-up as described in this chapter.

2. Describe a project you have worked on where you experienced scope creep. Begin by defining scope creep in your own words. Describe the project, how the scope creep occurred, and the effect it had on the project cost, quality, and completion date.

\section{Discussion}

The exercises in this section are designed to promote exchange of information among students in the classroom or in an online discussion. The exercises are more open ended, which means that what you find might be completely different from what your classmates find, and you can all benefit by sharing what you have learned.

1. Client satisfaction. Should the project manager go beyond the written requirements in the project scope statement to satisfy the client? Does the answer to this question depend on the role of the project in the organization? For example, does it matter if the organization is a consulting firm that sells project management or if the project is done for another department in the same organization? Form an opinion on this topic, and write a few paragraphs on it to organize your thoughts on the subject. Be prepared to share your thoughts with classmates. Submit the work as directed by your instructor.

2. Organizational priorities. Consider that three different organizations are planning to construct a building for their own use. The organizations are a for-profit company, a religious group, and a local school district. Choose three project knowledge areas, and consider how the project might be affected in each of these areas by the different types of organizations behind the project. Write a few paragraphs on this topic to organize your thoughts on the subject, and be prepared to share your thoughts with classmates. Submit the work as directed by your instructor. 


\subsection{Web Exercise}

\section{Learning Objective}

1. Find pronunciation of terms using an online dictionary.

\section{Use an Online Audio Pronunciation Aid}

One of the problems with learning a new vocabulary in an online class is that you do not get to hear the instructor pronounce the terms. If the pronunciation is not obvious from the spelling, it can be embarrassing if you say the word incorrectly. Fortunately, several online dictionaries have features that say the word. You must have speakers or headphones attached to the computer, and they must be enabled.

\section{How to Use an Online Audio Pronunciation Aid}

1. Obtain speakers or headphones and plug them into the audio output jack on your computer. The location of this jack on computers varies greatly, but it is usually green as shown in Figure 1.10 “Audio Output Ports on Two Computers”.

Figure 1.10 Audio Output Ports on Two Computers
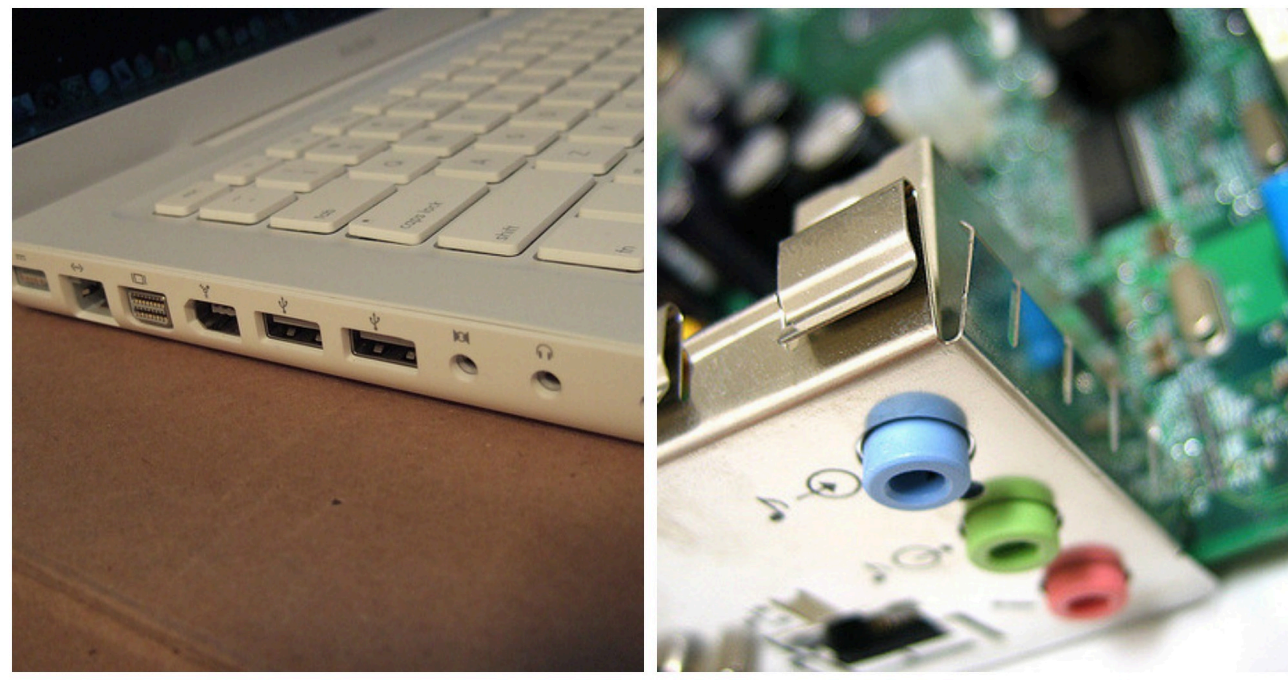
Rob DiCarterino - White 13” Apple Macbook - CC BY 2.0; Ryan Franklin - Audio Port - CC BY 2.0.

2. Enable the speaker output. In Windows computers, look for a speaker icon in the lower right corner of the screen. If the speakers/headphone jack is turned off, it will have the universal symbol for "No" on it. If that is the case, double-click the icon and remove the check mark next to Mute to enable the speaker output. The icon displays without the "No" symbol.

3. Use your web browser to go to http://www.thefreedictionary.com.

4. In the Search box, type synchronous and then click the Search button.

5. The term is displayed with a phonetic spelling and a speaker icon, as shown in Figure 1.11 "Pronunciation Option in an Online Dictionary".

Figure 1.11 Pronunciation Option in an Online Dictionary

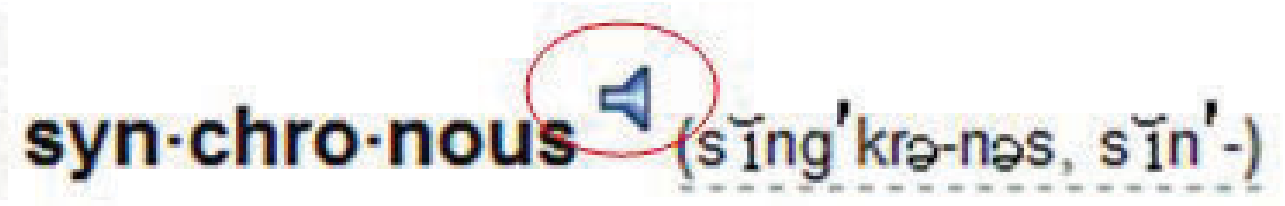

Source: www.thefreedictionary.com.

6. To the right of the word, click the speaker icon. You should be able to hear the pronunciation through the speakers or headphones.

7. Capture a screen that shows the dictionary definition of synchronous and then paste it into a word processing document.

8. Review your work and use the following rubric to determine its adequacy:

\begin{tabular}{|l|l|l|l|}
\hline Element & Best & Adequate & Poor \\
\hline File name & N/A & & $\begin{array}{l}\text { Choice of a website that does } \\
\text { not include audio }\end{array}$ \\
\hline $\begin{array}{l}\text { Used an online } \\
\text { audio aid to learn } \\
\text { to pronounce } \\
\text { terms correctly }\end{array}$ & $\begin{array}{l}\text { Used a browser to open an online } \\
\text { dictionary that has an audio } \\
\text { feature for pronouncing terms that } \\
\text { is indicated by an icon }\end{array}$ & $\begin{array}{l}\text { Same as } \\
\text { Best }\end{array}$ & $\begin{array}{l}\text { inability to activate the audio } \\
\text { output }\end{array}$ \\
\hline
\end{tabular}

9. Submit evidence of completion as directed by the instructor. 


\subsection{Software and Technology Exercises}

\section{Learning Objectives}

1. Download software from an Internet site and install it on a computer.

2. Capture a computer screen and paste it into a word processing document.

3. Create a folder of project management web addresses in a web browser.

\section{Download and Install Adobe Reader}

There are many programs that are useful for project managers that can be downloaded from a website. Some of them are free while others are trial versions or are available for a license fee. To download and install software on a computer, you must have administrative rights on that computer. If you are trying to use a computer at a company for your homework in this class, you probably do not have administrative rights to install software. You need to use a private computer on which you can log in as the administrator or as a user with rights to install software.

Alternatively, in some campus computer labs you are allowed to install software, but the computer is refreshed to its original configuration when the machine is restarted. If you use a computer in a common lab, be sure to complete the assignment before the machine is restarted.

In this exercise, you download and install Adobe Reader. This program allows you to read files that are saved in the PDF format. This format is very popular because it allows distribution of documents that may be easily viewed but not changed.

\section{How to Download and Install Adobe Reader}

1. Using a web browser, go to https://get.adobe.com/reader/. The Adobe home page displays as shown in Figure 1.12 “Adobe Reader Download Page”.

Figure 1.12 Adobe Reader Download Page 

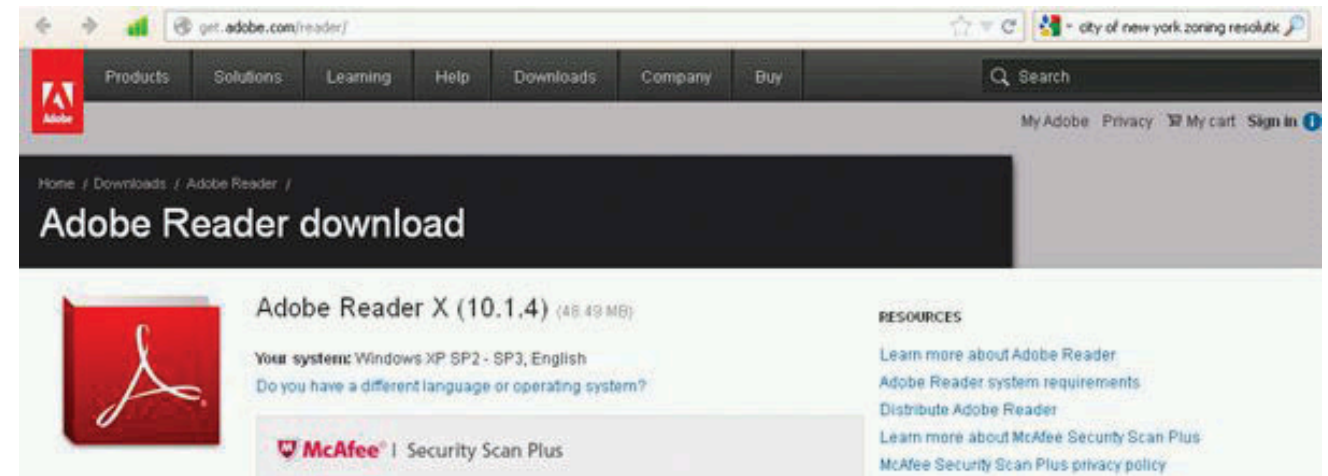

DESOURCES

Leam more about Adobe Reader

Adobe Reader system Iequirements

Distribute Asobe Reaces

Leatn more about Mesdee Security Scan Plus

Free: McAlee Secunity Scan Plus check the status of your PC secunty

[ Yes, install McAfee Securhy Scan Plus - optional (0 98 ME)

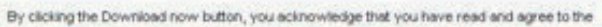
Adcce Sottware Licensing Agreenert and the MCA Afee Securty SCan Pus License Agreonert

$\checkmark$ Download now

Please note, depending on your settings, you may have to temporatily disable yout antivitus softwate.

Source: Adobe product screenshot reprinted with permission from Adobe Systems Incorporated.

2. Click the check boxes next to optional features, such as virus scans or toolbars, to deselect them and then click Download now.

3. Follow the directions on the screen to install Adobe Reader.

4. When the installation process is complete, the program is added to the list of available programs on your computer. It will start automatically whenever you try to open a file that is saved using the PDF file format.

5. From the list of programs on your computer start Adobe Reader to confirm that it is successfully installed, as shown in Figure 1.13 “Adobe Reader Installed”.

Figure 1.13 Adobe Reader Installed

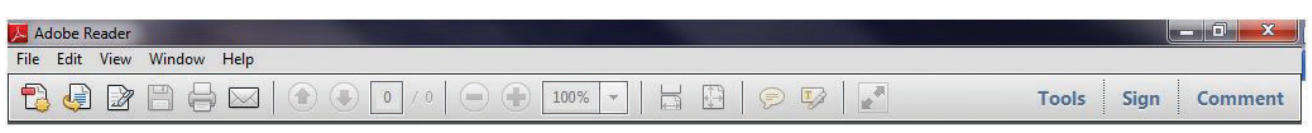

Source: Adobe product screenshot reprinted with permission from Adobe Systems Incorporated.

6. Review your work and use the following rubric to determine its adequacy:

\begin{tabular}{|l|l|l|l|}
\hline Element & Best & Adequate & Poor \\
\hline File name & N/A & \\
\hline $\begin{array}{l}\text { Downloaded software from an } \\
\text { Internet site and installed it on } \\
\text { a computer }\end{array}$ & $\begin{array}{l}\text { Program is } \\
\text { installed and } \\
\text { functioning }\end{array}$ & $\begin{array}{l}\text { Same as } \\
\text { Best }\end{array}$ & $\begin{array}{l}\text { Did not allow time to find a computer } \\
\text { on which software could be installed; } \\
\text { process failed }\end{array}$ \\
\hline
\end{tabular}


7. Submit evidence of completion as directed by the instructor.

\section{Download and Install Google Earth}

There are many programs that are useful for project managers that can be downloaded from a website. Some of them are free while others are trial versions or are available for a license fee. To download and install software on a computer, you must have administrative rights on that computer. If you are trying to use a computer at a company for your homework in this class, you probably do not have administrative rights to install software. You need to use a private computer on which you can log in as the administrator or as a user with rights to install software.

Alternatively, in some campus computer labs you are allowed to install software, but the computer is refreshed to its original configuration when the machine is restarted. If you use a computer in a common lab, be sure to complete the assignment before the machine is restarted.

In this exercise, you download and install Google Earth. This program provides information that would be valuable to a project manager who needs to consider the implications of the location of a project.

\section{How to Download and Install Google Earth}

1. Using a web browser, go to http://earth.google.com. The Google Earth home page displays as shown in Figure 1.14 "Google Earth Home Page”.

2. Click the Download Google Earth button.

3. Scroll through and review the Terms of Service. See Figure 1.15 "Terms of Service”.

4. Click the Agree and Download button if you agree to abide by the terms. If not, contact your instructor for an alternative assignment.

5. Choose a folder into which the file will be downloaded. The default choice in Windows is usually the Downloads folder in My Documents. Make note of where the file will be placed so you can find it in the next step.

The file that is downloaded is a program that can be executed by clicking the file name. It is an installation program that manages the rest of the download and installation process. In some browsers, the option to click the file name is available from the browser window, and in others, you must use a file management program like Windows Explorer to find the file and then double-click the file name. This process is typical of most programs that you download and install.

6. Click or double-click the file name to start the installation. A security warning box may display seeking your permission to install a program, as shown in Figure 1.16 "Permission to Run the Installation Program”. Only programs from trusted sites should be installed.

7. Click the Run button. The program will contact the Google Earth website and begin the 
process of downloading the main part of the program. A window with a progress bar displays to indicate how much of the file has been successfully transferred, as shown in Figure 1.17 "Progress Bar".

8. When the installation process is complete, the program starts. Any location on earth may be entered, and a satellite image with a variety of accompanying information is displayed, as shown in Figure 1.18 “Google Earth Installed”.

9. Enter a location of your choice in the Fly to box and then press Enter.

10. Capture the screen and then paste it into a word processing document.

11. Review your work and use the following rubric to determine its adequacy:

\begin{tabular}{|l|l|l|l|}
\hline Element & Best & Adequate & Poor \\
\hline File name & N/A & \\
\hline $\begin{array}{l}\text { Downloaded software from an } \\
\text { Internet site and installed it on } \\
\text { a computer }\end{array}$ & $\begin{array}{l}\text { Program is } \\
\text { installed and } \\
\text { functioning }\end{array}$ & $\begin{array}{l}\text { Same as } \\
\text { Best }\end{array}$ & $\begin{array}{l}\text { Did not allow time to find a computer } \\
\text { on which software could be installed; } \\
\text { process failed }\end{array}$ \\
\hline
\end{tabular}

12. Submit evidence of completion as directed by the instructor.

\section{Capture a Screen Using Windows XP and the Print Screen Button}

The operating system of your computer manages the display on the monitor or screen. The operating system can make a copy of the screen and save it to disk or to the clipboard-a temporary storage area-and then the image of the screen can be pasted into a word processing document. The document can be saved and then attached to an e-mail or otherwise sent to team members. This skill might be used to illustrate a computer problem, illustrate a point, or prove that you have followed directions properly.

\section{How to Capture a Screen Using Windows XP and the Print Screen Button}

1. Open a blank document in your word processing program.

2. Save the file to a folder of your choice, such as Ch01StudentName, where you use your name without spaces in place of StudentName. Save the file as a Word 97-2003 file type. Your display may show the .doc file extension that is characteristic of the file type if it is set to display file extensions. See Figure 1.19 "File Name in Save As Dialog Box".

3. In the first line of the document, type Chapter 1 Exercises by StudentName where you replace StudentName with your name. Press the Enter key to move the insertion point to the 
next line, as shown in Figure 1.20 “Document with Insertion Point on Second Line”.

4. Leave this document open. Start a web browser. Use the browser to go to http://maps.google.com. The Google Maps page displays.

5. On the keyboard, find the PrntScrn button. This is the Print Screen button. (Some laptop computers do not have a PrntScrn button. If you have a laptop with Windows XP and no PrntScrn button, use a search engine like Google to find a free screen capture software like ScreenHunter, and then install it.)

6. Press the PrntScrn button. An image of the screen is saved in a temporary memory area called the Windows clipboard.

7. Switch to the word processing document. Click below the first line of text. Hold the Control (CTRL) key and then press the V key to paste the image from the clipboard.

8. Press the Enter key twice to create a new empty line below the image. See Figure 1.21 "Capture of the Google Maps Screen with Insertion Point below the Image”.

9. Review your work and use the following rubric to determine its adequacy:

\begin{tabular}{|l|l|l|l|}
\hline Element & Best & Adequate & Poor \\
\hline File name & $\begin{array}{l}\text { Ch01StudentName in the } \\
\text { Word 2003 format where } \\
\text { StudentName is replaced by } \\
\text { your name }\end{array}$ & Same as Best & $\begin{array}{l}\text { Different file name } \\
\text { than specified } \\
\text { without the } \\
\text { student's name }\end{array}$ \\
\hline $\begin{array}{l}\text { Download software } \\
\text { from an Internet site } \\
\text { and install it on a } \\
\text { computer }\end{array}$ & $\begin{array}{l}\text { Title; screen capture of the } \\
\text { Google Maps site; insertion } \\
\text { point below the image }\end{array}$ & $\begin{array}{l}\text { Title plus screen } \\
\text { capture; insertion } \\
\text { point on same line } \\
\text { as image }\end{array}$ & Missing title \\
\hline
\end{tabular}

10. Save the file and submit it as directed by the instructor.

\section{Capture a Screen Using Windows Vista or Windows 7}

The operating system of your computer manages the display on the monitor or screen. The operating system can make a copy of the screen and save it to disk or to the clipboard-a temporary storage area-and then the image of the screen can be pasted into a word processing document. The document can be saved and then attached to an e-mail or otherwise sent to team members. This skill might be used to illustrate a computer problem, illustrate a point, or prove that you have followed directions properly. 


\section{How to Capture a Screen Using Vista or Windows 7 and the Snipping Tool}

1. Open a blank document in your word processing program.

2. Save the file to a folder of your choice, such as Ch01StudentName where you use your name in place of StudentName. Save the file as a Word 97-2003 file type. Your display may show the .doc file extension that is characteristic of the file type if it is set to display file extensions. See Figure 1.19 "File Name in Save As Dialog Box”.

3. In the first line of the document, type Chapter 1 Exercises by StudentName where you replace StudentName with your name. Press the Enter key to move the insertion point to the next line, as shown in Figure 1.20 "Document with Insertion Point on Second Line”.

4. Leave this document open. Start a web browser. Use the browser to go to http://maps.google.com. The Google Maps page displays.

5. Click the Windows Start button to display a menu of options.

6. On the menu of options, click All Programs.

7. On the menu of programs, click the Accessories folder.

8. On the menu of accessories, click Snipping Tool.

9. In the Snipping Tool, click the New Snip button arrow and then click Window Snip.

10. Click anywhere on the screen. In the Snipping Tool dialog box, on the toolbar, click the Copy button.

11. Switch to the word processing document. Click below the first line of text. Hold the CTRL key, and then press the V key to paste the image from the clipboard.

12. Press the Enter key twice to create a new empty line below the image. See Figure 1.21 "Capture of the Google Maps Screen with Insertion Point below the Image”.

13. Review your work and use the following rubric to determine its adequacy:

\begin{tabular}{|l|l|l|l|}
\hline Element & Best & Adequate & Poor \\
\hline File name & $\begin{array}{l}\text { Ch01StudentName in the } \\
\text { Word 2003 format where } \\
\text { StudentName is replaced by } \\
\text { your name }\end{array}$ & Same as Best & $\begin{array}{l}\text { Different file name } \\
\text { than specified } \\
\text { without the } \\
\text { student's name }\end{array}$ \\
\hline $\begin{array}{l}\text { Capture a computer } \\
\text { screen and paste it into } \\
\text { a word processing } \\
\text { document }\end{array}$ & $\begin{array}{l}\text { Title; screen capture of the } \\
\text { Google Maps site; insertion } \\
\text { point below the image }\end{array}$ & $\begin{array}{l}\text { Title plus screen } \\
\text { capture; insertion } \\
\text { point on same line } \\
\text { as image }\end{array}$ & Missing title \\
\hline
\end{tabular}

14. Save the file and submit it as directed by the instructor. 


\section{Capture a Screen Using OSX on a Mac}

The operating system of your computer manages the display on the monitor or screen. The operating system can make a copy of the screen and save it to disk or to the clipboard - a temporary storage area-and then the image of the screen can be pasted into a word processing document. The document can be saved and then attached to an e-mail or otherwise sent to team members. This skill might be used to illustrate a computer problem, illustrate a point, or prove that you have followed directions properly.

\section{How to Capture a Screen Using OSX on a Mac}

1. Open a blank document in your word processing program.

2. Save the file to a folder of your choice, such as Ch01StudentName where you use your name in place of StudentName. Save the file as a Word 97-2003 file type. Your display may show the .doc file extension that is characteristic of the file type if it is set to display file extensions. See Figure 1.19 "File Name in Save As Dialog Box".

3. In the first line of the document, type Chapter 1 Exercises by StudentName where you replace StudentName with your name. Press the Enter key to move the insertion point to the next line, as shown in Figure 1.20 “Document with Insertion Point on Second Line”.

4. On the keyboard, press Command + Control + Shift +3 . An image of the screen is saved in the clipboard.

5. Switch to the word processing document. Click below the first line of text. Hold the CTRL key, and then press the V key to paste the image from the clipboard.

6. Press the Enter key twice to create a new empty line below the image. See Figure 1.21 "Capture of the Google Maps Screen with Insertion Point below the Image”.

7. Review your work and use the following rubric to determine its adequacy:

\begin{tabular}{|l|l|l|l|}
\hline Element & Best & Adequate & Poor \\
\hline File name & $\begin{array}{l}\text { Ch01StudentName in the } \\
\text { Word 2003 format where } \\
\text { StudentName is replaced by } \\
\text { your name }\end{array}$ & Same as Best & $\begin{array}{l}\text { Different file name } \\
\text { than specified } \\
\text { without the } \\
\text { student's name }\end{array}$ \\
\hline $\begin{array}{l}\text { Capture a computer } \\
\text { screen and paste it into } \\
\text { a word processing } \\
\text { document }\end{array}$ & $\begin{array}{l}\text { Title; screen capture of the } \\
\text { Google Maps site; insertion } \\
\text { point below the image }\end{array}$ & $\begin{array}{l}\text { Title plus screen } \\
\text { capture; insertion } \\
\text { point on same line } \\
\text { as image }\end{array}$ & Missing title \\
\hline
\end{tabular}

8. Save the file and submit it as directed by the instructor. 


\section{Create a Folder of Bookmarks in a Web Browser in Chrome}

You will visit sites that contain supporting information and useful templates. To save the addresses of these sites, you can create in a folder named Project Management in your web browser.

\section{How to Create a Folder of Bookmarks in Google Chrome}

1. Open your web browser program. In the address box, type http://maps.google.com and then press Enter. The Google Maps home page displays as shown in Figure 1.22 "Google Maps Home Page”.

2. On the toolbar, click the Bookmarks button. The Bookmark Added dialog box displays. The default location for the bookmark is the Bookmarks bar, which is a toolbar that contains links to the websites. It is also a folder.

3. In the Bookmark dialog box, click the Close button. The web address for http://maps.google.com is placed in the Bookmarks bar folder and is available for display on the toolbar.

4. On your keyboard, at the lower left, locate the Control (CTRL) key. Press and hold the CTRL key, and then on the keyboard press B. ${ }^{2}$ The Bookmark toolbar displays, as shown in Figure 1.23 “Chrome Bookmarks Bar”.

5. On the toolbar above the Bookmarks bar, click the Tools button. On the menu, click Bookmark Manager. The Bookmark Manager dialog box displays, as shown in Figure 1.24 “Chrome Bookmark Manager Dialog Box”.

6. In the Bookmark Manager dialog box, on the toolbar, on the Organize button, click the small arrow. $^{3}$

In the menu, click New Folder. The New Folder dialog box displays.

7. In the New Folder dialog box, in the Name box, type Project Management and then click OK. The Project Management folder is added to the Bookmarks bar as shown in Figure 1.25 "Folder Added to the Bookmarks Bar".

8. On the toolbar, click the Tools button. On the menu, click Bookmark manager. The Bookmark manager dialog box displays, as shown in Figure 1.26 "Managing Bookmarks".

9. Move the mouse pointer onto Google Maps. Press and hold the left mouse button and move the mouse to move the pointer on the screen to the Project Management folder in either pane of the dialog box. ${ }^{4}$

The link is moved into the Project Management folder.

10. In the Bookmark Manager dialog box, in the left pane, click the Project Management folder.

1. This assumes that you have not previously added this site as a bookmark.

2. In the future, this sequence of holding the Control key and pressing another key will be written with a plus sign (e.g., Ctrl + B).

3. This is an example of Microsoft syntax. In the future, the process of clicking the arrow on a button will be shortened (e.g., click the Organize arrow).

4. In the future, description of this type of process will be shortened (e.g., drag Google Maps to the Project Management folder). 
The link to Google Maps is displayed in the right pane to indicate that it is now in the Project Management folder. The link to Google Maps displays in the pane to the right, as shown in Figure 1.27 "Link Placed in the Project Management Folder”.

11. Use the skills you practiced previously to capture an image of this dialog box and then paste it into Ch01StudentName.doc.

12. In the Bookmark Manager dialog box, in the upper right corner, click the close button. ${ }^{5}$ Close the Chrome web browser.

13. Start the Chrome browser again. On the Bookmarks bar, click the Project Management folder. The link to Google Maps is displays under the Project Management folder on the Bookmarks bar, as shown in Figure 1.28 "Project Management Folder on the Chrome Bookmarks Bar”.

14. Click the link to Google Maps. The Google Maps home page displays. Close the browser.

15. Review your work and use the following rubric to determine its adequacy:

\begin{tabular}{|l|l|l|l|}
\hline Element & Best & Adequate & Poor \\
\hline File name & Ch01StudentName.doc & $\begin{array}{l}\text { Same } \\
\text { name } \\
\text { using } \\
\text { docx } \\
\text { format }\end{array}$ & $\begin{array}{l}\text { Does not include student name in file } \\
\text { name }\end{array}$ \\
\hline $\begin{array}{l}\text { Create a folder of } \\
\text { project } \\
\text { management web } \\
\text { addresses in a web } \\
\text { browser }\end{array}$ & $\begin{array}{l}\text { Folder named Project } \\
\text { Management on the } \\
\text { Bookmarks toolbar with a } \\
\text { working link to Google } \\
\text { Maps }\end{array}$ & $\begin{array}{l}\text { Same as } \\
\text { Best }\end{array}$ & $\begin{array}{l}\text { Project Management folder without a } \\
\text { working link to Google Maps or just a } \\
\text { link to Google Maps as one of the } \\
\text { Favorites but not in a folder }\end{array}$ \\
\hline
\end{tabular}

16. Submit evidence of completion as directed by the instructor.

\section{Create a Folder of Bookmarks in a Web Browser in Firefox 3}

You will visit sites that contain supporting information and useful templates. To save the addresses of these sites, you can create a folder named Project Management in your web browser.

\section{How to Create a Folder of Bookmarks in Mozilla Firefox 3}

1. Open your web browser program. In the address box, type http://maps.google.com and then press Enter. The Google Maps home page displays as shown in Figure 1.29 "Firefox 3 Browser”. 
2. On the toolbar, click the Bookmarks button. The Edit This Bookmark dialog box displays ${ }^{6}$ as shown in Figure 1.30 "Bookmark Dialog Box in Firefox". The default location for the bookmark is the Unsorted Bookmarks.

3. In the Edit This Bookmark dialog box, click the Done button. The web address for http://maps.google.com is placed in the list of unsorted bookmarks, and the Bookmarks toolbar displays, as shown in Figure 1.31 "Firefox Bookmarks Bar".

4. On the Menu bar, click Bookmarks. On the menu, click Organize Bookmarks. The Library dialog box displays, as shown in Figure 1.32 "Library of Bookmarks in Firefox".

5. In the Library dialog box, in the left pane, click Bookmarks Toolbar. On the Library dialog box, on the toolbar, click Organize. On the menu, click New Folder. The Add Folder dialog box displays.

6. In the Add Folder dialog box, in the Name box, type Project Management as shown in Figure 1.33 "Folder Added to the Bookmarks Bar".

7. In the Add Folder dialog box, click the Add button. The new folder is added to the Bookmarks toolbar.

8. In the Library dialog box, in the left pane, click the arrow to the left of Bookmarks Toolbar to show its subfolders. The Project Management folder displays as a subfolder.

9. In the Library dialog box, in the left pane, click Unsorted Bookmarks to show its bookmarks. Locate the link to Google Maps, as shown in Figure 1.34 "Managing Bookmarks".

10. Move the mouse pointer onto Google Maps. Press and hold the left mouse button and move the mouse to move the pointer on the screen to the Project Management folder in the left pane of the dialog box.

The link is moved into the Project Management folder.

11. In the Library dialog box, in the left pane, click the Project Management folder. The link to Google Maps is displayed in the right pane to indicate that it is now in the Project Management folder, as shown in Figure 1.35 "Link Placed in the Project Management Folder”.

12. In the Library dialog box, in the upper right corner, click the Close button. ${ }^{8}$ Close the Firefox web browser.

13. Start the Firefox browser again. On the Bookmarks bar, click the Project Management folder. The link to Google Maps displays under the Project Management folder on the Bookmarks bar, as shown in Figure 1.36 “Project Management Folder on the Bookmarks Bar”.

14. Capture this screen and paste it into a blank word processing document. Save the document as Ch01StudentName.doc

15. In the browser, click the link in the Project Management folder to Google Maps. The Google Maps home page displays. Close the browser.

16. Review your work and use the following rubric to determine its adequacy:

6. This assumes that you have not previously added this site as a bookmark.

7. In the future, description of this type of process will be shortened (e.g., drag Google Maps to the Project Management folder).

8. In the future, description of this process will be shortened (e.g., close the dialog box). 


\begin{tabular}{|l|l|l|l|}
\hline Element & Best & Adequate & Poor \\
\hline File name & N/A & \\
\hline $\begin{array}{l}\text { Create a folder of } \\
\text { project } \\
\text { management web } \\
\text { addresses in a web } \\
\text { browser }\end{array}$ & $\begin{array}{l}\text { Folder named Project } \\
\text { Management on the } \\
\text { Bookmarks toolbar with a } \\
\text { working link to Google } \\
\text { Maps }\end{array}$ & $\begin{array}{l}\text { Same as } \\
\text { Best }\end{array}$ & $\begin{array}{l}\text { Project Management folder without a } \\
\text { working link to Google Maps or just a } \\
\text { link to Google Maps as one of the } \\
\text { Favorites but not in a folder }\end{array}$ \\
\hline & & & \\
\hline
\end{tabular}

17. Submit evidence of completion as directed by the instructor.

\section{Create a Folder of Bookmarks in a Web Browser in Internet Explorer 8}

You will visit sites that contain supporting information and useful templates. To save the addresses of these sites, you can create a folder named Project Management in your web browser.

\section{How to Create a Folder of Favorites in Internet Explorer 8}

1. Open your web browser program. In the address box, type http://maps.google.com and then press Enter. The Google Maps home page displays as shown in Figure 1.37 “Google Maps Home Page”.

2. On the toolbar, click the Favorites button. The Add to Favorites menu displays as shown in Figure 1.38 “Add to Favorites Menu”.

3. To the right of Add to Favorites, click the arrow. ${ }^{9}$

On the menu, click Add to Favorites bar. Click outside the menu to close it. The web address for maps.google.com is placed in the Favorites toolbar and the toolbar is displayed, as shown in Figure 1.39 "Internet Explorer Favorites Toolbar”.

4. On the Favorites toolbar, click the Favorites button. On the menu, click the Add to Favorites arrow. On the menu, click Organize Favorites. The Organize Favorites dialog box displays, as shown in Figure 1.40 "Internet Explorer Favorites Dialog Box". Your favorites and folders will be different from those shown.

5. In the Organize Favorites dialog box, click the New Folder button. A new folder is added with the default name-New Folder-selected and ready to be replaced.

6. Type Project Management and then press Enter. The Project Management folder is added at the bottom of the list of favorite links and folders, as shown in Figure 1.41 "Folder Added to the List of Favorites".

7. Locate the Favorites Bar folder on the list of favorites. Drag the Project Management folder

9. In the future, arrows associated with buttons will be referred to with the button name (e.g., click the Add to Favorites button). 
onto the Favorites Bar folder and release the mouse button. The Project Management folder is a subfolder of the Favorites Bar, as shown in Figure 1.42 "Project Management Folder Moved into the Favorites Bar Folder".

8. In the Organize Favorites dialog box, drag the Google Maps link onto the Project Management folder. The link to Google Maps is placed in the Project Management folder.

9. Click the Project Management folder. The Google Maps link displays in the Project Management folder, as shown in Figure 1.43 "Google Maps Link in the Project Management Subfolder".

10. In the Bookmark Manager dialog box, click the Close button. Close the web browser.

11. Start the Internet Explorer browser again. On the Favorites toolbar, click the Project Management folder. The link to Google Maps displays under the Project Management folder on the Bookmarks bar, as shown in Figure 1.44 "Project Management Folder on the Internet Explorer Bookmarks Bar”.

12. Capture this screen and paste it into Ch01StudentName.doc.

13. In the browser, click the link to Google Maps. The Google Maps home page displays. Close the browser.

14. Review your work and use the following rubric to determine its adequacy:

\begin{tabular}{|l|l|l|l|}
\hline Element & Best & Adequate & Poor \\
\hline File name & Ch01StudentName.doc & $\begin{array}{l}\text {.docx } \\
\text { format }\end{array}$ & Student name not in file name \\
\hline $\begin{array}{l}\text { Create a folder of } \\
\text { project } \\
\text { management web } \\
\text { addresses in a web } \\
\text { browser }\end{array}$ & $\begin{array}{l}\text { Folder named Project } \\
\text { Management on the } \\
\text { Favorites toolbar with a } \\
\text { working link to Google } \\
\text { Maps }\end{array}$ & $\begin{array}{l}\text { Same as } \\
\text { Best }\end{array}$ & $\begin{array}{l}\text { Project Management folder without a } \\
\text { working link to Google Maps or just a } \\
\text { link to Google Maps as one of the } \\
\text { Favorites but not in a folder }\end{array}$ \\
\hline
\end{tabular}

15. Submit evidence of completion as directed by the instructor.

\section{Create a Folder of Bookmarks in a Web Browser in Internet Explorer 9}

You will visit sites that contain supporting information and useful templates. To save the addresses of these sites, you can create a folder named Project Management in your web browser.

\section{How to Create a Folder of Favorites in Internet Explorer 9}

1. Open your web browser program. In the address box, type http://maps.google.com and then 
press Enter. The Google Maps home page displays as shown in Figure 1.45 "Google Maps Home Page”.

2. On the toolbar, click the View Favorites button, and then click the Add to Favorites button. The Add a Favorite dialog box displays as shown in Figure 1.46 “Add a Favorite Dialog Box”.

3. Click the New Folder button. In the Create a Folder dialog box, in the Folder Name box, type Project Management. Confirm that Favorites is chosen in the Create in box, as shown in Figure 1.47 “Create a New Folder”.

4. Click the Create button.

5. In the Add a Favorite dialog box, observe that the new folder displays in the Create in box, as shown in Figure 1.48 "Internet Explorer Add a Favorite Dialog Box".

6. Click the Add button.

7. Click the View Favorites button. Click the Favorites tab, if necessary. Scroll to the new Project Management folder and then click it. The link to Google Maps is stored within the Project Management folder, as shown in Figure 1.49 "Google Maps Link in the Project Management Folder”.

8. In the Bookmark Manager dialog box, click the Close button. Close the web browser.

9. Capture this screen and paste it into Ch01StudentName.doc.

10. In the browser, click the link to Google Maps. The Google Maps home page displays. Close the browser.

11. Review your work and use the following rubric to determine its adequacy:

\begin{tabular}{|c|c|c|c|}
\hline Element & Best & Adequate & Poor \\
\hline File name & Ch01StudentName.doc & $\begin{array}{l}\text {.docx } \\
\text { format }\end{array}$ & StudentName not in file name \\
\hline $\begin{array}{l}\text { Create a folder of } \\
\text { project } \\
\text { management web } \\
\text { addresses in a web } \\
\text { browser }\end{array}$ & $\begin{array}{l}\text { Folder named Project } \\
\text { Management on the } \\
\text { Favorites toolbar with a } \\
\text { working link to Google } \\
\text { Maps }\end{array}$ & $\begin{array}{l}\text { Same as } \\
\text { Best }\end{array}$ & $\begin{array}{l}\text { Project Management folder without a } \\
\text { working link to Google Maps or just a } \\
\text { link to Google Maps as one of the } \\
\text { Favorites but not in a folder }\end{array}$ \\
\hline
\end{tabular}

12. Submit evidence of completion as directed by the instructor.

\section{Create a Folder of Bookmarks in a Web Browser in Safari}

You will visit sites that contain supporting information and useful templates. To save the addresses of these sites, you can create a folder named Project Management in your web browser. 


\section{How to Create a Folder of Bookmarks in Apple Safari}

1. Open your web browser program. In the address box, type http://maps.google.com and then press Enter. The Google Maps home page displays as shown in Figure 1.50 "Safari Browser”.

2. On the toolbar, click the Bookmarks button. A dialog box displays ${ }^{10}$ as shown in Figure 1.51 "Dialog Box in Safari”. The default location for the bookmark is the Bookmarks bar.

3. In the dialog box, click the Add button. The web address for http://maps.google.com is placed on the Bookmarks toolbar, as shown in Figure 1.52 "Safari Bookmarks Bar".

4. On the Menu bar, click Bookmarks. On the menu, click Add Bookmarks Folder. The Bookmarks dialog box displays, as shown in Figure 1.53 "New Folder”.

5. In the Bookmarks dialog box, with untitled folder selected, type Project Management as shown in Figure 1.54 "Folder Added to the Bookmarks Bar".

6. In the Bookmarks dialog box, in the Collections pane, click Bookmarks Bar to display its contents. The Google Maps link displays in the right pane.

7. Move the mouse pointer onto Google Maps. Drag the Google Maps link onto the Project Management folder. The link is moved into the Project Management folder.

8. In the Bookmarks dialog box, in the left pane, click the Project Management folder. The link to Google Maps is displayed in the right pane to indicate that it is now in the Project Management folder, as shown in Figure 1.55 "Link Placed in Project Management Folder".

9. Use the skills you practiced previously to capture an image of this dialog box. If necessary, open Ch01StudentName.doc. Paste the screen capture below the previous screen. Save the file and leave it open.

10. From the Collections pane, drag the Project Management folder onto the Bookmarks toolbar. The Project Management folder is added to the Bookmarks toolbar, as shown in Figure 1.56 "Project Management Folder on Bookmarks Toolbar".

11. In the Bookmarks dialog box, in the upper left corner, click the close button. ${ }^{11}$ Close the Safari web browser.

12. Start the Safari browser again. On the Bookmarks bar, click the Project Management folder. The link to Google Maps displays under the Project Management folder on the Bookmarks bar, as shown in Figure 1.57 “Project Management Folder on Bookmarks Toolbar”.

13. Capture this screen and paste it into a blank word processing document. Save the document as Ch01StudentName.doc.

14. In the browser, click the link to Google Maps. The Google Maps home page displays. Close the browser.

15. Review your work and use the following rubric to determine its adequacy: 
44 [Author removed at request of original publisher]

\begin{tabular}{|l|l|l|l|}
\hline Element & Best & Adequate & Poor \\
\hline File name & Ch01StudentName.doc & $\begin{array}{l}\text { Same as } \\
\text { Best }\end{array}$ & $\begin{array}{l}\text { Other word processing program } \\
\text { format }\end{array}$ \\
\hline $\begin{array}{l}\text { Create a folder of } \\
\text { project } \\
\text { management web } \\
\text { addresses in a web } \\
\text { browser }\end{array}$ & $\begin{array}{l}\text { Folder named Project } \\
\text { Management on the } \\
\text { Bookmarks toolbar with a } \\
\text { working link to Google } \\
\text { Maps }\end{array}$ & $\begin{array}{l}\text { Same as } \\
\text { Best }\end{array}$ & $\begin{array}{l}\text { Project Management folder without a } \\
\text { working link to Google Maps or just a } \\
\text { link to Google Maps as one of the } \\
\text { Favorites but not in a folder }\end{array}$ \\
\hline
\end{tabular}

16. Submit evidence of completion as directed by the instructor. 


\section{Chapter 2: Project Profiling}

A project profile provides a snapshot look at a project and provides valuable information in the development of the project execution plan and the assignment of resources to the project. An analysis of the project environment, including the internal and external environment, provides information that allows the project's parent organization to allocate the organizational resources and assign the appropriate organizational leadership to the project. Most organizations have some form of project profiling process. Some simple processes consider the project size, technology, and location to develop the project profile. This chapter discusses different processes for profiling projects and discusses one method for developing a project profile based on the project's complexity. 


\subsection{Using a Project Profile}

\section{Learning Objectives}

1. Identify project attributes that can be used for project profiling.

2. Define project profiling.

A few years ago, I observed a project manager with a long list of successful projects absolutely struggle with a project. As I looked around, I noticed that often times project managers who do superb jobs on some projects will fail on others. What causes this to happen? Why were project managers successful on some projects but struggling on others?

Even though all projects are by definition unique, there are attributes that are common among projects that allow the characterization or profiling of a project. We can look at just two project attributes and develop some understanding of the project. A large project that will be executed in at least three locations will have a very different profile from a small project that will be executed in one location. These two attributes - size and location-provide information about the project that will enable a manager in the parent organization to assign a project manager with the appropriate knowledge and skills. We can then develop an execution approach to increase the likelihood of success.

Project managers have not always been assigned to projects based on their skills and the skills required by the project. Research by the Construction Industry Institute (Construction Industry Institute, 2009) indicated that the number one criterion for assignment of a project manager to a project was availability. Even if available, the ideal project manager for a large construction project may not be a good fit for a software development project. The technical knowledge needed to manage these projects is not the same and having the wrong technical knowledge may make the difference between a successful project and project failure.

Even within the same industry, like the construction industry, different skills are needed by the project manager for different projects. For example, the construction of an office building in downtown Philadelphia is a very different project from the construction of a chemical plant in Mexico. The differences in these projects require different skills and different execution approaches. Organizations have not had good tools for understanding and matching the needs of a project with the project manager who has the right skills and experience. Developing a project profile is one method for developing an understanding of the project that will allow a systematic approach to developing an execution plan based on the profile of the project and selecting a project manager who has the right kind of experience and skills.

Project profiling is the process of extracting a characterization from the known attributes of a project. The characterization will provide a more comprehensive understanding of the project that should result in developing an appropriate execution approach and the assignment of organizational resources. In 
different terms, project profiling is a process that summarizes what is known about the attributes of a project and places the project into a category with other projects that have similar characteristics. For example, you can characterize a project as a large project or a small project. The size of the project becomes the profiling attribute. You can characterize a project as domestic or global, and the location of the project becomes the profiling characteristic.

A company that has twenty projects may determine that four of these projects are estimated to cost more than \$1 million dollars and the remaining sixteen projects are estimated to cost much less. The company then communicates that all projects over $\$ 1$ million be considered a large project. The company now establishes a rule that large projects will require a project manager with at least five years experience, it will have a vice president as executive sponsor, and it will require formal quarterly reports. In this example, one characteristic is used to develop the organization's project management approach to their twenty projects.

\section{Key Takeaways}

- Project profiles can be created based on attributes such as budget and size to determine a systematic approach to developing an execution plan and selecting a project manager.

- Project profiling is the process of extracting a characterization from the known attributes of a project.

\section{Exercises}

1. Several types of project profiles use budget size, location, and knowledge.

2. Project profiling is the process of extracting a characterization from the known of a project.

3. Describe how location can make a difference in the difficulty of a project.

4. Why is it valuable to create a project profile? Base your answer on the text of this chapter but use your own words.

Project Profiling

Propose another attribute that might be used for project profiling besides budget size, location, and technical knowledge. Include the following in your answer:

- Describe the categories into which you would divide your attribute.

- Describe the skills or knowledge a project manager would need to work on a project in each of your categories. 
48 [Author removed at request of original publisher]

\section{References}

Construction Industry Institute, “Executive Summary,” RR103-11-Optimizing Project Organizations, 2009, https://www.construction-institute.org/scriptcontent/more/rr103_11_more.cfm (accessed June 18, 2009). 


\subsection{Project Profiling Models}

\section{Learning Objective}

1. Identify different methods of typing projects.

Aaron J. Shenhar and Dov Dvir (Shenhar \& Dvir, 1996) developed a typology_classification or profile- of engineering projects that reflected two dimensions. The first dimension reflected the technological uncertainty and ranged from low tech, medium tech, and high tech to super high tech. Although projects involve the use of various levels of technology, Shenhar and Dvir develop criteria for each type of technological uncertainty that enabled the project to be typed. The second dimension reflected the system scope. The system scope dimension ranged from assembly projects that dealt with building a single component, to system projects that included interactive elements, to array projects that included a wide dispersal of interactive systems and subsystems.

Shenhar and Dvir observed that the project execution approach was connected to the project type. The study identified different management patterns associated with project type as well as different management tools and practices. As the project system scope became more complex and the system scope of the project became larger, more sophisticated management tools were put in place to reduce project uncertainty. As project technology increased, project managers became more invested in processes to manage technical issues such as redesign and testing. As projects increased in system scope, project managers became more invested in formal planning and control issues. In later research, Shenhar (Shenhar, 1999) developed recommendations for adjusting the project management approach based on the project typology-systematic classification or profile. For example, project managers will use more risk management techniques (see Chapter 11 “Managing Project Risk” on risk management) when the technological uncertainty is high.

Robert Youker (Youker, 1998) identified basic differences in project types. Among the attributes he used were the uncertainty and risk, level of sophistication of the workers, the level of detail in the planning, the newness of the technology, and the time pressure. Youker also looked at project size, duration, industrial sector, geographic location, number of workers, cost, complexity, urgency, and organizational design as attributes that help determine a project profile.

\section{Key Takeaways}

- The typology of Shenhar and Dvir characterized projects based on the attributes of technological uncertainty and complexity of scope. 
- Youker used the attributes of uncertainty and risk, sophistication of workers, planning detail, industrial sector, location, number of workers, cost, complexity, urgency, and organizational design.

\section{Exercises}

1. The typology of Shenhar and Dvir used attributes of technological and project scope.

2. The typology of Youker used several attributes, including the of workers.

3. What are the two attributes of a project that Shenhar and Dvir used to characterize projects?

Simple versus Complex Profiles

Simple profiles are easier to use than profiles that consider many attributes. Compare the profiling method of Shenhar and Dvir with the profiling method of Youker. Address the following issues:

- Which profiling method would be faster and easier to communicate to team members? (Explain your choice.)

- Which attributes used by Youker but not used by Shenhar and Dvir do you think are important? Explain your answer and give an example of a situation where consideration of the attribute would make a difference to the project.

\section{References}

Shenhar, A. J., Adapting Your Project Management Style: The Key to Project Success (Hoboken, NJ: Stevens Institute of Technology, 1999).

Shenhar, A. J. and Dov Dvir, “Toward a Typological Theory of Project Management,” Research Policy 25 (1996): 607-32.

Youker, R., "Defining the Hierarchy of Project Objectives," IPMA Conference (Slovenia: American Society for Advancement of Project Management, 1998). 


\subsection{Complex Systems and the Darnall-Preston Complexity Index}

\section{Learning Objectives}

1. Describe the characteristics of complex systems.

2. Identify the categories used by the Darnall-Preston Complexity Index.

Understanding and managing complex systems like a project require some systems concepts that have been developed in other disciplines and applied to project management as a tool to make complex projects manageable.

\section{Complex Systems}

When is a project complex? The answer to this question depends on how you define complex. One way to explore this question is to look at complexity models in various disciplines for insights that may apply to project management. In biology, the simplest plant is composed of one cell. As the cellular structure increases in number of cells and the number of connections to other cells increases, the plant life is seen as more complex. In the animal kingdom, the single cell ameba is the simplest animal, and life becomes more complex as the numbers of cells combine to form muscles and organs.

The complexity of a system is usually determined by the number of parts or activities, the degree of differentiation between the parts, and the structure of their connections. Heterogeneous and irregularly configured systems are complex, such as organisms, airplanes, and junkyards. Order is the opposite of complex. Ordered systems are homogenous and redundant, like an interstate toll booth or a production line in a factory. Complex systems have multiple interacting components whose collective behavior cannot be simply inferred from the behavior of the components (Gould, 1996).

In addition to the number of parts, the degree of differentiation between parts and the number, type, and strength of relationships between parts also influences the degree of complexity. For example, the transistors in a computer have three connections to other parts of the computer, but each nerve cell in the human brain can be connected to thousands of other cells in the brain, which is why the human brain is more complex than a computer. Complexity is context dependent. A project is more or less complex in relation to the number of activities, the type and strength of relationships to other project activities, and the degree and type of relationships to the project environment.

Projects are complex adaptive systems. A complex adaptive system is a system consisting of a large number of parts or activities that interact with each other in numerous and various ways. A complex 
adaptive system is adaptive if the activities adjust or react to the events of the environment. Successful adaptive systems adjust in a way that facilitates or allows the system or project to achieve its purpose.

The dependence of the project on the activities, the interdependence of the activities, and the specialization of the activities underscore the relationship dependence of project activities. This relationship dependence is a key aspect of complex adaptive systems. The nature of complex adaptive systems can be probed by investigating the impact of change in one activity and the effect on other activities and the behavior of the whole. Activities must be studied and understood as interrelated, connected parts of the whole. If you remove a computer chip from a computer and the computer powers down, do not assume the purpose of the chip was to provide power to the computer. If you remove or shorten a project kickoff activity, do not assume the project will finish earlier because of the dependence of later project activities on project kickoff activities. Any change to the kickoff activities will impact other activities and the project as a whole.

\section{Chemical Company}

A chemical company was building a new plant in Tennessee with a new design model that was intended to shorten the design phase on the project and lower the cost. The design of the plant was managed by a United States-based company with part of the design work contracted to an Indian company. The engineers in the United States would work on the design and would electronically transfer the design work to India at the end of the day. Engineers in India, many who had graduated from U.S. colleges, continued to work on the design and at the end of the day would electronically transfer the work back to the United States. The project would benefit from differences in time zones that would allow work on the project twenty-four hours per day. The project would also benefit from the lower engineering wages in India. The project approach was abandoned when the project started falling behind schedule. The added complexity of the project offset the scheduling and cost benefit. The project complexity profile became significantly less complex when the execution approach changed from global to domestic partnering. The execution model could have worked but would have required more investment during the start-up phase of the project.

Complex adaptive systems have three characteristics that are also reflected in complex projects.

\section{Complex Adaptive Systems Tend to Self-Organize}

Formal organizational charts indicate reporting relationships but are not very effective at displaying project relationships. Projects organize around the work, phases, or activities. The organization of the project reacts to the nature of the work at any given phase.

During the start-up meeting of a large complex project, the project manager facilitated the development of the project organization chart that included all the major companies and leaders from the client and key subcontractors. After the chart was complete, the project manager ripped the chart up in front of the entire project team to demonstrate his key message, which was that there are formal reporting relationships, but the real leadership and communication will change during the life of the project. In other words, the system will adapt to meet the needs of the project at each phase. During the design phase, 
the engineering team will identify the primary needs and communication will center on supporting the engineering efforts. Later, the procurement team will take the lead as critical equipment and supplies are identified and purchased. Later in the project, the construction team takes the lead as the project moves from the design offices to the field and the engineering and procurement teams support the construction effort.

Informally, the project team reorganizes information flows and priorities to support the current work of the project and a good project manager facilitates this adaptive behavior of the project organization by minimizing the impact of formal authority and processes.

\section{Complex Systems Adapt to Changing Environments}

A deterministic system is a system that will produce the same results if you start with the same conditions. The outcome can be reliably predicted if you know the starting conditions. For example, if you fire a rifle several times at a target, the hits on the target will be closely grouped if all the initial conditions are almost identical. A nonlinear, or chaotic, system can produce wildly different results even if the starting conditions are almost exactly the same. If today's weather pattern is almost exactly the same as it was on a previous date, the weather a week later could be entirely different. Projects are usually nonlinear systems. If we execute an identical complex project three different times, we would deliver three different outcomes. We start with the assumption that the project is deterministic and use scenarios and simulations to develop the most likely outcome, yet a small change such as the timing of someone's vacation or a small change in the delivery date of equipment can change the entire trajectory of a project.

\section{Drug Manufacturing Facility}

A pharmaceutical company in California developed a drug that improved the quality of life for people with arthritis and in some cases prevented serious debilitations and even death. The drug was in the final FDA testing stage, and the company decided to accept the risk and proceed with designing and building a facility to manufacture the drug. The company had done this type of project before, and some managers felt that the outcome would be fairly predictable. The company assigned the lead scientist as the project manager to get the project started. Two weeks into the project start-up, the company president realized the project needed a project manager with more engineering and construction expertise and hired a new person to manage the project. Then the company decided to build the facility on land the company owned in Colorado, and the project team began designing a facility that would fit the existing site. Thirty days into the design phase, the company found an existing facility that could be retrofitted to meet the production needs of the new drug. During the first week of construction, the drug failed an FDA test and the project was placed on hold. This project environment was highly volatile, and the project plan and organization adjusted and evolved to respond to each of these changes.

Not all projects experience this degree of environmental turbulence, yet all projects experience some forms of environment shift during the life of the project. This is one of the reasons project managers develop an aggressive change management process. The purpose of the change management process is not to stop change but to incorporate the change into the project planning and execution processes. 
Projects, like all other complex adaptive systems, must respond to the evolving environment to succeed. Plan as if the project is deterministic but be prepared for unpredictable changes.

In addition to responding to changes in the project environment, the internal project organization and environment is in a constant state of change. New people become members of the team, people quit, retire, and get sick. The office roof starts leaking, headquarters rolls out a new computer program required for all workers, or the project's lead engineer cannot get her immigration visa extended. These are real examples of events that occurred on one project, and the project team adjusted to each event. The adaptation to changes in the project's internal situation while also adapting to the external environment reflects the coevolving nature of a complex adaptive system. An increase in the number of events within the project and the project environment that are likely to change during the life of the project is reflected in an increase in the complexity of a project.

\section{Darnall-Preston Complexity Index}

Profiling a project correctly requires a system that is relatively easy to use but that includes enough attributes to capture all the most important characteristics of a complex project. The Darnall-Preston Complexity Index (DPCI ${ }^{\mathrm{TM}}$ ) achieves this objective by grouping eleven attributes into four broad categories: internal attributes, external attributes, technological complexity, and environmental attributes.

Projects are more likely to fail in the beginning, not in the end. This generalized statement reflects the importance of understanding the environment in which a project will be executed and the importance of developing an execution plan that can be successfully implemented within this environment. Recovery costs can be extremely high for projects where the environment is misread or the execution plan does not address critical issues of the project environment. In addition to cost overruns and delays in the project, execution plans that are not aligned with the project environment can create barriers that make recovery difficult, and in some cases, the business purpose of the project cannot be met. The DPCI is a tool to assist project stakeholders in developing a comprehensive analysis of the project environment and a project execution plan more aligned with that environment. Understanding and aligning a project with the project's environment increase the likelihood of achieving project success.

The foundation of a sound project execution plan is an assessment of the project environment. This assessment provides the information on which the execution plan is built. In the absence of an accurate assessment of the project environment, the project leadership makes assumptions and develops the execution plan around those assumptions. The quantity and quality of those assumptions will significantly influence the effectiveness of the project execution plan. The amount of information available to the project manager will increase over time and assumptions will be replaced with better information and better estimates. As better tools are developed for evaluating the project environment, better information will become available to the project manager.

The project environment includes all the conditions that can influence the outcome or success of the project. Project size, technological complexity, cultural and language barriers, the political landscape, and resource constraints are some of the components of the project environment that can influence the project success. Understanding these influences and developing a project profile creates a foundation for building an effective project execution plan. 
The DPCI is one model for understanding and profiling projects. This index assesses the complexity level of key components of a project and produces a unique project profile. The profile indicates the project complexity level, which provides a benchmark for comparing projects and provides information about the characteristics of a project that can then be addressed in the project execution plan.

The DPCI provides project stakeholders with information about the project to define the experience, knowledge, skills, and abilities needed by the project manager. The DPCI also has implications for the composition, organization, and skills needed by the project leadership team. The DPCI provides information and a context for developing the project execution plan and for assessing the probability of success.

\section{Key Takeaways}

- Complex systems have many different parts that interact with each other in different and often unpredictable ways. They adapt to changes in their external and internal environments.

- The Darnall-Preston Complexity Index (DPCI) groups project attributes into four categories: external attributes, internal attributes, technological complexity, and environmental attributes.

\section{Exercises}

1. Complex systems to changes in their external and internal environments.

2. The Darnall-Preston Complexity Index (DPCI) groups project attributes into four categories: external, internal, and environmental.

3. What are the characteristics of a system that make it complex?

Complex Systems

Consider the example of the drug manufacturing facility. Describe in your own words how this project demonstrated the attributes of a complex system.

- External

- Internal

- Technological

- Environmental

\section{References}

Gould, S. J., Full House: The Spread of Excellence from Plato to Darwin (New York: Three Rivers Press, 1996). 


\subsection{Darnall-Preston Complexity Index Structure}

\section{Learning Objectives}

1. Describe each of the external attributes that contribute to project complexity.

2. Describe each of the internal attributes that contribute to project complexity.

3. Describe each of the technological attributes that contribute to project complexity.

4. Describe each of the environmental attributes that contribute to project complexity.

The Darnall-Preston Complexity Index (DPCI ${ }^{\mathrm{TM}}$ ) is designed to develop a project profile that reflects different aspects of the project that will influence the approach to leading and executing the project. The DPCI is built on four categories of attributes:

1. External. Environmental attributes that are in existence at the beginning of the project, such as size, duration, and available resources

2. Internal. Clarity of project objectives, the clarity of scope, the organizational complexity, and stakeholder agreement

3. Technological. Newness of the technology and familiarity of team members with the technology

4. Environmental. Legal, cultural, political, and ecological

The DPCI was developed around four assumptions:

1. All projects are unique.

2. Projects have common characteristics.

3. These characteristics can be grouped together to create a project profile.

4. There is an optimum execution approach for each project profile and therefore an optimum set of skills and experience for the project manager and execution team.

\section{External Attributes}

The external attributes include those issues that are typically established early in the project definition phase and are usually outside the direct control of the project management team. The project size can be a product of the dollars needed to execute the project or project cost. The cost of the project is estimated during the conceptual phase of the project. At the time the project is authorized, the cost or size of the 
project is established. The duration or time allocated to complete the project and the resources available are also attributes that are established when the project is authorized.

\section{Size}

Project size is a relative concept. How do we decide if something is large or small? A 150-pound person is big if the person is ten years old. A 150-pound person is small if the person is a professional football lineman. The frame of reference provides the context in which size is determined.

The size of a project is also relative. A \$250 million oil refinery expansion is a relatively small project in an industry where billion dollar projects are common. A \$250 million pharmaceutical development project or software development project would be considered a large project. The size of a project is determined by the context of the industry and the experience of the team executing the project.

Within the construction industry, firms usually specialize in projects that fall within a defined range. Small firms usually execute small projects and large firms usually execute larger projects. There is a size range for which the company experience, management skills, tools, and work processes are primarily designed. This size range or comfort zone exists for both the company and the members of the project team executing the project.

When a project team executes a project outside their comfort zone, stress is placed on both the tools and project team. When a project is larger than the comfort zone of a company, stresses are placed on the ability to provide experience and appropriate work processes, and the results are typically cost overruns and schedule delays. To mitigate this stress, some companies will divide large projects into smaller projects and execute the smaller projects with separate dedicated staff and resources. The key to success then becomes the coordination of the small projects to behave as if they are one large project.

\section{Copper Mining in Argentina}

One example of this process was a copper mining project in Argentina. The comfort zone of the company was projects ranging from $\$ 150$ million to $\$ 500$ million. Projects over \$500 million were divided into smaller projects. The mining project was estimated to cost a little over $\$ 1$ billion and the project was divided into three projects, each with a project manager and leadership team. Although the projects shared some resources and reported to an oversight project manager, each project developed a separate execution plan that included a budget and schedule.

When a company is executing a project that is much smaller than the company norm, resources are often misused and inappropriate work processes are utilized. The result often increases the project costs. Some companies with a history of executing large projects have set up a small project group to execute smaller projects. These groups establish a different culture, develop appropriate work processes, and use tools designed to execute smaller projects.

The more the project size is outside the comfort zone of the project, the more stress is created for the 
project. This is true on both ends of the spectrum. Both smaller and larger projects that fall outside the comfort zone of the project management team will create stress for the project. New skills, tools, and processes will need to be developed to manage the project, and this activity will absorb management time and energy. The higher the stress level created by executing a project outside the comfort zone of the organization, the greater the impact on the complexity level of the project.

\section{Duration}

The duration of a project is often set by the parent organization that charters the project with a deadline that reflects the business purpose of the project. The following are examples of projects with end dates that are established to meet the organization's business purpose:

- A new software program for a university to be implemented in time for registering students in the fall

- A new product to be introduced to the marketplace at the industry's major conference

- A new high school to be constructed and open next fall

The project team also estimates the duration of the project and establishes a project end date based on normal work (e.g., forty hours per week) and the availability of resources.

Sometimes the normal time needed to complete a project is longer than the time available.

\section{Super Bowl Hotel Space}

The investors in a planned hotel start booking rooms for an upcoming Super Bowl weekend a year before the hotel is finished. This is six weeks ahead of the time estimated to build and open the hotel. People will be working overtime, suppliers will be paid a bonus to supply materials early, and management is meeting with city officials to expedite permitting issues. A new project schedule is developed based on these changes to the execution approach, and now the project schedule has zero float.

The result of this six-week compression to the project schedule is additional stress on the project. Significant management time and energy will be invested in tracking and managing schedule issues. Every issue that arises will need to be resolved quickly and involve the project's senior manager to assure the project schedule does not slip. This additional stress increases the overall project complexity.

\section{Resource Availability}

Projects require both human and tangible resources. The project requires people with the right experience, knowledge, and skills to accomplish the assigned tasks. Construction projects typically require resources such as bricks and cranes. Some projects require specialized subcontractors with skills not 
found within the project team. Each of these resources required by the project will be needed at the point in the project schedule when the materials or skills are required. When these resources are scarce or not available, additional management time and energy is needed.

\section{Boeing Dreamliner}

In 2003, Boeing announced the development of the new 787 Dreamliner Airplane. The airframe for the new airplane was a new composite material. During the same period that Boeing was beginning construction of the new manufacturing facility, other new planes were announced, and the Air Force increased its demand for people with airplane manufacturing and maintenance experience. A project was chartered to train the people the new plant would need to manufacture the Boeing Dreamliner. The project manager found that the people with the skills and knowledge needed to develop the curriculum and train the workers were in short supply. In addition to the lack of skilled trainers, the materials needed for the workers to train on were also scarce. The project manager dedicated significant time and energy developing the resources the project needed.

When resources needed to execute the project are not readily available, the project leadership dedicates more management time and energy to acquiring the resources or finding innovative solutions to accomplish the project goals without the needed resources or with creative alternative solutions. The more time and energy the management team must dedicate to searching for resources or alternatives, the more stress on the project. The more scarce and more important the resources, the more stress that is placed on the project.

\section{Internal Attributes}

The internal attributes are within the control or influence of the project manager. Internal attributes include clarity of objectives, clarity of scope, the organizational complexity, and stakeholder agreement. Although the clarity of objectives, as with the other attributes, can be improved during the life of the project, the project profile reflects the project at a given time. If the project objectives are not clear during the evaluation of the project, this lack of clarity impacts the complexity of the project.

\section{Clarity of the Project Objectives}

Project decisions are made based on how these decisions help the project meet its objectives. If the objectives are unclear, the team will not make the best decisions. The greater the confusion for the project team on the goals and objectives of the project, the greater the impact on the complexity of the project. 


\section{Confusion Over Objectives in Philadelphia}

A consultant was asked to evaluate the likelihood of success of a large project in Philadelphia. The consultant interviewed the project leadership and asked if the goals of the projects were clear. Each member of the leadership team responded that the goals and objectives were clear. When asked what the goals were, the answers varied greatly.

\section{Clarity of Objectives Saves Millions}

A critical piece of equipment was being fabricated in Europe for a construction project in South America. The cost to transport the equipment by air was $\$ 200,000$ more than by ship. Transporting the equipment by ship would also delay the project two months. Early in the project, it was determined that any delay in the project would cost the project over \$1 million per month. Because the goals of the project were well understood, the decision to transport the equipment by air was made quickly and easily.

\section{Island Ecology Protected}

A large mining company initiated a copper mining project on an ecologically sensitive island in Indonesia. The company stated very clearly and forcefully that every effort would be made on the project to protect both the human and natural environment of the island during construction and operation. Every major decision passed through an evaluation of the impact on the island ecology. Although the island ecology increased the complexity of the project, the clear goals mediated the project complexity.

\section{Clarity of Scope}

The project scope defines what is inside the project and what is outside. Does the project to train five hundred technicians for the Boeing 787 include recruiting and assessing potential employees? The project scope did include recruitment and assessment, but hiring processes and drug testing belonged to Boeing. This scope was clear about which responsibilities belonged to the contractor doing the training and which responsibilities belonged to the parent organization.

Not all project scopes are this clear. The development of a clear project scope depends on information available about what products and services will be required. A project to develop a vaccine for a new strain of flu may not include sufficient information to develop the processes the team will utilize to understand the flu virus and develop a vaccine. As the team develops more information, the scope can be further developed. 
Leadership time and energy will be focused on developing scope clarity. The lack of clarity and the amount of time needed by the leadership team to develop a clear scope will add to the project complexity.

\section{Organizational Complexity}

The structure of the project's client organization and the organizational decision-making processes influence the project complexity. A project with one client as the central point for making decisions and providing client approvals and technical information has only one relationship to manage and a streamlined communication process. Projects with a team representing the client require more of the project manager's time and energy managing the client relationships and communication process. The client team approach brings more expertise and often more comprehensive project oversight, but it adds to the project complexity.

\section{Stakeholder Agreement}

Often there is more than one major stakeholder in the project. An increase in the number of stakeholders adds stress to the project and influences the project's complexity level. The business or emotional investment of the stakeholder in the project and the ability of the stakeholder to influence the project outcomes or execution approach will also influence the stakeholder complexity of the project. In addition to the number of stakeholders and their level of investment, the degree in which the project stakeholders agree or disagree also influences the complexity of the project.

A small commercial construction project will typically have several stakeholders in addition to the client. All the building permitting agencies, environmental agencies, and labor and safety agencies have an interest in the project and can influence the execution plan of the project. The neighbors will have an interest in the architectural appeal, the noise, and the purpose of the building.

\section{Tire Plant in India}

A U.S. chemical company chartered a project team to design and build a plant to produce the raw materials for building truck tires designed for nonpaved roads. The plant was to be built in India a few years after an accident that killed several Indians and involved a different U.S. chemical company. When the company announced the new project and began to break ground, the community backlash was so strong that the project was shut down. A highly involved stakeholder can significantly influence your project. 


\section{Wind Turbine on a College Campus}

A small college in South Carolina won a competitive grant to erect and operate a wind turbine on campus. The engineering department submitted the grant as a demonstration project for engineering students to expose students to wind technology. The campus facilities department found only one location for the wind turbine that would not disrupt the flow of traffic on campus. The engineering department found that location unacceptable for students who had to maintain the wind turbine. The county construction permitting department had no policies for permitting a wind turbine and would not provide a building permit. The college had to go to the county council and get an exception to county rules. The marketing department wanted the wind turbine placed in a highly visible location to promote the innovativeness of the college.

Each of the college's stakeholders had a legitimate interest in the location of the wind turbine. The number of stakeholders on the project, multiplied by their passion for the subject and the lack of agreement on the location, increased the complexity of the project. Significant time and resources of the project will be dedicated to identifying, understanding, and managing client expectations.

\section{Technological Complexity}

The technology of a project refers to the product of the project and not the technology used to manage the project. This technology is typically unique to the industry. A pharmaceutical project technology is the drug-making technology or pharmacology. The technology for a project to build a new automobile plant is the car production process. The key stress on the project is the newness of the technology. What aspects of the technology are known, and what aspects are unknown? Does the project combine technologies on the project that have never been combined?

Project technology that is newer and more complex will require more technological expertise on the project team.

\section{Family Life Center}

A church in western New York decided to build a new family life center that would not use electricity from the power grid. The charter of the project included statements that required the building to use renewable power sources and have an environmentally friendly footprint. The project required the adaptation of a new technology for producing and managing power, location of the building relative to the sun, and landscaping to minimize water usage. Most of the technology was tested, and the project team brought in experts to help design and implement a program to meet the requirements of the project. The technology of the project required the project team to develop a new understanding of this technology and work processes to adapt the project to address the requirement of the technology. 
Typically, the newer the technology and the less familiar the project team is with the technology, the greater the stress and the contribution to the complexity of the project.

\section{Project Environment}

The project environment includes all the issues related to the environment that will influence the development and execution of the project plan. A project to build an airport expansion in Pittsburgh, Pennsylvania will have very different legal, cultural, political, and ecological issues to address from an airport expansion in São Paolo, Brazil. The environment attributes in Brazil require more planning, resources, and leadership attention to successfully execute the project. The greater the number and difficulty of the issues, the greater the influence on the complexity of the project.

\section{Legal}

The legal issues on a project can be broad and include many different levels of government. Most local governments have various permits, such as business licenses and building permits, required to do work. Some projects will have security issues and will work with local law enforcement.

Workforce laws vary significantly in country, regional, and local jurisdictions. The hiring and management of workers can be a complex and time-consuming issue for some projects. Companies not used to working in a union environment will invest project resources in learning and adapting to the new environment. Scheduling holidays, supporting maternity leave, and dealing with workforce reduction issues surrounding project closeout will vary in each environment, industry, and project. Understanding and managing workforce issues on a project can be simple or very complex.

National, regional, and local taxes require a project tax approach or policy on most international projects and some domestic projects. Duties for equipment and material brought into a country add complexity to the procurement plan. Equipment used temporarily to execute the project, such as a crane, is treated differently than permanently installed equipment, such as a pump. In some countries, a third party is hired to expedite the flow of materials through complex custom processes.

\section{Copper Mining in Argentina}

The new president of Argentina instituted a program to encourage economic development. One of the projects to support this program was a copper mining project in northern Argentina. This is the desert area of Argentina with a basic agrarian economy. A joint venture was formed with the encouragement of the Argentina government between a Canadian and Australian Company with all three entities owning a share of the new company.

The conceptual design work was done in Canada with support from offices in Chile, Argentina, and the United States. A U.S. contractor was awarded the contract to design, procure equipment, and build the mine. The project leadership team included members from the United States, Canada, Australia, Argentina, Chile, Puerto 
Rico, Cuba, and Lebanon. Materials were procured, transported, and brought through customs from twenty-one different countries. Legal issues on this project consumed a great deal of management attention and sometimes affected the project execution. Materials were occasionally delayed in customs, people with critical skills could not get visas to enter Argentina, and which country’s laws would apply to the contracts had to be debated.

Not every project will have significant legal issues. When legal issues are involved, they are typically significant and will add to the complexity of the project. Understanding the legal issues than can affect the project and developing a plan to address these issues will reduce the complexity of the project.

\section{Cultural}

Culture is a term that reflects the community's assumptions, norms, values, and artifacts. Community includes the parent organization charting the project, the local community or communities where the project is executed, and the region and country where the project is located. The project team must understand the community's culture and its potential impact on the project.

Culture also defines the meaning of work, truth, the value of nature, relationships, and how to communicate. Projects executed in various cultures will often experience cultural conflict.

\section{Gender Difficulties in Argentina}

A project team from the United States was responsible for executing a project in Argentina. The U.S. leadership team included women in key leadership positions, and the Argentines refused to take direction from females. The U.S. team believed strongly in their leadership capability and refused to make changes. This conflict was settled by senior managers of both organizations, and rules were established that respected all team members in leadership roles. The conflict did not go away, but the team was able to successfully execute the project with the original team. Delays were experienced on the project that could be traced to this cultural conflict.

Many organizations have rule-based cultures. Institutions of higher learning, organizations related to judicial organizations, and most government organizations are examples of rule-based organizations. The organizational structure and culture inhibits risk taking through established rules and policies. Projects are goal based and focus on plans and processes to achieve goals. Goal-based cultures promote assuming risk to achieve goals. Projects that are closely tied to a rule-based parent organization will often find conflict with the parent organization's need to follow rules and the project's need to accomplish goals. This conflict creates additional stress that adds to the project complexity.

On global projects, language, cultural conflict with the role of women, the religious role in daily activities, and even the concept of time can becomes issues on the project. These issues require project leadership to resolve and they add to the project complexity. In some countries and even different companies in the same country, meetings start on time, and a person arriving five minutes late will cause major dis- 
ruption. In other situations, meetings can start within thirty minutes of the starting time without anyone objecting.

\section{Communication Problem in India}

A team of project experts was sent to India to evaluate a large construction project. The team arrived and reviewed the project documents and found the project on time and meeting all project goals. After spending three days with various contractors and team managers, the team discovered the project was significantly behind schedule and would miss an important window during the monsoon season. A culture existed on the project where workers told the project management what they expected to hear, and the difference between the progress of the project team and the progress reports became so large that the difference could not be reconciled during the original schedule of the project.

An increase in the number of cultures represented on the project team raises the cultural complexity. Increases in the number of cultures with which the project team must interface also increase the complexity of a project. Although this cultural diversity creates leadership challenges, it also presents opportunities. The diversity of cultures presents various approaches to solving problems, and the project manager may find innovative solutions easier to develop with a diverse project team.

\section{Political}

Every project operates within one or more communities that reflect organizational dynamics and power struggles. The more important the project is to the organizational leadership, the more invested various organizational leaders will be in the project. The more people that become invested in the project and the more influence these people exhibit on the resources and activities of the project, the more time and energy will be expended by the project team in managing these outside influences. This additional stress on project leadership time and resources adds complexity to the project.

\section{Stakeholders and a Bridge Project}

The Department of Highways chartered a project to upgrade a number of bridges that crossed the interstate in one of the larger cities in South Carolina. The closing of these bridges severely impacted traffic congestion, including a large shopping mall. The contract included provisions for minimizing the impact on the traffic and communities near the construction areas. This provision allowed businesses or interested parties to review the project schedule and make suggestions that would lessen the impact of the construction. The project leadership invested significant time and resources in developing alignment among the various political stakeholders on the project approach and schedule. 


\section{Ecological}

Projects have the potential to impact the living conditions or the health of people, plants, and animals. In addition to the potential impact to land, water, and air, the ecology includes the sights and sounds that can impact the quality of life. An increasing number of clients expect the project team to minimize the impact of the project on the ecology. An ecology that is more sensitive to disruption and a more disruptive technology will place greater stress on the project and increase the project complexity. Construction projects that require the use of explosions to effectively move rocks and dirt, projects that require the addition of twenty-five people in existing office space, and projects that require the release of strong odors like those from adhesives in an office environment will all impact the ecology. The project team develops means and methods to minimize the impact of the disruption in a manner consistent with the requirements as communicated by the client. The effort that is needed to minimize the ecological impact will influence the complexity of the project.

The ecology will also impact the execution of a project. The weather is an attribute of most construction projects. Construction projects in India are often scheduled around the monsoon season, and construction projects in the Caribbean consider the hurricane season. A project to build an offshore wind farm will require an understanding of the ocean currents, the wind currents, and temperature fluctuation to understand the impact of the ecology on the project execution plan.

The larger the number of potential ecological attributes and the greater the impact of each attribute, the greater the influence on the project complexity.

\section{Key Takeaways}

- The external attributes are the relative size of the project, duration of the project, and the available resources.

- The internal attributes are the clarity of its scope, the complexity of the organization, and the agreement among stakeholders.

- The technological attributes are the technology of the product (not the technology used to manage the project), the newness of the technology, and the familiarity of the team with the technology.

- The environmental attributes are the legal issues, cultural conflicts, political interests, the impact of the project on the ecology, and the impact of the ecology on the project.

\section{Exercises}

1. The external attributes considered in the DPCI are relative size, and available resources.

2. The internal attributes considered in the DPCI are clarity of scope, complexity of the organiza- 
tion, and agreement among

3. The technological attributes considered in the DPCI are of the technology and familiarity of the team with the technology.

4. The environmental attributes considered in the DPCI are , cultural, political, impact on the ecology, and impact of the ecology on the project.

5. Under what circumstances would a large project qualify for a low DPCI score?

6. Describe an organization structure that would receive a high score for complexity.

7. Does the technology attribute refer to the technology used by the project team or the project itself?

8. Give an example of a cultural problem that would have a high-complexity score.

9. Give an example of an ecological problem that would have a high-complexity score.

10. What is the difference between an external and an internal attribute in the DPCI?

Behind the Scenes

Stanley Portny (Portny, 2007) advocates that as a project manager, you research the source of a project to determine who had the original idea by asking questions of your boss, reading meeting minutes and feasibility studies, and checking other correspondence and contacts. The purpose of this investigation is to find out who is most likely to champion the project if you have trouble, who opposed the project, or whose interests will be harmed by the project. Consider this advice in light of the Darnall-Preston Complexity Index and answer the following questions:

- Is this an external, internal, technological or environmental attribute? Explain your reasoning and refer to the definitions provided. A case can be made for putting it in more than one.

- What might you find that would increase the project's complexity and what might you find out that would reduce the complexity? Provide examples of each.

\section{References}

Portny, S. E., Project Management for Dummies, 2nd ed. (Hoboken, NJ: Wiley, 2007). 


\subsection{Exercises}

Exercises at the end of the chapter are designed to strengthen your understanding and retention of the information recently acquired in the chapter.

\section{Essay Questions}

Write several paragraphs to provide more in-depth analysis and consideration when answering the following questions.

1. Compare the attributes used by the Darnall-Preston Complexity Index and those used by Youker. Which attributes are used in both typologies? Which attributes are not in common? If you chose to add one attribute to either typology what would it be? Explain your answer.

2. Complex systems. A complex system adapts to changes in its external and internal characteristics. Describe a project with which you are familiar that has experienced changes in its external or internal characteristics during the life of the project and describe how the project manager and the management team changed their behavior to adapt to the new situation or how they failed to adapt and the result of that failure.

\section{Discussion}

The exercises in this section are designed to promote exchange of information among students in the classroom or in an online discussion. The exercises are more open ended, which means that what you find might be completely different from what your classmates find, and you can all benefit by sharing what you have learned.

1. Institutional memory. One of the responsibilities of a project manager is to keep a history of past projects to create an organizational knowledge base. Do you think using the DPCI ${ }^{\mathrm{TM}}$ as a basis for organizing those past projects would be useful? How would you go about creating a storage and retrieval system that uses the DPCI?

2. Environmental impact. Describe a project that might have an impact on the environment and the steps the project manager might have to take. Describe the score you would give this attribute if you were using the DPCI. 


\subsection{Software and Technology Exercise}

\section{Learning Objective}

1. Calculate and interpret the DPCI.

\section{Calculate the DPCI}

Russell Darnall (Darnall 1996) introduced a method that rates characteristics of a project on a scale from 1 to 5. The characteristics are grouped into four categories: external attributes, internal attributes, technology, and project environment. Each category is rated based on the average of the scores of its attributes.

A method of calculating and representing the final Darnall-Preston Complexity Index (DPCI) was added by John Preston and Darnall in this publication to allow the DPCI to be represented by a four-number code. The rules for calculating the DPCI are as follows:

1. The scores in each category are averaged and then rounded to a whole number to create a category rating.

2. Averages that are halfway between two whole numbers are rounded up.

3. If one of the characteristics has a score that is higher than the average for that category by 2 or more, the average for that category is shown in boldface.

A project can be quickly characterized using the DPCI. For example, a project that is similar in size to previous projects with plenty of time to complete it and with adequate resources available would have a low average external complexity score of 2 (see Table 2.1 “Calculating the DPCI”). If there is significant disagreement among the stakeholders on the objectives and several scope issues are not well defined because there is overlap between responsibilities of groups within the organization, the internal complexity score would be high—4 (see Table 2.1 "Calculating the DPCI”). If the project relies on technology that is fairly new and some of the team members are unfamiliar with it, the average score would be 2.5, rounded up to 3 (see Table 2.1 "Calculating the DPCI”). If the legal and cultural attributes have low complexity, and there is little impact on the project by ecological factors, the average is low-2 - in spite of a high complexity score for the effect of politics of the project. In this case, the score is shown in boldface to warn the user that there is an individual score that is at least two points higher than the average, and the details of that category must be investigated. 
70 [Author removed at request of original publisher]

\begin{tabular}{|l|l|l|l|l|l|}
\hline Category & Attribute & Score & Average & Rating & DPCI \\
\hline External & Size & 2 & 2 & 2 & 2.4 .3 .2 \\
\hline & Duration & 1 & & & \\
\hline Internal & Resource availability & 2 & & & \\
\hline & Clarity of objectives & 4 & 3.75 & 4 & \\
\hline & Clarity of scope & 3 & & & \\
\hline & Organizational complexity & 4 & & & \\
\hline Technological & Stakeholder agreement & 4 & & & \\
\hline & Newness & 2 & 2.5 & 3 & \\
\hline & Familiarity of team & 3 & & & \\
\hline Environmental & Legal & 2 & 2 & 2 & \\
\hline & Culture & 1 & & & \\
\hline & Political & 4 & & & \\
\hline & Ecological & 1 & & \\
\hline
\end{tabular}

The final DPCI in this example is 2.4.3.2, which tells you at a glance that this project has fairly low external complexity, a fairly high degree of internal complexity, and a moderate technological complexity and that a majority of the environmental attributes are low complexity, but at least one of them has a rating of 4 or 5 and needs attention.

Projects with different profiles require different management approaches, applications of different tools, and mitigation of different levels of risk. Information derived from the complexity profile can be used in the selection of the project manager, the project leadership team, and the execution approach to the project and in the analysis of the project risk.

There is no generally agreed-upon project typology or classification system. In this text, we will utilize the DPCI as a tool for analyzing projects and choosing appropriate tools, but the same skills could be used with other taxonomies.

\section{How to Calculate a DPCI Rating}

Assume that a project went through the DPCI rating process and it achieved the following scores in each attribute: 


\begin{tabular}{|c|c|c|c|c|c|}
\hline Category & Attribute & Score & Average & Rating & DPCI \\
\hline \multirow[t]{3}{*}{ External } & Size & 1 & & & \\
\hline & Duration & 1 & & & \\
\hline & Resource availability & 2 & & & \\
\hline \multirow[t]{4}{*}{ Internal } & Clarity of objectives & 1 & & & \\
\hline & Clarity of scope & 4 & & & \\
\hline & Organizational complexity & 4 & & & \\
\hline & Stakeholder agreement & 3 & & & \\
\hline \multirow[t]{2}{*}{ Technological } & Newness & 3 & & & \\
\hline & Familiarity & 2 & & & \\
\hline \multirow[t]{4}{*}{ Environmental } & Legal & 2 & & & \\
\hline & Culture & 1 & & & \\
\hline & Political & 4 & & & \\
\hline & Ecological & 1 & & & \\
\hline
\end{tabular}

1. Start a spreadsheet program such as Excel 2010. Refer to Table 2.2 "Calculating the DPCI" and then type the category and subcategory labels into the first two columns and the scores in column C. Some of the labels will appear to be cut off if there is not enough width to display the entire label, as shown in Figure 2.9 "Labels in a Spreadsheet”.

2. Click cell B15 and then type your name.

3. Capture a screen that shows the worksheet at this point in its development with your name in cell B15. (Refer to Section 1.7 "Web Exercise" and Section 1.8 "Software and Technology Exercises”, if necessary, for instruction on how to capture a screen.)

4. Open a new word processing document and then paste the screen capture into the new document. Your name must be included in the screen capture. Save the document as Ch02DPCIStudentName using the Word 2003 .doc file format.

5. Move the mouse pointer to the boundary between the headers of columns A and B, where it turns into a double-headed pointer. Double-click the boundary to automatically adjust the column width to the widest label, as shown in Figure 2.10 “Adjust Column Width”. Alternatively, drag the boundary to the right to adjust the column width manually.

6. Repeat the skill you practiced in the previous step to widen column B to accommodate the longest label (or your name) in column B.

7. Click cell D3. Type $=A V E R A G E(C 1: C 3)$ and then press Enter. The average of numbers in cells C1, C2, and C3 is calculated and displayed in cell D3. A sequence of cells is denoted by the first cell address and the last cell address separated by a colon.

8. Click cell D7. Type $=A V E R A G E(C 4: C 7)$ and then press Enter. 
9. Use the skill you practiced in the previous steps to calculate the averages of the technological and environmental categories and display them in cells D9 and D13 respectively.

10. Click cell D13. Notice the formula displays in the formula bar, as shown in Figure 2.11 “Adjusted Column Widths and Average Functions" (You may ignore the alert boxes or notations due to the unused cells in column D.)

11. Capture this screen and then paste it into the word processing document Ch02DPCIStudentName below the previously captured screen.

12. In the spreadsheet, click cell E3. Type $=\operatorname{ROUND}(D 3,0)$ and then press Enter. The ROUND function requires two types of information. The first is a cell address and the second is the decimal place to which the number in that cell will be rounded. A zero indicates rounding to whole numbers. (See the spreadsheet Help menu if you would like more information about the ROUND function.)

13. Use the skill you practiced in the previous step to calculate the rounded values for each category. Click cell E13 to display the ROUND function in the formula bar, as shown in Figure 2.12 "Round Function Rounds to the Nearest Whole Number". Notice the ROUND function in cell E9 rounded the number 2.5 up to 3. This is the method used for rounding in the DPCI.

14. Capture this screen and paste it into Ch02DPCIStudentName.doc.

15. In cell B16, type DPCI rating:. In cell C16, type the DPCI rating 1.3.3.2 and then press Enter.

16. Visually examine the individual scores in column $\mathrm{C}$ and the rounded averages in column $\mathrm{E}$. Determine if any of the individual scores is 2 points or more higher than the rounded average. Notice that the political rating is 4 , and the environmental rating is 2 . Also notice that the clarity of objectives rating is 1 and the internal rating is 3. According to the DPCI method, the environmental rating should be displayed in bold. (Even though the internal rating has a score that is 2 points lower than the rounded average, it is not bold. An individual rating must be 2 points or more higher than the rounded average-not lower.)

17. Click cell C16. On the formula bar, select the 2 and then on the ribbon (or formatting toolbar) click the Bold button. The rating for environmental complexity is emphasized with bold font to indicate there is a significantly higher individual rating that should be considered, as shown in Figure 2.13 "Ratings That Contain Higher Individual Ratings Are Bold”.

18. Capture this screen and paste it into Ch02DPCIStudentName.doc. Save and close Ch02DPCIStudentName.doc.

19. In the spreadsheet, save the file as Ch02DPCIStudentName.xls using the Excel 2003 .xls file format.

20. Close the spreadsheet.

21. Review your word processing file, Ch02DPCIStudentName.doc and use the following rubric to determine its adequacy: 


\begin{tabular}{|l|l|l|l|}
\hline Element & Best & Adequate & Poor \\
\hline $\begin{array}{l}\text { File } \\
\text { name }\end{array}$ & Ch02DPCIStudentName.doc & Word 2010 .docx version & $\begin{array}{l}\text { Other file name or } \\
\text { format }\end{array}$ \\
\hline $\begin{array}{l}\text { Calculate } \\
\text { and } \\
\text { interpret } \\
\text { the DPCI }\end{array}$ & $\begin{array}{l}\text { Sequence of screen captures } \\
\text { shows the development of } \\
\text { the spreadsheet }\end{array}$ & $\begin{array}{l}\text { One or two screens taken out of } \\
\text { the exact sequence described; } \\
\text { student name displayed clearly in } \\
\text { each of the development screens }\end{array}$ & $\begin{array}{l}\text { Only one image of } \\
\text { the finished } \\
\text { spreadsheet; } \\
\text { development by the } \\
\text { student not proven }\end{array}$ \\
\hline
\end{tabular}

22. Review your spreadsheet file, Ch02DPCIStudentName.xls, and use the following rubric to determine its adequacy:

\begin{tabular}{|l|l|l|l|}
\hline Element & Best & Adequate & Poor \\
\hline File name & Ch02DPCIStudentName.xls & $\begin{array}{l}\text { Excel 2010 version using } \\
\text {.xlsx }\end{array}$ & Other file name \\
\hline $\begin{array}{l}\text { Calculate } \\
\text { and } \\
\text { interpret } \\
\text { the DPCI }\end{array}$ & $\begin{array}{l}\text { AVERAGE and ROUND } \\
\text { functions used correctly; } \\
\text { bold feature used correctly }\end{array}$ & $\begin{array}{l}\text { AVERAGE and ROUND } \\
\text { functions not in the cells } \\
\text { specified but used the correct } \\
\text { ranges }\end{array}$ & $\begin{array}{l}\text { Incorrect ranges in the } \\
\text { functions; last number in } \\
\text { the DPCI rating not bold }\end{array}$ \\
\hline
\end{tabular}

23. Submit the file(s) as directed by the instructor. 


\section{Chapter 3: Project Phases and Organization}

This chapter provides an overview of the organizational structure and phases of a project. The complexity level of a project influences the organizational structure and the resources and skills needed at each phase. This chapter also provides an overview of the typical functions within the organizational structure of a project. 


\subsection{Project Phases}

\section{Learning Objectives}

1. Identify the phases of a project.

2. Describe the types of activities in each phase of a project.

Projects, by definition, have a beginning and an end. They also have defined phases between the project kickoff and project closeout. A phase represents a grouping of similar activities that has a very loosely defined beginning and end. Phases are also typically sequential, where the prior phase is essentially complete before the beginning of the next phase. Phases do not have clear-cut end dates and some activities in an early phase of the project will continue into the later phases. This is in contrast to project beginning and ending dates and milestone dates, which do have clearly defined dates with the expectation that these dates will be met.

\section{Initiation}

The initiation phase of a project represents the activities associated with starting up the project. Activities during the initiation phase include project kickoff meetings, identifying the project team, developing the resources needed to develop the project plan, and identifying and acquiring the project management infrastructure (space, computers). On projects where the scope of work for the project is not well defined, the project team will invest time and resources in developing a clearer scope of work. On projects where the major project stakeholders are not aligned, the project team will expend resources and time creating stakeholder alignment.

The activities that occur within the initiation phase of the project vary on each project. They include all the activities necessary to begin planning the project. The initiation phase typically begins with the assignment of the project manager and ends when the project team has sufficient information to begin developing a detailed schedule and budget. Unlike project milestones, some activities associated with project initiation may be delayed without delaying the end of the project. For example, it is advantageous for the project to have the major project stakeholders aligned from the beginning, but sometimes it is difficult to get the commitment from stakeholders to invest the time and resources to engage in an alignment process. Sometimes it is only after stakeholders begin observing progress on a project that the project manager can facilitate the stakeholder alignment processes.

The knowledge, skills, and experience needed on the project can vary in each phase. During the early phases of a project, the project leadership needs good conceptual skills, the ability to build a team, and the experience to build a project roadmap. During project closeout, the project leadership provides a high 
degree of motivation and attention to details. On a large project, lasting two or more years, it is common to see the project management team change leadership to provide skills that are appropriate to the final phases of the project.

The Project Management Institute (Project Management Institute, Inc., 2008) identifies four major phases of a project as characteristics of the project life cycle. These four life-cycle phases are initiation, planning, execution, and project closeout. The initiation phase, which PMI labels "starting the project," includes all the activities necessary to start the project. These activities include holding the project kickoff meeting, confirming or developing conceptual schedules and budgets, and acquiring project execution resources such as office space, computers, and communications equipment.

\section{Planning}

The planning phase, which PMI labels "organizing and preparing," includes the development of more detailed schedules and a budget. The planning also includes developing detailed staffing, procurement, and project controls plans. The emphasis of the planning phase is to develop an understanding of how the project will be executed and a plan for acquiring the resources needed to execute it. Although much of the planning activity takes place during the planning phase, the project plan will continue to be adjusted to respond to new challenges and opportunities. Planning activities occur during the entire life of the project.

\section{Execution}

The execution phase, labeled by PMI as "carrying out the work," includes the major activities needed to accomplish the work of the project. On a construction project, this would include the design and construction activities. On an information technology (IT) project, this would include the development of the software code. On a training project, this would include the development and delivery of the training.

\section{Closeout}

The closeout phase — or using PMI's nomenclature, "closing of the project"-represents the final stage of a project. Project staff is transferred off the project, project documents are archived, and the final few items or punch list is completed. The project client takes control of the product of the project, and the project office is closed down.

The amount of resources and the skills needed to implement each phase of the project depends on the project profile. Typically, a project with a higher-complexity profile requires more skills and resources during the initiation phase. Projects with a profile that indicates problems with alignment among key stakeholders or political and legal issues will require specialized resources to develop plans that address 
these issues early in the project. A project with a lower complexity level will invest more resources in the execution phases to execute the project as effectively and efficiently as possible.

\section{Project Phases on a Large Multinational Project}

A United States Construction company won a contract to design and build the first copper mine in northern Argentina. There was no existing infrastructure for either the mining industry or large construction projects in this part of South America. During the initiation phase of the project, the project manager focused on defining and finding a project leadership team with the knowledge, skills, and experience to manage a large complex project in a remote area of the globe. The project team set up three offices. One was in Chile, where large mining construction project infrastructure existed. The other two were in Argentina. One was in Buenos Aries to establish relationships and Argentinean expertise, and the second was in Catamarca-the largest town close to the mine site. With offices in place, the project start-up team began developing procedures for getting work done, acquiring the appropriate permits, and developing relationships with Chilean and Argentine partners.

During the planning phase, the project team developed an integrated project schedule that coordinated the activities of the design, procurement, and construction teams. The project controls team also developed a detailed budget that enabled the project team to track project expenditures against the expected expenses. The project design team built on the conceptual design and developed detailed drawings for use by the procurement team. The procurement team used the drawings to begin ordering equipment and materials for the construction team; to develop labor projections; to refine the construction schedule; and to set up the construction site. Although planning is a never-ending process on a project, the planning phase focused on developing sufficient details to allow various parts of the project team to coordinate their work and to allow the project management team to make priority decisions.

The execution phase represents the work done to meet the requirements of the scope of work and fulfill the charter. During the execution phase, the project team accomplished the work defined in the plan and made adjustments when the project factors changed. Equipment and materials were delivered to the work site, labor was hired and trained, a construction site was built, and all the construction activities, from the arrival of the first dozer to the installation of the final light switch, were accomplished.

The closeout phase included turning over the newly constructed plant to the operations team of the client. A punch list of a few remaining construction items was developed and those items completed. The office in Catamarca was closed, the office in Buenos Aries archived all the project documents, and the Chilean office was already working on the next project. The accounting books were reconciled and closed, final reports written and distributed, and the project manager started on a new project.

\section{Key Takeaways}

- The phases of a project are initiation, planning, execution, and closeout.

- The initiation phase, which PMI calls "starting the project," includes activities such as holding alignment and kickoff meetings, identifying the project team, developing the resources needed to develop the project plan, and identifying and acquiring the project management infrastructure.

- The planning phase, which PMI calls “organizing and preparing,” includes developing detailed staffing, procurement, and project controls plans. 
- The execution phase, which PMI calls “carrying out the work," includes the major activities needed to accomplish the work of the project.

- The closeout phase, which PMI calls "closing of the project," includes transferring staff, archiving documents, closing offices, completing punch list tasks, and turning over the results of the project to the client.

\section{Exercises}

1. Completing the items on a punch list occurs during the phase.

2. The ___ phase includes start-up activities and is called "starting the project" by PMI.

3. The phase in which the project work is mainly accomplished is the phase.

4. How does the initiation phase differ from the planning phase?

5. What is a punch list and in which phase is it used?

6. What are the four phases of a project?

Project Phases

Consider a personal project that you have been involved with in the last few years, such as moving your residence, buying a car, or changing jobs. Describe the activities related to that project that fit into each of the four project phases.

\section{References}

Project Management Institute, Inc., A Guide to the Project Management Body of Knowledge (PMBOK Guide), 4th ed. (Newtown Square, PA: Project Management Institute, Inc., 2008), 11-16. 


\subsection{Project Organization}

\section{Learning Objectives}

1. Identify the various functions represented on a project.

2. Analyze and evaluate the influence of organizational structure on project functions.

3. Design a project organizational chart for various project complexity profiles.

There is no single organizational approach to projects. Each project is organized to accomplish the work effectively and efficiently. Several factors influence the organizational approach to execute a project. The complexity profile of a project, the culture of the parent organization, the preferences of the project manager, the knowledge and skills of the team, and a parent organization with a project management office are examples of factors that influence the project's organization.

In developing the project organizational structure, the project manager considers the span of control for each manager. The span of control represents the number of people reporting to a manager. For example, the project manager does not want all the engineers on a project reporting to the engineering manager and assigns senior engineers to report to the engineering manager with other engineers reporting to the senior engineers.

The engineering manager can organize the engineering reporting structure so that the various engineering discipline managers would report to him or her. For example, the structural, electrical, and mechanical engineering team leaders would report to the engineer manager. On a larger, more complex project, the engineer manager may establish area team leaders and have the structural, electrical, and mechanical engineers report to an area team leader. If the project is geographically dispersed, with the engineering office staff in different cities working on the project, then structuring the engineering function by area provides better coordination and control (see Figure 3.1 “Decreasing Span of Control by Increasing Levels of Reporting”).

Figure 3.1 Decreasing Span of Control by Increasing Levels of Reporting 
80 [Author removed at request of original publisher]
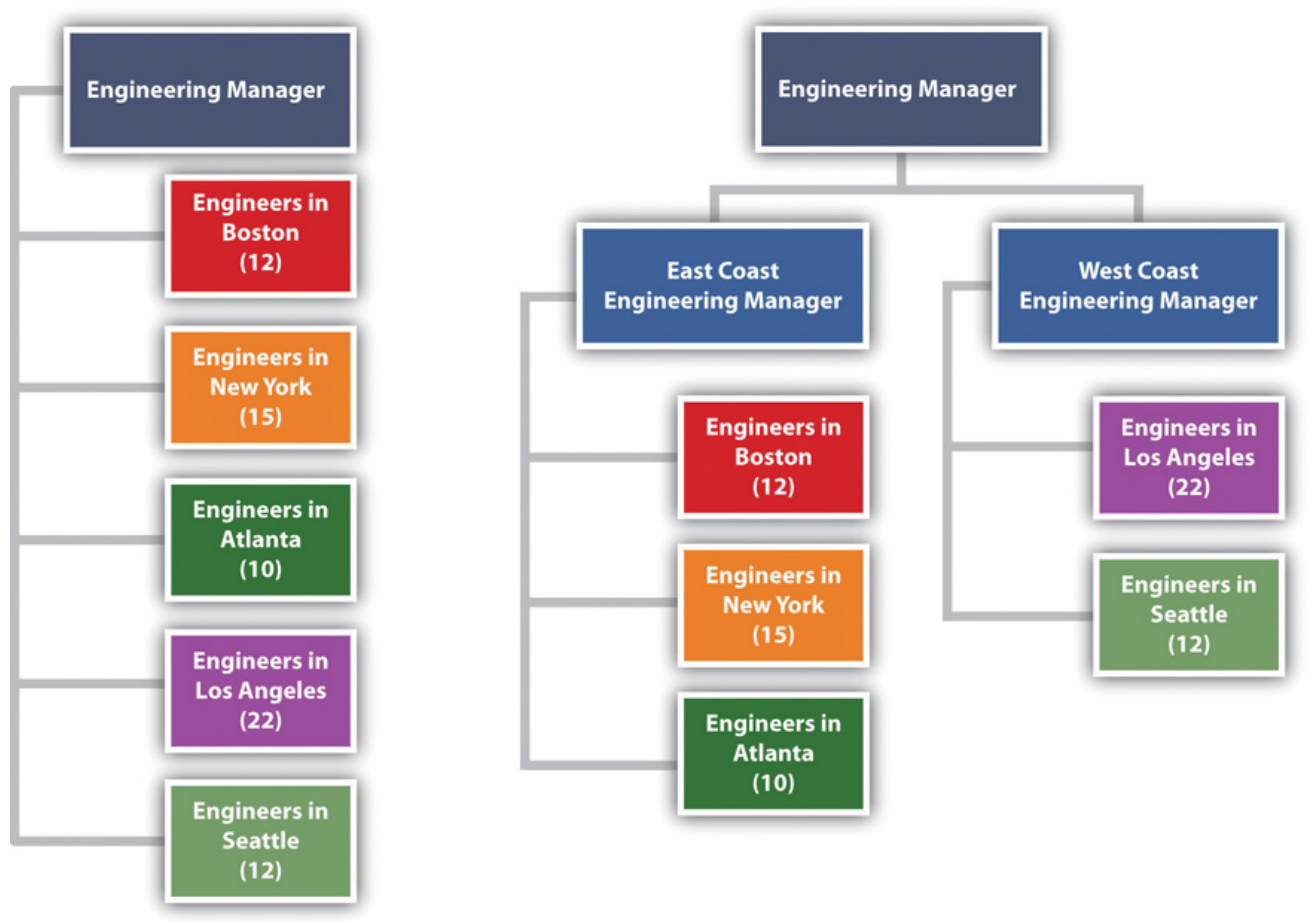

The organization on the left has seventy-one engineers reporting to the same person. The organization on the right creates two additional positions and reduces the span of control to thirty-seven and thirty-four, respectively.

Most projects have similar functions that are important to successfully managing the project. Included among these are the following:

- Sponsor

- Project manager

- Controls

- Procurement

- Technical management

- Quality

- Administration

Figure 3.2 Typical Project Organization 


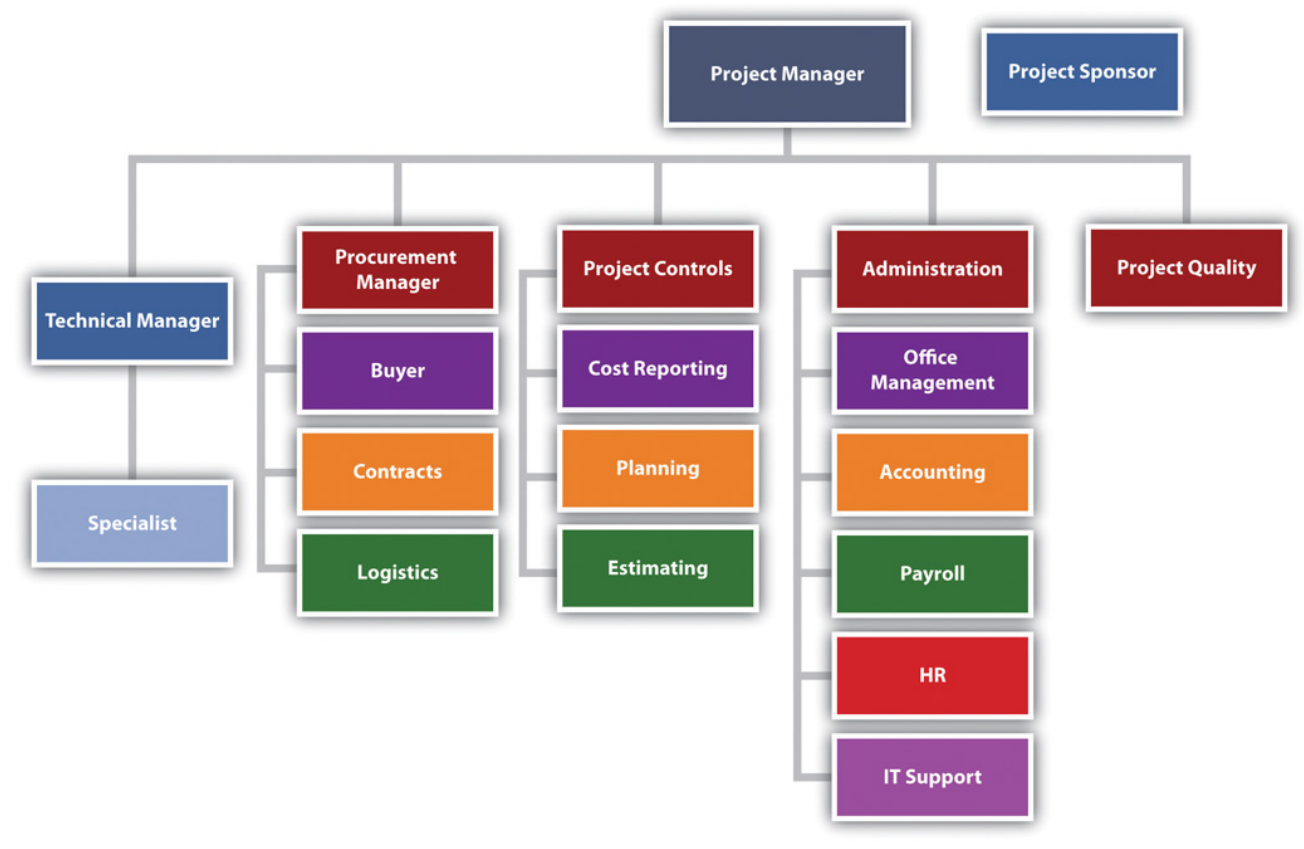

On smaller projects, more than one function can be managed by one person. On larger projects, large teams may be needed to accomplish the work within the function.

\section{Project Sponsor}

The project sponsor is outside the day-to-day operations of the project and has the organizational authority to provide resources and overcome barriers for the project. The project sponsor is typically a leader in the parent organization with an interest in the outcome of the project. As a leader in the parent organization, the project sponsor can provide input into the project scope and other documents that define project success. The guidance and support from the project sponsor enhances the ability of the project to successfully meet the parent organization's objectives.

\section{Southern Training Center Organization}

A training organization in South Carolina assigned a project sponsor to every project. For smaller projects, the regional manager fulfilled the role of project sponsor. On larger, more complex projects, the operations manager was the project sponsor. The vice president was the project sponsor of the three or four most complex projects, and the president was the project sponsor only on projects with a high degree of political risk. This approach to assigning project sponsors assured that each project had an organizational advocate that could address barriers and provide direction and resources. The project sponsor, in this organization, developed a relationship with a senior representative of the client organization, reviewed monthly reports, and conducted thorough quarterly reviews. 


\section{Project Manager}

Project managers often have the breadth of responsibility associated with corporate chief executive officers (CEOs). The project manager facilitates the start-up of a project and develops the staff, resources, and work processes to accomplish the work of the project. He or she manages the project effectively and efficiently and oversees the closeout phase. Some projects are larger than major divisions of some organizations, with the project manager responsible for a larger budget and managing more risk than most of the organizational leaders. A mining company that builds a new mine in South Africa, an automobile manufacturer that creates a new truck design, and a pharmaceutical company that moves a new drug from testing to production are examples of projects that may consume more resources in a given year than any of the organization's operating divisions.

The function of the project manager can vary depending on the complexity profile and the organizational structure. Defining and managing client expectations and start-up activities, developing the scope, and managing change are functions of the project manager. On some projects, the project manager may provide direction to the technical team on the project. On other projects, the technical leadership might come from the technical division of the parent organization.

Although the functional responsibilities of the project manager may vary, the primary role is consistent on every project. The primary role of the project manager is to lead, to provide a vision of success, to connect everyone involved in the project to that vision, and to provide the means and methods to achieve success. The project manager creates a goal-directed and time-focused project culture. The project manager provides leadership.

\section{Project Control}

In general, project controls is both the planning function and the function that tracks progress against the plan. Project control provides critical information to all the other functions of the project and works closely with the project manager to evaluate the cost and scheduling impact of various options during the life of a project.

Sometimes accounting functions such as payroll, budgeting, and cash management are included within project controls. On larger projects, accounting functions are typically separate because the accounting culture tracks expenses to the nearest penny, and cost estimating and tracking by project controls can often be off by hundreds and sometimes thousands of dollars. The lack of definitive information necessitates the development of cost estimates within ranges that are often inconsistent with accounting practices. Separating these two functions allows each to operate within their own accuracy comfort zone. The following are typical activities included within the project controls function:

- Estimating

- Tracking costs

- Analyzing trends and making projections

- Planning and scheduling 
- Managing change

- Tracking progress against schedule

The project controls team gathers this information from all the functions on the project and develops reports that enable each functional manager to understand the project plan and progress against the plan at both the project level and the functional level. On large complex projects, some project managers will assign project controls professionals to work within the major functions as well as the project management office. This approach allows each function to plan and track the function's work in more detail. The project controls manager then coordinates activities across functions.

\section{Project Procurement}

The approach to purchasing the supplies and equipment needed by the project is related to the complexity profile of the project. A small project with a low complexity level may be able to use the procurement services of the parent organization. In an organization where project resources reside in various departments, the departments may provide the supplies and equipment each team member of the project may need.

\section{Southern College Procurement Organization}

A college in South Carolina chartered a number of projects to increase the energy efficiency of the college. The project team included members from various college departments. Each department paid for the time, travel expenses, and supplies needed by the team member from their department. Each team member continued to use the computers and administrative support in their department for project work. The costs for this support was not included in the project budget nor tracked as a project expense. Equipment purchased by the project that was installed to reduce the energy consumption of the college was purchased through the college procurement department and charged to the project.

More complex projects with greater procurement activity may have a procurement person assigned to the project. This same South Carolina college retrofitted a warehouse to create a new training center for industry. A procurement person was assigned to the project to manage the contract with the construction firm remodeling the space, the purchase and installation of the new training equipment, and the purchase of the supplies needed by the project team. All the procurement activity was charged to the project. The procurement person reported to the project manager for better communication on what the project needed and when it needed it. The procurement person participated as a member of the project team to understand and provide input into the costs and scheduling decisions. The procurement person reported to the college procurement manager for developing and implementing project procurement processes that met college procurement policies and procedures.

Figure 3.3 


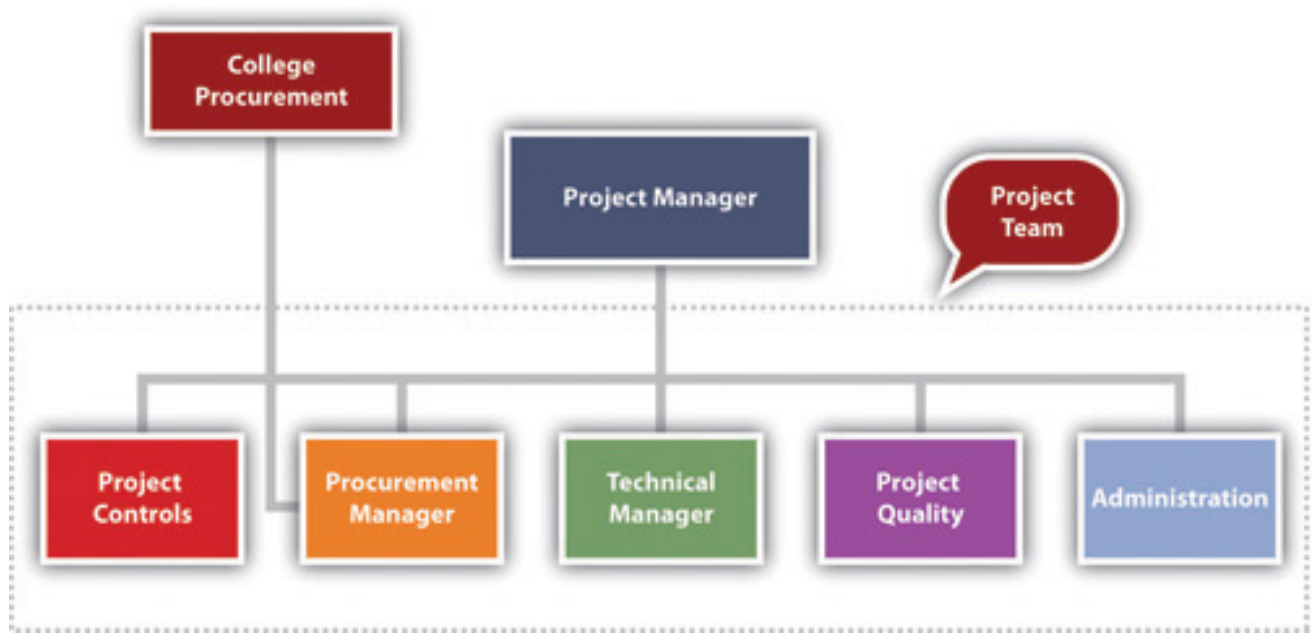

The procurement manager is part of the project team.

On larger, more complex projects, the procurement team has several responsibilities. The team is responsible for procuring the supplies and equipment (such as office supplies and computers) needed for the project team and the supplies and equipment (such as the training equipment) needed to execute the project. On a typical construction project, the procurement team would rent a construction trailer, office supplies, and computers for the project team to establish a construction office at the construction site. The procurement team would also purchase the concrete, rebar, steel, and other material needed to construct the building.

\section{Procurement for Mining Project in South America}

On the large mining project in South America, during the initiation phase of the project, the procurement department arranged for office space and supplies for the engineering teams in Canada, Chile, and Argentina and construction offices at the construction site in Argentina. As the design and engineering progressed, the procurement team managed bids for the major equipment and bids for the preparation of the construction site. The procurement team managed the logistics associated with transporting large equipment from Europe, North America, and Asia to the job site in rural Argentina. After the completion of the project, the procurement team managed the deposal of project property.

On large, complex projects, the procurement team manages at least three types of relationships with companies doing business with the project.

\section{Commodity Procurement}

The largest number of purchased items for most projects are commodity items. Commodities are items that can be bought off the shelf with no special modification for the project. These items are typically bid and the lowest prices that can meet the schedule of the project will win the contract. The procurement team assures the company that wins the bid can perform to the contact specifications and then moni- 
tors the progress of the company in meeting the projects requirements. Concrete for the project and the cranes leased to the project are examples of commodities. The key to success in managing commodity suppliers is the process for developing the bids and evaluating and awarding the contracts.

\section{Procurement from Vendors}

The second type of relationship is the vendor relationship. The terms supplier and vendor are often used interchangeably. In this text, suppliers provide commodities, and vendors provide custom services or goods. Suppliers bid on specialized equipment for the project. Engineers will specify the performance requirements of the equipment, and suppliers that have equipment that meets the requirements will bid on the project. The engineering team will assist in the evaluation of the bids to assure compliance with specifications. The lowest bid may not win the contract. Sometimes the long-term maintenance costs and reliability of the equipment may indicate a high price for the equipment. The key to success is the development of clear performance specifications, good communication with potential bidders to allow bidders to develop innovative concepts for meeting the performance requirements, and a bidding process that focuses on the goals of the project.

\section{Partnerships}

The third type of project procurement relationship is the partnership. Sometimes the partnership is legally defined as a partnership, and sometimes the success of each partner is so closely tied together that the relationship operates as a partnership. On the South American project, the project team partnered with an Argentinean construction company to access the local construction practices and relationship with local vendors. This was a legal partnership with shared profits. The partner also designed and procured some large mining equipment on which the success of the project and the company building the mining equipment depended. With this type of relationship, a senior manager on the project is assigned to coordinate activities with the partner, and processes are put in place to develop shared goals, align work processes, and manage change.

Figure 3.4 Procurement Manager Relationships 


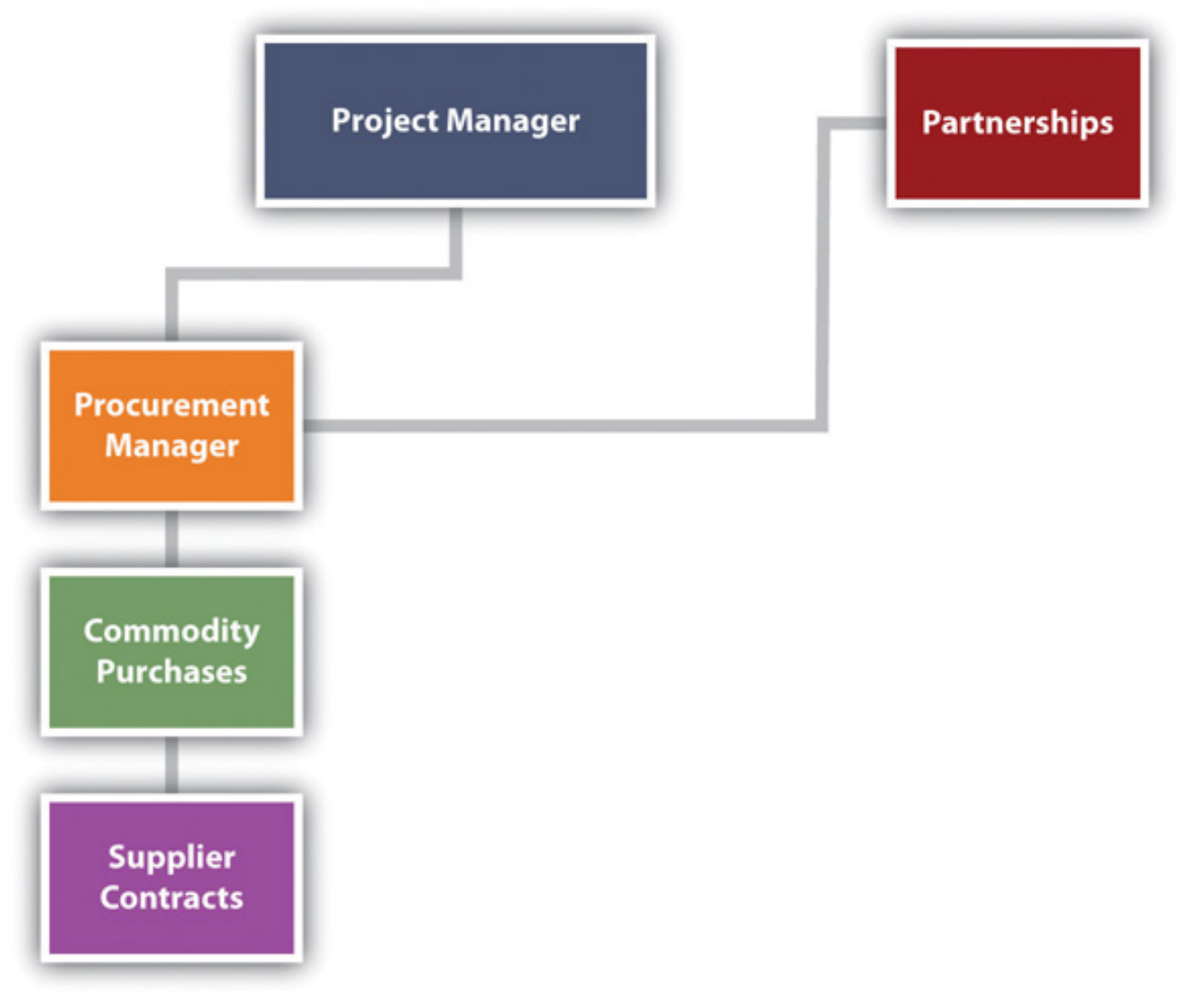

\section{Technical Management}

The technical management on the project is the management of the technology inherent in the project - not the technology used by the team to manage the project. The technical complexity on a project can vary significantly. The technological challenges required to build a bridge to span a five-hundredmeter canyon are significantly different from those required to span a five-thousand-meter body of water. The technological complexity of the project will influence the organizational approach to the project. The technological complexity for a project reflects two aspects: the newness of the technology and the team's familiarity with the technology. The newness refers to the degree to which the technology has been accepted in the industry. The more accepted the technology is in the industry usually means that more knowledge and experience will be available to the team. Familiarity refers to the experience the project team has with the technology. The less familiarity the team has with the technology, the more energy and resources the team will expend on managing the technological aspect of the project. For projects with high levels of project technology, a specialist may be hired to advise the technology manager.

\section{Indiana Steel Company}

A steel company in Indiana purchased a new coal injection technology that would improve the quality of steel, reduce the cost to produce the steel, and reduce air and water pollution. The contract to design and construct 
the new plant was awarded to an engineering and construction company. No one on the engineering and construction team had experience with the coal injection technology. The client's team understood the technology and provided guidance to both the project engineering and construction teams. The client owned the coal injection technology, and the engineering and construction team brought the project management technology.

\section{Project Quality}

Project quality is often part of the technical manager's responsibility. On large projects or projects with a high degree of technical complexity, the quality is sometimes a separate function reporting to the project manager. The project quality manager focuses on the quality of the project work processes and not the quality of the client's product. For example, if the project is to design and construct an automobile factory, the quality manager focuses on the project work processes and meeting the technical specification of the equipment installed by the project team. The project quality manager is not responsible for the quality of the car the plant produces. If the plant functions to the defined project specifications, the quality of the plant output is the responsibility of the plant quality department, and it may take several months for the plant to refine the work processes to meet the design specifications of the car.

On a construction project, the quality manager may test steel welders to assure the welders have the skills and that the welds meet project specifications. On a training project, the quality manager may review the training curriculum and the qualification of the instructors to assure the training provides the knowledge and skills specified by the client. On a drug development project, the quality manager may develop processes to assure the water and other raw material meet specifications and every process in the development process is properly documented.

\section{Project Administration}

The administrative function provides project specific support such as the following:

- Accounting services

- Legal services

- Property management

- Human resources (HR) management

- Other support functions found in most organizations

In most organizations, support for these functions is provided by the parent organization. For example, people assigned to the project will get human resources (HR) support from the HR department of the parent organization. Salary, benefits, and HR policies for employees assigned to the project will be supported out of the HR department. The parent organization will provide accounting functions such as 
determining the cost of cash, taxes, year-end project reports, and property disposal at the end of the project.

The project manager on smaller, less complex projects will have sufficient knowledge about these issues to coordinate with the parent organization's functional leaders. On more complex projects, the project may have an administrative manager responsible for coordinating the administrative functions of the projects. On larger, more complex projects, an administrative function may be established as part of the project team, with many of the functions assigning a resource to the project. In all cases, the administrative function on a project is closely related to the legal and organizational responsibilities of the parent organization and close coordination is important.

\section{South American Mining Project}

The South American mine project has major design work to accomplish in three different design offices: Vancouver, Santiago, and Argentina. The project manager and the leadership team reside in Santiago, Chile. During the design stage of the project, the engineering manager in each engineering office is leading the work with project controls, procurement, and administration, each assigning resources to support the engineering activities at each location. The project engineer manager assigned the engineering work based on the capabilities of the office and coordinates the work between offices. The procurement, project controls, and administrative leaders assign resources to support the work in each office. For example, the project controls manager assigned a planner in each office to support the engineering manager in that office to develop and track the schedule. The project planner in Vancouver supports the development of the engineering schedule in Vancouver and communicates and coordinates with the planning activities in the other locations

When the project construction activities started, project controls, procurement, and administrative resources moved from supporting engineering to supporting the construction activity. The project organizational structure changed as the engineering manager and the engineering effort changed from primarily designing the project to supporting the construction effort, by answering construction questions and developing solutions to construction challenges. The procurement effort changes from managing the bidding and contracting activities to managing the logistics. 


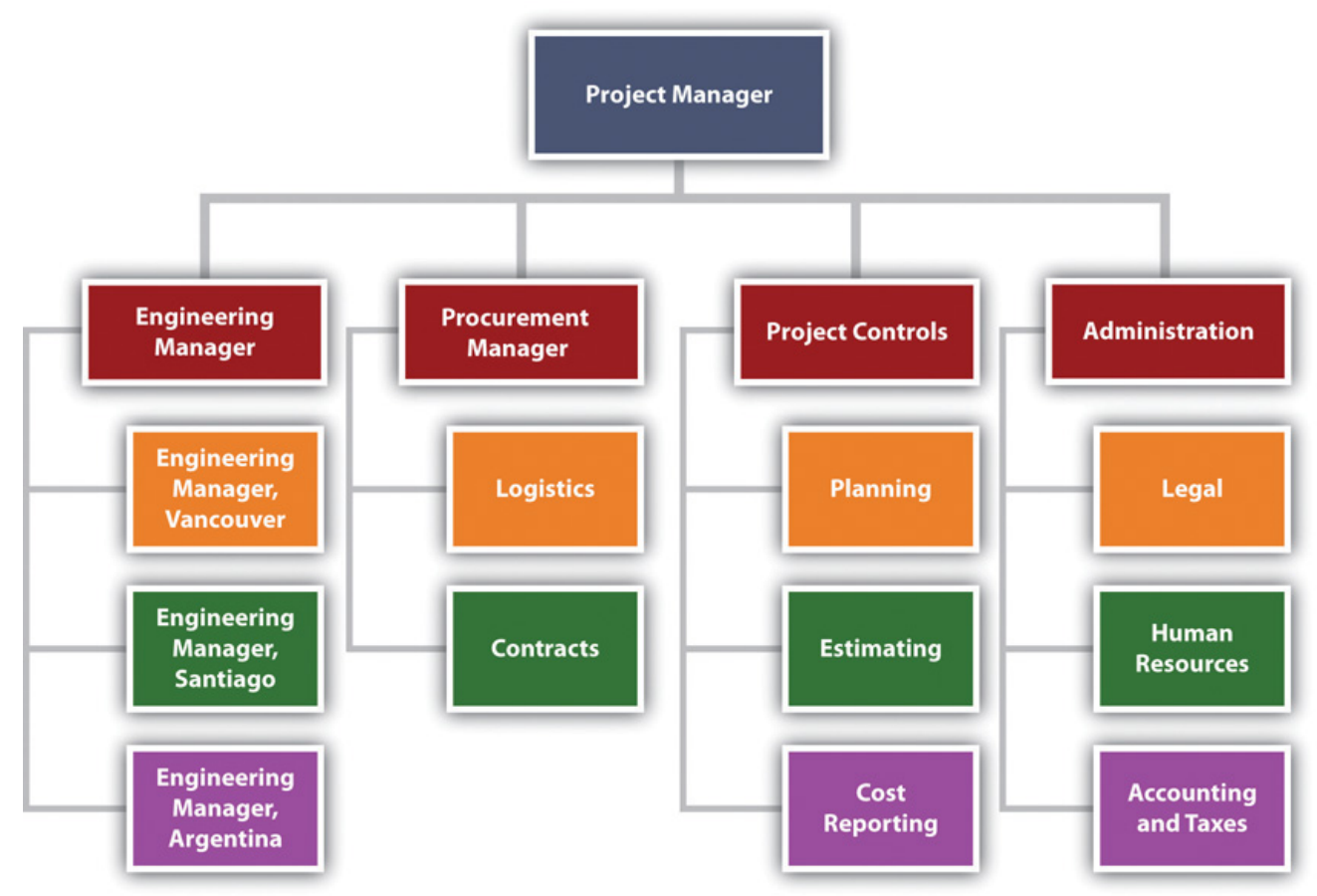

\section{Key Takeaways}

- Key functions on a project include sponsor, project manager, controls, procurement, technical, quality, and administration.

- The project sponsor has the organizational authority to provide guidance and resources and can overcome barriers for the project.

- The project manager is the project leader with broad responsibilities for all phases of the project and for meeting project goals and client expectations.

- The project controls manager is responsible for controlling the project processes, including cost estimating and tracking, developing schedules, tracking progress against schedules, managing changes to the schedule or budget, and analyzing trends.

- The procurement manager is responsible for obtaining the services and materials needed to complete the project. This is accomplished by purchasing commodities, managing contractors who provide services and products, and working with partners.

- The technical manager deals with the issues related to the technology of the project.

- The quality manager monitors the project's processes - not the quality of the product of the project—and takes steps to assure they are done correctly and meet specifications.

- Project administration manages accounting, legal, property, and human resources. 


\section{Exercises}

1. Materials or services whose quality is standardized and that are usually purchased based on lowest price are

2. Major components of a project that are specialized and that require the provider to help with solving problems and share in the profits are provided by

3. Worker benefits would be managed by the function.

4. Tracking costs and comparing them to the project budget is handled by the function.

5. Buying concrete for a bridge project would be handled by the function.

6. Checking to see that the work performed on the project is done consistently and up to specifications is managed by the function.

7. The number of people who report to a manager is referred to as the (three words).

8. If employees are responsible for estimating costs, to whom would they report?

9. Refer to Figure 3.1 "Decreasing Span of Control by Increasing Levels of Reporting”. How many additional employees were added to decrease the span of control of the engineering manager, and how was this accomplished?

10. Refer to Figure 3.4 “Procurement Manager Relationships”. How do partnerships affect the complexity of the project? Describe an example of a situation where the partnership could affect the complexity of the project.

11. How is procurement from suppliers different from buying commodities?

12. Refer to Figure 3.3. To whom does the procurement manager report? Provide an example of a situation where this reporting relationship might increase the complexity of the project.

Project Organization

Refer to the descriptions of the project functions and determine which manager would take care of each of the following problems. If you think the problem requires the attention of more than one function, explain why.

1. One of the project team members has filed a sexual harassment suit against another team member of equal rank.

2. A contractor is installing equipment that is substandard.

3. The computer software used to make a step improvement in the client's operations has a significant bug in it.

4. The client wants to use higher-quality materials in the project than was originally agreed on.

5. Your organization has announced budget cuts but you cannot afford to lose anyone at this crucial stage in the project.

6. A contractor has complained that the procurement manager has a conflict of interest with a competing contractor. 


\subsection{Using the Darnall-Preston Complexity Index to Measure Organizational Complexity}

\section{Learning Objective}

1. Analyze a project function for size, organizational complexity, technological newness, and technological familiarity and assign a complexity score.

Recall that the Darnall-Preston Complexity Index (DPCI ${ }^{\mathrm{TM}}$ ) ranks complexity in four categories: external, internal, technological, and environmental. The information provided in this chapter can be used to rate a project's complexity in the areas of size, organizational complexity, technological newness, and technology familiarity. Scores range from 1 (least complex) to 5 (most complex).

\section{Size}

Recall that size is relative to the organization's comfort zone for projects. Refer to the following descriptions for tips on arriving at a DPCI score for size:

1. The project size is the most common size the organization does. The project manager and team members have done many similarly sized projects, and the tools they use to manage this size project are well tested and reliable.

2. The project size is at the high or low end of the range of project sizes that the organization or team members have done before.

3. The project size is about 20 percent higher or lower than projects the organization or some of the team members have done before. The project leader and a few key team leaders are familiar with this size project from work they have done elsewhere. Project management tools and processes will have to be adjusted but will probably work.

4. The project size is about 50 percent higher or lower than projects the organization or most of the team members have done before. Project management tools and processes will have to be adjusted, and it is not certain that they will work well. New tools and procedures may be needed.

5. Neither the organization nor the team members are experienced working on a project this size. It is several times larger or smaller than previous projects. It is too small or too large for the tools and techniques with which the team is familiar. 


\section{Organizational Complexity}

Recall that system complexity is determined by the variety of types of elements and the number of connections there are between elements. Review a chart of the organizational structure that depicts the reporting relationships, the number of people involved, their familiarity with each other, and the amount of cross connections between reporting relationships and functions. Refer to the following descriptions for tips on arriving at a DPCI score for size:

1. The organizational structure is simple and involves few people. No new relationships need to be formed, and the people have worked together in these relationships before.

2. The team includes people who report to operations managers instead of the project manager, and more people are involved.

3. The organization chart has numerous segments, but most people are familiar with their roles and have worked in this type of role before.

4. The number of people involved is large, and the functions are handled by many different people. There are several levels of reporting in the organization chart.

5. The number of people is very large, and many of them do not know each other or have never met. Each major function requires a full-time person, and coordinating between functions requires frequent meetings among mid- and top-level managers.

\section{Technology Newness}

Recall that this category refers to the technology that is part of the project. It might be new technology that is being implemented to make a step change in the efficiency of an operation. Refer to the following descriptions for tips on arriving at a DPCI score for size:

1. The technology is not new. It has been around for years and is reliable.

2. The technology is only a few years old. Most of the initial bugs are out of it, but the fixes have not been thoroughly tested.

3. The technology is recent, and only a few other organizations have experience with it. The providers promise that the next release or version will have the problems resolved.

4. The technology is new and has just been released for general use. Problems are likely.

5. The technology is in an early testing phase, and your organization is one of the test sites. Problems are expected. 


\section{Technology Familiarity}

Recall that this category refers to the familiarity of the project team with the technology that is part of the project. Refer to the following descriptions for tips on arriving at a DPCI score for size:

1. The team members have all used the technology or have been involved with projects that used this technology. They are confident that they understand it and can handle problems related to it.

2. The technology is new to some of the team members who are not in key positions. Standardized training is available, if necessary, to teach them what they need to know about it to do their jobs.

3. Several team members have not worked with this technology, including some of the key team members. Standardized training is not available, and consultants might be needed.

4. The technology is new but is similar to previous technologies with which the team leaders are familiar. An advisor from the product's development team may serve as a technology advisor.

5. The technology is new, and no one has worked with it before. A specialist might be needed to avoid serious errors.

\section{Tips for Assigning a Score}

Assigning a score is not an absolutely accurate process. Your objective is to be approximately correct, and some people are not comfortable with this type of estimate. Recall that one of the attributes of a successful project manager is the ability to live with ambiguity. One method that will help when assigning a score is to consider the two extremes. For each factor in the DPCI, consider what the simplest-least complex - scenario would look like, which would be a 1 on the DPCI scale. Next consider what the most complex scenario would be, which would describe a 5. Then, compare actual projects to those two extremes. If it is close to, but not as simple as, the least complex, you would give it a 2 . If it is close to, but not as complex as, the most complex scenario you would give it a 4 . If it is about in the middle, it rates a 3 .

\section{Key Takeaway}

- Scores range from 1 to 5 , where 1 is the lowest level of complexity and 5 is the highest. In each situation, consider what the two extremes would look like and then judge where the current situation lies between those extremes. 


\section{Exercises}

1. If a project is about 20 percent larger or smaller than projects previously done by most of the team members, it should be rated as a for size complexity.

2. If the organizational structure is simple and involves few people and no new relationships need to be formed, the project rating for organizational complexity should be a

3. If the technology is in an early testing phase, your organization is one of the test sites, and problems are expected, the technology newness complexity rating should be a

4. If the technology is new to some of the team members who are not in key positions, but standardized training is available to teach them what they need to know about it to do their jobs, the technology familiarity complexity rating should be a

5. Why does the newness of a project's technology increase its complexity?

6. The project controls manager decides to change the software his team uses to track project activities from Microsoft Project to Primavera. Few of the staff in that department are familiar with Primavera. How would this change affect the project technology complexity index score? Explain your answer.

Techniques for Assigning Scores

Refer to the tips for assigning scores to answer the following questions:

1. How does the ability to live with ambiguity relate to assigning scores using the DPCI?

2. How does considering extremes help to assign a score?

\section{Choosing a Complexity Score}

Consider a project that involves the merger of computer systems of two banks. The acquiring bank wants to convert the other bank's computer system to its own software, and the project is to convert all the client account files. The software used by the acquiring bank is relatively new, and only about a third of the project team is familiar with it. Your task is to determine a DPCI rating for the familiarity of the project team with the technology.

1. Describe a scenario that would qualify for a rating of 1 .

2. Describe a scenario that would qualify for a rating of 5 .

3. Indicate the rating you would choose and explain your choice. 


\subsection{Exercises}

Exercises at the end of the chapter are designed to strengthen your understanding and retention of the information recently acquired in the chapter.

\section{Essay Questions}

Write several paragraphs to provide more in-depth analysis and consideration when answering the following questions.

1. In June 2009, the CEO of Fiat took on the management of Chrysler and began a project with the objective of joining the two companies. He chose to "flatten" the management organization by increasing the number of people who report to him from a "handful" to twenty-three. Video conferences between the Chrysler and Fiat management teams take place from a conference room in Chrysler headquarters in Michigan where there are twenty-three seats and microphones for the Chrysler team members (Boudette, 2009). What do you think are the pros and cons of changing the CEO's span of control in this manner? Will this increase or decrease the complexity of the organization? Your answer should display an understanding of span of control and organizational complexity.

2. The DPCI ${ }^{\mathrm{TM}}$ and the Myers-Briggs Type Indicator ${ }^{\circledR}$ (MBTI): The human personality is more complex than a project; an evaluation system developed by Isabel Myers-Briggs based on the work of psychologist Carl Jung attempts to provide a simple profile based on four ranges of personality traits: introverted versus extroverted, intuitive versus sensing, thinking versus feeling, and judging versus perceiving. How does the Myers-Briggs profile compare and contrast with using the DPCI to determine the strengths and challenges of a project?

\section{Discussion}

The exercises in this section are designed to promote an exchange of information among students in the classroom or in an online discussion. The exercises are more open ended, which means that what you find might be completely different from what your classmates find, and you can all benefit by sharing what you have learned.

1. Controls and procurement. Under what circumstances would the responsibilities of the controls manager and the procurement manager overlap? Describe the situation. Your description should indicate an understanding of the roles and duties of each manager. Consider the examples provided by your classmates and compare them with your example to determine if you correctly understand these two roles.

2. Describe the four phases of a project in your own words. Pick a project that would have a score of 1 on the Darnall-Preston Complexity Index in the areas of size, organizational complexity, tech- 
nology newness, and technology familiarity. Consider the examples provided by your classmates and compare them with your example to determine if you correctly understand how to score a project's complexity in these areas.

\section{References}

Boudette, N. E., "Fiat CEO Sets New Tone at Chrysler," Wall Street Journal, June 19, 2009, http://online.wsj.com/article/SB124537403628329989.html (accessed June 21, 2009). 


\subsection{Web Exercise}

\section{Learning Objective}

1. Locate, download, and analyze project templates.

\section{Use Templates to Standardize Project Development}

Many organizations standardize their project development process using templates. The use of templates makes it easier to compare projects and to assure that all the requirements are met. In this exercise, you locate and download a template for creating a scope statement and its completion instructions. The template is used by the State of Virginia. This template and its instructions for completion provide an overview of the structure of a project because the main parts of a project are clearly identified.

\section{How to Download a Project Template and Its Instructions for Completion}

1. Start a web browser program and go to the Office of Enterprise Technology for the State of Virginia at http://www.vita.virginia.gov/oversight/projects/default.aspx?id=567. A list of templates displays, as shown in Figure 3.6 "State of Virginia Project Management Templates”.

2. Under Project Initiation, in the Project Charter row, in the Instructions column, click the Word icon. Save the file to your computer. Notice the folder in which you choose to save the file so you can find it again later.

3. Open the file. Scroll down to page 2 and display section E, steps 1 through 3 , as shown in Figure 3.7 “Description of the Project and Its Scope, Milestones, and Deliverables".

4. Read each of the three items. Capture this screen to the computer's memory.

5. Start a word processing program and open a new document. On the first line, type your name. Below your name, paste the screen capture.

6. Save that document as Ch03ScopeStudentName in the .doc format used by Microsoft Word 2003.

7. Return to the Scope Statement Development Instructions document. Scroll to item F and then read the instructions for describing the project authority. 
8. Capture this screen to the computer's memory. Switch to Ch03ScopeStudentName.doc and paste the screen below the first screen capture image.

9. Return to the Scope Statement Development Instructions document. Scroll to item G and then read the instructions for describing the project organization.

10. Capture this screen to the computer's memory. Switch to Ch03ScopeStudentName.doc and paste the screen.

11. Switch to the web browser program. On the Project Charter row, in the Word Template column, click the Word icon. Save this document to the same folder as the instructions. Open this document.

12. In the Scope Statement Template, scroll through all eleven pages to review the elements of the project.

13. Scroll to the top of page 7. In section F, below item 2, enter your name as the project manager. Capture this screen to the computer's memory. Switch to Ch03ScopeStudentName.doc and paste the screen below the other screen images.

14. Review your work and use the following rubric to determine its adequacy:

\begin{tabular}{|l|l|l|l|}
\hline Element & Best & Adequate & Poor \\
\hline File name & Ch03ScopeStudentName.doc & $\begin{array}{l}\text { Word } \\
2010 \\
\text { version } \\
\text { using } \\
\text { docx }\end{array}$ & Another file name \\
\hline $\begin{array}{l}\text { Locate, } \\
\text { download, } \\
\text { and analyze } \\
\text { project } \\
\text { templates }\end{array}$ & $\begin{array}{l}\text { Name on first line followed by screen captures } \\
\text { of sections E, F, and G of the instructions and } \\
\text { page 7 of the template with your name as the } \\
\text { project manager }\end{array}$ & $\begin{array}{l}\text { Same as } \\
\text { Best }\end{array}$ & $\begin{array}{l}\text { Some screens missing } \\
\text { or name not shown as } \\
\text { the project manager in } \\
\text { the template }\end{array}$ \\
\hline
\end{tabular}

15. Save Ch03ScopeStudentName.doc and submit it as directed by the instructor. Close all documents and programs. 


\section{Chapter 4: Understanding and Meeting Client Expectations}

Project management is about managing work processes and leading people. The technical skills of a project manager - the ability to organize the project and develop a scope, budget, and schedule-are critical to executing a project that will finish on time, within budget, and to the project specifications. However, the project will not be a success if the important stakeholders are unhappy with the results.

Project stakeholders often have a significant role in the success of a project. The ability of the project manager to understand the expectations of the various stakeholders and motivate them to contribute to the project success is a major aspect of the project manager's leadership role. In this chapter, we explore the concepts and skills needed by the project manager to understand and meet the expectations of the one of the most important stakeholders - the client — and the various means and methods for motivating the client to contribute to project success.

One of the definitions of project success focuses on achieving client satisfaction. This definition highlights the importance of the client as critical for both defining and achieving project success. The client is an important project constituent and in most cases the most important constituent. DarnallRussell W. Darnall, The World's Greatest Project(Newtown Square, PA: Project Management Institute, Inc., 1996), 48-55. described actions for the project manger focused on defining and meeting client expectations. Project success often includes meeting project goals and specifications, and it also includes understanding and meeting the expectations of the client. Depending on the complexity level of the project, the plan to meet the client's expectations can range from having a general discussion with the project leadership team to developing a formal plan that is tracked during the life of the project. 


\subsection{Including the Client}

\section{Learning Objectives}

1. Describe what the client needs to know about changes in management style during different phases of a project.

2. Identify advantages and disadvantages of including the client on project teams.

To appreciate the skill and effort expended by the project team in achieving the objectives of the project, the client needs to know more about what the team does.

\section{Educate the Client from the Beginning}

Often the client does not have the project management experience of the project manager or project team. An experienced project manager understands the phases of the project and the requirements of the different phases. A less experienced client may become frustrated at the changes in the management approach required for the different phases of the project. For example, during the early phases, the project leadership is encouraging creative approaches to accomplishing the project goals. As the project proceeds and the project plan becomes more firm, the project leadership focuses on accomplishing the project goals. The types of meetings, the agenda of the meetings, and the general project atmosphere change as the project moves from the planning phase to the production mode of the execution phase of the project.

During the last phases on a project, project team members are often tired and beginning to anticipate the transition that will take place at the end of the project. The motivational approach that worked during the early phases of the project is less effective during the final phases, and the project manager applies different approaches to motivating the project team. These changes can be disconcerting on a person's first project. By explaining what to expect and planning with the client a process to minimize the impact of these changes, the project manager prepares the client for these events and reduces the frustration.

\section{Include the Client on Selected Project Teams}

The project client translates the needs of the organization through chartering the project and defining the project scope to the project manager and the project team. The client also has an oversight role. This oversight is often accomplished through regular project reviews and reports from the project team. 
Depending on the complexity level of the project, the reviews can vary significantly. On less complex projects, the review might be conducted in a one-hour meeting with a one-page summary document serving as the project progress report. On more complex projects, a full-day meeting might be necessary for the project progress to be fully understood, and the project report may be one hundred pages or more.

In addition to providing the formal overview of the project, most clients would like to actively participate in the success of the project. This is a delicate balance. The participation of the client can have undue influence on project decisions. The advantage of including the client in project activities is to gain the client's personal investment in the project plan, to create a better understanding for the client of the problems the project encounters during the life of the project, and to gain the insights and contributions of the client in problem solving.

Involving the client in teams where the client's special knowledge can add value to the team discussions and activities contributes both to the success of the team and the satisfaction of the client. During the construction of a chemical plant in Tennessee, the project team struggled with a very tight project schedule. A team was established to explore ways to reduce the approval process for the drawings of the plant design. It was taking two weeks for the design review, and even though this was within the normal time frame for design reviews, the project management team believed there were opportunities to reduce this time and shorten the length of the project.

The client's engineering manager participated in the brainstorming sessions that explored ways to reduce the design review time. Several good ideas were developed and put into place. The client's engineering manager took these ideas back to the client's team and instituted many of the same ideas. The result was a shortened schedule that saved two weeks by the end of the plant design. The other result was a client that contributed to the project success and was emotionally engaged in the positive outcomes.

\section{Key Takeaways}

- The project manager's style changes with each phase of the project. The client could be surprised when the style changes from one that is open to any new idea in the initiation phase to a more task-oriented style during execution or a more demanding style during closeout.

- Client participation in project teams can have undue influence on decisions, but this is offset by the buy-in of the client and the insights the client can offer when special knowledge is needed or schedules need to be changed.

\section{Exercises}

1. The client might be surprised when the project manager's style changes from inviting new ideas during the conceptual phase to discouraging them during the phase.

2. One problem with client participation in project teams is that a client can have influence.

3. What should the client know about the different management styles used in the initiation, execu- 
tion, and closeout phases of the project?

4. What is an advantage of having the client participate in some project teams?

\section{Client Influence}

Consider a project you have been involved in which the client took part in meetings and decision making. If you were to do the project again, describe how you would manage the client's involvement. Specifically, describe the positive aspects that you would repeat and the negative aspects that you would try to avoid. 


\subsection{Understanding Values and Expectations}

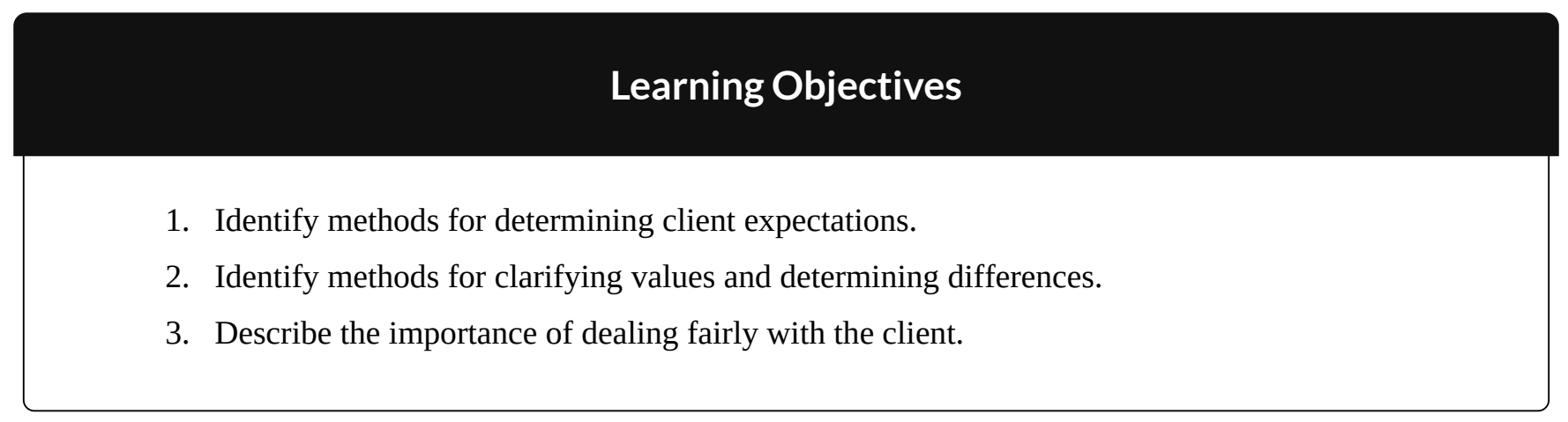

Two of the sources of dissatisfaction in personal and business interactions are unmet expectations and a misunderstanding or ignorance of the values held by the other party. The project manager needs to avoid having a dissatisfied client due to a clash of values or a failure to meet expectations.

\section{Clarify Expectations}

Client expectations are expressed in chartering documents such as the scope of work, the project purpose statement, and the list of project deliverables. Other expectations exist that are more difficult to express in written documents.

\section{Managing Expectations}

One project client had such a difficult time with the billing processes on her previous project that significant project management time and resources were expended on reconciling billing issues. This client has an expectation in the next project that project accounting and billing processes operate effectively and efficiently. Another client had been constantly surprised by changes and nonplanned events happening on the project. This client wanted to participate early in the discussion of problems that arise during the life of the problem and contribute to finding solutions and minimizing the negative impact on project performance.

Understanding and capturing these expectations in a written document is an important step in effectively meeting client expectations. Often it is the next question that enables a project manager to discover the less obvious expectations. The next question is the one the project manager asks after the initial response to inquiries about expectations. In our example, the client may express that he or she wants project billings to be accurate and timely. This is an easily understandable expectation, but when the project manager asked the next question-“Can you tell me more about what you mean?”-the client revealed the problems on her previous project, and the project team developed a better understanding of the client's concern. The project team developed measures for tracking project billings that measured 
both timeliness and accuracy. This process enabled the project team to understand the client's concern, develop work processes that demonstrated a response, and provide data to the client on the timeliness and the accuracy of the billing processes.

For the client that expected to hear about problems early and participate in the problem-solving discussions, the project team shared the project action item register and highlighted issues the team felt may be important to the client. The project manger also discussed potential concerns with the client during their weekly project update.

After the project team captures the client expectations, the team then develops a method for tracking performance against expectations. In our example, the project team defined accuracy and timeliness in measurable terms and tracked the team performance. The project team developed a survey to track the client's perception of inclusion in the problem-solving process and tracked the client's response. These measures were then presented in the project review meetings with other measures of project performance such as cost and schedule.

As the project team meets and exceeds the client expectations, these expectations tend to change. If the goal is 85 percent accuracy on all project billings, and the project team begins to perform with an average of 95 percent accuracy or higher and never falls below 90 percent, then the client begins to expect 95 percent accuracy. This is a realistic expectation of the client; it also changes the expectation so that meeting the client's expectation becomes harder. Even if expectations change, it is important to maintain the original goal. This reminds the client at the end of the project that the project team not only met expectations but also raised them during the life of the project.

\section{Clarify Values}

Values are desirable principles or qualities (Merriam-Webster Unabridged Online Dictionary, 2009). Disagreements based on differences in values are extremely difficult to resolve because compromising means compromising your values. Organizations often have developed a list of corporate values. Sometimes these are real and sometimes they are more important to the corporate brand. The project manager needs to understand the real organizational and personal values related to the project.

On construction projects, safety is an important consideration in the planning and execution of a project. Every construction company will assert a strong safety value. The value is tested when safety rules are developed. Is the organization willing to terminate or sanction an employee for a major safety violation? This is not a yes or no question but the beginning of a dialogue. Everyone on the project needs to understand safety rules, and consistent application of the approach to safety is critical to establishing a safety culture on the project. Agreeing on a safety program based on a value for safety at the beginning of a project will prevent serious confrontations later. 


\section{Phone Etiquette}

A large project in Washington had a client that valued communications. All the members of the client's team had the newest phone technology and took calls during project meetings. The project team saw this behavior as rude and interfering with the effectiveness of the project. The client was very comfortable in this chaotic environment and saw constant communication as a value that helped the organization identify and respond to opportunities. This provided the organization with a competitive advantage in their marketplace. The same behavior was preventing the project team from developing a common understanding and agreeing on a project plan because they could not focus on the needs of the project long enough to develop this common understanding. The project manager and the lead client recognized the potential conflict for the project and developed a list of project meetings that would be "cell-less," which meant that the team members would turn cell phones off for that meeting. Other meetings would follow the cultural standards of the client.

Developing a mutual understanding of the personal and organizational values and dealing with differences during the early phases of the project will significantly reduce the potential for insolvable conflicts. This becomes more important on a large, complex project where the likelihood of a diverse project team is high, and the team may have to deal with different laws, customs, and cultural values. Developing an understanding of these differences and developing an appreciation for the value of this diversity for project team members can prevent conflict later in the project.

\section{Deal Fairly with the Client}

During the life of the project, the project manager will often have the opportunity to take advantage of the client, either because a clause in the contract is not written accurately or because the project manager has access to more detailed information. For example, a client finds a mistake in the original documents provided to the project team. The project team analyzes the new information to access the potential impact on the project cost and schedule. A skilled project manager can demonstrate a negative impact and increase project profits by requesting a change order. A skilled project manager can also usually find an innovative approach to finding a solution without increasing the cost or schedule. In most cases, the client wants to be treated fairly. Fairness is characterized by impartiality and honesty that is free from self-interest, prejudice, or favoritism (Merriam-Webster Unabridged Online Dictionary, 2009). If the client interprets the change order as fair, then the project manager has the opportunity to create a satisfied client. If the client believes the behavior of the project manager is unfair, then it is difficult to create a satisfied client.

\section{Key Takeaways}

- To identify client expectations, review written documents, but have a dialogue with the client to uncover unwritten expectations by asking questions and listening. Manage increasing expectations by reminding the client of the original objectives. 
- Determine the stated corporate values by reviewing written documents and review actions related to those stated values to see which ones are the basis for action. Attempt to avoid conflicts of values by identifying the differences before they become problems.

- Do not take advantage of clients' mistakes, but help them meet their objectives in spite of their errors. Live your own values of fairness.

\section{Exercises}

1. If a project is regularly exceeding the stated goal for quality, it is important to remind the client of the objective.

2. Values are desirable or qualities.

3. Treating a client fairly means avoiding prejudice, or favoritism.

4. What are some written sources of client expectations?

5. What is an example of a corporate value?

6. What does it mean to treat a client fairly?

Organizational Values

Choose an organization with which you are familiar that proclaims to support a particular set of values. Describe actions that it has taken that either support or differ from its stated values.

\section{References}

Merriam-Webster Unabridged Online Dictionary, s.v. “values," http://unabridged.merriam-webster.com/cgi-bin/collegiate (accessed June 18, 2009). 


\subsection{Dealing with Problems}

\section{Learning Objectives}

1. Describe standards and procedures for dealing with problems.

2. Describe the advantages of dealing with difficult issues as soon as they arise.

3. Describe the importance of establishing methods for revising major decisions.

Projects always experience unexpected problems that produce stress. Dealing with problems with competence is vital to maintaining a good relationship with clients.

\section{Establish Standards and Procedures for Decisions}

There are competing interests on projects, and the larger and more complex the project, the greater the number of issues and concerns that need to be addressed.

\section{Competing Interests}

It's 7:30 in the morning and the client called and wants you to have coffee in an hour with the new CEO, who flew in last night, to give him an update on the project. The concrete trucks were supposed to be on site at 7:00, but they have not arrived. A storm is predicted for tomorrow, and the concrete has to be in and covered before the storm hits. A news reporter called and said she has an unnamed source who claims that there is contamination of a nearby river coming from the project site.

The project manager decided to postpone a team meeting about project scheduling and cancelled lunch plans with his wife. It was going to be a busy day.

On large, complex projects, hundreds of decisions are made every day. Most of the decisions focus on the day-to-day operation of the project. Early in the project, decisions focus on choosing between alternative options for accomplishing project goals and determining how the project will be executed. Later, the focus is typically on solving problems. The project team develops solutions to deal with the barriers that emerge and develops alternative plans to meet project goals. The authority to make decisions is typically established early in the project and identified in a responsibility matrix - a table of people and types of problems that might require decisions-as shown in Figure 4.5 “The Responsibility Matrix”. 
The responsibility matrix identifies roles and client involvement.

\begin{tabular}{|c|c|c|c|c|c|c|}
\hline Title & $\begin{array}{l}\text { Scope } \\
\text { Statememtn }\end{array}$ & $\begin{array}{l}\text { Work } \\
\text { Breakdown } \\
\text { Structure }\end{array}$ & Budget & Quality & $\begin{array}{l}\text { Change } \\
\text { Management } \\
\text { Procedures }\end{array}$ & $\begin{array}{l}\text { Change } \\
\text { Approvals }\end{array}$ \\
\hline $\begin{array}{l}\text { Project } \\
\text { Chartering } \\
\text { Committee }\end{array}$ & $\mathrm{X}$ & & & & & \\
\hline $\begin{array}{l}\text { Client } \\
\text { Representative }\end{array}$ & $\mathrm{X}$ & $\mathrm{X}$ & $\mathrm{X}$ & $\mathrm{X}$ & $\mathrm{X}$ & $\mathrm{X}$ \\
\hline Project Manager & $\mathrm{X}$ & $\mathrm{X}$ & $\mathrm{X}$ & & $\mathrm{X}$ & $\mathrm{X}$ \\
\hline Technology Team & & $\mathrm{X}$ & & $\mathrm{X}$ & & \\
\hline Finance Team & & & $\mathrm{X}$ & & $\mathrm{X}$ & \\
\hline $\begin{array}{l}\text { Schedule Coordi- } \\
\text { nation Team }\end{array}$ & & $\mathrm{X}$ & & $\mathrm{X}$ & $\mathrm{X}$ & \\
\hline
\end{tabular}

Decisions that influence the outcome of the project, such as a delay to the project completion date or an increase in the project costs, typically involve the client. Some clients prefer to make the final decision, with the project manager developing alternative solutions with a cost-benefit analysis of each of the alternatives. Others prefer to be involved in discussions to better understand the barriers, developing alternative solutions and making decisions in a team environment. Understanding the client's decisionmaking preference and developing procedures and processes that support that preference is important to meeting client expectations.

Develop processes and methods that encourage both client and team members to identify issues and concerns early. Develop processes for dealing with these issues and concerns effectively. Define how and when decisions are made.

On projects with a low complexity level, the project manager and team leaders can make decisions informally, with short meetings or phone calls. Weekly or monthly staff meetings are appropriate for more complex decisions. Even though the decision-making process may be simpler on less complex projects, it is still important to understand the client's expectation for inclusion in the decision-making process and recording decisions and changes in project plans.

On more complex projects, the use of action item registers, weekly staff meetings, responsibility matrices, and other tools foster the decision making on a timely basis. For project teams operating in diverse locations, Internet-based tools for recording and tracking action items can provide a location for capturing issues and concerns. 


\section{Deal with Difficult Issues Early}

Project managers typically have a high degree of confidence in their ability to deal with issues and concerns as they arise. The delivery of some equipment is delayed a week, causing changes in the project schedule, or the beta test of a software program identified far more problems than expected. The project manager knows the problems, the team developed a solution, and the project has a plan for recovering. The project will be back on track soon. Should the project manager inform the client? The answer seems like an easy yes, yet many project managers often believe there is no reason to bother the client with a problem they have under control.

Then the second delay occurs on the equipment delivery or the fixes for the beta test are more costly than expected. Now the problems have elevated to the point the clients should be informed. The greater the distance between the time of the event and the time the client knows about the events, the greater the client's frustration and mistrust. Including the client in the processes for analyzing project issues or concerns as well as the recovery planning enables the client to develop confidence that problems are being addressed. Including the client early in the process for dealing with problems enables the client to contribute with solutions and builds confidence that he or she is aware of critical issues on the project.

\section{New Estimates Increase Cost Projections}

On a large, complex project in South America, the project team was reestimating the project cost and schedule projections after the project design was complete. The team was also conducting a new risk analysis, and the results of the cost and schedule projections, together with the risk analysis, provided the client with better cash flow projections. Early in the process, the project team understood that the cost projections would significantly increase, and the final project cost would be significantly above the contingency set aside for the project.

The client looked for an early indication of the results of the analysis, and the project manager kept reporting it was too early to know. The project team debated how much contingency the project needed and how to inform the client. When the client was told the results of the cost projections, the response was a combination of frustration and anger. The project manager was removed from the project and a new project manager assigned.

The project manager should have dealt with the increased cost of the project early on. When first indications suggested that estimates were low and several items in the budget needed extra funds, the project manager should have had conversations with the client. Including one or more members of the client's team in the reevaluation effort would have kept the client informed of the progress regularly and built trust in the new numbers. The project team could have offered suggestions and contributed to possible solutions for addressing the concerns that were developing, as costs were higher than expected. Dealing openly and early with the client is critical to client satisfaction. 


\section{Provide Mechanisms for Revisiting Major Decisions and Issues}

The project environment moves fast, and decisions are made and implemented to keep pace. Decisions made in the conceptual phase of the project seem less effective during the design phase. It is not that the decision was necessarily wrong; based on the data at the time, most decisions are understandable. With new information, it is sometimes important to revisit and change decisions made earlier in the project. As obvious as this sounds, many project teams are reluctant to challenge earlier decisions. Without a mechanism in place to revisit decisions, decisions may be seen as final. This sense of finality may slow down the decision-making process to make sure every decision is right. Delays in decisions can put activities behind schedule and affect the project completing on time.

Mechanisms for revisiting decisions are similar to project change orders. Similar to a change order, a request to revisit a decision must be initiated by someone on the team. The formality of methods used by the project to revisit a decision depends on the complexity profile of the project. On less complex projects, an informal discussion in project meetings can develop the awareness that a decision needs to be revisited. On more complex projects, the action item register and the weekly project meetings provide a venue for revisiting decisions.

Sometimes people asked that decisions be revisited because they did not like the decision that was made.

\section{Revisiting Decisions}

On an engineering project, the electrical design schedule was changed to support the completion of the activities on the critical path by a project milestone date. The change increased the number of hours needed to complete the work because of the change in work processes. The project manager accepted the costs of the change to achieve the milestone date, but the manager of the electrical engineering team objected because the change would cause their part of the job to exceed the budgeted amount. The project manager decided not to revisit the decision because no new information was available that would cause the decision to change.

Clients are often involved in major decisions on the project. For example, if the project invested another million dollars, the project could be completed a month early. The client will conduct the cost-benefit analysis and decide if the extra expense is worth the gain in time. Once this decision is made, the necessary changes are made in the execution plan and new goals are established through the change management process. Later, for reasons outside the control of the project, the project will not experience the time savings from the additional investment of funds. It is important to revisit the decision. A culture that encourages project team members to bring up the need for revisiting decisions and a mechanism that makes it easy to surface issues and concerns will increase the likelihood that these issues will come to the attention of the management team. 


\section{Vendor Decision Not Revisited}

On a major pharmaceutical project in Ireland, a United States-based company was building a new plant to produce a new drug, and the priority was completing the plant to get the drug to the marketplace. The client was involved in the process to select major equipment, and after an expedited bidding process, an equipment vendor was selected for a critical piece of the plant equipment. Later, members of the project team learned that this vendor was overcommitted, and there was a high risk that the vendor would not be able to meet the schedule dates. Because it was the client's decision, the project leadership was not warned of the possible risk. Weeks later, the vendor began missing critical dates, and the leadership became aware of the risks.

The client was furious that the decision was not revisited earlier in the project. Even though changes were made that brought the project back on track, the client did not trust the project team again. The project finished on time and within budget while meeting all quality specifications, but the client was not pleased.

Establishing a culture and a mechanism for revisiting project decisions is important for meeting client expectations.

\section{Emergency Button}

An experienced project manager came up with a clever idea to enable his clients to capture the attention of the project team. He gave the client's team a bright red index card and said, "This is your emergency button.” The card was a symbol. It empowered the client with the ability to capture the complete attention of the project team. When the client presented the red button, the project manager instantly stopped current activities and focused on the client. The red button meant the project leadership focused on understanding the issue or concern presented by the client and developing project priorities to meet the client's concerns.

Although the red button was rarely used, it gave a sense of power to the client and communicated that the client was important. One project manager used the "red button" on four projects, and on two of the projects the card was never used. On one project, the client used the card to get the project ready for a visit from the client's boss, and on the fourth project, the client used the card often. Although the project manager believed the card was overused to get the total attention of the project leadership team, he never regretted providing the client with the card. The "red button" card provided them a method to distinguish the really important needs of the client.

\section{Key Takeaways}

- Determine who should be included in decisions for each category using a decision matrix

- Decide at what level of problem the client should be involved by discussing the threshold with the client. Involve the client early in the process to give them a chance to contribute to the solution before the problem gets worse.

- Decide what criteria to use to determine when a decision should be revisited. Additional informa- 
tion that is developed during the design and planning phase can require that decisions made during the conceptual phase need to be reconsidered.

\section{Exercises}

1. A table that displays who should be included in making different types of decisions is a decision

2. A client should be involved in decisions in the process of dealing with a problem.

3. Information that is developed in the planning phase can require reconsidering decisions that were made in the phase.

4. Describe a responsibility matrix and how it is used.

5. Why is it important to inform a client early in the process of resolving a problem?

6. Why should earlier decisions be revisited?

Threshold for Client Involvement

Consider a project with which you are familiar where the client was not included in making day-to-day decisions. Describe a type of problem that would be too small to take to the client for input and another problem that would be just large enough to require client involvement. If you were trying to communicate the reasons for your decision to another team member, describe the threshold that had to be crossed for the second problem to qualify for client involvement. 


\subsection{Nurturing a Feeling of Satisfaction}

\section{Learning Objectives}

1. Describe the advantages of using project milestones.

2. Describe the advantages of including the client in celebrations and guidelines for doing so.

\section{Manage around Project Milestones}

Project milestones represent significant events on the project. Some project milestones signify external events that provide critical information or resources to the project or an external event that requires information or deliverables from the project.

\section{Board of Directors Meeting}

The client's board of directors meets on March 15, and the client must report the project progress and submit the project final budget for approval. The project team develops the information needed for the project progress report and finalizes the project estimate by March 10 to provide the client with five days to review the information and make any changes.

Recall that a milestone is an event that consumes no time or resources. In this example, the Provide Client with Report is the milestone event. All the activity to develop and deliver the report takes place before the milestone event.

\section{Extra Effort to Meet a Milestone}

On March 8, the project team determines that the progress report and estimate cannot be completed by March 10. The team will need one more day to complete the report and estimate. Should the project manager ask the client for a one-day extension? The client may be able to review and revise the information before it goes to the board in four days, but the message to the client has a bigger impact on the project. By missing the deadline, the client can develop the perception that client deadlines are less important, that the project team is unable to complete critical tasks on time, or that the project team is not dedicated.

Instead of asking the client for one more day, the project manager pulls together the project team and asks what 
it will take to make the milestone date. If the estimator works overtime tonight and the project controls team starts a few hour early on March 9, then the project controls team can work late on March 9 to finish the report. The project administrative staff can come in early on March 10 to do the revisions and make copies, and the reports can be ready by noon. Other activities will have to be delayed and critical staff will work overtime, but the client will get the needed information by the promised date.

Making the extra effort to deliver by the milestone date communicates to the client and the project team the importance of meeting milestones. The client develops confidence that the project team is dedicated to meeting client expectations and that deadlines are important. The extra efforts by the team to meet the client's critical dates will often result in the client making an extra effort to help the project team meet critical dates.

During the life of a project, the project team encounters a large number of small problems that can cause small delays. A thunderstorm caused the loss of electricity in the office building, and the bidders' conference had to be delayed one day; a computer virus shut down the use of computers, causing the loss of another day; and the airplane flights were late, so the project reviews were one day late. None of these events caused significant problems for the project, but together they add up to delays that could affect the end date of the project.

If these delays continue to add up, then the project end date will begin to slip. As the project nears the completion date, the team will work overtime, decisions will be rushed, and resources will be added to the project to avoid missing the project end date. This type of end-of-project atmosphere will leave a strong lasting impression with the client and usually does not produce a satisfied client.

Project milestones provide the opportunity for the project manager to spread the end-of-project pressure over the life of the project. Project managers add resources, authorize overtime, and expedite work to accomplish what is required to meet the milestone. The project work increases in intensity, motivating project team members to accomplish the work on time until the milestone is achieved. After the milestone is achieved, the project celebrates and acknowledges the success of the team and then begins working toward the next milestone. Project managers use milestones to increase this intensity and focus to keep the project on schedule and prevent the delays of hard decisions to the end of the project.

This approach allows the project manager to lower the intensity of the project after a milestone is accomplished. After celebrating the successful completion of the milestone, a project manager will often review the future plans and allow the team to reflect on finding new ways of approaching the project work. Adjustments are made to the project work plan and the milestone cycle begins again.

Milestones are rarely evenly distributed over the length of the project. Project managers often select key events and make them milestone events to create roughly equal spacing between milestone dates. On large, multiyear projects, managing to a milestone each quarter provides good timing for the project. On shorter projects, monthly milestones can provide the right timing. On larger, more complex projects, typically a large number of activities can be designated as milestones for the project. On smaller projects, the project manger may need to artificially create milestones. 


\section{Include the Client in Celebrations}

Project celebrations are a time when the project manager and the management team can thank the project team members for their contribution to the project's success at various stages of the project. Celebrations for successfully accomplishing project milestones are good examples of creating the opportunity to honestly celebrate. Some projects have birthday celebrations for the team or holiday celebrations, and although these events can be a positive contribution to the project morale, they are not connected to the success of the team in accomplishing project objectives.

Successful celebrations reinforce the effort and activities that created the success. Successful celebrations communicate appreciation for the energy and commitment of the team, focused on team goals. Successful celebrations communicate progress and confidence to project stakeholders, and successful celebrations share the success of the project with the client and reinforce the meeting of client expectations.

Successful celebrations result from good planning and the application of some basic principles for celebrations. The following are some of the basic principles for developing a successful celebration:

- What was accomplished and why it was important to the overall success of the project should be communicated to the team. Discuss the goals that were accomplished and the milestones met and how that advanced the project. For example, the civil design team on a construction project completed the site work design early, the bids for the site work were on the street early, and the project met the milestone of moving dirt on the site by May 1 . Starting the site work early helps assure that the construction work will be under a roof before the bad weather hits in the late fall.

- Appreciation should be expressed specifically. A general statement that the project met all the goals does not carry the same meaning as "the project team completed the development of the new training curriculum by December 1.” People associate their activities with meeting the milestone and take pride in their contribution to the project's success. Team members appreciate it when the project manager and others recognize their contribution.

- Celebrations should occur in the work area where the accomplishments were achieved. Celebrating holidays in the cafeteria is appropriate. Celebrating the accomplishments of the project in the project task force area brings a stronger association of the work of the project with the accomplishments being celebrated.

- Accomplishments of the team should be celebrated shortly after the milestone is achieved. The more time elapsed between the accomplishments and the celebrations, the less the impact.

- The persons that publicly recognize the team are important. The project leadership expressing personal appreciation reinforces the recognition of the work and effort to achieve project goals. Senior managers of the company reinforce the importance of the project to company goals and recognition of the role of individual project team members' contribution to company success.

- In many cultures, food is associated with times of reflection, such as the dinner table discussion or lunch meetings. Serving food communicates that this event is special. Serving food 
also communicates that someone took the time to prepare and serve the project team as a form of appreciation.

- Clients play a special role in celebrations, and celebrations play a special role in meeting client expectations. A client expression of appreciation to the project team is often more significant than the appreciation expressed by senior managers. Clients in most commercial organizations are acknowledged as the source of profits, bonuses, and future business. A client expressing appreciation to the project team, especially in front of the company's senior management, gives the project team special status for creating goodwill with clients.

When clients speak at a celebration, their remarks usually provide high praise for the work of the project team. This event provides an opportunity for the client to reflect and appraise the progress of the project team. Often the client concludes that the team is meeting or exceeding expectations. The celebration reinforces that conclusion.

If the client has doubts about some of the project performance but still speaks at the celebration and praises the team, the client may experience cognitive dissonance. The client will typically reevaluate the perception of the project team's performance and conclude the team really has done a good job. The perception is now consistent with the client's remarks and the end result is a client perception of a project as meeting expectations.

Understanding and meeting client expectations is a proactive process. The project manager and the project team develop plans and processes that focus on defining both specifications and expectations that are often difficult to quantify. The team executes the project in a way that meets both the specifications of the client and also the more subtle expectations not reflected in the measured data.

\section{Key Takeaways}

- Making extra efforts to meet milestone dates keeps the project on track and avoids large problems at the end of the project. It allows for lessening of intensity after a milestone to provide stress relief for team members, and it builds confidence in the client that the project will be completed on time.

- If the client is included in milestone celebrations, he or she has a better understanding of what effort it takes to keep the project on track. If asked to say something at the celebration, the client will usually say positive things that have an effect on his or her perception of the project. Celebrations should communicate the importance of the milestone to the project and praise specific accomplishments. The celebration should occur in the workplace. Get high-ranking people to praise the project team in front of each other to reinforce a sense of satisfaction and include food in the celebration to make it more social. 


\section{Exercises}

1. Managing a project using keeps the project on track and allows for periodic celebrations of achieving interim objectives.

2. Clients should be encouraged to in celebration of project achievements.

3. Why should extra effort be expended to meet a milestone when the final project's due date is months away?

4. Why should the client be included in milestone celebrations?

Milestone Celebrations

Consider a workplace with which you are familiar. If it utilizes milestone celebrations to mark completion of special tasks or phases of work, compare the components of the celebration with those recommended in the text. If it does not, describe how you would use milestone celebrations in this workplace. 


\subsection{Exercises}

Exercises at the end of the chapter are designed to strengthen your understanding and retention of the information recently acquired in the chapter.

\section{Essay Questions}

Write several paragraphs to provide more in-depth analysis and consideration when answering the following questions.

1. Describe a project with which you are familiar that resulted in a dissatisfied client. The project can be personal or professional if it serves to illustrate the concepts in this chapter. Identify how the client was included or excluded from project teams and how they were informed of problems. Analyze the situation and draw a conclusion regarding how a similar client might be satisfied on a future project.

2. Describe a project with which you are familiar that resulted in a satisfied client. The project can be personal or professional if it serves to illustrate the concepts in this chapter. Identify how the client was included or excluded from project teams and how they were informed of problems. Analyze the situation and draw a conclusion regarding which aspect of client relations was most effective in achieving client satisfaction.

3. Describe a project with which you are familiar where early decisions had to be changed based on information that became available later in the project. Analyze the process by which the decision was made and at what point the client was informed of the need for a change. Describe any changes you would make in the process or timing that might improve client satisfaction.

\section{Discussion}

The exercises in this section are designed to promote exchange of information among students in the classroom or in an online discussion. The exercises are more open ended, which means that what you find might be completely different from what your classmates find, and you can all benefit by sharing what you have learned.

1. Milestone celebrations. Consider celebrations of milestone events in your life and how those celebrations affected your memory and attitudes toward achieving those objectives. Do you think using milestone celebrations can be a useful tool for projects? Express your opinion and support it with examples.

2. Client participation. Where would you place the threshold for involving a client in a decision? What criteria would you use and how would you involve the client with that process of establishing the threshold? 


\subsection{Web Exercises}

\section{Learning Objectives}

1. Locate and analyze information online related to managing client relationships.

2. Locate, download, and analyze a project milestone analysis and then create your hypothetical project milestone analysis for distribution to your team and client.

\section{Locate and Analyze Information Online Related to Managing Client Relationships}

Managing relationships with clients is a challenging task, and it is often discussed online. In this exercise, you locate online articles and other publications dealing with client relationships and then compare and analyze them.

\section{How to Read about Client Relationships}

1. Start a web browser program and go to the an idea website at http://anidea.com/etc/how-tocreate-a-cooperative-relationship-between-account-and-project-management.

2. Review the five topics listed in this article.

3. Start a word processing program and open a new document. On the first line, type your name. Below your name, write a brief summary of the points made in each of the five major topics.

4. Save the word processing document as Ch04ClientStudentName using the Word 2003 .doc file format.

5. In the web browser, use a search program such as Google to search for a combination of key terms such as Project Management Client Relationships.

6. Review the results of the search and choose a site that addresses some of the same points. Consider the similarities and differences between this site and the article from an idea.

7. Copy the web address from the browser's address bar.

8. Switch to Ch04ClientStudentName. Paste the web address into the document.

9. Switch to the browser. Capture the screen and paste it into Ch04ClientStudentName. 
10. Below the screen image, compare the content of the two sites point by point using a separate paragraph for each point. Be specific. If the site does not address one of the five points in the first site, briefly mention that it does not.

11. Save the document.

12. Review your work and use the following rubric to determine its adequacy:

\begin{tabular}{|l|l|l|l|}
\hline Element & Best & Adequate & Poor \\
\hline File name & Ch04ClientStudentName.doc & $\begin{array}{l}\text { Word } \\
2010 \\
\text { version } \\
\text { using } \\
\text { docx }\end{array}$ & Another file name \\
\hline $\begin{array}{l}\text { Locate and analyze } \\
\text { information online related } \\
\text { to managing client } \\
\text { relationships }\end{array}$ & $\begin{array}{l}\text { Summary of the five points; } \\
\text { web address; screen capture; } \\
\text { comparison of each point }\end{array}$ & $\begin{array}{l}\text { Same as } \\
\text { Best }\end{array}$ & $\begin{array}{l}\text { Summary not accurate; } \\
\text { missing web address or } \\
\text { screen; all five topics not } \\
\text { addressed }\end{array}$ \\
\hline
\end{tabular}

13. Save the file and submit it as directed by the instructor. Close all documents and programs.

\section{Project Milestone Analysis ${ }^{1}$}

Morale and psyche are an important component in any project; this includes both the team and the client. Project milestones represent significant events within the project. Some project milestones signify external events that provide critical information or resources to the project or an external event that requires information or deliverables from the project. Nonetheless, the proper creation and distribution of this information can be an integral part of the overall success of your project.

\section{How to Download a Project Milestone Analysis}

1. Open a blank word processing document and type Milestone and your name and date on the first line. Save the file as Ch04MilestonesStudentName using the Word 2003 file format that ends with .doc.

2. Start a web browser program and go to the Orion Crew Exploration Vehicle Project Milestones page for NASA at http://www.nasa.gov/pdf/479023main_Orion_2010_Milestones.pdf. A screen capture of this milestone analysis is shown in Figure 4.9 "Orion Milestone-NASA".

\section{Written by Eric Ouellette as his additional project for graduate credit, December 2010, Eastern Michigan University. Edited by Professor Preston on June 20, 2012.}




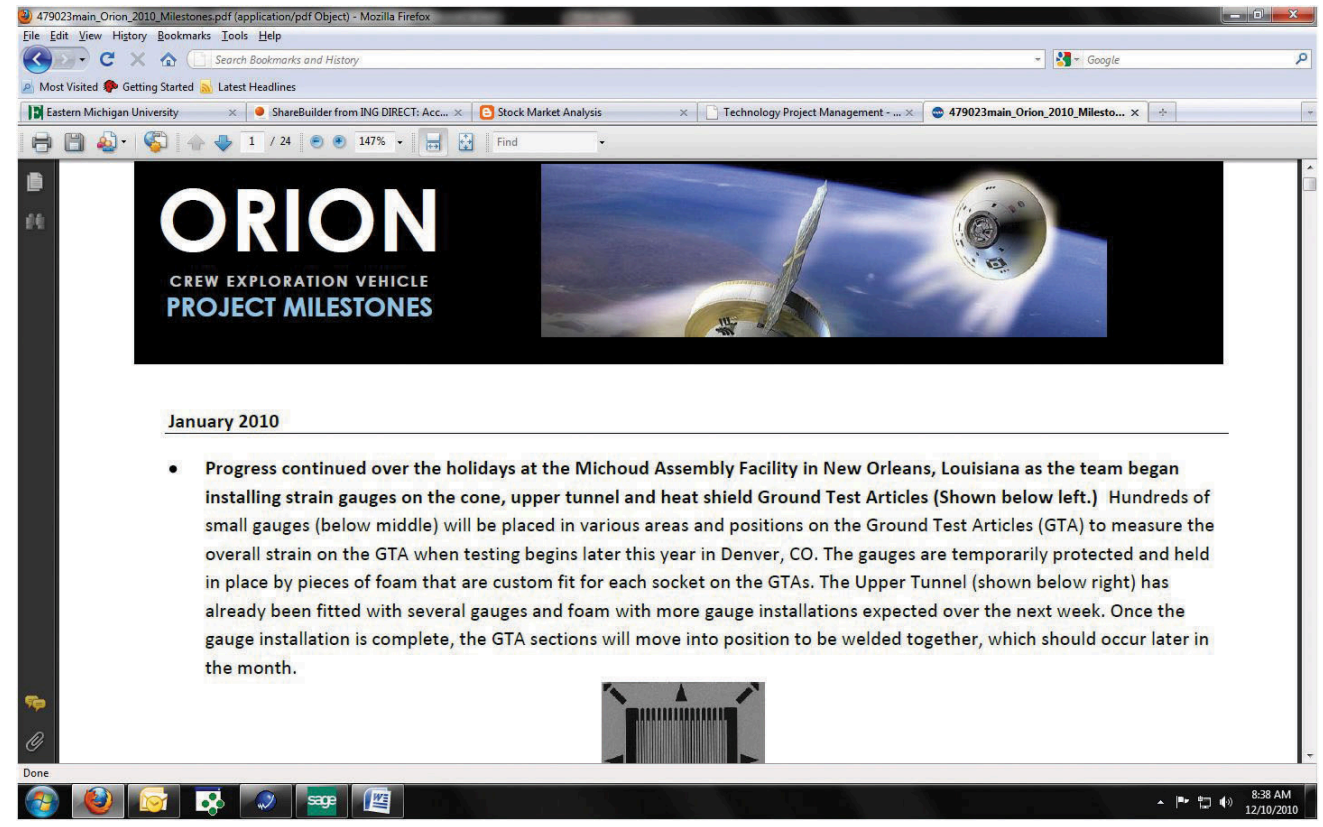

NASA - public domain.

3. Add this website to your browser's favorites list, in a folder named Milestones.

4. Capture a screen that shows a link to this site in the Projects folder of your bookmarks or favorites and then paste it into the word processing document.

5. Within the PDF file locate the milestone attribute within the analysis that you feel to be most significant, capture the screen of that milestone accomplishment, and paste it in the Word document.

6. Below the Word document, include a brief summary (250 words) as to why you think this accomplishment is of merit and utilize references from the reading in Chapter 4 "Understanding and Meeting Client Expectations” to correlate this accomplishment to things you've learned in the text. Describe the advantages of using project milestones.

\section{How to Create an Analysis}

1. Now that you have familiarized yourself with the reading on the importance of project milestones and witnessed a firsthand account of a project milestone analysis on behalf of NASA, create your hypothetical 1,000-word milestone analysis document including a minimum of four digital images. Make sure that the analysis is pertinent and consistent-maintain a common theme.

2. Use appropriate verbiage that will be comprehendible by everyone who may read this analysis: team members, clients, and so on.

3. Insert this 1,000 -word analysis with imagery below the final screen capture from the NASA 
website.

4. Review your work and use the following rubric to determine its adequacy:

\begin{tabular}{|c|c|c|c|}
\hline Element & Best & Adequate & Poor \\
\hline File name & Ch04MilestonesStudentName.doc & Ch04MilestonesStudentName & $\begin{array}{l}\text { Another file } \\
\text { name }\end{array}$ \\
\hline $\begin{array}{l}\text { Locate, } \\
\text { download, } \\
\text { and analyze } \\
\text { a project } \\
\text { milestone } \\
\text { analysis and } \\
\text { then create } \\
\text { your } \\
\text { hypothetical } \\
\text { project } \\
\text { milestone } \\
\text { analysis for } \\
\text { your team } \\
\text { and client }\end{array}$ & $\begin{array}{l}\text { Milestone and name/date on first } \\
\text { line; screen captures that show } \\
\text { the web link in the Milestone } \\
\text { folder of your browser's favorites } \\
\text { and an image of the initial screen } \\
\text { capture of the NASA milestone } \\
\text { analysis; your perceived, most } \\
\text { important aspect and rebuttal } \\
\text { ( } 250 \text { words); a hypothetical } \\
1,000 \text {-word milestone analysis } \\
\text { that is entirely consistent }\end{array}$ & $\begin{array}{l}\text { Milestone and name on first } \\
\text { line; screen captures that } \\
\text { show the web link in the } \\
\text { Milestone folder of your } \\
\text { browser's favorites and an } \\
\text { image of the NASA } \\
\text { milestone analysis; a brief } \\
\text { rebuttal (150 words or less) } \\
\text { as to why you think this is the } \\
\text { most important aspect of the } \\
\text { milestone; a hypothetical } \\
500 \text {-word milestone analysis } \\
\text { that is somewhat consistent }\end{array}$ & $\begin{array}{l}\text { Missing or } \\
\text { incomplete } \\
\text { screen captures; a } \\
\text { rebuttal that is } \\
\text { too general and } \\
\text { lacks significant } \\
\text { educational } \\
\text { correlation from } \\
\text { the text; a } \\
\text { hypothetical } \\
\text { milestone } \\
\text { analysis that is } \\
\text { not consistent } \\
\text { and lacks } \\
\text { evidence of } \\
\text { thought } \\
\text { provocation }\end{array}$ \\
\hline
\end{tabular}

5. Save Ch04MilestoneStudentName and submit it as directed by the instructor. Close all documents and programs. 


\section{Chapter 5: Working with People on Projects}

Project management encompasses the concepts of management and leadership. Although leadership and management research have made distinctions between the two concepts, the project management profession has integrated the two concepts, and project management refers to the leadership and management needed to lead and manage a project. A project manager leads people and manages work processes.

Project management is both art and science. It is the art of creating a vision of success, building a project team, and developing a project story. Project leadership encompasses the personality, leadership style, and leadership skills of the project manager. Project management also includes formulas and processes for calculating the critical path, developing goals, and managing meetings.

Some projects are more leader sensitive,Albert A. Einsiedel, "Profile of Effective Project Managers," Project Management Journal 18 (1987): 5. and the success of the project is more dependent on the leadership skills of the project manager. Leadership is a function of the project manager's leadership style, personality type, and understanding of emotions. Management is mastery of the skills needed to organize and execute the work of the project. Each project includes challenges that require both leadership and management. The leadership and management skills needed are related to the project complexity profile. In general, more complex projects require a greater degree of leadership and management skill. This chapter will review various leadership approaches and management skills. 


\subsection{Working with Individuals}

\section{Learning Objectives}

1. Describe emotional intelligence.

2. Describe personality types and tools used to describe them.

3. Describe the relationship between leadership style and personality types.

4. Describe people skills that are necessary for negotiation and conflict resolution.

5. Describe how work is delegated.

6. Describe individual goals that are related to personality types.

Working with other people involves dealing with them both logically and emotionally. A successful working relationship between individuals begins with appreciating the importance of emotions and how they relate to personality types, leadership styles, negotiations, and setting goals.

\section{Emotional Intelligence}

Emotions are neither positive nor negative. Emotions are both a mental and physiological response to environmental and internal stimuli. Leaders need to understand and value their emotions to appropriately respond to the client, project team, and project environment. Daniel Goleman (Goleman, 1995) discussed emotional intelligence quotient (EQ) as a factor more important than IQ in predicting leadership success. According to Robert Cooper and Ayman Sawaf, "Emotional intelligence is the ability to sense, understand, and effectively apply the power and acumens of emotions as a source of human energy, information, connection, and influence” (Cooper \& Sawaf, 1997).

Emotional intelligence includes the following:

- Self-awareness

- Self-regulation

- Empathy

- Relationship management

Emotions are important to generating energy around a concept, to building commitment to goals, and to developing high-performing teams. Emotional intelligence is an important part of the project manager's ability to build trust among the team members and with the client. It is an important factor in establishing 
credibility and an open dialogue with project stakeholders. Emotional intelligence is a critical ability for project managers, and the more complex the project profile, the more important the project manager's EQ becomes to project success.

\section{Personality Types}

Personality types refer to the difference among people. Understanding your personality type as a project manager will assist you in understanding your tendencies and strengths in different situations. Understanding personality types can also help you understand the contributions of various members of your team and the various needs of your client.

There are a number of tools for helping people assess personality types, such as the DISC acronym, which stands for the following:

- Dominance-relates to control, power, and assertiveness

- Influence-relates to social situations and communication

- Steadiness - relates to patience, persistence, and thoughtfulness

- Conscientiousness - relates to structure and organization

These four dimensions are then grouped to represent various personality types.

The Myers-Briggs Type Indicator (MBTI) is one of most widely used tools for exploring personal preference, with more than two million people taking the MBTI each year. The MBTI is often referred to as simply the Myers-Briggs. It is a tool that can be used in project management training to develop awareness of preferences for processing information and relationships with other people.

Based on the theories of psychologist Carl Jung, the Myers-Briggs uses a questionnaire to gather information on the ways individuals prefer to use their perception and judgment. Perception represents the way people become aware of people and their environment. Judgment represents the evaluation of what is perceived. People perceive things differently and reach different conclusions based on the same environmental input. Understanding and accounting for these differences is critical to successful project leadership.

The Myers-Briggs identifies sixteen personality types based on four preferences derived from the questionnaire. The preferences are between pairs of opposite characteristics and include the following:

- Extroversion (E)-Introversion (I)

- Sensing (S)-Intuition (N)

- Thinking (T)-Feeling (F)

- Judging (J)-Perceiving (P)

Sixteen Myers-Briggs types can be derived from the four dichotomies. Each of the sixteen types describes a preference: for focusing on the inner or outer world (E-I), for approaching and internalizing 
information (S-I), for making decisions (T-F), and for planning (J-P). For example, an ISTJ is a MyersBriggs type who prefers to focus on the inner world and basic information, prefers logic, and likes to decide quickly.

It is important to note that there is no best type and that effective interpretation of the Myers-Briggs requires training. The purpose of the Myers-Briggs is to understand and appreciate the differences among people. This understanding can be helpful in building the project team, in developing common goals, and communicating with project stakeholders. For example, different people process information differently. Extraverts prefer face-to-face meetings as the primary means of communicating, while introverts prefer written communication. Sensing types focus on facts, and intuitive types want the big picture.

On larger, more complex projects, some project managers will use the Myers-Briggs as a team-building tool during project start-up. This is typically a facilitated work session where team members take the Myers-Briggs and share with the team how they process information, what communication approaches they prefer, and what decision-making preferences they have. This allows the team to identify potential areas of conflict, develop communication strategies, and build an appreciation for the diversity of the team.

\section{Personality Type Badges}

One project team in South Carolina used color-coded badges for the first few weeks of the project to indicate Myers-Briggs type. For this team, this was a way to explore how different team members processed information, made decisions, and took action.

Some people use a description of personality types that is based on research that shows that some functions of thinking and perception are localized on the left or right side of the brain. In this system, the left side of the brain is associated with recalling specific facts and definitions and performing calculations, while the right side of the brain is associated with emotions, estimates, and comparisons. The attraction of this system is that it categorizes people into just two categories-left or right brain dominance-but it should be used cautiously to avoid oversimplification.

Understanding the differences among people is a critical leadership skill. This includes understanding how people process information, how different experiences will influence the way people perceive the environment, and how people develop filters that allow certain information to be incorporated while other information is excluded. The more complex the project, the more important the understanding of how people process information, make decisions, and deal with conflict.

\section{Leadership Styles}

Leadership is a function of both the personal characteristics of the leader and the environment in which the leadership must occur. Several researchers have attempted to understand leadership from the per- 
spective of the characteristics of the leader and the environment of the situation. Robert Tannenbaum and Warren Schmidt (Tannenbaum \& Schmidt, 1958). described leaders as either autocratic or democratic. Harold Leavitt (Leavitt, 1986) described leaders as pathfinders (visionaries), problem solvers (analytical), or implementers (team oriented). James MacGregor Burns (Burns, 1978) conceived leaders as either transactional (focused on actions and decisions) or transformational (focused on the long-term needs of the group and organization).

Fred Fiedler (Fiedler, 1971) introduced contingency theory and the ability of leaders to adapt their leadership approach to the environment. Most leaders have a dominant leadership style that is most comfortable. For example, most engineers spend years training in analytical problem solving and often develop an analytical approach to leadership.

A leadership style reflects personal characteristics and life experiences. Although a project manager's leadership style may be predominantly a pathfinder (using Leavitt's taxonomy), most project managers become problem solvers or implementers when they perceive the need for these leadership approaches. The leadership approach incorporates the dominant leadership style and Fiedler's contingency focus on adapting to the project environment.

No particular leadership approach is specifically appropriate for managing a project. Each project has a unique set of circumstances because, by definition, projects are unique endeavors. The leadership approach and the management skills required to be successful vary depending on the complexity profile of the project. The Project Management Institute published research that studied project management leadership skills (Shi \& Chen, 2006) and concluded that project managers needed good communication skills and the ability to build harmonious relationships and motivate others. Beyond this broad set of leadership skills, the successful leadership approach will depend of the profile of the project.

A transactional project manager with a strong command and control leadership approach may be very successful on a small software development project or a construction project, where tasks are clear, roles are well understood, and the project environment is cohesive. This same project manager is less likely to be successful on a larger, more complex project with a diverse project team and complicated work processes.

Matching the appropriate leadership style and approach to the complexity profile of the project is a critical element of project success. Even experienced project managers are less likely to be successful if their leadership approach does not match the complexity profile of the project.

Each project phase may also require a different leadership approach. During the start-up phase of a project, when new team members are first assigned to the project, the project may require a command and control leadership approach. Later, as the project moves into the conceptual development phase, creativity becomes important, and the project management takes on a more transformational type leadership approach. Most experienced project managers are able to adjust their leadership approach to the needs of the project phase. Occasionally, on very large, complex projects, some companies will change project managers after the conceptual phase of the project to bring in a different project leadership approach or change project managers to manage the closeout of a project. Changing project managers may bring the right level of experience and the appropriate leadership approach but is also disruptive to a project. Senior management must balance the benefit of matching the right leadership approach with the cost of disrupting the project. 


\section{Multinational Chemical Plant Project}

On a project to build a new chemical plant that produced dyes for paint, the project manager led a team that included members from partners that were included in a joint venture. The design manager was Greek, the construction manager was German, and other members of the team were from various locations in the United States and Europe. In addition to the traditional potential for conflict that arises from team members from different cultures, the design manager and construction manager were responsible for protecting the interest of their company in the joint venture.

The project manager held two alignment or team-building meetings. The first was a two-day meeting held at a local resort and included only the members of the project leadership team. An outside facilitator was hired to facilitate discussion, and the topic of cultural conflict and organizational goal conflict quickly emerged. The team discussed several methods for developing understanding and addressing conflicts that would increase the likelihood of finding mutual agreement.

The second team-building session was a one-day meeting that included the executive sponsors from the various partners in the joint venture. With the project team aligned, the project manager was able to develop support for the project's strategy and commitment from the executives of the joint venture. In addition to building processes that would enable the team to address difficult cultural differences, the project manager focused on building trust with each of the team members. The project manager knew that building trust with the team was as critical to the success of the project as the technical project management skills and devoted significant management time to building and maintaining this trust.

\section{Negotiation and Conflict Resolution}

Einsiedel (Einsiedel, 1987) discussed qualities of successful project managers. The project manager must be perceived to be credible by the project team and key stakeholders. The project manager can solve problems. A successful project manager has a high degree of tolerance for ambiguity. On projects, the environment changes frequently, and the project manager must apply the appropriate leadership approach for each situation.

The successful project manager must have good communication skills. Barry Posner (Posner, 1987) connected project management skills to solving problems. All project problems were connected to skills needed by the project manager:

- Breakdown in communication represented the lack of communication skills.

- Uncommitted team members represented the lack of team-building skills.

- Role confusion represented the lack of organizational skills.

The research indicates that project managers need a large numbers of skills. These skills include administrative skills, organizational skills, and technical skills associated with the technology of the project. The types of skills and the depth of the skills needed are closely connected to the complexity profile of the project. Typically on smaller, less complex projects, project managers need a greater degree of technical skills. On larger, more complex projects, project managers need more organizational skills to 
deal with the complexity. On smaller projects, the project manager is intimately involved in developing the project schedule, cost estimates, and quality standards. On larger projects, functional managers are typically responsible for managing these aspects of the project, and the project manager provides the organizational framework for the work to be successful.

\section{Listening}

One of the most important communication skills of the project manager is the ability to actively listen. Active listening takes focus and practice to become effective. Active listening is placing yourself in the speaker's position as much as possible, understanding the communication from the point of view of the speaker, listening to the body language and other environmental cues, and striving not just to hear, but to understand.

Active listening enables a project manager to go beyond the basic information that is being shared and to develop a more complete understanding of the information.

\section{Client's Body Language Indicates Problems at a Board Meeting}

A client just returned from a trip to Australia where he reviewed the progress of the project with his company's board of directors. The project manager listened and took notes on the five concerns expressed by the board of directors to the client.

The project manager observed that the client's body language showed more tension than usual. This was a cue to listen very carefully. The project manger nodded occasionally and clearly demonstrated he was listening through his posture, small agreeable sounds, and body language. The project manager then began to provide feedback on what was said using phrases like "What I hear you say is..." or "It sounds like...." The project manager was clarifying the message that was communicated by the client.

The project manager then asked more probing questions and reflected on what was said. "It sounds as if it was a very tough board meeting." "Is there something going on beyond the events of the project?" From these observations and questions, the project manager discovered that the board of directors meeting did not go well. The company had experienced losses on other projects, and budget cuts meant fewer resources for the project and an expectation that the project would finish earlier than planned. The project manager also discovered that the client's future with the company would depend on the success of the project. The project manager asked, "Do you think we will need to do things differently?" They began to develop a plan to address the board of directors' concerns.

Through active listening, the project manager was able to develop an understanding of the issues that emerged from the board meeting and participate in developing solutions. Active listening and the trusting environment established by the project manager enabled the client to safely share information he had not planned on sharing and to participate in creating a workable plan that resulted in a successful project.

The project manager used the following techniques:

1. Listening intently to the words of the client and observing the client's body language 
2. Nodding and expressing interest in the client without forming rebuttals

3. Providing feedback and asking for clarity while repeating a summary of the information back to the client

4. Expressing understanding and empathy for the client

The active listening was important to establishing a common understanding from which an effective project plan could be developed.

\section{Negotiation}

Negotiation is a process for developing a mutually acceptable outcome when the desired outcome for parties in the negotiation is sufficiently different that both cannot achieve the desired outcome. A project manager will often negotiate with a client, with team members, with vendors, and with other project stakeholders. A larger and more complex project will have a large number of stakeholders, often with conflicting desired outcomes. Negotiation is an important skill in developing support for the project and preventing frustration among stakeholders, which could delay or cause project failure.

Vijay Verma (Verma, 1996) suggests that negotiations involve four principles:

1. The first principle is to separate people from the problem. If the person is seen as the problem, then finding a mutually acceptable solution will be difficult. Framing the discussions in terms of desired outcomes enables the negotiations to focus on finding new outcomes.

2. The second principle is to focus on common interests. By avoiding the focus on differences, both parties are more open to finding solutions that are acceptable.

3. The third principle is to generate options that advance shared interests. Once the common interests are understood, solutions that do not match with either party's interests can be discarded, and solutions that may serve both parties' interests can be more deeply explored.

4. Verma's final principle is to develop results based on standard criteria. The standard criterion is the success of the project. This implies that the parties develop a common definition of project success.

For the project manager to successfully negotiate issues on the project, he or she should first seek to understand the position of the other party. If negotiating with a client, what is the concern or desired outcome of the client? What are the business drivers and personal drivers that are important to the client? Without this understanding, it is difficult to find a solution that will satisfy the client. The project manager should also seek to understand what outcomes are desirable to the project. Typically, more than one outcome is acceptable. Without knowing what outcomes are acceptable, it is difficult to find a solution that will produce that outcome.

One of the most common issues in formal negotiations is finding a mutually acceptable price for a service or product. Understanding the market value for a product or service will provide a range for developing a negotiations strategy. The price paid on the last project or similar projects provides information on the market value. Seeking expert opinions from sources who would know the market is another 
source of information. Based on this information, the project manager can then develop an expected range from the lowest price that would be expected within the current market to the highest price.

Additional factors will also affect the negotiated price. The project manger may be willing to pay a higher price to assure an expedited delivery or a lower price if delivery can be made at the convenience of the supplier or if payment is made before the product is delivered. Developing as many options as possible provides a broader range of choices and increases the possibility of developing a mutually beneficial outcome.

The goal of negotiations is not to achieve the lowest costs, although that is a major consideration, but to achieve the greatest value for the project. If the supplier believes that the negotiations process is fair and the price is fair, the project is more likely to receive higher value from the supplier. The relationship with the supplier can be greatly influenced by the negotiation process and a project manager that attempts to drive the price unreasonably low or below the market value will create an element of distrust in the relationship that may have negative consequences for the project. A positive negotiation experience may create a positive relationship that may be beneficial, especially if the project begins to fall behind schedule and the supplier is in a position to help keep the project on schedule.

\section{Negotiation on a Construction Project}

After difficult negotiations on a construction project in Indiana, the project management team met with a major project supplier and asked, "Now that the negotiations are complete, what can we do to help you make more profit?” Although this question surprised the supplier, the team had discussed how information would flow, and confusion in expectations and unexpected changes always cost the supplier more money. The team developed mechanisms for assuring good information and providing early information on possible changes and tracked the effect of these efforts during the life of the project.

These efforts and the increased trust did enable the supplier to increase profits on the project, and the supplier made special efforts to meet every project expectation. During the life of the project, the supplier brought several ideas on how to reduce total project costs and increase efficiency. The positive outcome was the product of good supplier management by the project team, but the relationship could not have been successful without good faith negotiations.

\section{Conflict Resolution}

Conflict on a project is to be expected because of the level of stress, lack of information during early phases of the project, personal differences, role conflicts, and limited resources. Although good planning, communication, and team building can reduce the amount of conflict, conflict will still emerge. How the project manager deals with the conflict results in the conflict being destructive or an opportunity to build energy, creativity, and innovation.

David Whetton and Kim Cameron (Whetton \& Cameron, 2005) developed a response-to-conflict model that reflected the importance of the issue balanced against the importance of the relationship. The model presented five responses to conflict: 
1. Avoiding

2. Forcing

3. Collaborating

4. Compromising

5. Accommodating

Each of these approaches can be effective and useful depending on the situation. Project managers will use each of these conflict resolution approaches depending on the project manager's personal approach and an assessment of the situation.

Most project managers have a default approach that has emerged over time and is comfortable. For example, some project managers find the use of the project manager's power the easiest and quickest way to resolve problems. "Do it because I said to" is the mantra for project managers who use forcing as the default approach to resolve conflict. Some project managers find accommodating with the client the most effective approach to dealing with client conflict.

The effectiveness of a conflict resolution approach will often depend on the situation. The forcing approach often succeeds in a situation where a quick resolution is needed, and the investment in the decision by the parties involved is low.

\section{Resolving an Office Space Conflict}

Two senior managers both want the office with the window. The project manager intercedes with little discussion and assigns the window office to the manager with the most seniority. The situation was a low-level conflict with no long-range consequences for the project and a solution all parties could accept.

Sometimes office size and location is culturally important, and this situation would take more investment to resolve.

\section{Conflict Over a Change Order}

In another example, the client rejected a request for a change order because she thought the change should have been foreseen by the project team and incorporated into the original scope of work. The project controls manager believed the client was using her power to avoid an expensive change order and suggested the project team refuse to do the work without a change order from the client.

This is a more complex situation, with personal commitments to each side of the conflict and consequences for the project. The project manager needs a conflict resolution approach that increases the likelihood of a mutually acceptable solution for the project.

One conflict resolution approach involves evaluating the situation, developing a common understanding 
of the problem, developing alternative solutions, and mutually selecting a solution. Evaluating the situation typically includes gathering data. In our example of a change order conflict, gathering data would include a review of the original scope of work and possibly of people's understandings, which might go beyond the written scope.

The second step in developing a resolution to the conflict is to restate, paraphrase, and reframe the problem behind the conflict to develop a common understanding of the problem. In our example, the common understanding may explore the change management process and determine that the current change management process may not achieve the client's goal of minimizing project changes. This phase is often the most difficult and may take an investment of time and energy to develop a common understanding of the problem.

After the problem has been restated and agreed on, alternative approaches are developed. This is a creative process that often means developing a new approach or changing the project plan. The result is a resolution to the conflict that is mutually agreeable to all team members. If all team members believe every effort was made to find a solution that achieved the project charter and met as many of the team member's goals as possible, there will be a greater commitment to the agreed-on solution.

\section{Project Goals Accomplished}

In our example, the project team found a new way to accomplish the project goals without a change to the project scope. On this project, the solution seemed obvious after some creative discussions, but in most conflict situations, even the most obvious solutions can be elusive.

\section{Delegation}

Delegating responsibility and work to others is a critical project management skill. The responsibility for executing the project belongs to the project manager. Often other team members on the project will have a functional responsibility on the project and report to a functional manager in the parent organization. For example, the procurement leader for a major project may also report to the organization's vice president for procurement. Although the procurement plan for the project must meet the organization's procurement policies, the procurement leader on the project will take day-to-day direction from the project manager. The amount of direction given to the procurement leader, or others on the project, is the decision of the project manager.

If the project manager delegates too little authority to others to make decisions and take action, the lack of a timely decision or lack of action will cause delays on the project. Delegating too much authority to others who do not have the knowledge, skills, or information will typically cause problems that result in delay or increased cost to the project. Finding the right balance of delegation is a critical project management skill.

When developing the project team, the project manager selects team members with the knowledge, skills, and abilities to accomplish the work required for the project to be successful. Typically, the more 
knowledge, skills, abilities, and experience a project team member brings to the project, the more that team member will be paid. To keep the project personnel costs lower, the project manager will develop a project team with the level of experience and the knowledge, skills, and abilities to accomplish the work.

On smaller, less complex projects, the project manager can provide daily guidance to project team members and be consulted on all major decisions. On larger, more complex projects, there are too many important decisions made every day for the project manager to be involved at the same level, and project team leaders are delegated decision-making authority. Larger projects, with a more complex profile will typically pay more because of the need for the knowledge and experience. On larger, more complex project, the project manager will develop a more experienced and knowledgeable team that will enable the project manager to delegate more responsibility to these team members.

\section{Construction Project in Peru}

A construction project in Peru was falling behind schedule, and the project manager decided to assign a new construction manager for the construction site that was the most behind schedule. An experienced project manager from the United States with a reputation for meeting aggressive schedules was assigned to the construction site and delegated the authority to meet scheduled milestones.

The construction manager did not have experience outside the United States and began making decisions that would have worked in the United States but met cultural resistance in Peru. The project began falling further behind and another construction manager was assigned to the site.

The project manager must have the skills to evaluate the knowledge, skills, and abilities of project team members and evaluate the complexity and difficulty of the project assignment. Often project managers want project team members they have worked with in the past. Because the project manager knows the skill level of the team member, project assignments can be made quickly with less supervision than with a new team member with whom the project manager has little or no experience.

Delegation is the art of creating a project organizational structure with the work organized into units that can be managed. Delegation is the process of understanding the knowledge, skills, and abilities needed to manage that work and then matching the team members with the right skills to do that work. Good project managers are good delegators.

\section{Setting Individual Goals}

The Myers-Briggs rates an individual's preferences-not their limitations. It is important to understand that each individual can still function in situations for which they are not best suited. For example, a project leader who is more Thinking $(\mathrm{T})$ than Feeling $(\mathrm{F})$ would need to work harder to be considerate of how a team member who is more Feeling (F) might react if they were singled out in a meeting because they were behind schedule. If a person knows their preferences and which personality types are most successful in each type of project or project phase, they can set goals for improvement in their ability to perform in those areas that are not their natural preference. 
Another individual goal is to examine which conflict resolution styles are least comfortable and work to improve those styles so that they can be used when they are more appropriate than your default style.

\section{Key Takeaways}

- Emotional intelligence is the ability to sense, understand, and effectively apply emotions.

- Two common tools for describing personality types are DISC (Dominance, Influence, Steadiness, and Conscientiousness) and the Myers-Briggs Type Indicator (MBTI). The MBTI is the most common. It rates personalities on the position between extremes of four paired terms: Extroversion (E)-Introversion (I), Sensing (S)-Intuition (I), Thinking (T)-Feeling (F), and Judging (J)-Perceiving (P).

- Leadership styles are usually related to the personality of the leader. The type of leadership style that is most effective depends on the complexity and the phase of the project.

- Negotiation and conflict resolution require skill at listening and an understanding of emotional intelligence and personality types.

- Delegation is the art of creating a project organizational structure that can be managed and then matching the team members with the right skills to do that work.

- Individual goals can be set for improving abilities that are not natural personality strengths to deal with projects and project phases.

\section{Exercises}

1. Ability to sense and understand emotions is called (two words).

2. A personality assessment tool that is commonly used that identifies preferences between pairs of terms is the MBTI, or more commonly known as the

3. What is emotional intelligence?

4. What do the letters INTJ stand for in a Myers-Briggs personality profile?

5. How does delegation involve the organization and its people?

Internalize your learning experience by preparing to discuss the following.

Identify which leadership style you think is most suitable for your personality and which is least suitable. Next, identify a level of project complexity or project phase where your preferred style is least suitable. Describe an individual goal and how you might pursue that goal for strengthening your ability to lead on that type of project or during that phase. 


\section{References}

Burns, J. M., Leadership (New York: Harper \& Row, 1978).

Cooper, R. K. and Ayman Sawaf, Executive EQ, Emotional Intelligence in Leadership and Organizations (New York: Perigree Book, 1997), xiii.

Einsiedel, A. A., “Profile of Effective Project Managers,” Project Management Journal 18 (1987): 5.

Fiedler, F. E., "Validation and Extension of the Contingency Model of Leadership Effectiveness," Psychological Bulletin 76, no. 2 (1971): 128-48.

Goleman, D., Emotional Intelligence (New York: Bantam Books, 1995).

Leavitt, H., Corporate Pathfinders (New York: Dow-Jones-Irwin and Penguin Books, 1986).

Posner, B. Z., “What It Takes to Be a Good Project Manager,” Project Management Journal 18 (1987): 32-46.

Shi, Q. and Jianguo Chen, The Human Side of Project Management: Leadership Skills (Newtown Square, PA: Project Management Institute, Inc., 2006), 4-11.

Tannenbaum, R. and Warren Schmidt, “How to Choose a Leadership Pattern,” Harvard Business Review 36 (1958): 95-101.

Verma, V. K., Human Resource Skills for the Project Manager (Sylvia, NC: PMI Publications, 1996), 145-75.

Whetton, D. and Kim Cameron, Developing Management Skills (Upper Saddle River, NJ: Pearson Education, 2005). 


\subsection{Working with Groups and Teams}

\section{Learning Objectives}

1. Describe the value of trust and how it relates to contracts and complex projects.

2. Identify four types of trust.

3. Describe how a project manager can build trust.

4. Identify three common meeting types and then describe how they differ.

5. Identity types of teams.

6. Describe the HUMM method of measuring project performance.

7. Describe the importance of developing a project story.

A team is a collaboration of people with different personalities that is lead by a person with a favored leadership style. Managing the interactions of these personalities and styles as a group is an important aspect of project management.

\section{Trust}

Trust is the foundation for all relationships within a project. Without a minimum level of trust, communication breaks down, and eventually the project suffers in the form of costs increasing and schedules slipping. Often, when reviewing a project where the performance problems have captured the attention of upper management, the evidence of problems is the increase in project costs and the slippage in the project schedule. The underlying cause is usually blamed on communication breakdown. With deeper investigation, the communication breakdown is associated with a breakdown in trust.

\section{Filters}

On projects, trust is the filter through which we screen information that is shared and the filter we use to screen information we receive. The more trust that exists, the easier it is for information to flow through the filters. As trust diminishes, the filters become stronger and information has a harder time getting through, and projects that are highly dependent on an information-rich environment will suffer from information deprivation. 


\section{Contracts and Trust Relationships}

The project typically begins with a charter or contract. A contract is a legal agreement that includes penalties for any behavior or results not achieved. Contracts are based on an adversarial paradigm and do not lend themselves to creating an environment of trust. Contracts and charters are necessary to clearly establish, among other things, the scope of the project, but they are not conducive to establishing a trusting project culture.

A relationship of mutual trust is less formal but vitally important. When a person or team enters into a relationship of mutual trust, each person's reputation and self-respect are the drivers in meeting the intent of the relationship. A relationship of mutual trust within the context of a project is a commitment to an open and honest relationship. There is nothing that enforces the commitments in the relationship except the integrity of the people involved. Smaller, less complex projects can operate within the boundaries of a legal contract, but larger, more complex projects must develop a relationship of mutual trust to be successful.

\section{Types of Trust}

Svenn Lindskold (Lindskold, 1978) describes four kinds of trust:

1. Objective credibility. A personal characteristic that reflects the truthfulness of an individual that can be checked against observable facts.

2. Attribution of benevolence. A form of trust that is built on the examination of the person's motives and the conclusion that they are not hostile.

3. Nonmanipulative trust. A form of trust that correlates to a person's self-interest and the predictability of a person's behavior in acting consistent in that self-interest.

4. High cost of lying. The type of trust that emerges when persons in authority raise the cost of lying so high that people will not lie because the penalty will be too high.

\section{Creating Trust}

Building trust on a project begins with the project manager. On complex projects, the assignment of a project manager with a high trust reputation can help establish the trust level needed. The project manager can also establish the cost of lying in a way that communicates an expectation and a value for trust on the project. Project managers can also assure that the official goals (stated goals) and operational goals (goals that are reinforced) are aligned. The project manager can create an atmosphere where informal communication is expected and reinforced.

The informal communication is important to establishing personal trust among team members and with the client. Allotting time during project start-up meetings to allow team members to develop a personal 
relationship is important to establishing the team trust. The informal discussion allows for a deeper understanding of the whole person and creates an atmosphere where trust can emerge.

\section{High Cost of Lying in a Charleston Project}

On a project in Charleston, South Carolina, the client was asking for more and more backup to information from the project. The project manager visited the client to better understand the reporting requirements and discovered the client did not trust the reports coming from the project and wanted validating material for each report. After some candid discussion, the project manager discovered that one of the project team members had provided information to the client that was inaccurate. The team member had made a mistake but had not corrected it with the client, hoping that the information would get lost in the stream of information from the project.

The project manager removed the team member from the project for two main reasons. The project manager established that the cost of lying was high. The removal communicated to the project team an expectation of honesty. The project manager also reinforced a covenant with the client that reinforced the trust in the information the project provided. The requests for additional information declined, and the trust relationship between project personnel and the client remained high.

Small events that reduce trust often take place on a project without anyone remembering what happened to create the environment of distrust. Taking fast and decisive action to establish a high cost of lying, communicating the expectation of honesty, and creating an atmosphere of trust are critical steps a project manager can take to ensure the success of complex projects.

Project managers can also establish expectations of team members to respect individual differences and skills, look and react to the positives, recognize each other's accomplishments, and value people's selfesteem to increase a sense of the benevolent intent.

\section{Managing Team Meetings}

Team meetings are conducted differently depending on the purpose of the meeting, the leadership style that is appropriate for the meeting, and the personality types of the members of the team.

\section{Action Item Meetings}

Action item meetings are short meetings to develop a common understanding of what the short-term priorities are for the project, individual roles, and expectations for specific activities. This type of meeting is for sharing, not problem solving. Any problems that emerge from the discussion are assigned to a person, and another meeting is established to address the issue. Action item meetings focus on short-term activities, usually less than a week in duration.

The action item meeting is fact based and information oriented. It is a left-brain-type focus. The action 
item meeting has very little dialogue except to ask clarification questions. If discussion is needed or disagreement is not easily resolved, another problem-solving meeting is established to deal with that issue. On smaller topics, that meeting might take place immediately after the action item meeting and only include those people with an interest in the outcome of the discussion.

The project manager keeps the successful action item meeting short in duration and focused on only those items of information needed for the short-term project plan. The project manager will restate the common understandings of what activities are priorities and who will be responsible for the activities. Often these meetings can include a review of safety procedures or security procedures when these issues are important to the project. The leadership approach to action item meetings focuses on data, actions, and commitments. Although the project manager may observe stresses between project team members or other issues, they are not addressed in this meeting. These are fact-based meetings. If issues begin to arise between people, the project manager will develop other opportunities to address these issues in another forum. Using the Myers-Briggs descriptions, team members who favor thinking more than feeling and judging more than perceiving are more comfortable with this type of meeting.

\section{Management Meetings}

Management meetings are longer in duration and are focused on planning. They are oriented toward developing plans, tracking progress of existing plans, and making adjustments to plans in response to new information.

These meetings include focused discussion on generating a common understanding of the progress of the existing plan. This discussion is based on quantitative information provided on the progress of the schedule and other data, but the discussion is qualitative in evaluating the data to develop a more complete understanding of the data. The experience and opinions of the project leaders are solicited, and disagreement about meaning of the data is even encouraged to develop a deeper understanding of the data. Through this discussion, a common understanding of the status of the project should emerge, and the project manager invites discussion, includes people to offer their thoughts, and assures that disagreements are positive discussions about interpretation of the information and that disagreements do not become personal.

Management meetings also focus on developing midterm goals. For larger, more complex projects, the goals may be monthly or even quarterly. For smaller or less complex projects, weekly goals will provide the focus. The project manager focuses the discussion on the broad priorities for the next period and includes all the functional leaders in the discussion. The goals that emerge from the discussion should represent a common understanding of the priorities of the project for the next term.

For example, during the early phases of a project, the team is focused on developing a conceptual understanding of the project. A major milestone on complex projects is typically the completion of the conceptual plan. The project manager would lead a discussion on what needs to be accomplished to meet the project milestone and asks what potential barriers exist and what key resources are needed. From the discussion, the project team develops a few key goals that integrate the various functions of the project team and focus the team on priorities. 
The following are some examples of goals during the conceptual phase:

- Developing a list of the procurement long lead items and defining critical dates

- Developing a human resources plan that identifies critical positions

- Developing and building agreement with the client on the project scope of work

Each of these goals is measurable and time framed. They can be developed as positive motivators and will take the project leaders and most of the project team to accomplish. They develop a general understanding of the priorities and are easy to remember.

Management meetings are a combination of left-brain thinking, which is fact based, and right-brain thinking, which is creative and innovative. Using the Myers-Briggs terminology, team members who prefer feeling over thinking and perceiving over judging can contribute ideas and perspectives on the project that the more fact-oriented members might miss.

The project manager allows and encourages conversation in developing and evaluating the goals but focuses the discussion on the goals and obstacles. Management meetings take on a different focus during the month. Meetings at the beginning of the month spend time addressing the progress and potential barriers to the goals developed the previous month. During the middle of the month, the project manager leads the team to develop next month's goals as the team also works on the current month's goals. Toward the end of the month as the goals for the month are accomplished, the meeting focuses more on the next month, enabling the team to remain goal focused during the life of the project.

Management meetings are also an opportunity to discover obstacles to goal achievement. The project team reallocates resources or develops alternative methods for accomplishing the goals. As the project team discusses the progress of project goals, the project manger explores possible obstacles and encourages exposing potential problems in achieving goals. The project manager focuses the team on finding solutions and avoids searching for blame.

The project manager uses a facilitative leadership approach, encouraging the management team to contribute their ideas, and builds consensus on what goals will bring the appropriate focus. The project manager keeps the focus on developing the goals, tracking progress, identifying barriers, and making adjustments to accomplish the management goals. Although there are typically meetings for scheduling and procurement and other meetings where goals are established and problems solved, the management meeting and the goal development process create alignment among the project leadership on the items critical to the project's success.

\section{Leadership Meetings}

Leadership meetings are held less frequently and are longer in length. These meetings are used by the project manager to reflect on the project, to explore the larger issues of the project, and to back away from the day-to-day problem solving. The project manager will create a safe environment for sharing thoughts and evaluations of issues that are less data oriented. This is a right-brained, creative meeting that focuses on the people issues of the project: the relationship with the client, vendors, and project team. Team members who favor feeling, perceiving, and intuition often contribute valuable insights in 
this type of meeting. The team might also share perceptions by upper management and perceptions of the community in which the project is being executed. Where the time frame for action item meetings is in weeks and management meetings is in months, the time frame for leadership meetings is longer and takes in the entire length and impact of the project.

The project manager's meeting management skill includes creating the right meeting atmosphere for the team discussion that is needed. For discussions based on data and facts, the project manager creates the action item type meeting. The conversation is focused on sharing information and clarification. The conversation for leadership meetings is the opposite. Discussion is more open ended and focused on creativity and innovation. Because each type of meeting requires a different meeting atmosphere, mixing the purposes of a meeting will make it difficult for the project manager to develop and maintain the appropriate kind of conversation.

Skilled project managers know what type of meeting is needed and how to develop an atmosphere to support the meeting type. Meetings of the action item type are focused on information sharing with little discussion. They require efficient communication of plans, progress, and other information team members need to plan and execute daily work. Management type meetings are focused on developing and progressing goals. Leadership meetings are more reflective and focused on the project mission and culture.

These three types of meetings do not cover all the types of project meetings. Specific problem-solving, vendor evaluation, and scheduling meetings are examples of typical project meetings. Understanding what kinds of meetings are needed on the project and creating the right focus for each meeting type is a critical project management skill.

\section{Types of Teams}

Teams can outperform individual team members in several situations. The effort and time invested in developing a team and the work of the team are large investments of project resources, and the payback is critical to project success. Determining when a team is needed and then chartering and supporting the development and work of the team is another critical project management ability.

Teams are effective in several project situations:

- When no one person has the knowledge, skills, and abilities to either understand or solve the problem

- When a commitment to the solution is needed by large portions of the project team

- When the problem and solution cross project functions

- When innovation is required

Individuals can outperform teams on some occasions. An individual tackling a problem consumes fewer resources than a team and can operate more efficiently-as long as the solution meets the project's needs. A person is most appropriate in the following situations: 
- When speed is important

- When one person has the knowledge, skills, and resources to solve the problem

- When the activities involved in solving the problem are very detailed

- When the actual document needs to be written (Teams can provide input, but writing is a solitary task.)

In addition to knowing when a team is appropriate, the project manager must also understand what type of team will function best.

\section{Functional Teams}

A functional team refers to the team approach related to the project functions. The engineering team, the procurement team, and the project controls team are examples of functional teams within the project. On a project with a low complexity profile that includes low technological challenges, good team member experience, and a clear scope of work, the project manager can utilize well-defined functional teams with clear expectations, direction, and strong vertical communication.

\section{Cross-Functional Teams}

Cross-functional teams address issues and work processes that include two or more of the functional teams. The team members are selected to bring their functional expertise to addressing project opportunities.

\section{Cross-Functional Teamwork on Concrete Project}

A cross-functional project team in Tennessee was assigned to develop a project approach to procuring, delivering, and erecting precast concrete without storing the concrete on the site. Although the complexity of this goal is primarily related to delivering the precast concrete in a sequence that will allow erection from the delivery trucks, the planning involved coordination of the design, procurement, and project controls. Team members from each of these functions developed and tracked a plan to meet the project goal. The cross-functional team was successful in designing a process and executing the plan in a way that saved three weeks on the schedule and several thousand dollars in cost.

\section{Problem-Solving Teams}

Problem-solving teams are assigned to address specific issues that arise during the life of the project. 
The project leadership includes members that have the expertise to address the problem. The team is chartered to address that problem and then disband.

\section{Problem-Solving Teamwork on Equipment Manufacturing}

On a project in Indiana, a company selected to design and build a critical piece of equipment began having financial problems, and the delivery of the equipment on the date needed by the project was at risk. A problemsolving team was chartered to assess the problem and develop a solution for the project. The team brought in some accounting expertise from the parent company and assessed the status of the vendor. The engineering team assessed the current state of the design, and the construction team developed an alternative schedule to allow for a late delivery of the equipment. The team developed a plan to support the vendor with funds and expertise that allowed the project to complete on time. The problem-solving team was organized to address a specific problem, developed and executed a plan to address the problem, and then was disbanded.

\section{Qualitative Assessment of Project Performance}

Project managers should provide an opportunity to ask such questions as "What is your gut feeling about how the project going?” and “How do you think our client perceives the project?” This creates the opportunity for reflection and dialogue around larger issues on the project. The project manager creates an atmosphere for the team to go beyond the data and search for meaning. This type of discussion and reflection is very difficult in the stress of day-to-day problem solving.

The project manager has several tools for developing good quantitative information-based on numbers and measurements_-such as the project schedules, budgets and budget reports, risk analysis, and goal tracking. This quantitative information is essential to understanding the current status and trends on the project. Just as important is the development of qualitative information-comparisons of qualities — such as judgments made by expert team members that go beyond the quantitative data provided in a report. Some would label this the "gut feeling” or intuition of experienced project managers.

The Humm Factor is a tool developed by Russ Darnall (Caudron, 1995) to capture the thoughts of project participants that are not reflected in the project reporting tools. The Humm Factor derived its name from a project manager who always claimed he could tell you more by listening to the hum of the project than reading all the project reports. The tool developed qualitative information for the project manager and leadership team.

The Humm Factor is essentially a survey that is developed during the early phases of the project. A series of questions are selected from a database of questions that are designed to elicit responses that require reflection and do not require data. "Do you feel the project is doing the things it needs to do to stay on schedule?" and "Is the project team focused on project goals?" are the types of questions that can be included in the Humm Factor. The qualitative responses are converted to a quantitative value as a score from 1 to 10 .

Someone on the project or assigned to support the project is responsible for distributing the survey on a 
weekly or less frequent basis depending on the complexity profile of the project. A project with a high level of complexity due to team-based and cultural issues will be surveyed more frequently.

Responses are tracked by individual and by total project, resulting in qualitative comparisons over time. The project team reviews the ratings regularly, looking for trends that indicate an issue may be emerging on the project that might need exploring.

\section{Humm Survey Uncovers Concern About a Vendor}

On a project in South Carolina, the project surveyed the project leadership with a Humm Survey each week. The Humm Factor indicated an increasing worry about the schedule beginning to slip when the schedule reports indicated that everything was according to plan. When the project manager began trying to understand why the Humm Factor was showing concerns about the schedule, he discovered an apprehension about the performance of a critical project supplier. When he asked team members, they responded, "It was the way they answered the phone or the hesitation when providing information—something didn't feel right."

The procurement manager visited the supplier and discovered the company was experiencing financial problems and had serious cash flow problems. The project manager was able to develop a plan to help the supplier through the period, and the supplier eventually recovered. The project was able to meet performance goals. The Humm Factor Survey provided a tool for members of the project team to express concerns that were based on very soft data, and the project team was able to discover a potential problem.

Another project team used the Humm Factor to survey the client monthly. The completed surveys went to a person who was not on the project team to provide anonymity to the responses. The responses were discussed at the monthly project review meetings, and the project manager summarized the results and addressed all the concerns expressed in the report. "I don't feel my concerns are being heard” was one response that began increasing during the project, and the project manager spent a significant portion of the next project review meeting attempting to understand what this meant. The team discovered that as the project progressed toward major milestones, the project team became more focused on solving daily problems, spent more time in meetings, and their workday was becoming longer. The result was fewer contacts with the clients, slower responses in returning phone calls, and much fewer coffee breaks where team members could casually discuss the project with the client.

The result of the conversation led to better understanding by both the project team and client team of the change in behavior based on the current phase of the project and the commitment to developing more frequent informal discussion about the project.

\section{Developing a Project Story}

Every project develops a story. It is the short explanation that project team members give when asked about the project. This is also called the elevator speech, which is the explanation a person would give if he or she were in the elevator with the CEO and the CEO asked him or her to describe the project. Project stories often express important aspects of the project and can create a positive picture of the project or one that is less appealing.

A project story will develop, and creating a positive project story is a project management skill that helps 
the project. A positive project story is inviting to people and helps with the recruitment of talent to the project. A positive project story also helps when services are needed from functional departments within the company and in developing management support for the project.

Creation of the project story is an active process. The project manager actively sets out to create the story. Every project, by definition, is unique. Creating the positive story entails identifying those unique aspects of the project and building a positive outcome.

\section{Project Story of a Drug to Save Lives}

A pharmaceutical project team in Colorado was building a plant to produce a drug that would save lives. The faster the plant was completed, the more lives would be affected by the drug. One story addressed the challenges of designing and building a plant in record time. A second story emerged: the balance of safety against speed. Safety procedures limited the number of subcontractors and people working in the same area.

To accomplish the work, the project team found creative ways of accomplishing the work off-site and scheduling work to minimize safety problems while meeting aggressive timelines. The story became the challenge. People identified with the challenge and wanted to be part of the success.

\section{Building a Reputation for Project Completion Speed}

A project manager in South Carolina always challenged people with speed. He identified the last project with similar characteristics and challenged the team to beat the time by weeks or months. The story became, "If you want a project done on time, this is the project team you need." The project manager created a spirit of competition and fun. The project manager was a high-energy person, and the idea of finding a way to finish a project early seemed a natural outcome.

Every project manager can find the unique aspect of the project and build a sense of specialness about the project. The project becomes a good place to work, provides the team with a sense of accomplishment, and becomes the story created by the project manager.

\section{Key Takeaways}

- Trust is important to reduce delays caused by excessive filtering and fact checking. Contracts are specific about the project scope, but personal relationships of mutual trust are necessary on complex projects.

- Four types of trust are objective credibility, attribution of benevolence, nonmanipulation, and a high cost of lying.

- To create trust, the project manager needs a reputation for trustworthiness and needs to align official goals with operational goals, establish a high cost of lying, and create an atmosphere of 
respect and benevolent intent.

- Meeting types are action item, management, and leadership. Action item meetings focus on specific short-term priorities. Management meetings focus on planning, and leadership meetings focus on larger issues.

- The types of teams are functional, cross-functional, and problem solving.

- The Humm Factor measures project performance and uses a questionnaire to identify qualitative information about project performance.

- A short statement of the purpose and character of the project is useful in recruiting and obtaining support for a project.

\section{Exercises}

1. A type of trust that is formed by observing that a person's truthfulness is supported by observable facts is called (two words).

2. A type of trust that is formed by knowing that the other person would not risk the penalties for being untruthful is called the high cost of

3. A type of trust that is formed by knowing that the other person is acting in his or her own selfinterest is called trust.

4. A type of trust that is formed by evaluating a person's motives and concluding that they are not hostile is called an attribute of

5. To create trust, a manager should align official goals with goals.

6. The Humm Factor is a method to collect "gut feeling" that the project team has about a project.

7. A short statement about the project that captures its purpose and character that could be relayed in less than a minute is called an story.

8. How does lack of trust affect filtering of information, and how does that affect the project?

9. What are four types of trust?

10. How can a manager create trust?

11. What are three main meeting types and what are their characteristics?

12. How do functional, cross-functional, and problem-solving teams differ from each other?

13. What is the purpose of the Humm Factor?

Internalize your learning experience by preparing to discuss the following.

Consider someone you met recently and whom you felt you could trust. Which of the four types of trust do you think you have for this person? Is there a relationship of mutual trust between you? If so, what would be an example of something each of you would trust the other to do? What would be an example of a project team function or type of team where this trust would be beneficial? 
148 [Author removed at request of original publisher]

\section{References}

Caudron, S., “Industry’s Unsung Heroes,” Industry Week, December 4, 1995, 12-16.

Lindskold, S., “Trust Development, the GRIT Proposal, and the Effects of Conciliatory Acts on Conflict and Corporation,” Psychological Bulletin 85, no. 4 (1978): 772-93. 


\subsection{Creating a Project Culture}

\section{Learning Objectives}

1. Describe how project culture is developed and enforced.

2. Describe how differences in culture between stakeholders can influence the project.

3. Describe the role of innovation on projects.

Project managers have a unique opportunity during the start-up of a project. They create a project culture, something organizational managers seldom have a chance to do. In most organizations, the corporate or organizational culture has developed over the life of the organization, and people associated with the organization understand what is valued, what has status, and what behaviors are expected. Edgar Schein defined culture as a pattern of basic assumptions formed by a group on how to perceive and address problems associated with both internal adaptation and external integration (Schein, 1990). Schein also described organizational culture as an abstract concept that constrains, stabilizes, and provides structure to the organization. At the same time, culture is being constantly enacted, created, and shaped by leadership behavior.

\section{Characteristics of Project Culture}

A project culture represents the shared norms, beliefs, values, and assumptions of the project team. Understanding the unique aspects of a project culture and developing an appropriate culture to match the complexity profile of the project are important project management abilities.

Culture is developed through the communication of

- the priority

- the given status

- the alignment of official and operational rules

Official rules are the rules that are stated, and operational rules are the rules that are enforced. Project managers who align official and operational rules are more effective in developing a clear and strong project culture because the project rules are among the first aspects of the project culture to which team members are exposed when assigned to the project. 


\section{Operational Rules on a Project in India}

During the start-up of a project in India, members of the project team were given a policy that stated all travel expense claims must be submitted within three days of completion of travel. During the first few weeks, the administrative team began to understand that this was a difficult policy to enforce without creating morale problems on the project. Instead of changing the official rule, it was seldom enforced. The official rules and operational rules differed.

Later on in the project, a worker was injured after crossing an area that was marked as unsafe. Workers indicated that they knew the official rules but it took too much time to go around the unsafe area. They assumed that official rules could be ignored if they were difficult to obey. The difference between official rules and operational rules of the project created a culture that made communication of the priorities more difficult.

In addition to official and operational rules, the project leadership communicates what is important by the use of symbols, storytelling, rituals, rewards or punishments, and taboos.

\section{Creating a Culture of Safety}

A project manager in South America who wanted to create a strong safety culture on a construction project with significant safety concerns used several methods to create the desired culture. In the first meeting that project team members attended upon joining the project was a safety orientation. Members were issued a card—a symbol-after the meeting granting permission to participate on the project. The project leadership team told stories of previous projects where people were fired for breaking safety rules and often warned that the fastest way to get fired on the project was to break a safety rule—an example of storytelling. Every project meeting started with a discussion of a safety topic — a ritual—and any discussion of lessening the safety rules was forbidden — taboo — and was quickly and strongly cut off by the project leadership if it occurred.

Culture guides behavior and communicates what is important and is useful for establishing priorities. On projects that have a strong safety culture, team members feel free to challenge anyone who breaks a safety rule, even managers. The safety aspects of culture are stronger than the cultural aspects of the power of management.

\section{Culture of Stakeholders}

When project stakeholders do not share a common culture, project management must adapt its organizations and work processes to cope with cultural differences. The following are three major aspects of cultural difference that can affect a project:

\section{Communications}

2. Negotiations 


\section{Decision making}

Communication is perhaps the most visible manifestation of culture. Project managers encounter cultural differences in communication in language, context, and candor. Language is clearly the highest barrier to communication. When project stakeholders do not share the same language, communication slows down and is often filtered to share only information that is deemed critical. The barrier to communication can influence project execution where quick and accurate exchange of ideas and information is critical.

The interpretation of information reflects the extent that context and candor influence cultural expressions of ideas and understanding of information. In some cultures, an affirmative answer to a question does not always mean yes. The cultural influence can create confusion on a project where project stakeholders share more than one culture.

\section{Culture Affects Communication in Mumbai}

A project management consultant from the United States was asked to evaluate the effectiveness of a U.S. project management team executing a project in Mumbai, India. The project team reported that the project was on schedule and within budget. After a project review meeting where each of the engineering leads reported that the design of the project was on schedule, the consultant began informal discussions with individual engineers and began to discover that several critical aspects of the project were behind schedule, and without a mitigating strategy, the project would miss a critical window in the weather between monsoon seasons. The information on the project flowed through a cultural expectation to provide positive information. The project was eventually cancelled by the U.S.-based corporation when the market and political risks increased.

Not all cultural differences are related to international projects. Corporate cultures and even regional differences can create cultural confusion on a project.

\section{Cultural Differences between American Regions}

On a major project in South America that included project team leaders from seven different countries, the greatest cultural difference that affected the project communication was between two project leaders from the United States. Two team members — one from New Orleans and one from Brooklyn — had more difficulty communicating than team members from Lebanon and Australia.

\section{Innovation on Projects}

The requirement of innovation on projects is influenced by the nature of the project. Some projects are chartered to develop a solution to a problem, and innovation is a central ingredient of project success. A project to develop a vaccine in response to a recent flu outbreak is an example of a project where innovation is important to achieving the purpose of the project. 
Innovation is also important to developing methods of lowering costs or shortening the schedule. Traditional project management thinking provides a trade-off between cost, quality, and schedule. A project sponsor can typically shorten the project schedule with an investment of more money or a lowering of quality. Finding innovative solutions can sometimes lower costs while also saving time and maintaining the quality.

\section{Innovation on a Steel Plant Project}

On a project to design and build a plant to make steel using new technology, the project leadership was committed to generating cost savings on the project that would allow needed technical modifications later on during the project. The project was in the early design phase, and the project leadership established a goal for generating \$1 million in cost saving suggestions. The goal was established in early fall, and the project manager declared that he would swim the lake on the day of the project review in February if the project met its goal.

A process was established to track cost saving ideas using highly visible green paper for documenting ideas, and a chart was placed on the project communication wall recognizing people and teams that submitted ideas. Each team was allocated a specific cost savings goal, and a team lunch was provided when the goals were met. The project manager created a balance between the message that this is a serious goal and that the project will have some fun with the process.

On one occasion, the project manager talked with the electrical engineering lead to understand why no suggestions were emerging from the electrical design team. The electrical design team was struggling to maintain the project schedule and did not have time to focus on project contests. The project manager emphasized that the project had several goals, and generating the cost savings for the client was an important project goal.

The electrical engineering lead gathered some senior electrical engineers into a small conference room, and for the next three hours, this impromptu team reviewed electrical drawings and concepts and began to generate ideas on how to accomplish the design specifications and cut costs. The electrical engineering lead maintained a flip chart in the front of the conference room, and as soon as the team found enough savings to meet the electrical target, the team disbanded and went back to working on the electrical design.

The team exceeded the goal prior to the February project review. The project manager swam the lake during an enjoyable project celebration.

Innovation is a creative process that requires both fun and focus. Fun reduces the amount of stress on the project. Stress is a biological reaction to perceived threats. Stress, at appropriate levels, can make the work environment interesting and even challenging. Many people working on projects enjoy a highstress, exciting environment. When the stress level is too high, the biological reaction increases blood flow to the emotional parts of the brain and decreases the blood flow to the creative parts of the brain, making creative problem solving more difficult. Project managers recognize the benefits of balancing the stress level on the project with the need to create an atmosphere that enables creative thought.

\section{Stress Managed on Steel Project}

The electrical lead engineer on the steel project was able to create the environment for the electrical team to 
focus on the electrical design and explore alternative designs that could generate cost savings. The electrical lead also saw the investment in creating cost savings as an addition to the job. The electrical team stopped to contribute to the project goal and went back to the design work once the electrical cost-saving target was met.

Exploring opportunities to create savings takes an investment of time and energy, and on a time-sensitive project, the project manager must create the motivation and the opportunity for creative thinking.

\section{Key Takeaways}

- Project culture is developed by communicating priority, status, and the alignment of official and operational rules. It is enforced through use of symbols, storytelling, rituals, rewards or punishments, and taboos.

- Differences in culture between stakeholders can affect communications, negotiations, and decision making.

- Innovation can be the main focus of the project, or it can be used to achieve improvement in goals that are usually mutually exclusive, such as lowering costs and shortening schedule.

\section{Exercises}

1. The project is developed by communicating what is important, communicating what gives status, and aligning operational and official rules.

2. How can innovation achieve improvement in goals?

Internalize your learning experience by preparing to discuss the following.

Describe a team project with which you are familiar where the objective was to find an innovative solution. What was the level of stress and how was it managed to support an innovative atmosphere?

\section{References}

Schein, E., “Organizational Culture,” American Psychologist 45 (1990): 109-19. 


\subsection{Exercises}

Exercises at the end of the chapter are designed to strengthen your understanding and retention of the information recently acquired in the chapter.

\section{Essay Questions}

Write several paragraphs to provide more in-depth analysis and consideration when answering the following questions.

1. Describe two situations that involve delegating work to other people. The first is a positive example that worked well, and the other is one that did not. Analyze the reasons for the success and failure of the two examples using the information about trust and personality types from this chapter.

2. Choose a project with which you are familiar that does not have a good elevator story. Attempt to create one and explain how it could be used to promote the project.

\section{Discussion}

The exercises in this section are designed to promote exchange of information among students in the classroom or in an online discussion. The exercises are more open ended, which means that what you find might be completely different from what your classmates find, and you can all benefit by sharing what you have learned.

1. Describe a project where trust or distrust became a major factor in the success or failure of the project. Using the four kinds of trust described by Lindskold, explain how trust was formed or lost. Consider the descriptions offered by other students of their trust experiences and identify a situation where one of the same types of trust was established or lost. Compare the effects on both projects.

2. Describe a project where differences in culture affected communications, negotiations, or decision making. 


\subsection{Web Exercises}

\section{Learning Objectives}

1. Describe the characteristics of the Myers-Briggs personality profile.

2. Describe the characteristics of emotional intelligence.

3. Locate, download, and analyze meeting agenda examples.

\section{Explore Personality Testing}

A popular tool for categorizing personality types is the Myers-Briggs Type Indicator (MBTI). In this exercise, you learn about the MBTI and other tests based on the personality types described by psychologist Carl Jung.

\section{MBTI}

1. Start a web browser and go to the Myers and Briggs Foundation website by typing http://www.myersbriggs.org/my-mbti-personality-type/mbti-basics.

2. Read the section titled MBTI Basics.

3. Scroll down to the table of sixteen personality types. Move the mouse pointer over one of the types to display the pop-up window that shows the explanation of that type.

4. Point to one of the other types in the table and then capture the screen.

5. Open a Word document. In the first line, type your name. Below your name, paste the screen capture.

6. Save that document as Ch05MBStudentName.doc using the Word 2003 .doc file format.

7. Switch back to the web page. Below the table, click All types are equal to move to that web page. Read the page.

8. Capture a portion of the All types are equal page and paste it into the Word document.

9. Leave the word processing document open. 


\section{Free Online Personality Tests}

The Myers-Briggs test is administered and interpreted by trained and certified people who help explain the meaning of the results. This is an important function because terms like introvert do not mean what many people normally assume them to mean, and self-evaluation can be misinterpreted. It can still be instructive to take one of the free, online tests that are similar to the MBTI.

1. In a web browser, type http://www.humanmetrics.com/cgi-win/jtypes1.htm.

2. Follow the directions to take the Jung Typology Test (it consists of seventy-two Yes/No questions).

3. Display the test score, as shown in Figure 5.13 "Example of a Result", except it may be any of the sixteen types.

Figure 5.13 Example of a Result

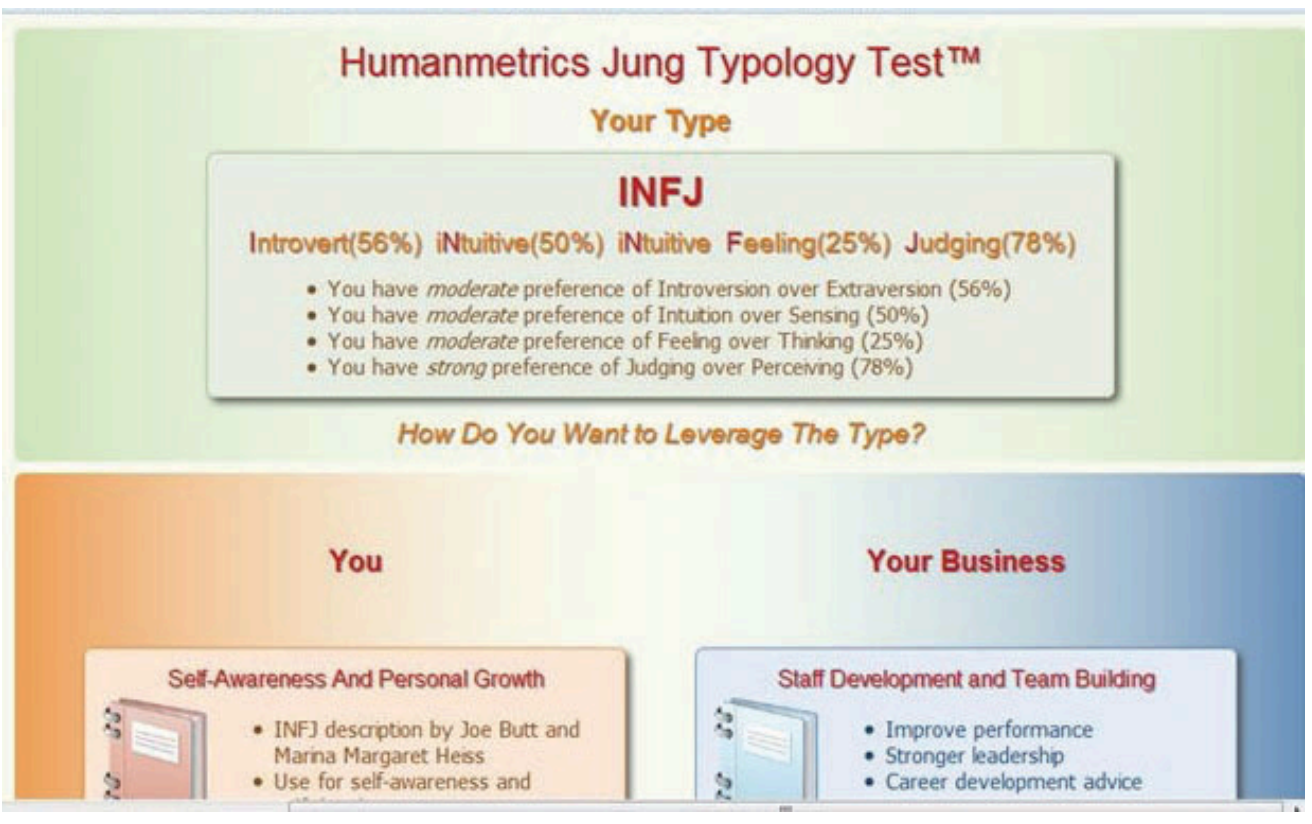

Source: Courtesy of www.humanmetrics.com.

4. Notice the brief explanation in bulleted list format. Capture this screen and paste it into the word processing document.

5. Return to the Myers and Briggs Foundation website by typing http://www.myersbriggs.org/ my-mbti-personality-type/mbti-basics. Scroll down to the table of types and click the one that corresponds to your score from the other website. Capture the screen and paste it into the word processing document.

6. Below the screens, reflect on what you learned about the MBTI and the Jung personality types. Relate any experiences you might have had with this personality typing and your impressions of its accuracy in describing your personality.

7. Review your work and use the following rubric to determine its adequacy: 


\begin{tabular}{|l|l|l|l|}
\hline Element & Best & Adequate & \multicolumn{1}{|c|}{ Poor } \\
\hline File name & Ch05MBStudentName.doc & Ch05MBStudentName.docx & $\begin{array}{l}\text { Another } \\
\text { file name }\end{array}$ \\
\hline $\begin{array}{l}\text { Describe the } \\
\text { characteristics } \\
\text { of the } \\
\begin{array}{l}\text { Myers-Briggs } \\
\text { personality } \\
\text { profile }\end{array}\end{array}$ & $\begin{array}{l}\text { First line with name; four screen } \\
\text { captures that show one of the types in } \\
\text { the table, a screen from the All types are } \\
\text { equal page, the results of your test, and } \\
\text { that type on the table }\end{array}$ & Same as Best & $\begin{array}{l}\text { Some } \\
\text { screens } \\
\text { missing or }\end{array}$ \\
\hline
\end{tabular}

8. Save the file and submit it as directed by the instructor.

\section{Emotional Intelligence: Developing a Strong Mind ${ }^{1}$}

In the project management profession, developing strong people skills helps management understand how to deal with personality types, like the Myers-Briggs test uses the emotional intelligence test site to develop strong career building skills. Mind Tools helps develop strong people skills.

1. Start a web browser and go to the Mind Tools website at http://www.mindtools.com/pages/ article/newCDV_59.htm.

Read the first page, including the sections titled

- Developing Strong "People Skills"

- What Is Emotional Intelligence

- Characteristics of Emotional Intelligence

- How to Improve Your Emotional Intelligence

Figure 5.14 Mind Tools homepage 


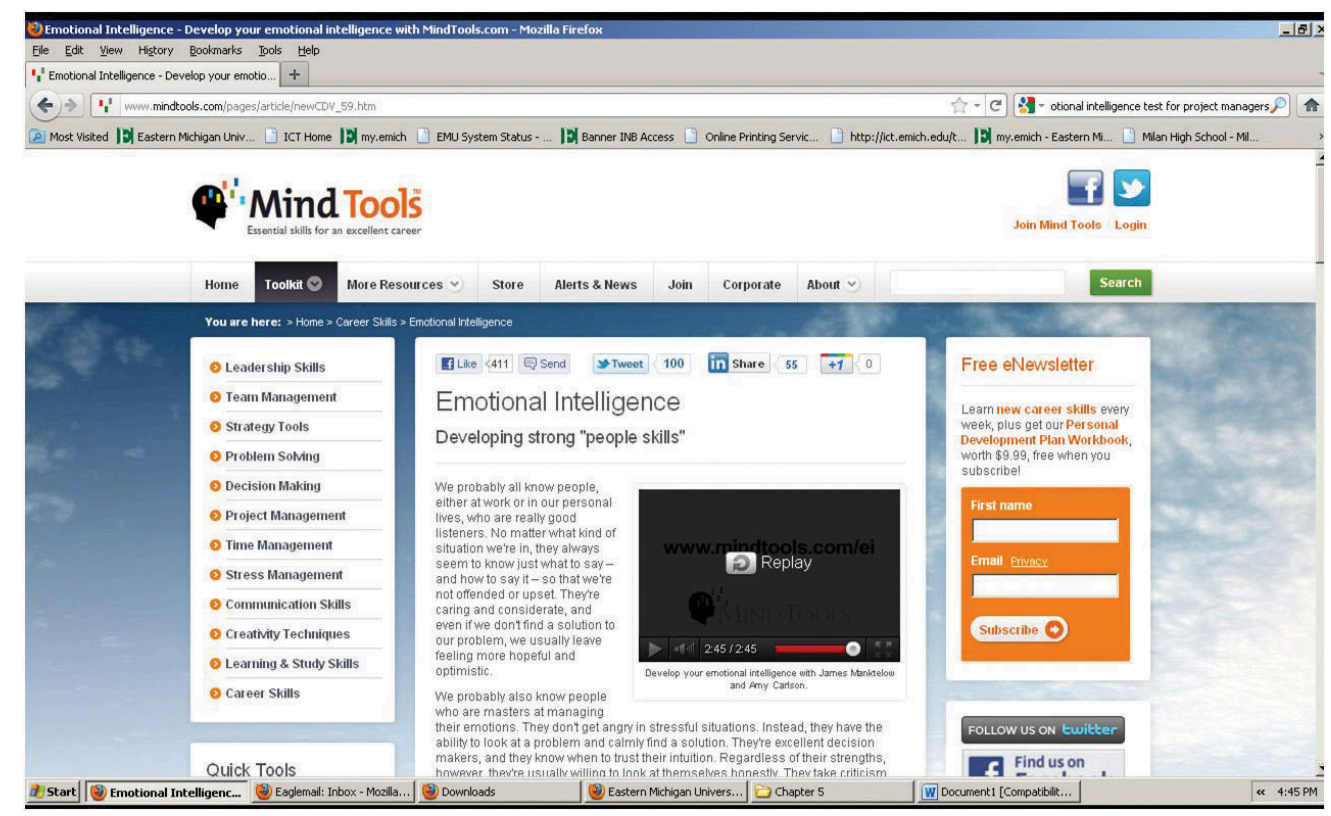

Source: Courtesy of www.mindtools.com.

2. Open MS Word and save a new document as Ch5EQStudentName.doc.

3. Click the Play button on the video. Capture a screen that shows the video playing and then paste it into your Word document.

4. In a browser, type http://www.ihhp.com/testsite.htm.

Figure 5.15 Institute for Health and Human Potential homepage

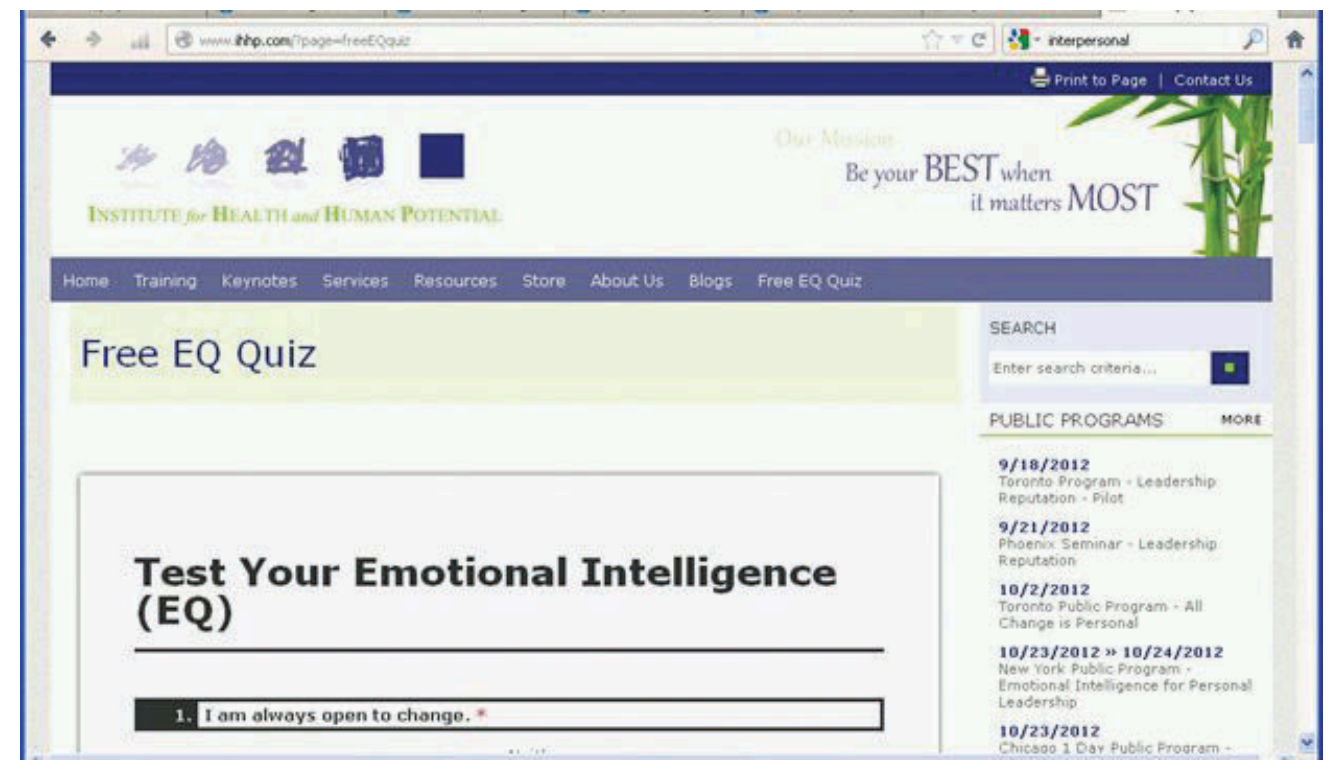

Source: Courtesy of The Institute for Health and Human Potential.

5. Begin the test and fill out the first few questions. Copy the screen and then paste it into your Word document. 
6. Complete the test and then click the Evaluate button.

7. In the Word document below the screen captures, reflect on what you learned about emotional intelligence (EQ) and then describe how being more aware of EQ might improve the work environment on a project.

8. Review your work and use the following rubric to determine its adequacy:

\begin{tabular}{|c|c|c|c|}
\hline Element & Best & Adequate & Poor \\
\hline File name & Ch05EQStudentName.doc & Ch05EQStudentName.docx & $\begin{array}{l}\text { Another } \\
\text { file name }\end{array}$ \\
\hline $\begin{array}{l}\text { Describe the } \\
\text { characteristics } \\
\text { of emotional } \\
\text { intelligence }\end{array}$ & $\begin{array}{l}\text { First line with name; four screen captures } \\
\text { that show the video playing and the first } \\
\text { few questions of the EQ test; a reflective } \\
\text { essay of two hundred to three hundred } \\
\text { words in which you describe what you } \\
\text { learned and how it might be useful on a } \\
\text { project }\end{array}$ & $\begin{array}{l}\text { Correct screen captures } \\
\text { with a reflective essay } \\
\text { between one hundred and } \\
\text { two hundred words }\end{array}$ & $\begin{array}{l}\text { Some } \\
\text { screens } \\
\text { missing; } \\
\text { very brief } \\
\text { essay that } \\
\text { did not } \\
\text { cover both } \\
\text { objectives }\end{array}$ \\
\hline
\end{tabular}

9. Save the document, and then submit it as directed by your instructor.

\section{Use Templates to Standardize Project Development}

Different types of meetings have different objectives. To achieve those objectives, it helps to organize the agenda of the meeting around those objectives and to sequence them properly. Studying examples used by other organizations will assist in choosing an agenda that suits the purpose of a meeting.

\section{How to Download a Meeting Agenda}

1. Open a blank word processing document and type your name and date on the first line. Save the file as Ch05MeetingsStudentName using the Word 2003 file format that ends with .doc.

2. Start a web browser program and go to the Project Management Guidebooks and Templates page for the State of North Dakota at http://www.nd.gov/itd/standards/project-management/ project-management-guidebooks-and-templates. A list of links displays, as shown in Figure 5.16 "North Dakota Projects”

Figure 5.16 North Dakota Projects 


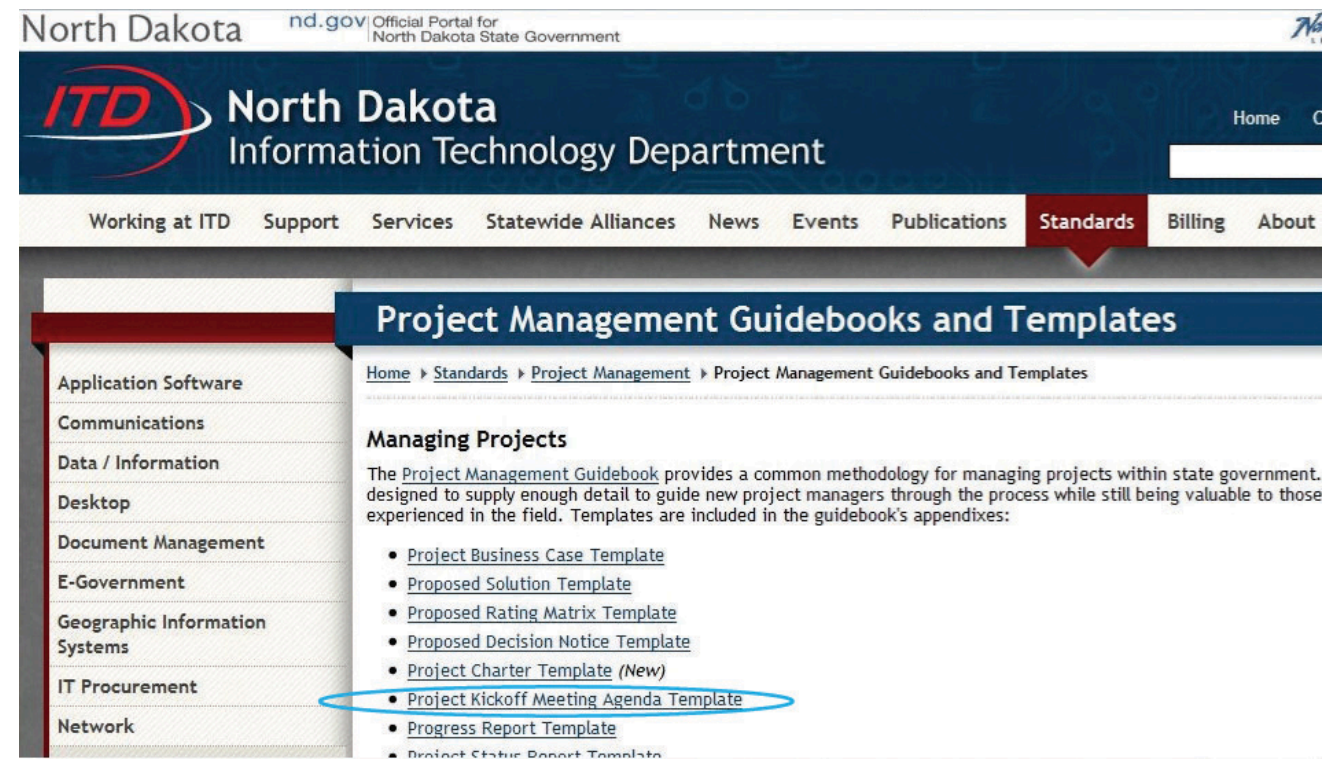

Source: Courtesy of the North Dakota Information Technology Department.

3. Add this website to your browser's favorites list, in a folder named Projects.

4. Capture a screen that shows a link to this site in the Projects folder of your bookmarks or favorites, and then paste it into the word processing document.

5. On the web page, under Managing Projects, click Project Kickoff Meeting Agenda Template ( $25 \mathrm{~kb} r t f)$. Notice the file is labeled " $25 \mathrm{~kb}$ rtf," which means that it is a small file saved in rich text format (rtf). The rtf format is a standard format that virtually all word processing programs can read.

6. Save the file to your computer and then open it.

7. Review the topics and the time allowed for each topic.

8. Near the top of the page, select the placeholder text to the right of Project, and then type Classwork for StudentName, where you use your name.

9. Capture a screen that shows your modification to the agenda and paste it into the word processing document.

\section{Analysis}

1. Compare this agenda with the concepts described in the text. Address the following questions:

- What type of meeting is this (action item, management, or leadership)? Support your analysis with references to the sample agenda and quotations from the text.

- Is this agenda designed to build trust? Compare this agenda to the section in the text titled Creating Trust. 
2. At the bottom of the word processing document, write an essay of between two hundred and five hundred words that consists of two parts that address these two questions.

3. Review your work and use the following rubric to determine its adequacy:

\begin{tabular}{|c|c|c|c|}
\hline Element & Best & Adequate & Poor \\
\hline File name & Ch05MeetingsStudentName.doc & Ch05MeetingsStudentName & $\begin{array}{l}\text { Another file } \\
\text { name }\end{array}$ \\
\hline $\begin{array}{l}\text { Locate, } \\
\text { download, } \\
\text { and } \\
\text { analyze } \\
\text { meeting } \\
\text { agenda } \\
\text { examples }\end{array}$ & $\begin{array}{l}\text { Name on first line; screen } \\
\text { captures that show the web link } \\
\text { in the Project folder of your } \\
\text { browser's favorites and an } \\
\text { image of the agenda with your } \\
\text { name next to Project; a two-part } \\
\text { essay that addresses the two } \\
\text { questions with specific } \\
\text { references in the text and in the } \\
\text { sample agenda to support your } \\
\text { analysis }\end{array}$ & $\begin{array}{l}\text { Name on first line; screen } \\
\text { captures that show the web link } \\
\text { in the Project folder of your } \\
\text { browser's favorites and an image } \\
\text { of the agenda with your name } \\
\text { next to Project; a single } \\
\text { paragraph that addresses the two } \\
\text { questions with paraphrased } \\
\text { references in the text and in the } \\
\text { sample agenda to support your } \\
\text { analysis }\end{array}$ & $\begin{array}{l}\text { Missing or } \\
\text { incomplete } \\
\text { screen captures; } \\
\text { an essay that is } \\
\text { too general and } \\
\text { that doesn't } \\
\text { address the } \\
\text { questions or does } \\
\text { not demonstrate } \\
\text { an intimate } \\
\text { familiarity with } \\
\text { the text or sample }\end{array}$ \\
\hline
\end{tabular}

4. Save Ch05MeetingsStudentName and submit it as directed by the instructor. Close all documents and programs. 


\section{Chapter 6: Communication Technologies}

Projects require teamwork, and team members must communicate with each other in a variety of ways. The documents they produce must be collected, distributed, and stored in an appropriate manner to assure timely and accurate communication between team members. This process is often assisted by a variety of technologies and computer software products. Communication technology can facilitate faster and better communication, or it can become a barrier if the technologies are not well understood and applied appropriately. 


\subsection{Types of Communication}

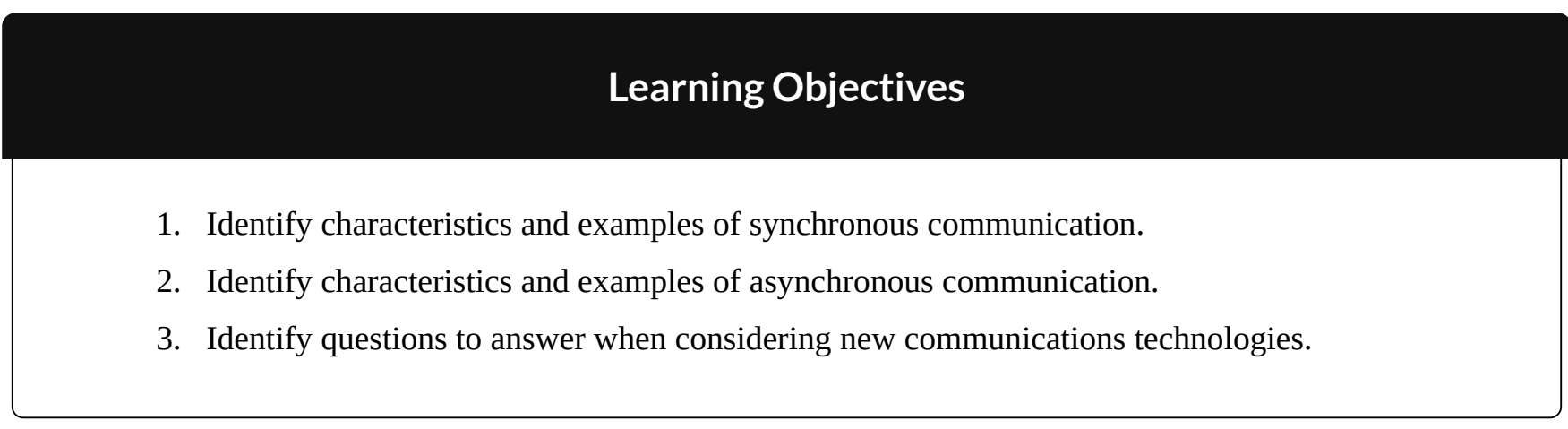

Completing a complex project successfully requires good communication among team members. If those team members work in the same building, they can arrange regular meetings, simply stop by each other's office space to get a quick answer, or even discuss a project informally at other office functions. Many projects are performed by teams that interact primarily through electronic communication and are, therefore, called virtual teams (Business Dictionary, 2010). To avoid miscommunication that can harm trust and to include team members in a project culture, the project team needs a plan for communicating reliably and in a timely manner. This planning begins with understanding two major categories of communication.

\section{Synchronous Communications}

If all the parties to the communication are taking part in the exchange at the same time, the communication is synchronous. A telephone conference call is an example of synchronous communication. When the participants are not interacting at the same time, the communication is not synchronous, or asynchronous.

The following are examples of synchronous communications:

- Live meeting. Gathering of team members at the same location.

- Audio conference. A telephone call between two individuals or a conference call where several people participate.

- Computer-assisted conference. Audio conference with a connection between computers that can display a document or spreadsheet that can be edited by both parties.

- Video conference. Similar to an audio conference but with live images of the participants. Some laptop computers have built-in cameras to facilitate video conferencing, as shown in Figure 6.1 "Video Conferencing by Laptop".

- IM (instant messaging). Exchange of text or voice messages using pop-up windows on the 
participants’ computer screens, as shown in Figure 6.2 “Instant Messaging Pop-Up Window”.

Figure 6.2 Instant Messaging Pop-Up Window

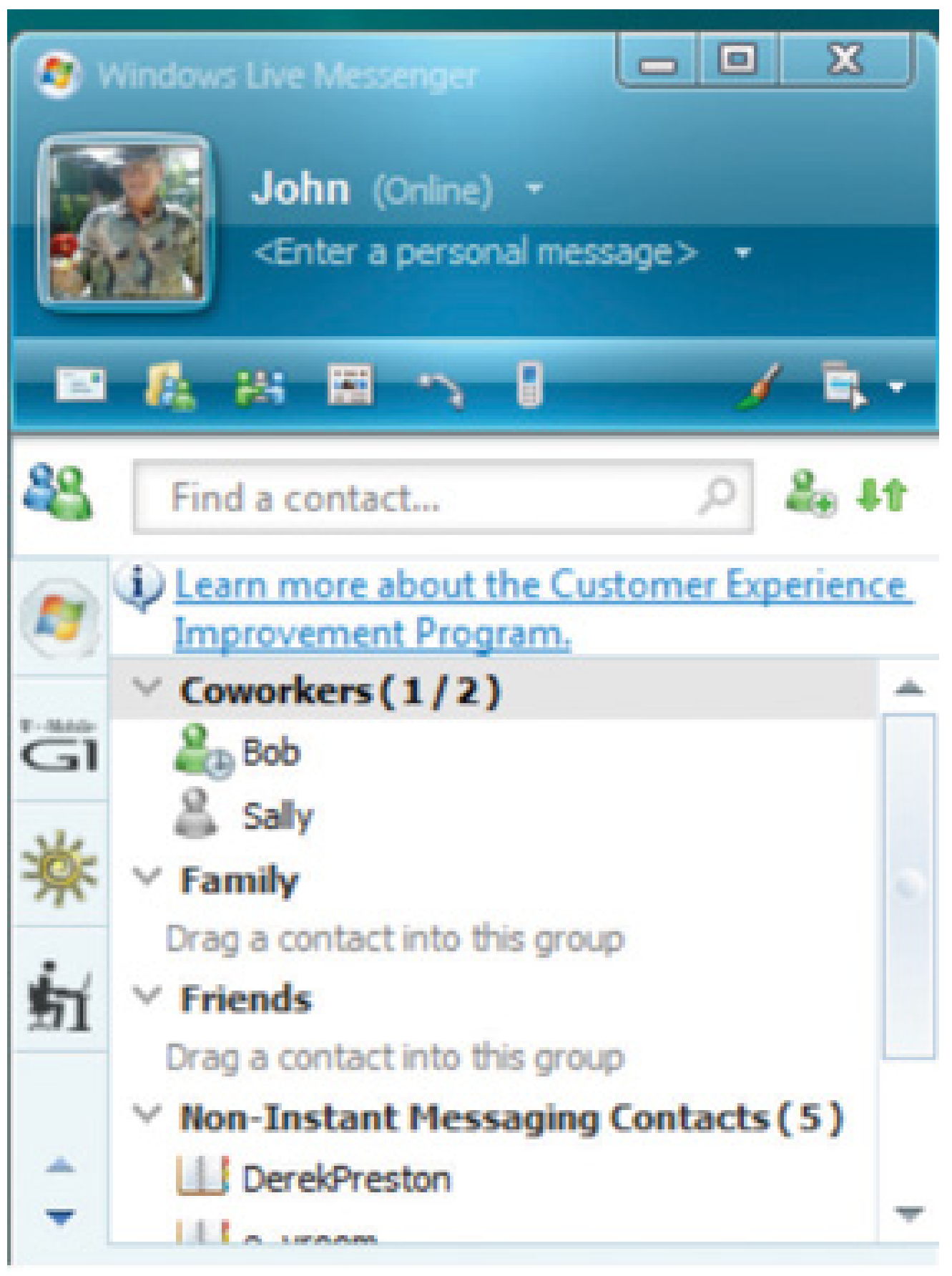

- Texting. Exchange of text messages that are 160 characters or fewer between mobile phones, pagers, or personal digital assistants (PDAs) — devices that hold a calendar, a contact list, a task list, and other support programs. See Figure 6.3 "Texting via Cell Phone”. 


\section{Time Zones}

The worldwide communication network makes it possible to assemble project teams from anywhere in the world. Most people work during daylight hours, which can make synchronous meetings difficult if the participants are in different time zones, where they start, end, and take meal breaks at different times. It can be an advantage in some circumstances. For example, if something must be done by the start of business tomorrow, team members in Asia can work on the problem during their normal work hours while team members in North America get some sleep.

As the earth turns, the sun appears to move across the sky from east to west. Local noon occurs when the sun is at its highest position in the sky. Cities and countries to the north or south of each other all observe local noon at the same time. For example, noon in New York occurs at the same time as it does in Bogotá, Colombia, in South America. Be aware that many well-educated people in the United States think of South America as directly south of North America. As you can see in Figure 6.4 "World Time Zones", most of South America is one or two time zones east of the United States.

To prevent confusion between a.m. and p.m., times are given using a twenty-four-hour clock. Noon is 12:00 and 1 p.m. is 13:00, and parts of an hour are divided by colons. For example, 13:25:21 is thirteen hours, twenty-five minutes, and twenty-one seconds.

\section{Local Time}

Local time is compared to the time zone that is centered at the historically significant naval observatory at Greenwich, England. The time at that location is Greenwich Mean Time (GMT). More recent references use UT for Universal Time (UT) instead of GMT.

\section{Conference Call between New York and Paris}

A project manager in New York is five time zones west of the reference zone, so the time is given as UT -5 (or GMT -5). If it is noon in the reference zone, it is 7 a.m. (five hours earlier) in New York. The manager would like to contact a project team member in Paris, France. Paris is one time zone west of the reference zone (UT +1 or GMT +1). If it is noon (12:00) in the reference zone, it is 13:00 (1 p.m.) in Paris.

This means that there is a six-hour difference between New York and Paris. If the project manager waits until after lunch to place the call (1 p.m. in New York), it might be too late in the day in Paris (7 p.m.) to reach someone.

\section{Asynchronous Communications}

Getting a team together at the same time can be a challenge-especially if they are spread out across 
time zones. Many types of communication do not require that the parties are present at the same time. This type of communication is not synchronous; it is asynchronous. There are several choices of asynchronous communications.

\section{Mail and Package Delivery}

Many companies prefer that final contracts are personally signed by an authorized representative of each party to the agreement. If several signatures are required, this can take weeks to get all the signatures if the contracts are transferred by the postal service. If this process is holding up the start of the project, you can use an overnight delivery service to minimize the time spent transferring the documents.

\section{Fax}

A telefacsimile (fax) machine is a device that scans a document a narrow band at a time converting it into tones that can be conveyed over traditional telephone lines to a receiving device that reproduces a facsimile - exact duplicate-of the document. A fax machine typically has a paper feeder that can be used for feeding multiple-page documents, a telephone key pad and handset, and a status display, as shown in Figure 6.5 "Fax Machine”.

Transmission rates of fax machines are typically limited by the use of traditional telephone lines. The data transmission uses the same method as a dial-up computer modem. A Group $\mathbf{3}$ fax machine has a maximum data rate of 14.4 kilobits per second (Kbps), but if the phone connection is poor, it will drop down to lower speeds automatically until it can establish a reliable connection between machines.

The Group 3 fax machine digitizes data in a form that is compatible with computers and the fax function is often integrated with other computer functions. A multifunction device, such as the one shown in Figure 6.6 "Multifunction Printer, Scanner, Fax, and Copier”, can scan a document and save it as an image, send it as a fax, or print multiple copies.

Fax machines have been around a long time and enjoy a high level of trust for transmitting documents accurately. In many countries, a fax of a signed contract is legal, but a computer-scanned image is not.

\section{Electronic Mail}

Electronic mail (e-mail) is widely used to coordinate projects and to communicate between team members. It has several valuable characteristics for project management:

- Copies can be sent to a list of team members.

- A preconference-call e-mail can list the agenda items of the conference call.

- A postconference e-mail can summarize the results of the discussion on each topic. 
- Messages can be saved to document the process in case of a misunderstanding or miscommunication.

- Files can be attached and distributed.

\section{Project Log and Web Log (Blog)}

A Web log is typically called a blog. It is an online journal that can be private, shared by invitation, or made available to the world. Some project managers keep a journal in which they summarize the day's challenges and triumphs and the decisions they made. They return to this journal at a later date to review their decision-making process after the results of those decisions are known to see if they can learn from their mistakes. Many decisions in project management are made with incomplete knowledge, and reflecting on previous decisions to develop this decision-making skill is important to growth as a project manager.

\section{Really Simple Syndication (RSS)}

Some projects are directly affected by external factors such as political elections, economic trends, corporate mergers, technological or scientific breakthroughs, or weather. To keep informed about these factors, you can subscribe to online news sources. A method that facilitates this process is Really Simple Syndication (RSS). To use an RSS feed, team members download a free news reader on the Internet. Web pages with RSS news feeds have labeled links, as shown in Figure 6.7 "Link to RSS Feed on a Web Page”.

Figure 6.7 Link to RSS Feed on a Web Page

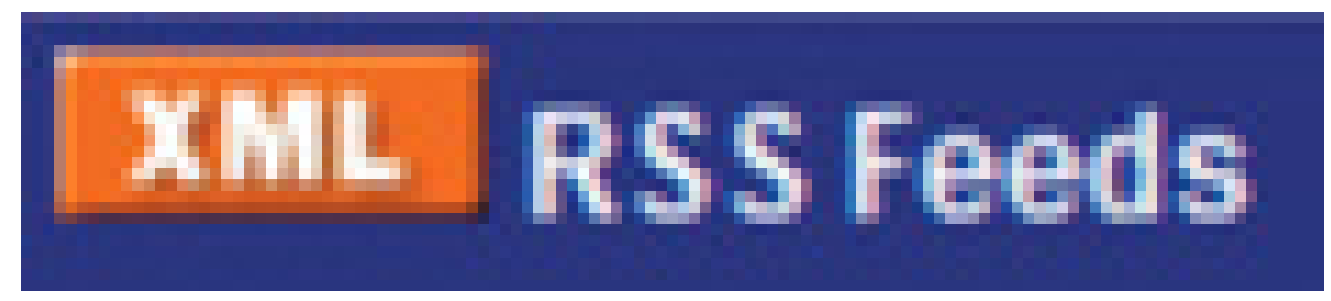

If the user clicks on the RSS feed, news from the Web site is automatically sent to the user's news reader. The news reader can be set to filter the news for key words to limit the stories to those that are relevant to the project.

The following are examples of asynchronous communications:

- Mail and package delivery. Transfer of objects and contracts that need signatures.

- Fax. Document transmittal over telephone. Facsimiles are accepted for some documents.

- Electronic mail (e-mail). Text messages with attachments can be distributed and managed by computer programs. 
- Web $\log (b \log )$. An online journal may be used to record events, thoughts, and lessons learned.

- Really Simple Syndication (RSS). News feeds that push relevant content to a reader to keep the manager informed of new events that could affect the project.

\section{Assessing New Communication Technologies}

New technologies for communicating electronically appear with increasing frequency. Using a new technology that is unfamiliar to the team increases the technology complexity, which can cause delays and increase costs. To decide if a new technology should be included in a communications plan, seek answers to the following questions:

- Does the new communication technology provide a competitive advantage for the project by reducing cost, saving time, or preventing mistakes?

- Does the project team have the expertise to learn the new technology quickly?

- Does the company offer support such as help desk and equipment service for new communication technology?

- What is the cost of training and implementation in terms of time as well as money?

\section{Key Takeaways}

- Synchronous communications take place when all the parties are present at the same time. Examples are telephone calls and video conferencing.

- Asynchronous communications take place when the parties are not present at the same time. Examples are e-mail, fax, package delivery, blogs, and RSS feeds.

- Determine if a new technology can save time, reduce cost, or prevent mistakes and if the increased complexity can be handled by the team and support staff for an affordable cost in time and money.

\section{Exercises}

1. Communications methods that do not require both parties to participate at the same time are called

2. A telephone call is an example of communication.

3. An exchange of e-mail messages is an example of communication.

4. A is an online journal used to share an individual's thoughts and experiences. 
5. A video conference is an example of communications.

6. What are two examples of synchronous communications technologies that you have used?

7. What are two examples of asynchronous communications technologies that you have used?

8. What is a virtual team?

9. Where is the reference time zone and why is it sometimes referred to as both GMT and UT?

10. Why are fax machines still used for legal documents?

Internalize your learning experience by preparing to discuss the following.

If you were managing a functional team that included people from three other countries, which synchronous communications technologies would you include in your communications plan and for what purposes? Which asynchronous technologies would you use and for what purposes? What new technologies would you consider?

\section{References}

Business Dictionary, s.v. "Virtual Team,” http:/www.businessdictionary.com/definition/virtualteam.html (accessed January 27, 2010). 


\subsection{Selecting Software}

\section{Learning Objectives}

1. Identify the types of software that are appropriate for projects of low complexity.

2. Identify the types of software that are appropriate for projects of medium complexity.

3. Identify the types of software that are appropriate for projects of high complexity.

4. Describe strategies for sharing documents that can be edited by a team.

Part of a communications plan is determining the type of computer software that will be used to create documents, spreadsheets, diagrams, and reports. The choice of software is related to the complexity of the project.

\section{Simple Projects}

Basic projects can be managed using some of the features available in general-purpose software that is available in most offices.

\section{Word Processing}

Even the most basic project will generate numerous documents using word processing software. A communications plan can specify standards for these documents that makes it easier to create, edit, combine, store, and retrieve the documents. Document standards include the following:

- Specifying the file format

- Using templates for commonly used forms

\section{File Format}

Word processing software programs display a document on a computer's screen and allow the user to enter and edit text. When the file is saved to a storage device, the text and all the various formatting 
such as font and font size are converted to a code for efficient storage. The code varies from one word processing program to another and even between releases of the same program.

The most common word processing program, by a wide margin, is Microsoft Word (MS Word). Several releases of MS Word run on the Windows operating system and on the Macintosh operating system. Versions of MS Word released prior to 2007 save files in a proprietary format. The format is indicated by a period and a three-letter extension-.doc — that is automatically attached to the file when it is saved. Beginning with MS Word 2007 for Windows and MS Word 2008 for Macintosh, files are saved using a different format that is indicated by a period and a four-letter extension-.docx — that identify the newer format.

Almost all word processing programs have the ability to save files in the doc file format, and it is a common standard for word processing files. Newer versions of word processing programs, including MS Word 2007 and MS Word for Mac 2008, can save files in the older .doc format. There are new features in MS Word 2007—such as the ability to format citations in a variety of styles, including APA, MLA, and Chicago - that are lost when the file is saved in the .doc format. Older versions of MS Word can be adapted to read the newer .docx file formats by downloading and installing a compatibility program that is available at no cost from Microsoft's Web site. Display of document file extensions is hidden by default in the Windows operating system. They can be displayed by turning off this feature. Instructions for displaying the file extensions are available from the operating system's help menu. In the Windows Vista operating system, the option is found on the Control Panel, in Appearance and Personalization, in Folder Options, on the View tab, under Advanced Settings, as shown in Figure 6.8 "Displaying File Name Extensions”.

Figure 6.8 Displaying File Name Extensions

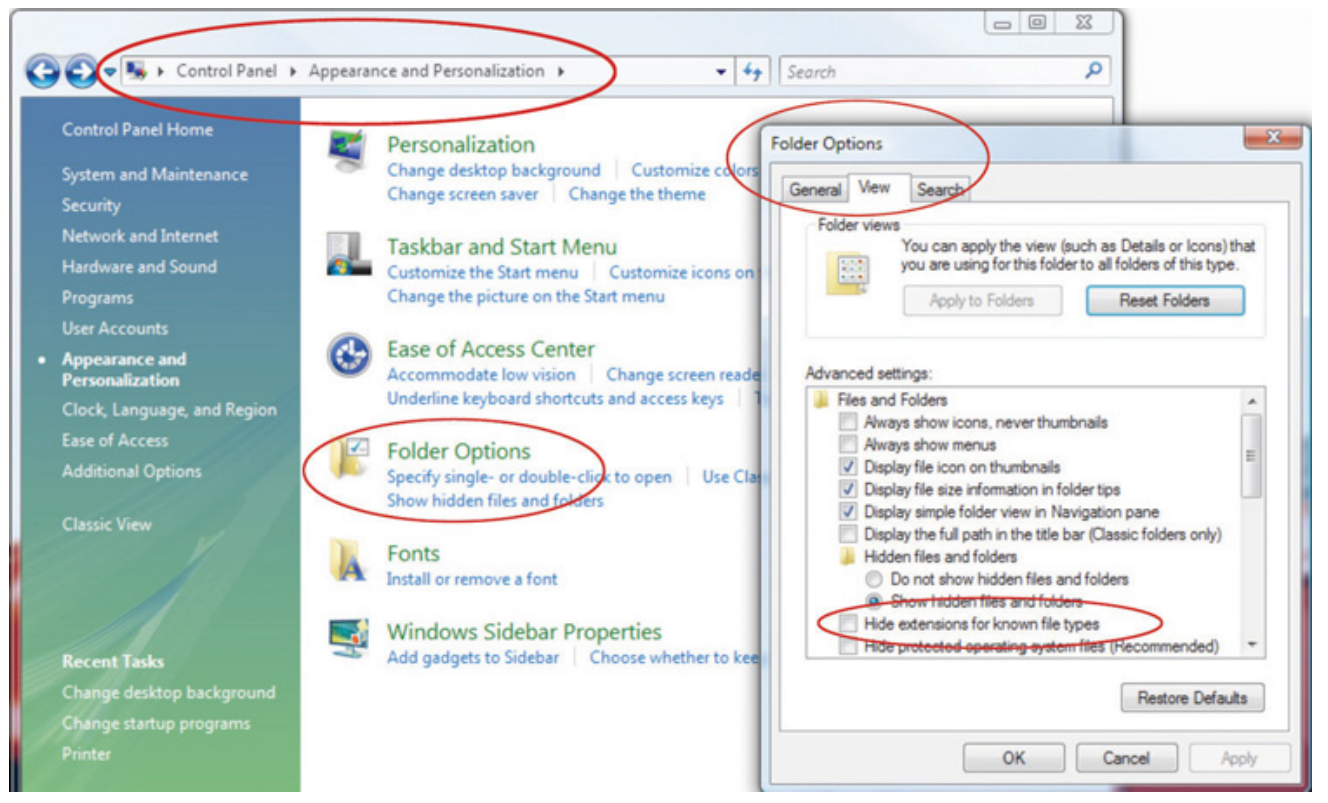

When a list of files is displayed in a dialog box, choose the Details option. In Windows Vista, the Details option is on the View button, as shown in Figure 6.9 “File Extensions Displayed in Details View”. 


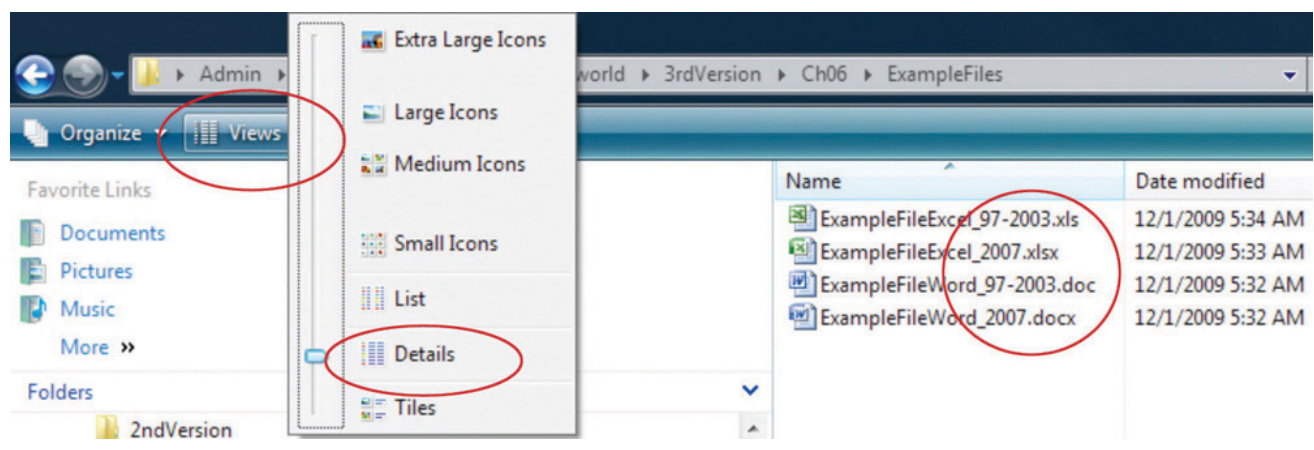

\section{Styles}

The combination of formatting, including font, font size, font color, shading, and other attributes used to display a segment of text and to identify its level of importance, is called a style. A style can be given a name and applied repeatedly to different portions of a document. Predefined styles are available in MS Word 2007 on the ribbon, on the Home tab, in the Styles group, as shown in Figure 6.10 "Style Choices". Users can define their own styles and give them names. Some organizations prefer that all of their documents have similar fonts and styles for headings, body text, and figure captions.

Figure 6.10 Style Choices

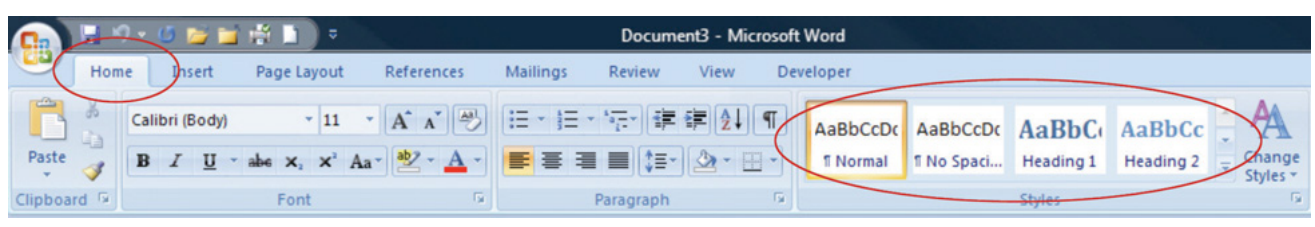

\section{Outlines}

An outline of a document consists of topic headings and subheadings, and it is useful when organizing or reorganizing a document. The Styles group in MS Word 2007 includes predefined styles for nine levels of headings. In addition to using different fonts, each heading is assigned a level of importance. A document that uses headings with assigned levels can be viewed in the Outline view, such as the book outline shown in Figure 6.11 "Outline View in MS Word 2007”. In this view, the level of detail displayed in the outline is selected to display the first two levels of the outline. The headings and the hidden text associated with each heading can be moved by selecting and dragging headings from one location in the outline to another. 


\section{Diagrams}

Reporting relationships and the flow of work are often described using diagrams that consist of boxes connected by arrows. Recent releases of popular word processing programs include drawing tools that can be used for basic diagrams. In MS Word 2007, a variety of shapes and connectors are available on the Insert tab, in the Illustrations group on the Shapes button, as shown in Figure 6.13 "Menu of Diagramming Shapes and Connectors in Word 2007”.

Figure 6.13 Menu of Diagramming Shapes and Connectors in Word 2007

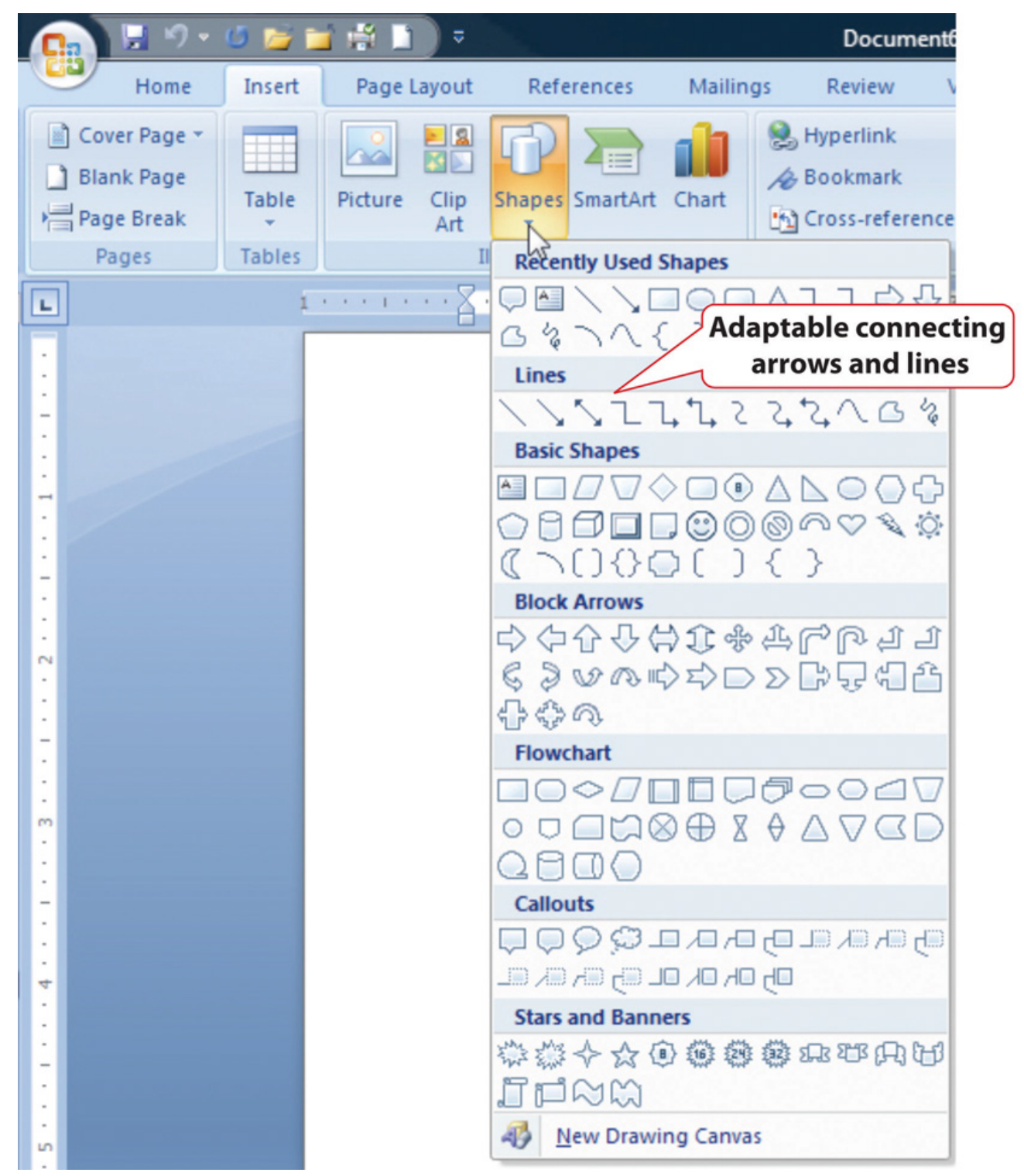

Adaptable connecting lines and arrows can be used that redraw automatically when the shapes are moved. This feature facilitates rapid revisions when the shapes must be moved, because the connecting arrows do not need to be redrawn.

A feature named SmartArt was introduced in Microsoft Office 2007 that has a variety of charts that can 
be used for displaying organization and relationships that use more sophisticated and artistic graphics, as shown in Figure 6.14 "SmartArt Feature in Microsoft Word”.

Figure 6.14 SmartArt Feature in Microsoft Word

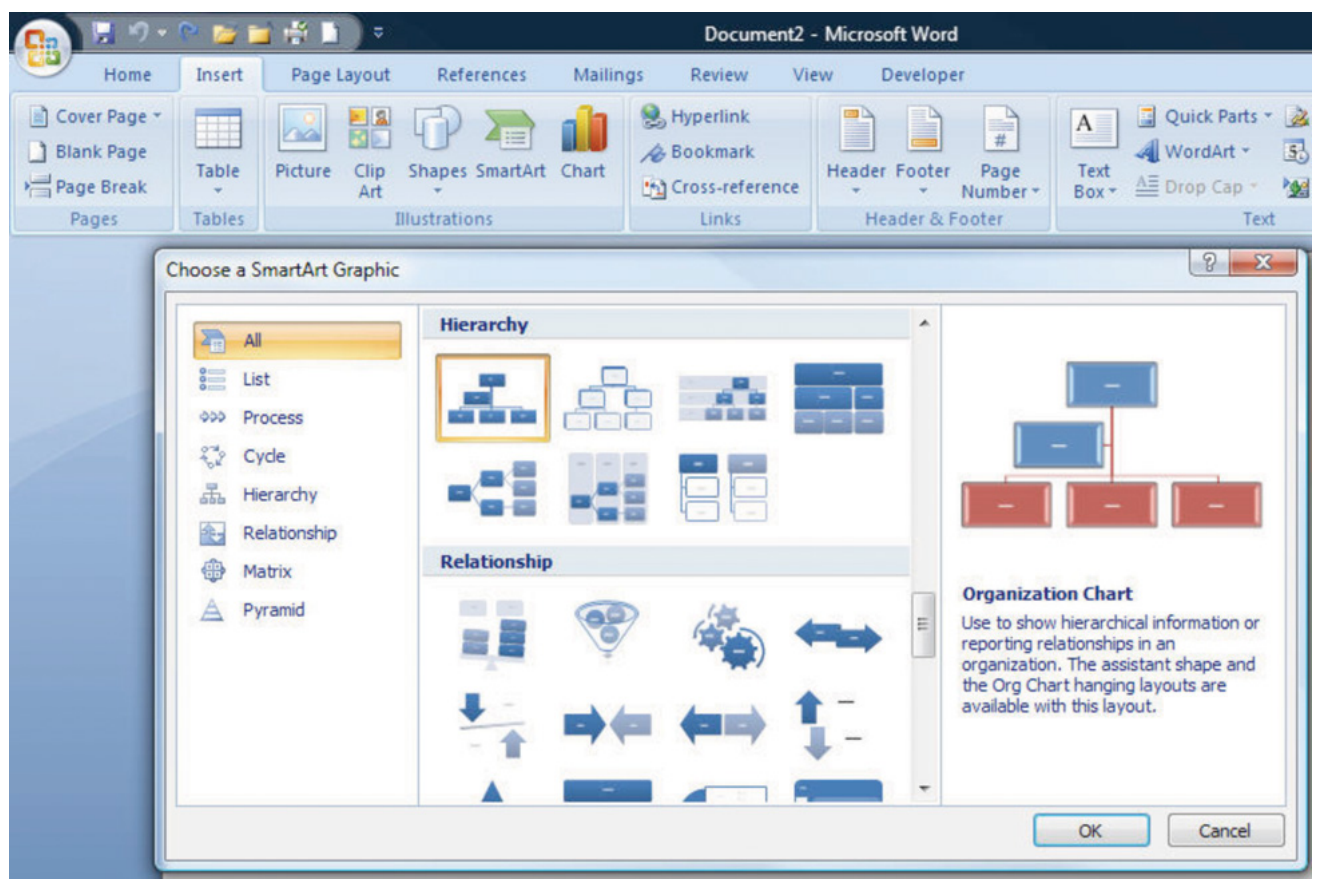

\section{Spreadsheets}

Another commonly available software creates a spreadsheet - a display of data in row and column format - in which financial or numerical data can be manipulated. The intersection of the rows and columns are cells into which numbers, text, dates, and formulas can be entered. The formulas can utilize values found in other cells and display the results in the cell in place of the formula. If the value in a cell to which the formula refers is changed, all the formulas that use that cell's value are immediately recalculated. This feature makes it convenient to examine several options quickly. Spreadsheets are often used to manage data on simple projects instead of a dedicated database or project management software.

\section{Organizing Data in Rows and Columns}

If a spreadsheet is used to store data, such as a list of project activities or a list of expenses, it is prudent to arrange the data in some way that would be used by more sophisticated data management software. Most data management programs arrange data in such a way that each type of data is represented by a column with a label at the top and each row contains the specific data for one type of item. A collection of data arranged in rows and columns is a table. For example, a list of expenses would be arranged so that individual expenses are recorded on each row, and each column would be a type of information related to the expenses, as shown in Figure 6.15 “Expenses Arranged in a Table in a Spreadsheet”. 
Figure 6.15 Expenses Arranged in a Table in a Spreadsheet

\begin{tabular}{|c|c|c|c|c|c|c|c|}
\hline 4 & A & B & C & & D & $E$ & \multirow{2}{*}{$\begin{array}{l}\text { Types of data in columns } \\
\text { with a label in the first row }\end{array}$} \\
\hline 1 & Category & Description & Quantity & Un & it Price & Cost & \\
\hline 2 & Packing Materials & Box tape & 2 & $\$$ & 3.85 & $\$ 7.70$ & \\
\hline 3 & Packing Materials & Bubble wrap & 1 & $\$$ & 19.95 & $\$ 19.95$ & \\
\hline 4 & Packing Materials & Extra large boxes & 7 & $\$$ & 3.75 & $\$ 26.25$ & \\
\hline 5 & Packing Materials & Furniture pads & 4 & $\$$ & 7.95 & $\$ 31.80$ & \\
\hline 6 & Truck & Gas at $10 \mathrm{mpg}$ & 200 & $\$$ & 2.25 & $\$ 45.00$ & One item per row \\
\hline 7 & Packing Materials & Large Boxes & 7 & $\$$ & 3.00 & $\$ 21.00$ & \\
\hline 8 & Packing Materials & Lift straps/pr & 1 & $\$$ & 24.95 & $\$ 24.95$ & \\
\hline 9 & Packing Materials & Markers & 2 & $\$$ & 1.50 & $\$ 3.00$ & \\
\hline 10 & Packing Materials & Mattress/spring bags & 2 & $\$$ & 2.95 & $\$ 5.90$ & \\
\hline 11 & Packing Materials & Medium Boxes & 15 & $\$$ & 2.35 & $\$ 35.25$ & \\
\hline 12 & Truck & Rental & 2 days & & 200.00 & $\$ 400.00$ & \\
\hline 13 & Packing Materials & Short hanger boxes & 3 & $\$$ & 7.95 & $\$ 23.85$ & \\
\hline 14 & Packing Materials & Small Boxes & 10 & $\$$ & 1.70 & $\$ 17.00$ & \\
\hline
\end{tabular}

\section{File Format}

The most common spreadsheet program, by a wide margin, is Microsoft Excel (MS Excel). There have been several releases of MS Excel that run on the Windows operating system and on the Macintosh operating system. Versions of MS Excel released prior to 2007 save files in a proprietary format. The format is indicated by a period and a three-letter extension-xls - that is automatically attached to the file when it is saved. Beginning with MS Excel 2007 for Windows and MS Excel 2008 for Macintosh, files are saved using a different format that is indicated by a period and a four-letter extension-.xlsx-that identifies the newer format.

Almost all spreadsheet programs have the ability to save files in the .xls file format, and it is a common standard for spreadsheet files. Newer versions of spreadsheet programs, including MS Excel 2007 and MS Excel for Mac 2008 can save files in the older .xls format. There are a few new basic features in MS Excel 2007 that would be lost by saving files to the older file format.

\section{Using a Spreadsheet to Manage Project Data}

If the data in the spreadsheet is arranged in simple rows of the same type of data, it can be manipulated to provide reports for basic projects.

If one or more of the columns in a table contain labels, identification numbers, or other descriptions, those labels can be used to specify sorting and filtering options. For example, if the spreadsheet has a list of expenses, the rows of data can be sorted in decreasing or increasing value by one of the data types such as the due date or the amount of the expense. The display can be restricted-filtered-to display only those rows that meet criteria specified by the user. For example, the table could be filtered to display the expenses for a particular department that were incurred between two dates. This ability facilitates the preparation of monthly progress reports and budgets. 
In MS Excel 2007, the sorting and filtering options are on the Data tab, in the Sort and Filter group under the Sort or Filter button. Once a filter is applied, option buttons are placed at the top of each column to facilitate changes in the sorting or filtering options. For example, the list of expenses shown in the previous figure can be sorted by the labels in the Category column and filtered to show only costs that are more than \$20, as shown in Figure 6.16 “Sorting and Filtering in Microsoft Excel 2007”.

Figure 6.16 Sorting and Filtering in Microsoft Excel 2007

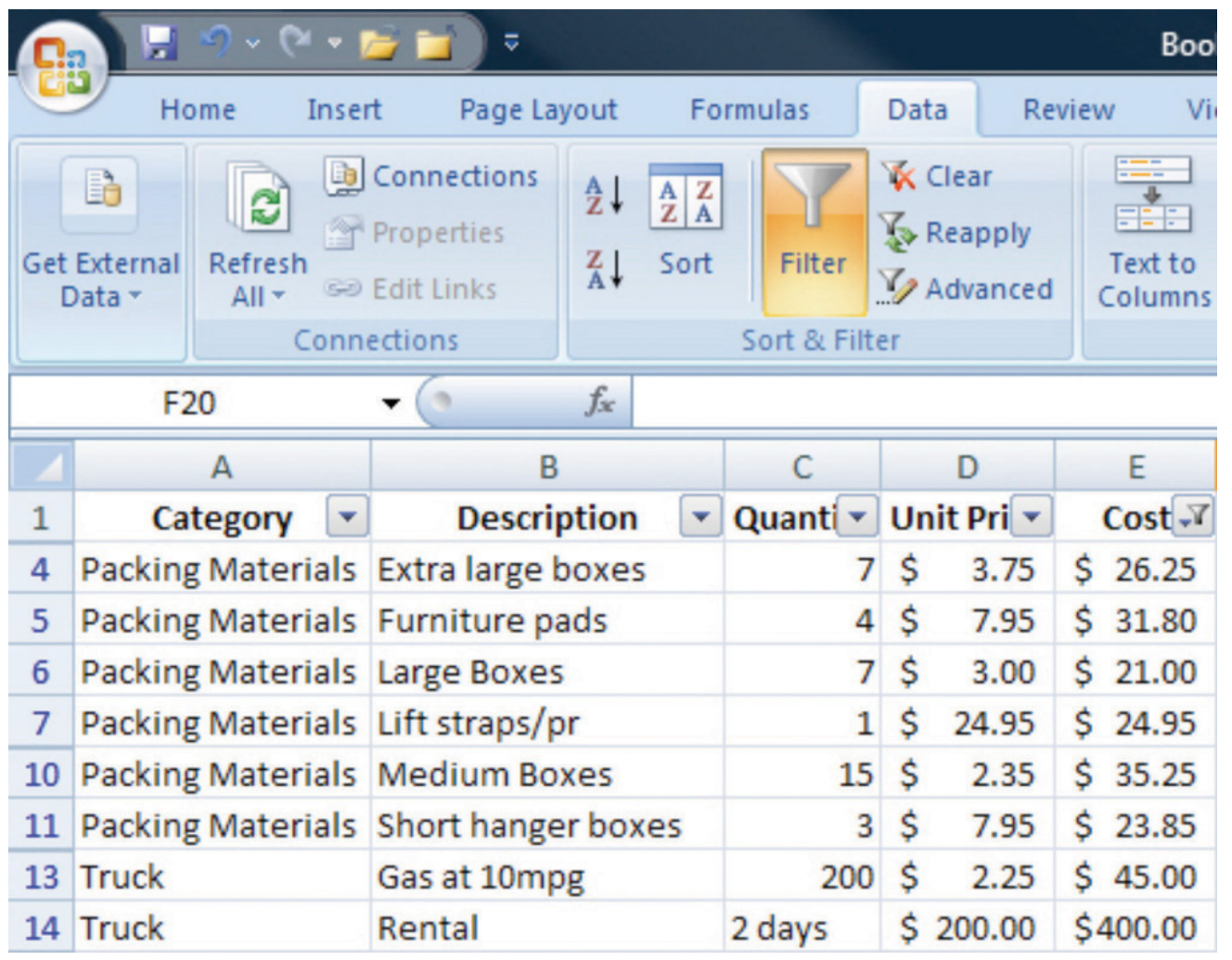

\section{Subtotals}

If the user wants to find a subtotal of the values that belong in a particular group, the groups must be identified by a label in one of the columns. Finding subtotals is a two-step process. First, the table is sorted by that column to bring all the rows in each group together. Next, the subtotal feature is applied. In Excel 2007, the subtotal option is found on the Data tab, in the Outline group. A dialog box allows the user to choose the columns to subtotal and the columns that contain the labels of the groups. A subtotal is inserted below the last row for each group, as shown in Figure 6.17 "Using Subtotals". 
178 [Author removed at request of original publisher]

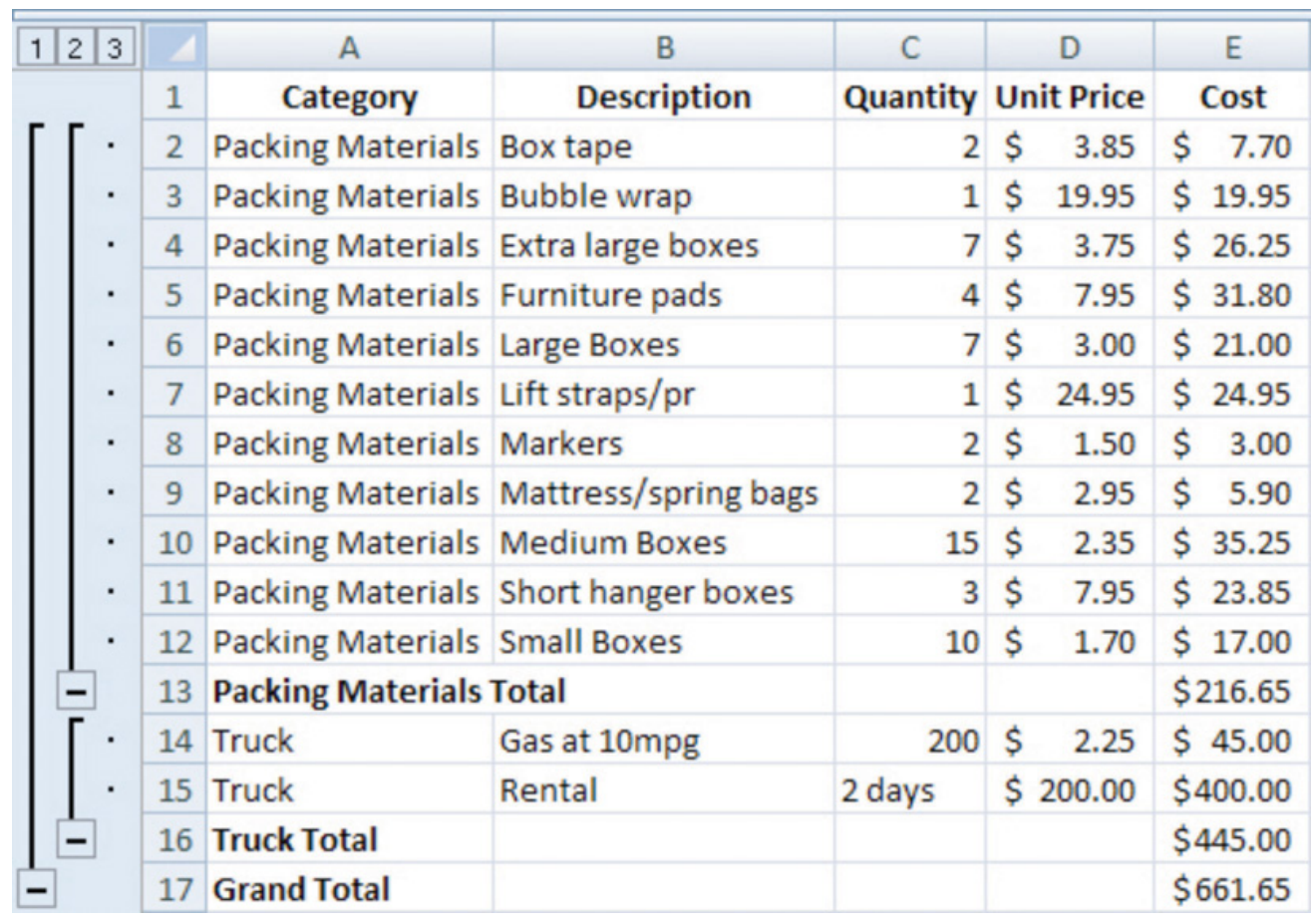

In a panel at the left of the screen are lines and symbols that indicate the level of detail that is displayed. By clicking on the boxes with minus signs, the rows containing the data can be hidden, leaving the subtotals or grand total, as shown in Figure 6.18 and Figure 6.19. This feature allows a manager to view summary data very quickly without the visual clutter of the details.

Figure 6.18

\begin{tabular}{|c|c|c|c|c|c|c|}
\hline \begin{tabular}{|l|l|l|}
1 & 2 & 3 \\
\end{tabular} & 1 & A & B & C & D & E \\
\hline \multirow{4}{*}{$\begin{array}{l}+ \\
+\end{array}$} & 1 & Category & Description & Quantity & Unit Price & Cost \\
\hline & 13 & \multicolumn{2}{|c|}{ Packing Materials Total } & & & $\$ 216.65$ \\
\hline & 16 & Truck Total & & & & $\$ 445.00$ \\
\hline & 17 & Grand Total & & & & $\$ 661.65$ \\
\hline
\end{tabular}

Third level details are hidden.

Figure 6.19

\begin{tabular}{|c|c|c|c|c|c|c|}
\hline \begin{tabular}{l|l|l}
1 & 2 & 3 \\
\end{tabular} & 4 & A & B & C & D & E \\
\hline & 1 & Category & Description & Quantity & Unit Price & Cost \\
\hline+ & 17 & Grand Total & & & & $\$ 661.65$ \\
\hline
\end{tabular}

All details in rows 2-16 are hidden. 


\section{Graphics for Bar Charts and Milestones}

Spreadsheets can be used for basic progress reports that show activities, dates, and horizontal bars that represent the duration of an activity. A sequence of dates can be created as column labels by entering the first two dates in the sequence, selecting both dates, and then dragging the fill handle-a small square in the lower right corner of the selected cell, as shown in Figure 6.20 "Creating a Sequence of Dates"-to extend the pattern.

Figure 6.20 Creating a Sequence of Dates

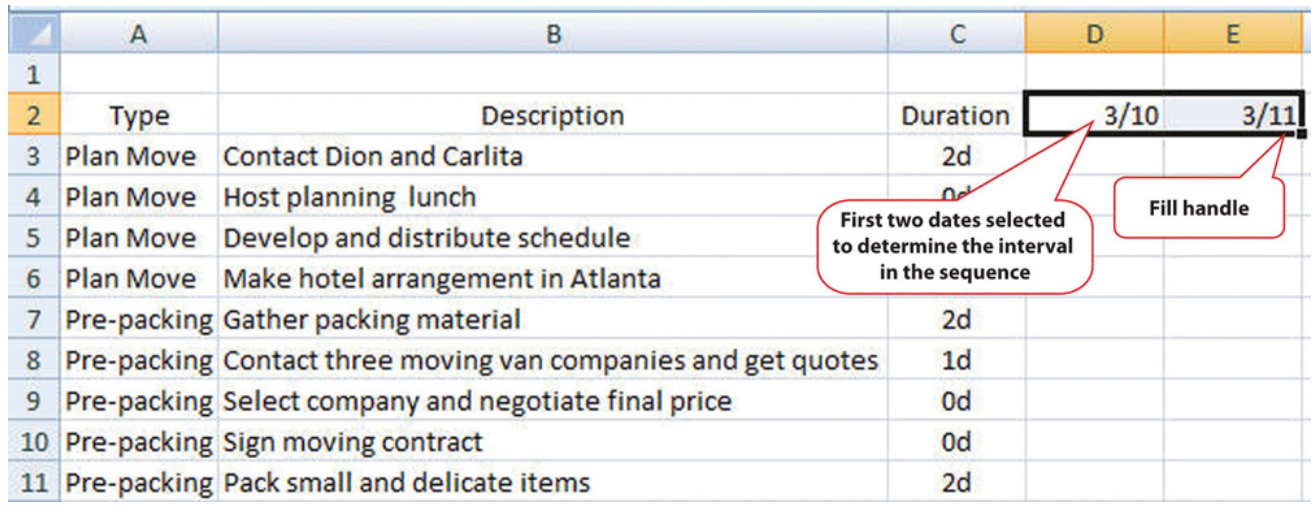

The program is sophisticated enough to correctly fill date sequences between months that have a different number of days and even account for leap years in February. Because more sophisticated project management software uses a table design in which the first two columns are description and duration, a similar structure, in which those two columns are adjacent and in that order will make it convenient to transfer the list of activities in a low-complexity project into the project management software at a later date if the spreadsheet is not sufficient. In the duration column, use the following abbreviations:

- d for days

- wk for weeks

- mons for months

The duration of each activity and the relationships between activities can be illustrated using the drawing shapes. In Excel 2007, the same set of shapes and connector arrows are available as those in Word 2007. A long rectangle can represent a bar whose length represents the duration of the activity. Events or significant dates in the project are identified with a diamond. The diamond can be created by using a small square shape and rotating it. Arrows can be drawn between the shapes to indicate their relationships, as shown in Figure 6.21 "Diagram of Activities". Unfortunately, the arrows in Excel 2007 connect to handles on the sides of the rotated squares instead of the corners. This detail may be overlooked in a simple project diagram.

Figure 6.21 Diagram of Activities 


\begin{tabular}{|c|c|c|c|c|c|c|c|c|c|c|c|}
\hline \multirow{3}{*}{$\begin{array}{l}1 \\
1 \\
2\end{array}$} & A & B & c & D & E & $\mathrm{F}$ & G & H & 1 & $\mathrm{~J}$ & $\mathrm{k}$ \\
\hline & & & & & & & & & & & \\
\hline & Type & Description & Duration & $3 / 10$ & $3 / 11$ & $3 / 12$ & $3 / 13$ & $3 / 14$ & $3 / 15$ & $3 / 16$ & $3 / 17$ \\
\hline 3 & Plan Move & Contact Dion and Carlita & $2 d$ & & & & & & & & \\
\hline 4 & Plan Move & Host planning lunch & od & & & & & & & & \\
\hline 5 & Plan Move & Develop and distribute schedule & $1 d$ & & & & & & & & \\
\hline 6 & Plan Move & Make hotel arrangement in Atlanta & od & & & & & & & & \\
\hline 7 & Pre-packing & Gather packing material & $2 d$ & & & & & & & & \\
\hline 8 & Pre-packing & Contact three moving van companies and get quotes & $1 d$ & & & & & & & & \\
\hline 9 & Pre-packing & Select company and negotiate final price & od & & & & & & & & \\
\hline 10 & Pre-packing & Sign moving contract & od & & & & & & & & \\
\hline 11 & Pre-packing & Pack small and delicate items & $2 d$ & & & & & & & & \\
\hline
\end{tabular}

This type of diagram is useful for projects with low complexity where a simple chart of a few activities will suffice.

\section{Software for Moderately Complex Projects}

More complex projects involve more people who are often separated geographically and who contribute to the same documents. Complex projects have more tasks with more complex relationships. To manage those tasks and relationships, using dedicated project management software and more sophisticated diagramming software is justified.

\section{Sharing Team Documents}

If more than one person on a team will be contributing to a document, the document must be accessible to them. To manage documents that are created by a team, it is necessary to control the edits so that work is not lost or confused.

\section{Version Control}

Files such as word processing documents and spreadsheets may be stored on an individual's computer and copies sent to participants who then make changes and return the revised version to the person who is responsible for the final version of the document. If more than one person is editing his or her own copy of a document at the same time, different versions of the document with different additions or corrections are created. Word processing programs such as MS Word 2007 have a feature that can compare two documents and identify the differences to help bring the two different documents back together. This feature is found on the Review tab, in the Compare group, as shown in Figure 6.22 "Compare Documents Feature".

Figure 6.22 Compare Documents Feature 


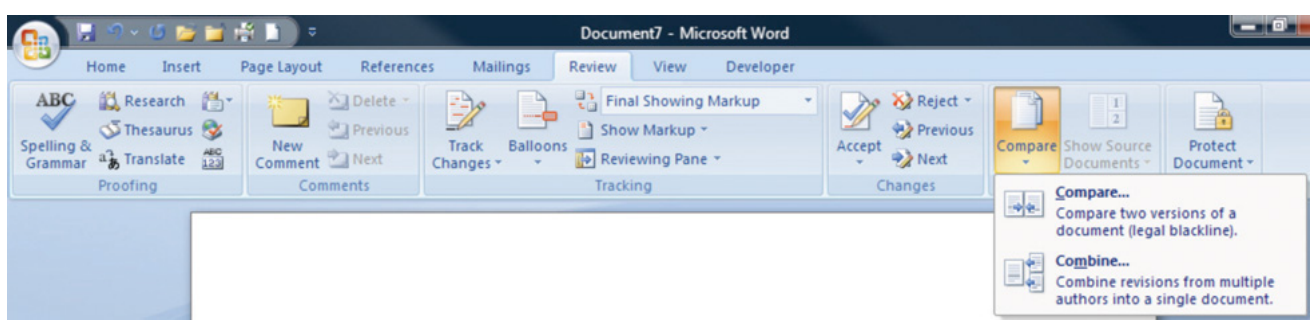

Most software programs make periodic backups to protect from accidental power loss. One of the ways that a user can still lose a lot of work is by replacing a newer version of a document with an older version. It is possible to display the date on which the file was last saved using the Details view. If more than one version of the file exists in two different locations, the dates can be compared to determine which is the most recent. These techniques are useful for simple projects with very few participants.

\section{File Storage and Access Control}

Managing versions of documents that are edited by more than one person can be done more effectively by placing the file in a location that can be accessed by all the team members. This can be a shared drive on the company's computer or on a document sharing service. People who need to use the document are grouped by their need for access. Three groupings are common:

1. View only

2. Edit only

3. Ownership/administrator

The owner or administrator of the document can set the access levels. These levels of access can be assigned to each individual, or they can be assigned to named groups and the person can be made a member of a group. The owner of the document can choose to accept or reject changes made by those with edit-only permission.

The advantage of this method is that there is only one version of the file. If a file is being edited, it is usually locked so that other team members may view the file but cannot edit it until the first editor closes the file.

If the file is stored on a computer that is on a secure network within an organization, it can be difficult for team members who do not have direct connections to the company's network to get access to the files. To protect the security of the company's network, the network administrator can grant an outside user permission to access the network from anywhere on the Internet using a virtual private network (VPN) connection. A VPN uses encryption-replacing readable content with a code-to protect the communication between the network and the user to make it secure. The VPN connection gets the user onto the company network as if they were directly connected, but they still need the appropriate passwords to access the shared documents. 


\section{Tracking Changes and Adding Comments}

One of the features that is particularly useful for keeping track of the changes made to a document by several users is called Track Changes. In Microsoft Word 2007, it is found on the Review tab, in the Tracking group. Changes may be shown in the document or in balloons at the side.

If a team member wishes to explain a change, it is very important that they do not insert their explanation as text into the document. Such explanations might not be deleted and would end up in the final version of the document with potentially damaging results. Instead, team members can use a form of electronic sticky note to make comments. This feature is found in MS Word 2007 on the Review tab, in the Comments group. A change and a comment are shown in Figure 6.23 "Tracking Changes and Adding Comments". The document owner must go through the document and accept or reject each change and delete all the comments before the document is released as a finished product. The Next, Accept, and Reject options are found in Microsoft Word 2007 on the Review tab, in the Changes group.

Figure 6.23 Tracking Changes and Adding Comments

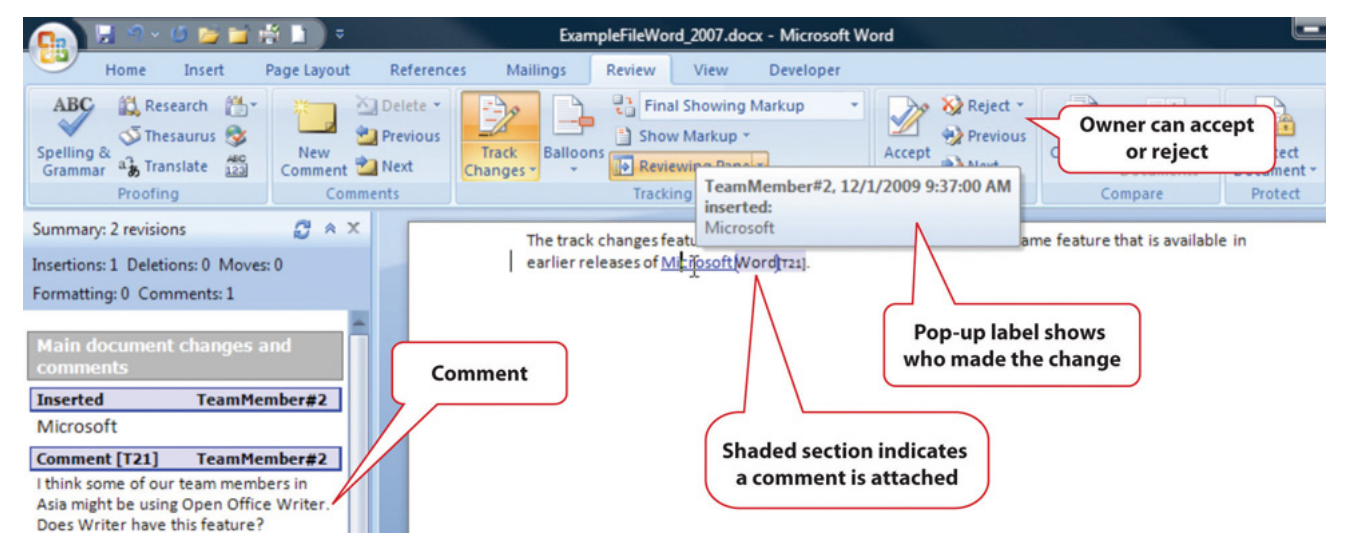

\section{Diagramming Software}

The processes and relationships in medium- and high-complexity projects usually require more sophisticated software tools for creating reporting diagrams and workflow charts. The market for diagramming software is more diverse than for word processing and spreadsheets, and it is not as likely that most team members will have the same programs that save files in the same formats. Microsoft Viseo 2007 is available as a stand-alone program that sells for several hundred dollars. For medium-complexity projects, a free alternative to Viseo is Open Office Draw. Open Office is a free software alternative that includes a word processing, spreadsheet, presentation, and drawing programs. The Open Office Draw program, and others like it, can create diagrams such as the one shown in Figure 6.24 "Diagram Created Using Open Office Draw". 
South American Mining Project

Organization Chart

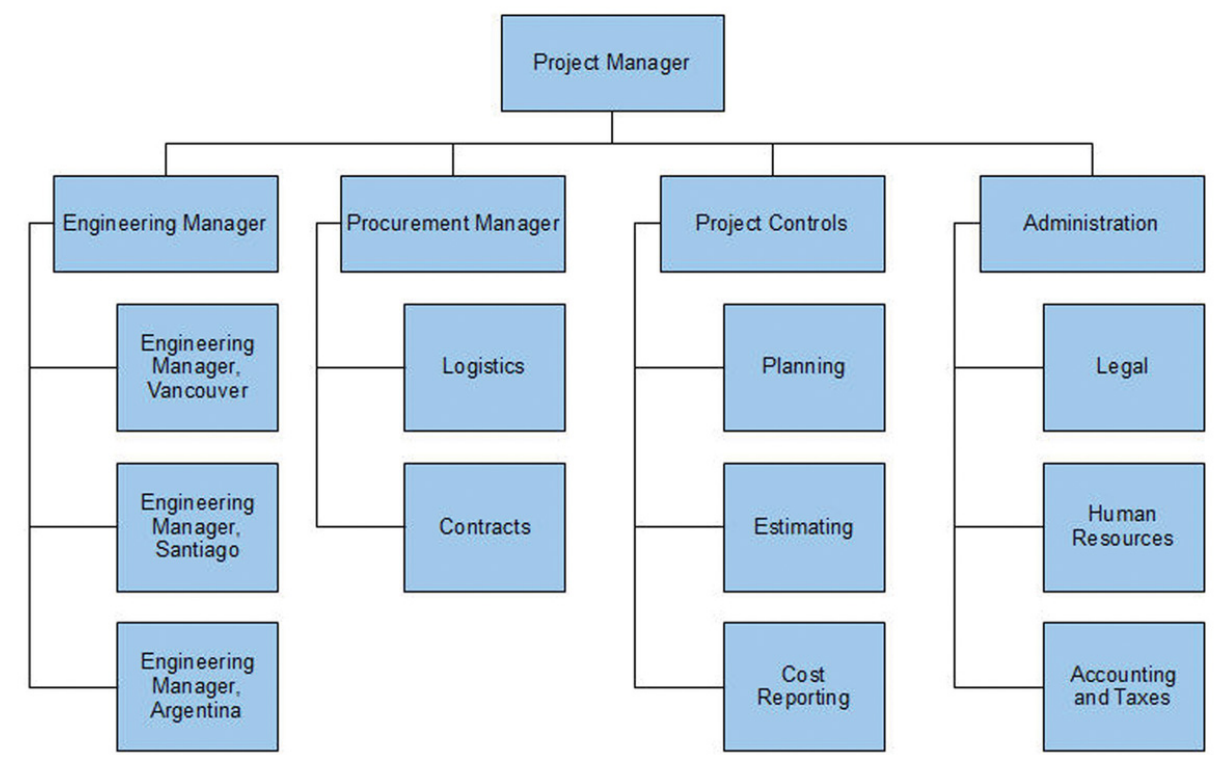

The files created by the various drawing programs might not be compatible with each other, but all the programs can create static image files that can be pasted into word processing documents.

\section{Project Management Software}

The relationships between project activities can become complicated in medium- and high-complexity projects. Dedicated project management software can compute the sum of activity durations along several different paths through complex relationships and recalculate them immediately if any of the durations or starting times are changed. Similarly, charts and reports are updated automatically based on the new data. The most popular software for medium-complexity projects is Microsoft Project. If a project manager begins work on the project in the belief that it can be managed using a list of activities in a word processing program or in a spreadsheet, the list of activities and their durations can be copied and pasted, or imported, into the project management software's table of activities, if the original document or spreadsheet was designed with that possibility in mind, as shown in Figure 6.25 "List of Activities Transferred to a Project Management Program”.

Figure 6.25 List of Activities Transferred to a Project Management Program 


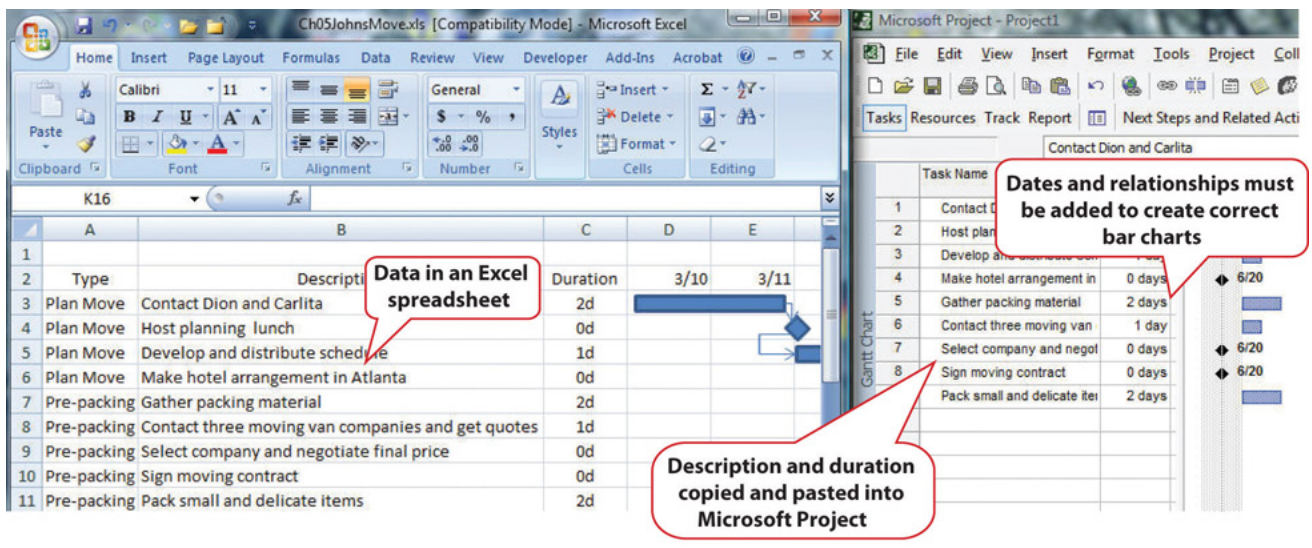

Once the data are placed in the project management software, the relationships can be defined and reports created. Organizations on a tight budget might consider using an open source program named OpenProject. Open source software is usually available at no cost for individual users and with fewer restrictions than proprietary software like Microsoft Project. OpenProject is similar to Microsoft Project, as shown in Figure 6.26 “Open Source Project Management Software”, and could be used on low- and medium-complexity projects that do not need the more advanced features available in Microsoft Project.

Figure 6.26 Open Source Project Management Software

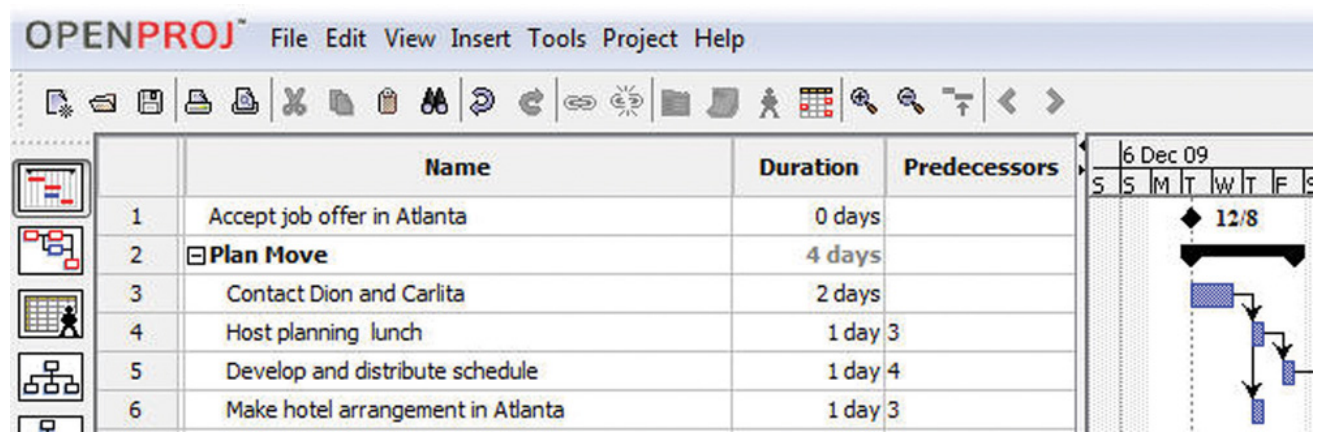

\section{Software for Complex Projects}

Complex projects can involve thousands of individual activities and a company might have several projects going at the same time. Large, complex projects are common in the construction industry. A software that is commonly used for complex projects in construction is P3 or P6 from Primavera. It has the ability to produce sophisticated reports that help project managers to anticipate problems and make projections.

Word processing documents often contain data that could be aggregated and analyzed. Beginning with Microsoft Word 2007 and the .docx file format, it is possible to insert characters called tags on either side of a particular section of a form or document and assign a data label. For example, the name of the supplier on an invoice could be enclosed between two tags: <supplier>Thompson Hardware </supplier>. These tags resemble those used in the hypertext markup language (HTML) to identify how to display text on a Web page, but instead of telling a Web browser how to display the name of the sup- 
plier, it identifies Thompson Hardware as the supplier. These tags are can be created by following a set of rules called the extensible markup language (XML). Forms created using XML can be scanned for the content that is marked by tags. The data can be imported into a spreadsheet or database for analysis. Creating documents that use XML to identify data in the forms can be done using Microsoft InfoPath. An example that identifies key facts in a document that was prepared using InfoPath is shown in Figure 6.27 "InfoPath Form with XML Tags". Because it takes extra effort to learn to use InfoPath, or a similar XML authoring program, and to create the forms, this approach is normally limited to complex and sophisticated organizations that have the need to manage large amounts of data.

Figure 6.27 InfoPath Form with XML Tags

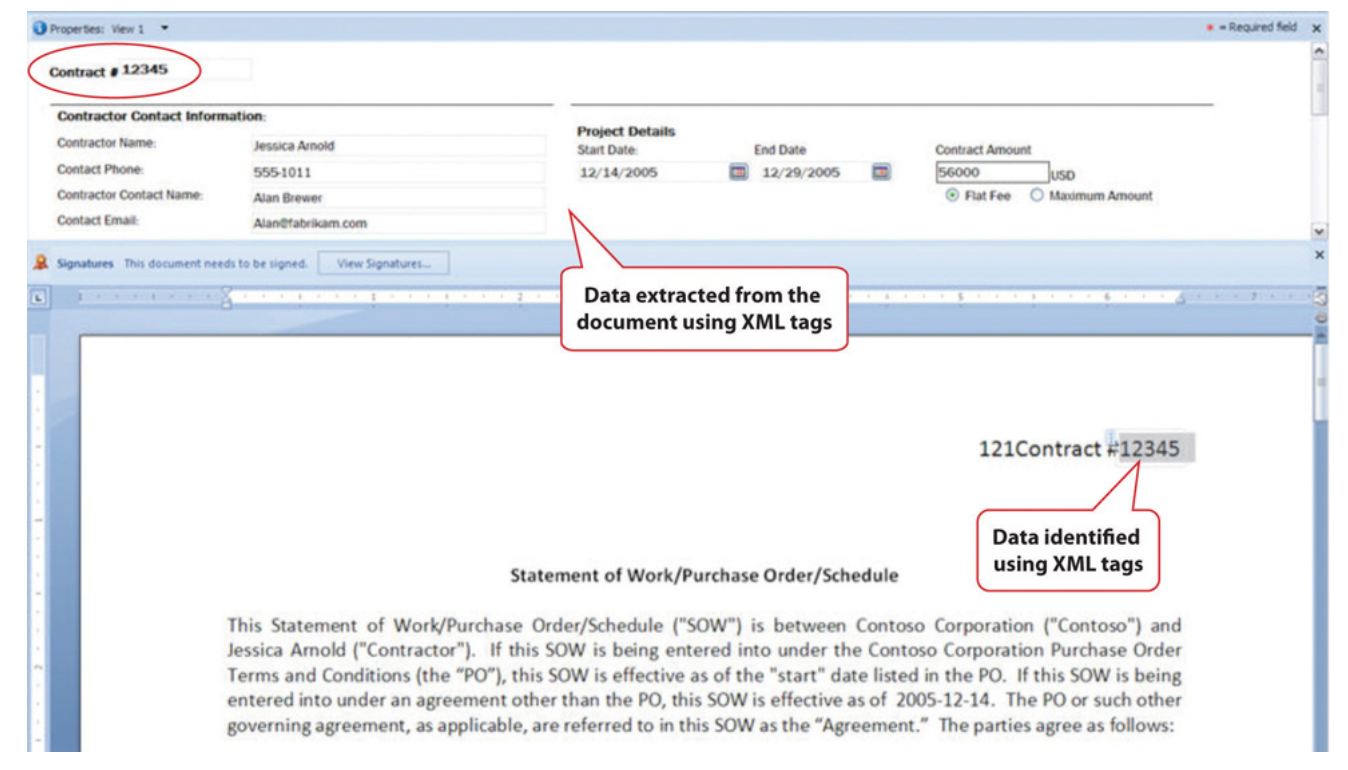

\section{Key Takeaways}

- Low-complexity projects might be managed using general purpose word processing and spreadsheet software by using the special features for outlining, managing data, and inserting graphic objects

- Medium-complexity projects need special purpose software for managing project activities, such as Microsoft Project, and graphic software such as VISEO. Open source software such as OpenProject and Open Office Draw may suffice.

- High-complexity projects need more sophisticated project management software like P6 from Primavera. Forms can be created using XML tags that allow data to be extracted from the documents.

- Files can be stored at a location that is accessible by all the team members. They can be granted different levels of access, including view only, edit only, and ownership. Features like track changes and compare documents can help manage edits. 


\section{Exercises}

1. General purpose word processing and spreadsheet software might be sufficient for managing (low-, medium-, high-) complexity projects.

2. Three features that are available in spreadsheet programs such as Microsoft Excel to manage tables of data are subtotal, sort, and

3. If outline levels are assigned in a word processing document, the outline may be or expanded to hide or display different levels of detail.

4. than proprietary software.

5. A VPN connection uses to protect the content of the communication.

6. How are XML tags similar to HTML tags and how are they different?

7. How should activity information be organized in a spreadsheet to make it easier to transfer to a project management program?

8. What are three options for creating a diagram that displays a project's reporting hierarchy for lowor medium-complexity projects?

9. What is an example of a software product that is commonly used for highly complex projects?

10. What are three levels of file access and editing permissions that can be assigned, and what are examples of user groups that would be assigned to each level?

Internalize your learning experience by preparing to discuss the following.

Describe an experience you might have had with editing the same word processing document and how you managed the revisions. If you used some of the features described above, how well did they work? What features were described that might have been helpful? 


\subsection{Exercises}

Exercises at the end of the chapter are designed to strengthen your understanding and retention of the information recently acquired in the chapter.

\section{Essay Questions}

Write several paragraphs to provide more in-depth analysis and consideration when answering the following questions.

1. Assume that you are the leader of a virtual team that includes members who are in New York, Bogotá, Honolulu, and Tokyo. You would like to choose a day and time for a weekly conference call to keep the project on track. Choose a day and time and explain your choice and the compromises and problems it might cause for each member. Use the term "synchronous" correctly and identify the specific time zone for each participant.

2. From the list of available templates in your word processing or spreadsheet software, choose a template and describe it. Fill it out and then describe how it could be modified to meet the needs of a particular situation or organization.

\section{Discussion}

The exercises in this section are designed to promote exchange of information among students in the classroom or in an online discussion. The exercises are more open ended, which means that what you find might be completely different from what your classmates find, and you can all benefit by sharing what you have learned.

1. Consider the newer synchronous and asynchronous communications technologies with which you are familiar. Describe how they might be used on projects in new and innovative ways. Relate these ideas to what you learned about project cultures - specifically about innovation on projects - and describe how the new communications technologies could be used to innovate.

2. Describe your experience using Excel to manage data such as lists of purchases. Discuss how the features of sorting, filtering, and subtotaling could help answer questions about that list. 


\subsection{Web Exercise}

\section{Learning Objective}

1. Determine the local time for team members in other time zones given GMT or UT zone designations.

\section{Using an Online Time Zone Map}

Fortunately, there are several websites that provide the information you need to schedule a conference call so that all the participants know the correct time and day of the week regardless of where they are in the world.

\section{How to Use a Website to Help Find Local Time}

1. Open a word processing document. Save it as Ch06TZStudentName.doc. Use the .doc file format.

2. On the first line, type Chapter 6 study documentation by and then type your name. Press Enter to move the insertion point to the next line

3. Open a web browser and go to http://www.worldtimezone.com.

4. The map will display the world's time zones at the time you visit the site. See Figure 6.28 "World Times Compared to 6:40 p.m. EST". The example in Figure 6.28 "World Times Compared to 6:40 p.m. EST" was displayed on the author's computer at 6:40 p.m. EST on Thursday, December 18 (23:40 GMT).

Figure 6.28 World Times Compared to 6:40 p.m. EST 


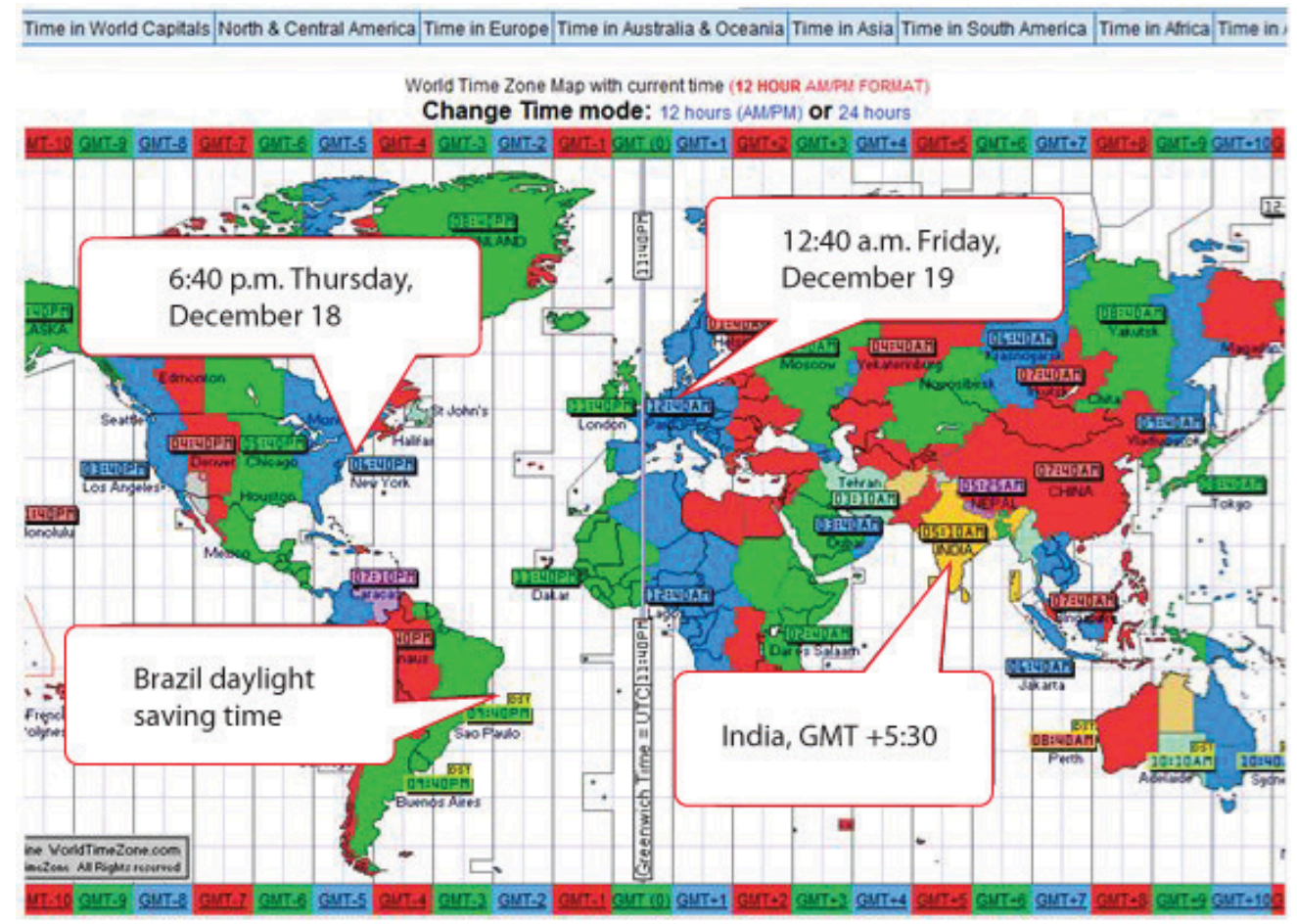

5. Capture the screen that displays the World Time Zone Map with your current time and date.

6. Switch to the word processing document and paste the screen capture below the first line of text.

7. Below the image, type The time and date in India would be and then type the time and date in India for your current time and date.

8. Review your work and use the following rubric to determine its adequacy:

\begin{tabular}{|l|l|l|l|}
\hline Element & Best & Adequate & Poor \\
\hline File name & Ch06TZStudentName.doc & Ch06TZStudentName.docx & $\begin{array}{l}\text { Different } \\
\text { file name or } \\
\text { incompatible } \\
\text { format }\end{array}$ \\
\hline $\begin{array}{l}\text { Determine the local time } \\
\text { for team members in other } \\
\text { time zones given GMT or } \\
\text { UT zone designations }\end{array}$ & $\begin{array}{l}\text { Title; screen capture with } \\
\text { current date and time; } \\
\text { correctly calculated day } \\
\text { and time in India. }\end{array}$ & Same as Best & $\begin{array}{l}\text { Incomplete } \\
\text { or an error } \\
\text { in the time } \\
\text { or date }\end{array}$ \\
\hline
\end{tabular}

9. Save the file and submit it as directed by the instructor. 


\subsection{Software and Technology Exercises}

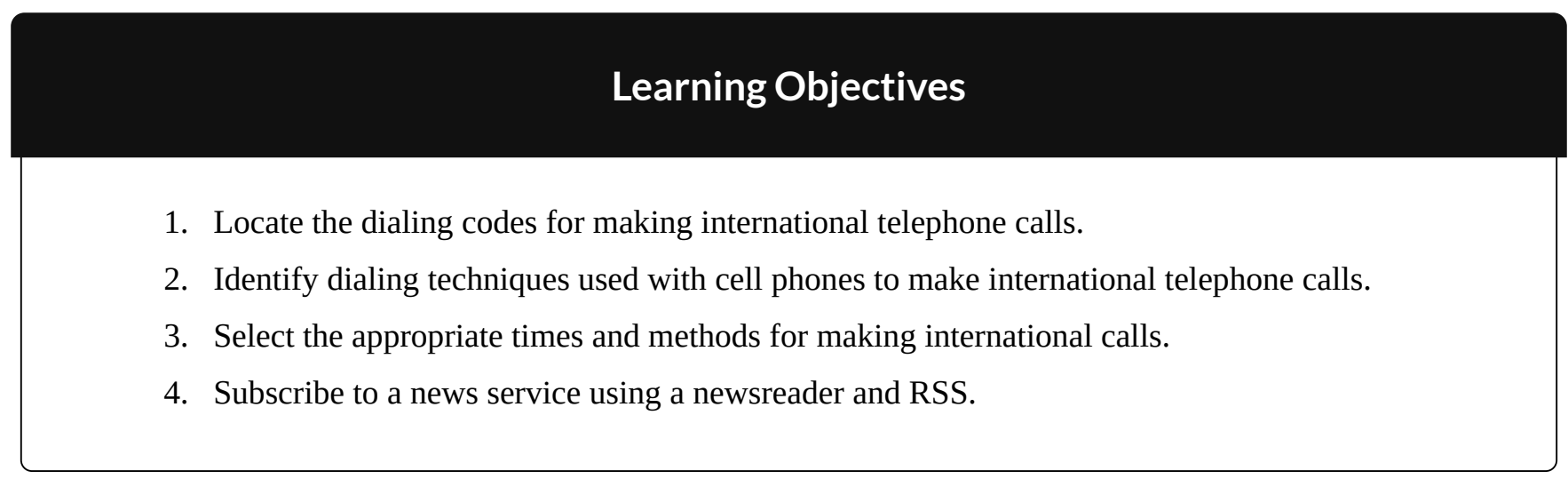

\section{Placing International Calls}

\section{International Telephone Calls Using Wired Phones}

The telephone may be used for two-person synchronous communication or in a multipart conference call. Using a telephone to make long-distance and international calls involves using international telephone numbering conventions.

\section{Calls within North America and the Caribbean}

The telephone companies in North America use the North American numbering plan (NANP) that includes the United States, its territories, Canada, Bermuda, and sixteen Caribbean nations.

Figure 6.29 Rotary Dial Telephone 


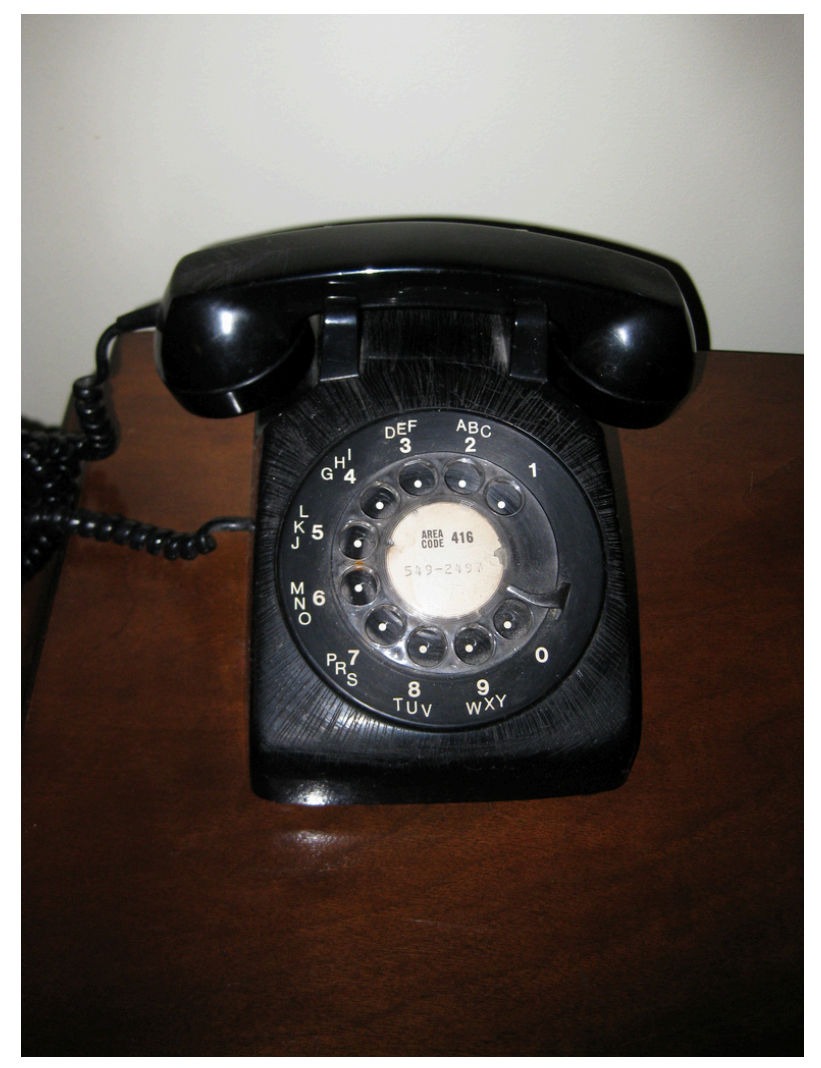

Erica Hargreave - Dialed in - CC BY-NC 2.0.

Wired telephones are connected physically to a local switch that can handle up to ten thousand connections represented by the last four-digit numbers in a telephone number from 0000 to 9999 . Each switch is identified by a three-digit number such as 555. A local telephone number consists of the switch number and one of the ten thousand four-digit numbers such as 5550112 . This system can provide up to ten million different unique phone numbers, but it does not have the capacity to provide service to billions of people.

The switches are grouped into areas and assigned a group number or area code. Area codes in North America were assigned at a time when numbers were converted to a sequence of electrical pulses by inserting your finger in a rotary disc — the dial—and pulling it to a stop on a phone like the one shown in Figure 6.29 “Rotary Dial Telephone”.

As a spring returns the dial to its original position, it opens and closes a set of electrical contacts to create a series of pulses that match the number dialed. Because it takes longer to dial higher numbers like 8 or 9, area codes that could be dialed quickly like 212 and 213 were assigned to densely populated areas like Manhattan (212) and Los Angeles (213). Higher numbers were assigned to rural areas or to newer areas. As a result, it is difficult to determine where a telephone is located by its area code. Do not assume that numbers with similar area codes in North America are located in the same time zone-they may be

1. The three-digit area code plus the next four digits make up a seven-digit number. A seven-digit number has ten million possible combinations from 0000000 to 999 9999. In practice, some area codes are reserved for special purposes such as trouble-shooting, emergencies, directory assistance, and maintenance, so the maximum is less than ten million per area code. For example, numbers 555-0100 through 555-0199 are reserved for fictional use and are not assigned to real customers. 
thousands of miles apart. To initiate a call to a different area code, the number 1 is dialed first. This is the national direct dialing (NDD) code for NANP members.

\section{Calling from North America to a Country outside the NANP}

The IDD code for the United States is 011.

To make an international call from an NANP member such as the United States to another country, you need to provide two codes: the international direct dialing (IDD) code and the country code. The IDD code for the United States is 011. For example, if you wanted to place a call to a number in Rio de Janeiro, you would enter 0115521 xxx xxxx, where 011 is the IDD code for the United States, 55 is the country code for Brazil, 21 is the area code for Rio de Janeiro, and Xxx Xxxx represents the final seven digits of the number.

\section{Calling to North America from a Country outside the NANP}

The IDD and the country code are not simply reversible. The country code for the United States is 1 (not 011).

If you traveled to Rio de Janeiro for a meeting and wanted to call back to a number in the United States from a local phone, you would have to look up the IDD code for the local service provider in Brazil. In Brazil, there is a different code for each of the five phone companies. The IDD for Brasil Telecom is 0014.

The IDD and the country code are not simply reversible. The country code for the United States is 1 (not 011), so you would enter $00141 \mathrm{xxx}$ xxx xxxx, where the last ten digits are the area code and telephone number in the United States.

\section{Reading the Phone Number on a Business Card in North America}

It is commonly understood in the United States that you do not enter the hyphens, parentheses, spaces, or periods that are used to make a telephone number more readable and that you dial 1 first — even though it is not included - for a call destined for a different area code. For example, if the phone number on the business card shows (555) 222-1111, you know that you would enter 2221111 if you are calling from 
within the 555 area code ${ }^{2}$

or 15552221111 for a call from a different area code, but you would not attempt to enter the parentheses, space, or hyphen. Spaces are used in some instances in the following discussion to make the numbers easier to read in this text, but it will be understood that they are not entered when dialing the number.

\section{Reading the Phone Number on an International Business Card}

Unlike those countries participating in the NANP, other countries use different numbers for the national direct dialing (NDD) code and the country code. They might use a different number of digits for the area or city code. A business card from a team member in Rio de Janeiro might be +55 (0)21-Xxxx xxxx where 55 is the country code and 0 is the NDD code. To call this team member from the United States on a wired telephone, you would enter $0115521 \operatorname{xxxx} \operatorname{xxxx}$, where 011 is the IDD for the United States, 55 is the country code for Brazil, and 21 is the code for Rio de Janeiro.

Notice the zero between 55 and 21 is not included when calling from outside the country. This is the NDD code that is used for calls between areas within the country. For example, if you land in the airport at Sao Paulo, Brazil, and want to call the person in Rio de Janeiro from a local phone, you would enter 0 21 xxxx xxxx (without the spaces) where 0 is the NDD code-like 1 in the United States —and 21 is the area/city code.

\section{Finding International Telephone Codes}

1. Open a word processing document. Save it as Ch06PhoneStudentName.doc. Use the .doc file format.

2. On the first line, type Chapter 6 study documentation by and then type your name. Press Enter to move the insertion point to the next line

3. Open a web browser and go to http://www.kropla.com. This site provides information on international dialing codes.

4. Near the middle of the page, click the International Dialing Codes link.

5. On the CountryCode.org page, in the Country column, scroll down and click Brazil. A list of country codes and city codes is displayed next to a map of the country.

6. Use the browser's Back button to return to the CountryCode.org web page. Add the address for this page to the Project Management folder in your browser's favorites or bookmarks.

7. Switch back to the browser. In the Country column, scroll down and click one of the country names other than Brazil.

8. Capture the screen that shows the country's code and map, paste it into a blank document, and then save the document as Ch06Exercises6.5.doc.

2. Some area codes cover large geographic areas, and the NDD code is required to dial a number from within the same area code if they are far apart. 


\section{Making International Telephone Calls Using a Mobile Phone}

To place an international call to a country outside the NANP using a mobile phone, you use the plus sign $(+)$ instead of the IDD code. For example, the number of the British Museum is +44 (0) 2073238000. To call this number from a wired phone in the United States, you would dial 011442073238000 . If you make the call from a mobile phone, you dial +44 2073238000 . Notice the plus sign takes the place of the IDD code.

\section{Finding the Plus Sign on a Mobile Phone}

Wired phones do not have a plus sign on their keypads, but recent model mobile phones include a method to dial a plus sign. Unfortunately, the method varies by brand of telephone.

\section{International Telephone Calls Using a Mobile Phone}

1. Open a web browser and go to http://www.howtocallinternationally.com. This site has a stepby-step demonstration of how to make calls using wired and mobile phones.

2. At the right of the page under Shortcuts, click From a mobile (cellphone). The How to call internationally from a mobile (cellular) telephone page displays. Read this page.

3. Scroll down to the video and click the play button.

4. During the video, when a telephone number with a plus sign is displayed on the cell phone, pause the video and capture the screen.

5. Paste the screen into Ch06PhoneStudentName.doc.

6. Switch back to the browser window and then watch the rest of the video.

7. Add a link to this web page in your browser's favorites or bookmarks.

8. Capture a screen that shows the links to CountryCode.org and Howtocallinternationally.com in the Project Management folder in your browser's favorites or bookmarks and then paste it into the Ch06PhoneStudentName.doc. 


\begin{tabular}{|c|c|c|c|}
\hline Element & Best & Adequate & Poor \\
\hline File name & Ch06PhoneStudentName.doc & Ch06PhoneStudentName.docx & $\begin{array}{l}\text { Different file } \\
\text { name or } \\
\text { incompatible } \\
\text { format }\end{array}$ \\
\hline $\begin{array}{l}\text { Choose the } \\
\text { correct } \\
\text { dialing } \\
\text { codes for } \\
\text { making } \\
\text { international } \\
\text { telephone } \\
\text { calls }\end{array}$ & $\begin{array}{l}\text { Title; screen capture showing the } \\
\text { country code and map of one of } \\
\text { the countries other than Brazil }\end{array}$ & Same as Best & $\begin{array}{l}\text { Incomplete or } \\
\text { used Brazil }\end{array}$ \\
\hline $\begin{array}{l}\text { Identify } \\
\text { dialing } \\
\text { techniques } \\
\text { used with } \\
\text { cell phones } \\
\text { to make } \\
\text { international } \\
\text { telephone } \\
\text { calls }\end{array}$ & $\begin{array}{l}\text { A screen capture from the video } \\
\text { on how to enter a plus sign on a } \\
\text { cell phone; a screen capture that } \\
\text { shows the links to } \\
\text { CountryCode.org and } \\
\text { Howtocallinternationally.com in } \\
\text { the Project Management folder in } \\
\text { the favorites or bookmarks }\end{array}$ & Same as Best & $\begin{array}{l}\text { Cell phone } \\
\text { screen capture } \\
\text { does not show a } \\
\text { plus sign or } \\
\text { shows only one } \\
\text { of the two } \\
\text { required sites in } \\
\text { the bookmarks } \\
\text { folder }\end{array}$ \\
\hline
\end{tabular}

9. Save the file and submit it as directed by the instructor.

\section{Practice Using International Dialing Codes}

Selecting the appropriate numbers to use from a business card for placing an international call requires practice. In this exercise, you practice using your knowledge of international calling codes to compare your answers to reference answers that are hidden on a spreadsheet.

\section{Using a Spreadsheet for Practice}

1. Navigate to the location where the student files for chapter exercises are located and then open 6.3.3_PhonePractice.xls. Save the file as Ch06PhonePracticeStudentName.xls using the Excel 2003 file format.

2. Use the skills you practiced in this chapter and in previous exercises to answer the first question in cell C2. You are allowed to open a browser and refer to websites for assistance.

3. Notice that if you type and enter the correct answer, in exactly the format indicated, the cell background turns green, as shown in Figure 6.30 "Background Turns Green If Correct”.

4. Observe that column D is hidden. It contains a set of correct answers. The spreadsheet's conditional formatting feature is used to change the background color if the cell content matches 
the hidden answer.

5. Use your web references and personal knowledge to answer the remaining questions. Place the answers in column C. If some of the answers do not turn green, check your work. If you cannot determine the error, move on to the next question. Answer all the questions, even if some of the answers are wrong or do not match the reference answer exactly.

6. Select columns $\mathrm{C}$ through E. To accomplish this, you may click and drag the column headings from $C$ through $\mathrm{E}$, or you can click the column $\mathrm{C}$ heading, hold the Shift key, and click the column E heading. Columns C, D, and E are selected, even though column D is hidden, as shown in Figure 6.31 "Columns C, D, and E Selected".

7. Move the pointer onto either column, then right-click. On the shortcut menu, click Unhide. The answers in column D are displayed.

8. Locate any answers that are still displayed in red. Compare your answer to the reference answer. In the Analysis column on the same row, analyze and explain why your answer did not match the reference answer. Use this opportunity to correct misunderstandings.

9. Save the spreadsheet. Check your work to assure that it is complete using the following table:

\begin{tabular}{|l|l|l|l|}
\hline Element & Best & Adequate & Poor \\
\hline File name & Ch06PhonePracticeStudentName.xls & Ch06PhonePracticeStudentName.xlsx & $\begin{array}{l}\text { Different } \\
\text { file name or } \\
\text { incompatible } \\
\text { format }\end{array}$ \\
\hline $\begin{array}{l}\text { Select the } \\
\text { appropriate } \\
\text { times and } \\
\text { methods for } \\
\text { making } \\
\text { international } \\
\text { calls }\end{array}$ & $\begin{array}{l}\text { All incorrect answers are analyzed; } \\
\text { the cause of the error correctly } \\
\text { identified }\end{array}$ & All correct & $\begin{array}{l}\text { Analysis } \\
\text { does not } \\
\text { correctly } \\
\text { identify the } \\
\text { cause of the } \\
\text { error }\end{array}$ \\
\hline
\end{tabular}

10. Save the file and submit it as directed by the instructor.

\section{Using a Newsreader}

Some projects are directly affected by external factors such as political elections, economic trends, corporate mergers, technological or scientific breakthroughs, or weather. To keep informed about these factors, you can subscribe to online news sources. A method that facilitates this process is Really Simple Syndication (RSS). To use this service, you need a newsreader so you can subscribe to RSS feeds. For this activity, you need a Google account. If you do not have one, go to Google.com and create one for no cost. 


\section{Chapter 7: Starting a Project}

This chapter provides an overview of the selection and initiation of a project. Prior to the initiation of a project, the chartering organization - the organization that determines the need for the project-develops a justification for the project. Often, several initiatives compete for the resources of the organization, and potential projects are evaluated to see which ones are best aligned with the mission and goals of the organization. This evaluation process can be very simple where the benefits to the organization are obvious and the economics of the project are very favorable. On larger, more complex initiatives, the process of gathering and evaluating the data to justify the project can take a year or more. The information gathered during this evaluation process provides the basis for the project charter, the initial scope of work, and other information required to initiate the project. 


\subsection{Project Selection}

\section{Learning Objectives}

1. Describe the difference between an organization's mission, goals, and objectives.

2. Describe how the missions are different depending on the type of organization.

3. Define economic terms used for choosing projects.

4. Define a project champion and his or her role.

5. Describe the influences of funding, timing, and unofficial considerations on project selection.

Projects are chosen for a variety of reasons and not all of them are apparent. The project manager must understand why a project was selected over other choices so that he or she can align the team toward justifying the choice that has been made by senior management.

\section{Mission of the Organization}

The mission of an organization is a statement of why it exists. For example, a police department might have its mission stated on the door of each patrol car - to protect and serve. A well-written mission statement is short and has the following sections:

- Purpose of the organization

- Primary stakeholders

- Responsibility of the organization toward the stakeholders

- Products or services offered

\section{Police Department Mission Statement}

The mission of the Philadelphia Police Department is to fight crime and the fear of crime, including terrorism, by working with our partners to enforce the laws, apprehend offenders, prevent crime from occurring, and improve the quality of life for all Philadelphians (Philadelphia Police Department, 2009).

The missions of organizations can be categorized as profit, not for profit, and government. A business that is created to make a profit for its owners and stock holders must consider the cost of each project 
and how much profit it is likely to generate. The mission statement of a not-for-profit organization like a charity would emphasize the service it provides. A not-for-profit organization must control its costs so that it does not exceed its funding, and it is always seeking funding and is in competition with other notfor-profit organizations for funding from the same sources. A government agency, like a police department, is similar to a not-for-profit organization, but its sources of funding are usually taxes and fees. Its mission would include its responsibilities to the citizens it represents. Government organizations compete for funding from higher levels of government. Projects are more likely to be funded if the proposal for the project is closely aligned with the mission of the organization. The project manager must be aware of that mission while building a team and aligning it behind the purpose of the project.

\section{Goals and Objectives}

Senior administrators of the organization decide on how to achieve the mission of the organization by choosing goals. For example, the director of a not-for-profit preschool that provides low-cost education for children of poor, single parents might set a goal of improving its reputation for quality. A goal is an end toward which effort is directed. The director meets with her staff and they consider several ways of achieving that goal. They decide to seek certification by a nationally known group that evaluates the quality of preschool programs. Obtaining this certification is an objective.

Figure 7.1 Relationships between Mission, Goals, and Objectives 


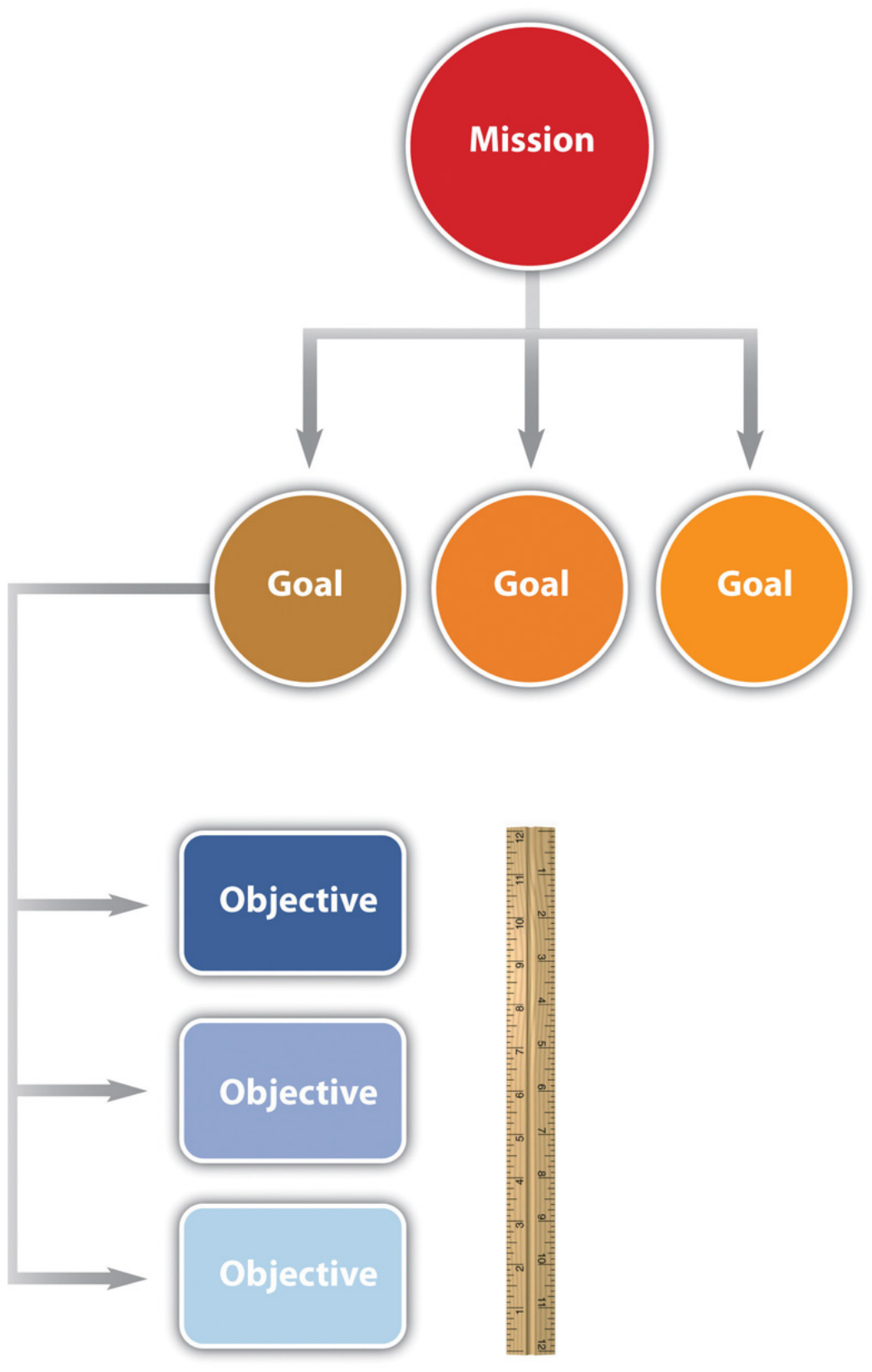

In this text, we distinguish between the terms goals and objectives. An objective must have a measurable outcome. In this example, it is easy to measure whether or not the organization receives the certification, which is the distinguishing characteristic of an objective. The use of these terms is not standardized across the industry or in business, but we will be consistent within this text. To determine whether a statement is a goal or an objective, simply ask if there is a measurable outcome. Seeking the certification is an objective that can be met by treating it as a project that has a measurable outcome and a limited time frame. 


\section{Economic Selection Criteria}

If an organization's mission is to make money, it will try to maximize the profits of the company by increasing the money coming in or decreasing the money going out. The flow of money is called cash flow. Money coming in is positive cash flow, and money going out is negative. The company can maximize profits by improving its operational efficiency or by executing projects. The company must raise money to fund projects. Companies can raise money in three ways:

1. Borrow it (government organizations, such as cities and schools, can sell bonds, which is a form of borrowing).

2. Fund the project from existing earnings.

3. Sell additional stock or ownership shares in the company.

If a company borrows money, it must pay back a portion of the amount it borrowed plus additional interest. The interest is a percentage of the amount of the loan that has not been repaid. The repayment of the loan and interest is usually paid quarterly or annually. To qualify for selection, a project that is intended to make or save money must be able to do the following:

- Repay loans if money must be borrowed to fund the project

- Increase future earnings for shareholders

- Make the company stock more valuable

When senior managers at a for-profit company decide which projects to fund, they must consider these economic issues.

\section{Simple Payback}

To help managers choose between projects, they can use an unsophisticated measurement called simple payback. If the purpose of the project is to improve cash flow-make it more positive or less negative- the improved positive cash flow each year is applied to the original cost (negative cash flow) of the project to determine how many years it would take to pay back the original cost. It is assumed that after that date, the improved cash flow could be used for other purposes or paid out to owners. For example, if the company borrows $\$ 100,000$ to fund the project and the project increases cash flow by $\$ 20,000$ a year, the simple payback would be five years, as shown in Figure 7.3 "Simple Payback".

Figure 7.3 Simple Payback 
202 [Author removed at request of original publisher]

\begin{tabular}{|c|c|c|c|c|c|c|c|}
\hline Year & $\mathbf{0}$ & 1 & 2 & 3 & 4 & 5 & 6 \\
\hline Expense & $\$(100,000)$ & & & & & & \\
\hline Income/Savings & & $\$ 20,000$ & $\$ 20,000$ & $\$ 20,000$ & $\$ 20,000$ & $\$ 20,000$ & $\$ 20,000$ \\
\hline Annual Cash Flow & $\$(100,000)$ & $\$ 20,000$ & $\$ 20,000$ & $\$ 20,000$ & $\$ 20,000$ & $\$ 20,000$ & $\$ 20,000$ \\
\hline $\begin{array}{l}\text { Cumulative Cash } \\
\text { Flow }\end{array}$ & $\$(100,000)$ & $\$(80,000)$ & $\$(60,000)$ & $\$(40,000)$ & $\$(20,000)$ & $\$-$ & $\$ 20,000$ \\
\hline
\end{tabular}

The cash flow from each year is summed up in the cumulative cash flow row. When the cumulative cash flow becomes zero or positive, it means that the original cost has been paid back by the increased income or savings created by the investment.

Companies can use simple payback to establish a cutoff for project consideration. For example, management could declare that no projects will be considered that have a payback of more than three years. For projects that meet this criterion, projects with shorter simple payback periods would have an advantage in the selection process. Not-for-profit or government organizations are likely to approve projects with longer simple payback periods because they are not compared to other not-for-profit or government agencies based on their profitability.

\section{Internal Rate of Return}

Companies whose mission is to make a profit are usually trying to make more profit than their competitors. Simply paying back the loan is not sufficient. If the project involves buying and installing equipment to make a profit, executives can use another method called internal rate of return (IRR). The IRR is like an internal interest rate that can be used to compare the profitability of competing projects. To calculate an IRR, the company considers the cash flow each year for the expected life of the product of the project. It assumes that some of the annual cash flows will be negative and that they can vary from year to year due to other factors, such as lost production during changeover, periodic maintenance, and sale of used equipment. For example, a company decides to upgrade a manufacturing line with new equipment based on new technology. They know that the initial cash flow-shown in year zero-will be negative due to the expense of the conversion. They know that the new equipment has an expected life of six years before newer technologies make it out of date, at which time they can sell it for a certain salvage value. The inputs to the IRR calculation are the net cash flow for each year where at least one of them is negative and at least one of them is positive. The result is a percentage that indicates how well this project performs as an investment. Refer to Figure 7.5.

Figure 7.5 


\begin{tabular}{|c|c|c|c|c|c|c|c|}
\hline Year & $\mathbf{0}$ & 1 & 2 & 3 & 4 & 5 & 6 \\
\hline $\begin{array}{l}\text { Equipment Cost, } \\
\text { Maintenance, } \\
\text { Salvage }\end{array}$ & $\$(100,000)$ & & & & & & $\$ 10,000$ \\
\hline Income/Savings & & $\$ 20,000$ & $\$ 20,000$ & $\$ 20,000$ & $\$ 20,000$ & $\$ 20,000$ & $\$ 20,000$ \\
\hline Annual Cash Flow & $\$(100,000)$ & $\$ 20,000$ & $\$ 20,000$ & $\$ 20,000$ & $\$ 20,000$ & $\$ 20,000$ & $\$ 30,000$ \\
\hline $\begin{array}{l}\text { Cumulative Cash } \\
\text { Flow }\end{array}$ & $\$(100,000)$ & $\$(80,000)$ & $\$(60,000)$ & $\$(40,000)$ & $\$(20,000)$ & $\$-$ & $\$ 30,000$ \\
\hline $\begin{array}{l}\text { Internal Rate of } \\
\text { Return (IRR) }\end{array}$ & $8 \%$ & & & & & & \\
\hline
\end{tabular}

The internal rate of return measures the profitability of an investment.

The life of the equipment is part of the IRR calculation. If a project manager knows that senior management intends to sell the equipment in six years, team members can be made aware of that decision if it affects their choices.

\section{Other Selection Criteria}

Besides making money, there are many other reasons for a project to be selected, including the following:

- Keeping up with competitors

- Meeting legal requirements, such as safety or environmental protection

- Improving the organization's public image

The timing of the project can be very important. A project might be selected at a particular time of year for some of the following reasons:

- Accumulating a year-end budget surplus

- Increasing executive bonus for the year or quarter

- Funding or certification review deadline

If the project manager must make changes to the schedule at some point in the project that could affect its completion date, it is valuable to know if the project was selected because of timing.

\section{Project Champions and Opponents}

In addition to knowing why a project was selected, it is valuable to know which senior executives supported or opposed the selection of the project and if the project manager's supervisor was in favor of it or not. Because most project teams consist of people who do not report to the project manager but who 
report to other unit managers, they might not be available when you need them if their boss thinks other projects are more important. If a particular executive proposed the project and actively advocated for its approval, that person could be a source of support if the project runs into trouble and needs additional resources. A project champion, sometimes called an executive sponsor, is an influential person who is willing to use his or her influence to help the project succeed.

To identify the advocates and opponents of the project, begin by reading public documents (if available), such as the minutes of the meeting at which the project was approved. Next, the project manager can use his or her unofficial network of trusted colleagues to get their opinions. Those discussions should be informal and off the record. Those opinions might be inaccurate, but it is valuable to know what misunderstandings exist about a project. If executives in an organization are assigned as project sponsors, the project champion might be a different person.

\section{Project Champions Support an Aircraft Project}

When Vought Aircraft won a contract with Boeing to build a significant portion of the fuselage for the new 787 Dreamliner in Charleston, South Carolina, there was no existing workforce with aircraft experience. To give Vought Aircraft an incentive to locate the plant in South Carolina, Governor Mark Sanford, with the support of the legislature, committed to the recruitment and training of the workforce needed for the plant to be successful. The legislature provided several million dollars and assigned the role of developing a trained workforce to the South Carolina Technical College System and Trident Technical College, the local community college in Charleston, South Carolina.

Dr. Jim Hudgins, president of South Carolina's Technical College System, assigned the most experienced project manager to the project and personally accepted the role of project sponsor.

Dr. Hudgins and Dr. Thornley, president of Trident Technical College, met with the project leadership at least monthly to review project plans and progress. Each month both Dr. Hudgins and Dr. Thornley assigned resources and removed barriers to project success. Dr. Thornley assigned procurement personnel to the project to assure materials were purchased and delivered in time to support the project schedule. She reallocated space to provide training laboratories for the project and assigned a college leader to the project full-time to coordinate actions with the college. Dr. Hudgins coordinated with the Governor's office to assure the project received the appropriate level of support.

Both Dr. Hudgins and Dr. Thornley had the political power and the resources to assure the project had the autonomy and the resources to succeed. The project met every milestone, exceeded every measurable goal, and received high praise from Vought Management as the plant began operations on schedule.

\section{Key Takeaways}

- A mission statement declares the purpose of the organization and identifies the primary stakeholders, the products or services offered, and the responsibility toward the stakeholders. Goals are statements of direction for the organization, and objectives are activities that achieve those goals with measurable outcomes.

- Profit-making organizations exist to make profits for their owners while in competition with other 
companies. The goals of those companies are directed at making as much or more money than the competition. Not-for-profit organizations are directed at providing a service to a particular group. They must control costs to perform their tasks with the funds they have, and they compete with other not-for-profit organizations for donations and funding. A government agency is similar to a not-for-profit organization, but its sources of funding are usually taxes, fees, and funding from a higher level of government, and it has a responsibility to the citizens it represents. Government organizations must justify their expenditure of tax money to elected or appointed officials.

- Two economic tools for evaluating and comparing projects are simple payback and internal rate of return. Simple payback is a calculation of the year when the cumulative income or savings due to spending money on a project will meet or exceed the original cost of the project. Internal rate of return is a calculation of the average percentage of increased cash flow over the life of the project's product.

- A project champion is an influential person who is willing to use his or her influence to help the project succeed. It is useful to know why the project champion wants the project to succeed and to be sure to accomplish that goal even if it is not stated.

- Project selection depends on the availability of funds, which depends on the way each type of organization receives money for projects. Funds might be available at certain times and projects are selected that can take advantage of that opportunity. Projects might be initiated for reasons that are not stated, and investigating the source of funding and likely motivation of project champions can provide better understanding of the project's chances for success.

\section{Exercises}

1. An end toward which effort is directed that has measurable outcomes is an in this text.

2. A general statement of the direction an organization should take is a

3. If a company has to make quarterly loan payments to the bank, this is an example of a negative (two words).

4. If you borrow $\$ 1,000$ and have to pay back $\$ 1,010$ a month later, the $\$ 10$ dollars is the

5. If a company had to choose between installing two different pieces of expensive equipment that had different expected lifetimes, different salvage values, and different production capabilities, it would compare the (four words) for each option

6. On Google's Web pages, it says that they want to "organize the world's information and make it universally accessible and useful." This is an example of a statement.

7. An influential person who is in favor of a project is one of the project

8. If upgrading the windows in a building costs $\$ 100,000$ and it reduces heating and cooling costs by $\$ 5,000$ a year, the investment in the window upgrade has a years. (two words) of twenty

9. The group that determines the need for a project is the organization.

10. What are four parts of a well-written mission statement? 
11. What is the primary mission of each of the following types of organizations: profit-making, notfor-profit, and government organizations?

12. What does it mean if the money spent on a project has a simple payback of five years?

13. Why is it important to identify project champions?

14. What is an example of funding for a project that is only available for a short period of time under special circumstances?

Internalize your learning experience by preparing to discuss the following.

Choose an example from outside the assigned reading of a mission, goal, and objective that demonstrates the characteristics of each and how they relate to each other. The example can be from a real organization or it can be fictional. Describe the characteristics of a mission, goal, and objective, as defined in this chapter, and how the example demonstrates those characteristics.

\section{References}

Philadelphia Police Department, Philadelphia Police Department: Mission Statement, 2009, http://phillypolice.com/about/mission-statement (accessed July 16, 2009). 


\subsection{Project Scope}

\section{Learning Objectives}

1. Define scope and describe how it is affected by project complexity.

2. Identify the uses of a scope document.

3. Describe how a scope document is developed and changed.

The project scope identifies the total work of the project.

\section{Definition of Scope and the Effects of Complexity}

The scope document defines what tasks the project team is expected to accomplish and, just as importantly, what is not part of the project. Depending on the complexity level of the project, the scope document can be as short as one page or as long as several hundred pages. On more technical projects, such as a project to design an offshore wind-turbine farm, the scope would include a significant amount of technical specifications, with a focus on the electrical output from the wind turbines. The size and character of the project scope document is related to the project complexity. Higher scores on the Darnall-Preston Complexity Index indicate the need for more detailed scope documents.

\section{Uses of a Scope Document}

A well-developed project scope statement provides the project team with information the team needs to design and implement the project execution plan. The well-developed project scope also provides the team with an understanding of the purpose of the project and the basis for defining project success.

\section{Scope Document for Training Auto Workers}

An automotive company is building a new plant to produce electric passenger cars in the southeast United States. As the plant nears completion, the plant's manager issues a contract to train the new plant workers. The training of workers who will be maintaining the production equipment will be done by the equipment suppliers and will not be in the scope of the training contract. 
The scope of work for the training project will include the identification of the knowledge, skills, and abilities needed by each classification of worker and the development of the delivery methodology that will effectively and efficiently develop the identified knowledge, skills, and abilities (online, classroom, hands-on). The scope will also include delivery of the training, evaluation of the workers after training, and the development of training records. Items not included in the project scope are items that will be the responsibility of the automotive company, such as the selection and hiring of the workers and the provision of the automotive tools and equipment needed for training. These exclusions are specifically stated in the scope document.

During the design of the plant, the Human Resources Division of the company explored different workforce models. The plant will be a typical assembly operation working three shifts. Experience in other plants indicated that a team-based approach combined with a lean manufacturing philosophy produced the highest productivity. This information was included in the documents provided to the team developing the training project's scope. The plant manager, the human resources manager, and the plant engineer reviewed and occasionally made changes to the draft training scope.

The scope of work for the training project was developed from a combination of information from experts with previous experience, documents that reflected the plant operation philosophy, and selected managers from operations and human resources. All the knowledge needed to develop the scope was within the automotive project team. Sometimes outside consultants are needed to develop a complete project scope. For example, if the team in our automotive training example did not have experience in the start-up of another automotive plant, then the hiring of a consultant with that experience might have been required to understand the entire scope of activities needed for training the automotive workforce.

The automotive project described above is a typical example of the types of information and the people involved in developing a project scope. From the information in the project description, the project team could develop a project scope document.

\section{Development of a Scope Document}

The project manager will often develop the first draft of the project scope and then solicit feedback and suggestions from the project team, client, and sometimes key vendors. The project manager will attempt to develop consensus around the project scope, but the final approval belongs to the project client or sponsor. Depending on the complexity profile of the project, the development of the project scope document can be a short discussion between the project manager and the client, or on a large, complex project, the process can take weeks.

\section{Managing Changes to the Scope Document}

The project scope is not a stagnant document, and changes are to be expected. Changes to the project scope are necessary to reflect new information. Changes to the project scope also create the opportunity for new purposes to emerge that will change the end results of the project. In some cases, these new results represent a positive outcome for the chartering organization. 


\section{Deviation versus Change}

If a minor change is made to the schedule that does not affect the completion date of the project, it is a deviation from the schedule. As long as the end date of the project or major objectives are not delayed, a formal change request to the client is not needed. Recording and communicating these schedule deviations is still important for coordinating resources and maintaining the client's awareness of the project's progress.

\section{Deviation of Labor Cost}

The labor cost was estimated at fifteen dollars per hour for cleaning the project office once per week. The winning bid for the contract was at sixteen dollars per hour. The cost deviated from the estimate and a change was made to the budget. This was a cost deviation, not a change in scope. The additional cost for the contract was covered from the project contingency reserves, and the budget was revised to reflect the changes.

\section{Truck Crash Causes a Deviation to the Schedule}

Installation of a fence around the project site was delayed when the truck delivering the fence was wrecked on the way to the job site. The fence project was delayed by one week and the delay did not affect any other activity on the project. This deviation from the original schedule did not cause a delay in the project, and the schedule was adjusted as a deviation to the schedule—not a change request.

\section{Documenting Changes}

It is important to have a written record of changes to the scope of a project. On the least complex projects, an e-mail message can be sufficient, but on larger projects a standard form is normally used. The following steps are paraphrased by Tom Mochal (Mochal \& Mochal, 2003), and they have the necessary components of a change documentation process:

- Inform project stakeholders of the change request process.

- Require that the change request is made in writing, including the business value of the change to the project.

- Enter the request in the scope change log.

- Estimate the time needed to evaluate the change. If the evaluation process is time consuming and would affect activity completion dates by diverting management resources, get approval from the project sponsor to evaluate the change request. If the evaluation is not approved, record the decision in the scope change log. 
- Evaluate the change and its impact on the schedule and budget if the evaluation is approved.

- Present the change request to the project sponsor for approval. Record the decision in the scope change log with the recommended course of action.

- Distribute the scope change log periodically to team members so they know what changes are being considered and what happened to those that were not approved or evaluated.

- If the change is approved, update the project charter or other initiation documents.

- Update the work plan.

- Distribute the revised work plan to stakeholders and team members.

\section{Key Takeaways}

- Scope is a description of the major tasks that are included in the project and some of the tasks that are specifically not included. More complex projects require more detailed and specific scope documents.

- A scope document is used to provide the project team with the information it needs to design and implement the project plan. It provides understanding of the purpose of the project and what project success would be.

- The scope document begins as a draft that is circulated for comments by the team, client, and in some cases, key vendors. The final draft is approved by the client or sponsor. Changes to the scope are documented carefully using standard forms and processes and approved by the project sponsor or client.

\section{Exercises}

1. How is the scope statement affected by the complexity of the project?

2. What negative aspect of the scope statement is important?

3. What are the uses of a scope statement?

4. Once a scope statement is agreed to, how is it changed and what is always required when a scope statement is changed?

Internalize your learning experience by preparing to discuss the following.

Describe a situation where the elements of the project scope did not specifically exclude an activity that caused a misunderstanding. 


\section{References}

Mochal, T. and Jeff Mochal, Lessons in Project Management (Berkeley, CA: Apress, 2003). 


\subsection{Project Start-Up}

\section{Learning Objectives}

1. Identify the major activities included in project start-up.

2. Explain how the project start-up activities may differ on a highly complex project.

The parent organization's decision-making process influences when start-up activities of the project will take place. The transition from planning to project initiation is typically marked by the decision to fund the project and selection of the project manager. However, selection of the project manager is not always the defining event. Some organizations will have the project manager involved in project evaluation activities, and some select the project manager after the decision to fund the project has been made. Including the project manager in the evaluation process enables the project manager to have an understanding of the selection criteria that he or she can use when making decisions about the project during later phases. Selecting the project manager prior to a complete evaluation also includes some risks. The evaluation of the project may indicate a need for project manager skills and experiences that are different from the project manager who is involved in the evaluation.

Selecting the best project manager depends on how that person's abilities match those needed on the project. Those skills can be determined using the Darnall-Preston Complexity Index (DPCI). If the project profile indicates a high complexity for external factors and a medium complexity for the project's technology, the profile would indicate the preference for a project manager with good negotiation skills and an understanding of external factors that affect the project. Because of the technological rating, the project manager should also be comfortable in working with the technical people assigned to the project. The project manager involved in the project selection process may not be the best match for the project execution.

During the start-up of a project, the project manager focuses on developing the project infrastructure needed to execute the project and developing clarity around the project charter and scope. Developing the project infrastructure can be a simple task on a project with a low complexity level. For example, the project manager of a worker training project in South Carolina who works for a training college has existing accounting, procurement, and information technology (IT) systems in the college that he or she can use. On large complex projects, a dedicated project office, IT system, and support staff might be needed that would be more challenging to set up. For example, on a large construction project in South America, the design and operations offices were set up in Canada, Chile, and Argentina. Developing compatible IT, accounting, and procurements systems involved a high degree of coordination. Acquiring office space, hiring administrative support, and even acquiring telephone service for the offices in Argentina required project management attention in the early phases of the project. 
The project manager will conduct one or more kickoff meetings to develop plans for the following activities:

- Establish the project office.

- Develop project policies and procedures.

- Begin refining the scope of work, the schedule, the budget, and the project execution plan.

Depending on the complexity level of the project, these meetings can be lengthy and intense. Tools such as work flow diagrams and responsibility matrices can be helpful in defining the activities and adding clarity to project infrastructure during the project start-up.

Typically, the project start-up involves working lots of hours developing the initial plan, staffing the project, and building both internal and external relationships. The project start-up is the first opportunity for the project manager to set the tone of the project and set expectations for each of the project team members. The project start-up phase on complex projects can be chaotic, and the project manager must be both comfortable in this environment and able to create comfort with the client and team members. To achieve this level of personal comfort, the project manager needs appropriate tools, one of which is an effective alignment process. This is one of the reasons there are a large number of meetings during the start-up of projects with a high-complexity profile.

\section{Key Takeaways}

- The major activities included in project start-up are selecting the project manager; establishing funding; developing project infrastructure such as accounting, procurement, and IT; holding a kickoff meeting, determining staffing; and building relationships.

- The start-up activities for small projects can utilize existing infrastructure for support functions and can have a single start-up meeting, while larger projects require more dedicated infrastructure and full-time staff, and the start-up meetings can take longer and involve more people.

\section{Exercises}

1. What are four of the major activities that occur during project start-up?

2. What is one type of start-up activity that is affected by the difference in a project's complexity? Describe the difference in that activity between low-, medium-, and high-complexity projects.

Internalize your learning experience by preparing to discuss the following.

How does the choice of project manager affect the start-up of the project? Include a discussion of the point in the process at which the project manager is assigned and how the personality of the manager affects the match between the manager and the complexity of the project. 


\subsection{Alignment Process}

\section{Learning Objectives}

1. Identify the purpose of the alignment process.

2. Identify the components of the alignment process.

3. Identify the effects of a lack of trust on a project.

Developing a common understanding among the key stakeholders of the purpose and goals of the project and the means and methods of accomplishing those goals is called the alignment process. It is important to accomplish this alignment during the initiation phase. Project managers usually conduct a start-up meeting that is sometimes called a kickoff meeting. The agenda and duration of the start-up meeting depends on the complexity level of the project. Projects with a limited scope and short duration may engage in a session start-up meeting over lunch. A medium-complexity project will require a four-hour meeting or more while a high-complexity project cannot achieve alignment in a single meeting. Alignment can require several days of activities.

\section{Five-Day Alignment Meeting on a Horse Ranch}

On one large, complex project, the project alignment required a five-day process. Over twenty members of the project team and client participated in this alignment. To create a relaxed atmosphere and facilitate an open discussion, the alignment meetings and activities were held on a horse ranch in Argentina.

A number of companies specialize in designing and facilitating alignment sessions for large complex projects. Although designed to meet the needs of each project, alignment sessions have some common agenda items:

- Developing a common understanding of the project purpose

- Agreeing on the means and methods for accomplishing the purpose

- Establishing trust among team members

\section{Common Understanding}

A common understanding does not mean building a consensus. People may disagree with the direction 
being developed, but they have the same basic understanding as those who agree. For a project plan to be effective, there must be a critical mass or sufficient commitment among the critical stakeholders. Therefore, disagreement is not fatal to the project execution, but a unified team with a common understanding is much more powerful and increases the likelihood of success. If disagreement does exist, an open and forthright discussion will enable the project leadership to address the disagreement in developing the project plan. If the disagreement stays hidden and is not openly discussed, problems will emerge later in the project.

Developing a common understanding can be as easy as an informal discussion that lasts a few hours, or it can be a lengthy, complex process. The methods and processes employed to develop a common understanding are directly related to the complexity of the project. The more complex projects will require more intense discussions around those issues that score high on the complexity profile.

Developing a common understanding among the key project stakeholders requires the following:

- Defining project success

- Determining potential barriers to success

- Establishing key milestones

- Identifying decision makers and the decision-making process

It is difficult to execute a successful project without first defining what makes a successful project. The first part of this discussion is easy: the project must be completed on time, within budget, and to all specifications. The next level of the discussion requires more reflection. During this discussion, reflection on the organization's mission, goals, and related issues such as safety and public perception of the project emerge.

After the team develops a common understanding of project success, a discussion of barriers to achieving that success enables team members to express skepticism. On more complex projects, the goals of a project often seem difficult to achieve. A discussion by the team of the potential barriers to project success places these concerns out in the open where team members can discuss and develop plans to address the barriers. Without this discussion, the perception of these barriers becomes powerful and can have an effect on project performance.

\section{Project Purpose}

The project purpose is sometimes reflected in a written charter, vision, or mission statement. These statements are developed as part of the team development process that occurs during the project initiation phase and results in a common understanding of the purpose of the project. A purpose statement derived from a common understanding among key stakeholders can be highly motivating and connects people's personal investment to a project purpose that has value.

A purpose statement-also called a charter, vision, or mission-provides a project with an anchor or organizational focus. Sometimes called an anchoring statement, these statements can become a basis for testing key decisions. A purpose statement can be a powerful tool for focusing the project on actions and 
decisions that can have a positive impact on project success. For example, a purpose statement that says that the project will design and build an airplane that will have the best fuel efficiency in the industry will influence designs on engine types, flight characteristics, and weight. When engineers are deciding between different types of materials, the purpose statement provides the criteria for making these decisions.

Developing a common understanding of the project's purpose involves engaging stakeholders in dialogue that can be complex and in-depth. Mission and vision statements reflect some core values of people and their organization. These types of conversations can be very difficult and will need an environment where people feel safe to express their views without fear of recrimination.

\section{Goals}

Goals add clarity to the anchor statement. Goals break down the emotional concepts needed in the development of a purpose statement and translate them into actions or behaviors, something we can measure. Where purpose statements reflect who we are, goals focus on what we can do. Goals bring focus to conversations and begin prioritizing resources. Goals are developed to achieve the project purpose.

Developing goals means making choices. Project goals established during the alignment process are broad in nature and cross the entire project. Ideally, everyone on the project should be able to contribute to the achievement of each goal.

Goals can have significantly different characteristics. The types of goals and the processes used to develop the project goals will vary depending on the complexity level of the project, the knowledge and skills of the project leadership team, and the boldness of the project plan. Boldness is the degree of stretch for the team. The greater the degree of challenge and the greater the distance from where you are to where you want to be, the bolder the plan and the higher the internal complexity score.

\section{Roles}

Role clarity is critical to the planning and execution of the project. Because projects by definition are unique, the roles of each of the key stakeholders and project leaders are defined at the beginning of the project. Sometimes the roles are delineated in contracts or other documents. Yet even with written explanations of the roles defined in documents, how these translate into the decision-making processes of the project is often open to interpretation.

A discussion of the roles of each entity and each project leader can be as simple as each person describing their role and others on the project team asking questions for clarification and resolving differences in understanding. On less complex projects, this is typically a short process with very little conflict in understanding and easy resolution. On more complex projects, this process is more difficult with more opportunities for conflict in understanding.

One process for developing role clarification on projects with a more complex profile requires project 
team members, client representatives, and the project's leadership to use a flip chart to record the project roles. Each team divides the flip chart in two parts and writes the major roles of the client on one half and the roles of the leadership team on the other half. Each team also prioritizes each role and the two flips charts are compared.

This and similar role clarification processes help each project team member develop a more complete understanding of how the project will function, how each team member understands their role, and what aspects of the role are most important. This understanding aids in the development or refinement of work processes and approval processes. The role clarification process also enables the team to develop role boundary spanning processes. This is where two or more members share similar roles or responsibilities. Role clarification facilitates the development of the following:

- Communication planning

- Work flow organization

- Approval processes

- Role boundary spanning processes

\section{Means and Methods}

Defining how the work of the project will be accomplished is another area of common understanding that is developed during the alignment session. An understanding of the project management methods that will be used on the project and the output that stakeholders can expect is developed. On smaller and less complex projects, the understanding is developed through a review of the tools and work processes associated with the following:

- Tracking progress

- Tracking costs

- Managing change

On more complex projects, the team may discuss the use of project management software tools, such as Microsoft Project, to develop a common understanding of how these tools will be used. The team discusses key work processes, often using flowcharts, to diagram the work process as a team. Another topic of discussion is the determination of what policies are needed for smooth execution of the project. Often one of the companies associated with the project will have policies that can be used on the project. Travel policies, human resources policies, and authorization procedures for spending money are examples of policies that provide continuity for the project.

\section{Trust}

Trust on a project has a very specific meaning. Trust is the filter that project team members use for evaluating information. The trust level determines the amount of information that is shared and the quality 
of that information. When a person's trust in another person on the project is low, he or she will doubt information received from that person and might not act on it without checking it with another source, thereby delaying the action. Similarly, a team member might not share information that is necessary to the other person's function if they do not trust the person to use it appropriately and respect the sensitivity of that information. The level of communication on a project is directly related to the level of trust.

Trust is also an important ingredient of commitment. Team member's trust in the project leadership and the creation of a positive project environment fosters commitment to the goals of the project and increases team performance. When trust is not present, time and energy is invested in checking information or finding information. This energy could be better focused on goals with a higher level of trust (Willard, 1999).

Establishing trust starts during the initiation phase of the project. The kickoff meeting is one opportunity to begin establishing trust among the project team members. Many projects have team-building exercises during the kickoff meeting. The project team on some complex projects will go on a team-building outing. One project that built a new pharmaceutical plant in Puerto Rico invited team members to spend the weekend spelunking in the lime caves of Puerto Rico. Another project chartered a boat for an evening cruise off the coast of Charleston, South Carolina. These informal social events allow team members to build a relationship that will carry over to the project work.

\section{Key Takeaways}

- The purpose of the alignment process is to develop a common understanding of the purpose, agree on the means and methods, and establish trust.

- The components of the alignment process are discussions of the purpose, goals, participant roles, methods of tracking progress and costs, methods of managing change, and building trust.

- The effects of a lack of trust are delays caused by fact checking or missing information that was not shared because the person's discretion was not trusted to handle sensitive information.

\section{Exercises}

1. The initial meeting that is designed to build understanding and consensus around the goals and objectives of the project is the meeting.

2. What are the objectives of the alignment process?

3. What are five of the seven components of the alignment process?

4. How can lack of trust between team members adversely affect the project?

Internalize your learning experience by preparing to discuss the following.

Why is an alignment meeting important? What needs to be accomplished, and what are two examples of things that could go wrong if the alignment meeting does not meet its objectives? 


\section{References}

Willard, M., "Building Trust: The Relationship Between Trust and High Performance," Axis Advisory 1999, http://www.paclink.com/ axis/M7trust.html. 


\subsection{Communications Planning}

\section{Learning Objectives}

1. Describe the differences between communications in an existing organization compared with a new project.

2. Describe how the detail of the communications plan is related to the complexity of the project.

3. Describe a communication matrix and its function.

4. Describe conventions for naming files to indicate their content and the version.

The flow of information between team members and stakeholders is managed by rules set forth in a communications plan.

When a person joins an existing organization, one of the early tasks is to learn the work processes of the organization, including where to find information, the meeting schedule, and what reports are required. In existing organizations, new members discover the gatekeepers of information: those persons in the organization who know how to generate or find information. Typically, the generation, flow, and storage of information reflects the organizational culture, and to effectively communicate in an organization, a person must be able to develop communication styles and processes consistent with that organization.

Projects do not have the advantage-or sometimes the disadvantage — of an existing organizational culture or communication structure. The project leadership team develops an understanding of the information needs of the various members and stakeholders of the projects and develops a communications plan that provides the right information, at the right time, to the right people.

The detail of the communications plan is related to the complexity level of the project. Highly complex projects require a detailed communications plan to assure that the information needed by the project team and stakeholders is both generated and distributed to support the project schedule and project decisions. Crucial information can be lost or delayed in a complex project if the communications plan is not functioning properly.

\section{Communicating Priorities}

During a project in Tennessee, the project management team was exploring ways to complete the project earlier to meet the changing requirements of the project's client. The team identified a number of actions that could create an earlier completion date. The plan required an early delivery of critical equipment by a supplier, and 
the team visited the supplier's senior management and agreed to pay a bonus for early delivery of the equipment.

Two weeks later, during a review of the project procurement team progress, the project manager discovered that the organization's procurement department had delayed approvals needed by the supplier because the engineering design was not submitted in the required format. This action effectively delayed the project two weeks and reduced the possibility of the project team meeting milestone requirements for earning a bonus.

The organization's procurement team did not understand the critical nature of this supplier's contribution to an early completion of the project. All the information needed by the organization's procurement team was in the meeting minutes distributed to the entire team. The procurement team did not understand the implications of their work processes, and the result was a delay to the project schedule and a reduction in client satisfaction and project profitability.

Effective communication on a project is critical to project success. The Tennessee project is a typical example of errors that can be created by the breakdown in communication flow. Highly complex projects require the communication of large amounts of data and technical information that often changes on a frequent basis. The project manager and the leadership team are responsible for developing a communications plan that provides the right information, at the right place, at the right time. The Tennessee project example demonstrates that even when the information is at the right place and at the right time, the project procurement leader must assist the procurement team in understanding the priorities of the project. On large, complex projects, that procurement lead would not be in the daily communication to subcontractors or vendors. In the Tennessee project example, the procurement leader's unique understanding that came from participation in the project leadership meeting required a more direct involvement with those subcontractors and vendors that impacted the project goals.

Just as important, an effective project communications plan does not overload team members and project systems with information that is not useful. Some project managers will attempt to communicate everything to the entire project team. Although this assures that each team member will receive critical information, the large influx information can make the distillation of the information to the critical and relevant people more difficult for each team member.

\section{Communication Matrix}

A Guide to the Project Management Body of Knowledge (PMBOK Guide) describes tools and techniques for identifying project stakeholders, defining their information requirements, and determining the appropriate communication technology. The project includes developing a list of all the people impacted by the outcome of the project and people who can influence the execution of the project, including project team members. The project leadership then generates a list of information needed or requested by each stakeholder.

The project leadership team develops a list of communication methods for gathering and communicating project information. These include a list of reports, meetings, and document flowcharts. The leadership team then typically develops a communication matrix that details who is included in each project meeting and the distribution of major documents in a table format. 
Figure 7.13 Simple Communication Matrix

\begin{tabular}{|l|l|l|l|l|l|l|}
\hline Project & $\begin{array}{l}\text { John } \\
\text { (Client) }\end{array}$ & $\begin{array}{l}\text { Sally (Proj } \\
\text { Mgr.) }\end{array}$ & $\begin{array}{l}\text { Robert (Technical } \\
\text { Mgr.) }\end{array}$ & $\begin{array}{l}\text { Jose (Executive } \\
\text { Sponsor) }\end{array}$ & $\begin{array}{l}\text { Isiah (Client } \\
\text { Consultant) }\end{array}$ & $\begin{array}{l}\text { Jorge (Procurement } \\
\text { Mgr.) }\end{array}$ \\
\hline Project Scope & A & R & R & A & R & A \\
\hline Changes & A & A & A & I & I & R \\
\hline Meeting notes & I & A & A & I & R & A \\
\hline RFIs & R & R & A & I & I & A \\
\hline RFQs & R & R & A & I & R \\
\hline $\begin{array}{l}\text { Schedule } \\
\text { updates }\end{array}$ & R & A & A & I & R & A \\
\hline $\begin{array}{l}\text { Technical } \\
\text { reviews }\end{array}$ & I & R & A & & & R \\
\hline
\end{tabular}

A = Approval required. $\mathrm{R}=$ Review and comment. $\mathrm{I}=$ For information only.

\section{Document Control}

On large, complex projects, organizing the creation, distribution, and storage of documents is a major and important activity. Organizations that execute a large number of complex projects will often have project document control systems that the project leadership team will adapt for their project. Document control systems distribute, store, and retrieve information that is needed by the project team. Documents originate from the various team members during the planning and execution of the work and then are transmitted to the document team for cataloging, distributing, and storing.

Document control systems have a systematic numbering system that allows a team member to derive information about the document through the document number.

\section{Document Naming Provides Information about the Content}

On a complex project, document names were chosen to indicate the category, location, purpose, author, and date. For example, a file named 323RFQDewateringPump_Darnall_10.08.2012 rev 3. contains five pieces of information about the content of the file. The first digit of the first number was used to indicate the category of the document. For example, all documents related to the project scope started with a 100 number and documents related to procurement started with 300. In this file name, the 3 indicates the document refers to procurement, the next two digits-23 - refer to a location on the project (the south pumping station). The naming convention was distributed to team members so that when they saw this file name, they could interpret it to mean that the document refers to a procurement document, specifically a request for a quote for a dewatering pump for the south pumping station and that the document was prepared by the procurement team member (Darnall) on August 10, 2012. One of the naming conventions that was specifically described was the use of date formats in the international format of $\mathrm{dd} / \mathrm{mm} / \mathrm{yyyy}$ instead of the American format of $\mathrm{mm} / \mathrm{dd} / \mathrm{yyyy}$, so team members know this document was created on August 10 rather than October 8. 
When files are stored on a computer, the names can be sorted alphabetically. The beginning of the name is used as the primary sorting criteria. In the example above, sorting a list of document names would place all the documents together by category (e.g., scope and procurement), because all the documents related to scope would begin with a 1 and all those that are related to procurement would begin with a 3 .

When a document is expected to be revised over the course of the project, version control becomes important. Version control means labeling each revision to enable the team to understand the latest activity and status of the document (or the activity behind the document). For example, on engineering and construction projects, document control tracks the development and distribution of documents. Each drawing is given a unique identification that reflects the type of drawing (electrical, civil, etc.), the location (first floor, mechanical room, etc.), and the version number. Because the design process includes several iterations of the drawings as more information is developed, document control uses an identification that indicates the version of the document.

For example, a project will use letters to indicate the version of the document until the document is approved for construction, and then it is given a number after approval. Therefore, a document with revision $\mathrm{D}$ will be the fourth version of the document. The same document with revision 3 means that this is third revision after the project was approved for construction.

To assure that everyone who should either review or approve the document received a copy, document control develops a distribution list for each type of documents. Each person reviews and signs the distribution list and then sends the document to the next person on the list. The design documents, distribution lists, and other project documents are archived by document control for future reference. In the example above, the document was the third revision after the design was approved for construction.

Naming conventions for files and the versions of files should be consistent with the practices of the parent organization or with the client organization so that the files may be archived with files from other projects. For example, California Road Construction Projects require a specific file naming convection.

\section{Document Naming Convention in California}

All Highway Construction Projects (Roadway) are required to be named in accordance with the following naming convention:

d12345ppXXX

- $\mathrm{d}$ = District code. The district code represents the district where the project is being constructed (not the district creating the CADD drawings). Districts 1-9 use a single numeric character (1-9, respectively). Districts 10 through 12 use a single alpha character (a-c, respectively).

- 12345 = First five characters of the project expenditure authorization.

- $\mathrm{pp}=$ Print Sequence Code (two alpha characters).

- $\mathrm{XXX}=$ Respective sheet numbers (numerical characters) for each Print Sequence Code used in the project.

For example,

512121ic007.dgn 
- $5=$ District 05 .

- $12121=$ First five characters of the project expenditure authorization.

- ic = Print Sequence Code (Drainage Details).

- 007 = Sheet number (seventh Drainage Detail sheet).

\section{Key Takeaways}

- In an existing organization, there are gatekeepers of information who know how to find it, when meetings are scheduled, and what reports are required. In a new project, the project manager can create a new flow of information and reporting requirements.

- More complex projects require more sophisticated communications plans.

- A communication matrix is a table that shows the names of people as column or row headings and the types of documents as row or column headings. In the cells where the name and document type intersect, a symbol indicates the person's responsibility or access with regard to that type of document.

- File names can be used as codes to describe the contents of the file. Parts of the name can be used to identify the category, location, subject, author, and date. File name conventions should be used that match those used by the parent organization or by the client.

\section{Exercises}

1. A table that relates types of documents, people, and their responsibilities and access is a communications

2. How do communications on a new project differ from communications in an existing organization?

3. How does the communications plan differ for a complex project compared to a simple project? Provide an example.

4. What is the purpose of using a document naming convention? Describe at least three types of information that the file name could contain.

Internalize your learning experience by preparing to discuss the following.

What is the purpose of a communications plan and what is an example of a problem that might arise if the communications plan is not complete and an example of a problem that might arise if the communications plan is not followed? 


\subsection{Exercises}

Exercises at the end of the chapter are designed to strengthen your understanding and retention of the information recently acquired in the chapter.

\section{Essay Questions}

Write several paragraphs to provide more in-depth analysis and consideration when answering the following questions.

1. Choose an organization of which you are a member. Identify the type of organization (profit, notfor-profit, government) and locate its mission statement. Quote the mission statement and then analyze it to determine if it has the four elements described in this chapter as necessary for a wellwritten mission statement. Revise the mission statement, if necessary, so that it addresses all four of the elements of a well-written mission statement.

2. Describe the pros and cons of assigning a project manager to the project during the design phase. Describe how the complexity of the project might affect that decision.

3. Describe a project with which you are familiar that suffered from lack of alignment. Identify the component of alignment that was missing and its effects.

4. Describe the function of a communication matrix and provide an example of how it would be used to create, edit, approve, and distribute a particular type of document.

\section{Discussion}

The exercises in this section are designed to promote exchange of information among students in the classroom or in an online discussion. The exercises are more open ended, which means that what you find might be completely different from what your classmates find, and you can all benefit by sharing what you have learned.

1. Effects of lack of trust: Relate an example of a project on which you worked where the participants did not know each other well enough to trust each other, and describe the effect of this lack of trust on the project. Describe alignment activities that could have increased trust on that project.

2. Describe an example of a project with which you have been personally involved that suffered from undocumented changes in scope. Consider an example provided by a classmate and determine if their example is a deviation or a scope change and if it requires a scope change, how should it have been handled? Demonstrate your knowledge of the steps for making scope changes described in the text.

3. What is the mission statement of your college or university? Give an example of a recent project 
undertaken by the organization. Determine if the project directly supports the stated mission and explain your opinion.

4. Do you think a communication matrix is necessary on a small project that only involves six people? Be prepared to support your opinion with examples. 


\subsection{Software and Technology Exercise}

\section{Learning Objective}

1. Use a spreadsheet to calculate cash flow, payback, and Internal Rate of Return (IRR).

\section{Create a Worksheet to Calculate Cash Flow, Payback, and IRR}

Projects that purport to save money or earn additional money in the future as a result of spending money now can be evaluated and compared using basic financial tools. A simple payback analysis determines how long it will be before the result of the project pays off the initial investment, and the Internal Rate of Return (IRR) is a percentage similar to an interest rate that can be compared to other projects or investment opportunities.

\section{How to Set Up a Spreadsheet to Show Cash Flow, Simple Payback, and Calculate IRR}

1. Start Excel 2007. In cells A1 through A5, type Payback and Internal Rate of Return, Year, Expense, Income/Savings, Annual Cash Flow, Cumulative Cash Flow, and Internal Rate of Return (IRR). Drag the boundary between column A and B to the right to increase the width of column A, as shown in Figure 7.14 "Widen Column to Fit Labels”. 


\begin{tabular}{|l|l|}
\hline 1 & Payback \\
\hline 2 & Year \\
\hline 3 & Expense \\
\hline 4 & Income/Savings \\
\hline 5 & Annual Cash Flow \\
\hline 6 & Cumulative Cash Flow \\
\hline 7 & Internal Rate of Return(IRR) \\
\hline
\end{tabular}

2. In cell B2, type 0 , and in cell C2, type 1 . Click and drag across cells B2 and C2 to select them both. Identify the fill handle at the lower right corner of C2 as shown in Figure 7.15 "Use Fill Handle to Extend a Pattern of Intervals". Selecting the first two numbers in a sequence determines the interval of the sequence.

3. Click and drag the fill handle to the right to cell H2. The sequence of years from zero to six is filled into cells B2 through $\mathrm{H} 2$.

4. In cell B3, type $\$(100,000)$ and then press the Enter key. Typing a number with the dollar sign and comma sets the formatting automatically. The parentheses indicate a negative number that the computer may display in red.

5. In cell C3, type $\$(2,000)$ and then press Enter. Click cell C3 again to select it. Drag the fill handle to the right to cell H3. Because a single value was selected, the same value is filled into cells D3 through H3, as shown in Figure 7.16 "Initial Expense in Year Zero Followed by Annual Expenses".

6. In cell C4, type 25,000 and then press Enter. Use the procedure you practiced in step 5 to fill this value into cells D4 through $\mathrm{H} 4$.

7. In cell $B 5$, type $=B 4+B 3$ and then press Enter. This formula adds the positive and negative cash flows in the two cells above its location to find the annual cash flow.

8. Click cell B5 and then drag the fill handle to cell $\mathrm{H} 5$ to fill this formula into the adjacent cells. The formulas adapt to their new locations to add the two cells immediately above. Click cell D5 to observe how the formulas change to sum the cells above, as shown in Figure 7.17 "Formula to Calculate a Running Total”.

9. In cell B6, type $=B 5$ and then press Enter. This formula transfers the value for the initial expense to cell B6 so the next formula can be used in the remaining cells. 
10. In cell C6, type $=B 6+C 5$ and then press Enter. This formula sums the value from the previous year with the annual cash flow for the current year.

11. Click cell C6 and then drag the fill handle to cell H6. Observe from the change in color or from the missing parentheses that the cumulative cash flow becomes positive in year five, as shown in Figure 7.18 "Initial Investment Paid Back in Year Five”.

12. In cell B7, type $=\operatorname{IRR}(B 5: H 5)$ and then press Enter. The spreadsheet program uses a built-in program named IRR to calculate the internal rate of return using the annual cash flows in cells B5 through $\mathrm{H} 5$ and determines the rate of return is 10 percent, as shown in Figure 7.19 "IRR Can Be Used to Choose between Very Different Projects". Notice that the IRR function uses the annual cash flows in row 5 and not the cumulative cash flow in row 6 .

13. Click cell A1. Type Payback and Internal Rate of Return and then press Enter. Click and drag cells A1 through $\mathrm{H} 1$ to select them. On the ribbon, in the Alignment group, click the Merge and Center button. The new title is centered across the columns, as shown in Figure 7.20 "Center the Title". This worksheet can be used and extended to determine simple payback and IRR for a variety of projects.

14. In cell A9, type your name.

15. Check your formulas and calculations. Change the initial expense in cell B3 to $\$(90,000)$. The values that depend on the initial expense should all change and produce new cash flows and a different IRR of 14 percent.

16. Click cell B7 to select it and to show the IRR function on the formula bar.

17. Capture a screen that shows the recalculated values, the IRR function, and your name. Open a word processing file and paste the screen into the document. Save the word processing file as Ch07FinanceStudentName.doc and close it.

18. Save the worksheet and close it. Keep it where you can find it to demonstrate the provenance of your work, if necessary.

19. Review your work and use the following rubric to determine its adequacy:

\begin{tabular}{|c|c|c|c|}
\hline Element & Best & Adequate & Poor \\
\hline File name & Ch07FinanceStudentName.doc & Ch07FinanceStudentName.docx & Other name \\
\hline $\begin{array}{l}\text { Use a } \\
\text { spreadsheet } \\
\text { to calculate } \\
\text { cash flow, } \\
\text { payback, and } \\
\text { Internal Rate } \\
\text { of Return } \\
\text { (IRR) }\end{array}$ & $\begin{array}{l}\text { Screen capture of spreadsheet } \\
\text { after the value in B3 is } \\
\text { changed to negative } \$ 90,000 \text {, } \\
\text { with cell B7 selected to show } \\
\text { the IRR function on the } \\
\text { toolbar }\end{array}$ & Same as Best & $\begin{array}{l}\text { Incorrect } \\
\text { formulas; } \\
\text { incorrect range } \\
\text { for the IRR } \\
\text { function; } \\
\text { negative } \\
\text { numbers not } \\
\text { formatted; name } \\
\text { not shown }\end{array}$ \\
\hline
\end{tabular}

20. Save the file and submit it as directed by the instructor. 


\section{Chapter 8: Project Time Management}

The project scope identifies the objectives of the project, what activities will be performed, and some of the activities that are not included in the project. The scope document is used to create a master schedule that identifies important dates and activities. In this chapter, the student learns how the scope and schedule are developed.

Project planning and scheduling is both an art and a science. No two project managers or planning professionals develop identical plans or project schedules. The planning process is creative and reflects the planner's approach and style. Even though the project plan is unique to the approach and style of the planner, methods for developing the schedule and documenting the resulting plan follow certain rules.

On larger and more complex projects, a planning function composed of a small team of planning and scheduling experts may be needed to develop and track the project schedule. Project planners facilitate the development of the information required to develop the project plan using templates, past or similar projects, and most importantly, the thoughts and plans of the project team leaders and members. On a smaller project, the project manager may be responsible for accomplishing this planning function.

After gathering this information, the planner begins developing the project's master schedule-a summary level schedule that encompasses the entire project scope- that includes major events and provides a view of the entire project. Working with the project team, the planning continues to include more details as additional information becomes available. The schedule continues to evolve during the life of the project, and major revisions may be necessary in response to events both inside and outside the project that change critical dates on the schedule.

Determining the schedule of activities that comprise the project is a key element of project management. 


\subsection{Types of Schedules}

\section{Learning Objective}

1. Define the types of project schedules.

The schedule develops as the project moves from its early conceptual phase into the execution phase.

\section{Conceptual}

When the scope of the project is being determined, a simple schedule that shows the major tasks and approximate start and end dates is developed to allow senior management to make decisions about the scope of the project. Detail is not required at this stage because entire tasks might be dropped from the scope, or the whole project might not be approved.

\section{Master}

If the project is chosen, a master schedule is created. It has major events and dates such as the starting date and the completion date. The master schedule is often part of a contract. Changes to the master schedule must be approved using a documented change process with approval by the project sponsor and client.

\section{Detail}

To execute the master schedule, the major activities are broken down into smaller activities and resources are assigned to those activities. The most detailed versions or portions of the schedule may be developed a few weeks prior to the execution of those activities and are called two-week plans. Portions of the master schedule that affect particular vendors might be sent to them so they can provide detailed activities that they would perform. 


\section{Key Takeaway}

- Types of schedules vary in detail. A broad, general conceptual schedule is used in the earliest phases of the project design. A master schedule with start date, milestones, and completion date becomes part of the contract and is changed by mutual agreement using a formal change process. Details are added to the master schedule as needed to perform the work of the project activities.

\section{Exercises}

1. A schedule identifies major types of activities and approximate start and end dates for use in decision making about the scope of the project.

2. A schedule of activities that is prepared every two weeks is the schedule.

3. How does a conceptual schedule differ from a master schedule?

Conceptual Schedule

Choose an activity that you are considering and describe a conceptual schedule for it. Limit the schedule to between five and ten major sections. Make a rough estimate of the duration and cost of each phase. 


\subsection{Elements of Time Management}

\section{Learning Objectives}

1. Describe a work breakdown structure and how it relates to activities.

2. Describe the use of graphic representations for time management.

According to the Project Management Institute (PMI), project time management includes the following elements (Project Management Institute, Inc., 2008):

- Define activities

- Sequence activities

- Estimate activity resources

- Estimate activity durations

- Develop schedule

- Control schedule

The list of activities, their relationship to each other, and estimates of durations and required resources comprise the work breakdown structure (WBS). The project WBS is a hierarchical—classified according to criteria into successive levels-listing and grouping of the project activities required to produce the deliverables of the project. The WBS represents a breakdown of the project into components that encompass the entire scope of the project. Each level of the WBS hierarchy represents a more detailed description of the project work so that the highest level represents broad categories, and the lower levels represent increasing amounts of detail.

Larger and more complex projects often require a larger WBS. The size of the WBS is directly related to the amount of work on the project and how that work is divided into work packages. The WBS can be developed around the project phases or the project units or functions that will be performing the work. A WBS organized around the project phases facilitates the understanding of the amount of work required for each phase of the project. A WBS developed around the project units or functions of the project facilitates the understanding of the amount of work required for each function.

The following example, named John's move, has a low level of complexity compared to a larger project. Normally, this project would not receive the amount of detailed planning described in the following examples, but the authors chose to use a basic project that is familiar to most students to help them focus on learning the new concepts. 


\section{Changing Jobs}

John has a small but important project. He has accepted a job in Atlanta and now has to move from Chicago to Atlanta and be there, ready to work, right after the Christmas holidays. If the furniture arrives in good condition at least two days before John starts work, and for less than Five thousand dollars, the project will be a success. The move to Chicago five years ago cost five thousand dollars, but John is smarter now and will use his friends to help, so he is confident he can stay within budget.

Developing a WBS begins by defining and developing lists of all activities - work performed on the project that consumes project resources, including cost and time--needed to accomplish the work of the project. The first draft of the WBS includes activities at the highest level of the hierarchy or the management level and typically includes the major activities or summary activities required to accomplish the deliverables identified in the project scope of work.

\section{Top-Level Activities in Move Planning}

On John's move project, these top-level activities are numbered 1, 2, 3, and so on. For example, a plan for the move is the major deliverable from 1 Plan Move, as shown below.

Figure 8.3 Top Level of WBS

1. Plan Move

2. Prepacking

3. Packing

4. Moving

5. Unpacking

6. Project Closeout

The work breakdown structure is then decomposed-broken down into smaller units. The 1.1, 1.2, and 1.3 numbers are the first subdivision of the work. For example, one of John's Summary Level Activities is Packing (3.0). Although some minor packing (delicate items: 2.4) are packed under another summary activity, 3.3 is the major packing and includes the coordination and support of labor (friends Dion and Carlita). The activity is then decomposed - separated into basic elements — to the next level by listing the individual rooms that need packed, as shown below. 
Figure 8.4 Major Activity Decomposed into Smaller Activities

3. Packing

3.1. Confirm Dion's and Carlita's help

3.2. Pick up donuts and coffee

3.3. Pack apartment

3.3.1. Pack kitchen

3.3.2. Pack living room

3.3.3. Pack bedroom

3.3.4. Pack remaining items

The WBS could be decomposed further to a greater level of detail by listing the tasks needed for each activity. For example activity 3.3.3, Pack Bedroom, can be decomposed into additional tasks, such as 3.3.3.1 Pack Closet, 3.3.3.2 Pack Drawers, and 3.3.3.3 Pack Blankets. This type of numbering of the activities is called intelligent numbering. In intelligent numbering, the numbering system has meaning so that a member of the project team knows something about the activity by the number of the activity. For example, any activity associated with packing begins with a 3; even picking up donuts can be an activity that supports packing. The donuts are a form of payment for the labor of Dion and Carlita.

The WBS is developed or decomposed to the level that the manager needs to control or manage the project. Typically, larger and more complex projects require a more detailed WBS.

\section{Estimation of Duration}

After the project team has created the WBS, each activity is reviewed and evaluated to determine the duration (how long it will take to accomplish from beginning to end) and what resources (time, materials, facilities, and equipment) are needed. An estimate is an educated guess based on knowledge, experience, and inference - the process of deriving conclusions based on assumptions. The accuracy of the estimate is related to the quality of the knowledge and how that knowledge is applied. The person with the most knowledge may not be the most objective person to provide duration estimates. The person responsible for the work may also want to build in extra time. Multiple inputs into the duration estimate and a more detailed WBS help reduce bias_-the making of decisions based on a prejudged perspective.

The unit of time used to develop the activity duration is a function of the level of detail needed by the user of the schedule. The larger and more complex the project, the greater the need for detail, which usually translates into shorter durations for activities. 


\section{Duration Estimate for Training}

On a new plant start-up, the plant manager may need to know when the new employees will start training, when they will be fully trained, and when they can begin working in the plant. The plant human resources manager may need to know what skills workers need and how much time each training class will take. The schedule detail the HR manager needs will include activities to locate facilities, schedule training, write contracts for trainers, and manage the initiation of training classes. The trainer will need an even greater level of detail, which could be measured in days or even hours.

On our John's move example, the project schedule may have been just as effective without detailing the packing of the individual rooms in the old apartment. If we deleted these items, would John know when he needed to pack each one of these rooms? If the answer is yes, then we may not need that level of detail.

The activity duration is the length of time the activity should take to complete from beginning to end. The unit of duration is typically working days but could include other units of time such as hours, weeks, or months. The unit chosen should be used consistently throughout the schedule.

An important event, such as a ground-breaking ceremony or receipt of occupancy from the building inspector, is called a milestone. A milestone has no duration or resources. It is simply an indicator of an important point in the project.

\section{Resource Allocation and Calendars}

A common resource constraint is availability. To consider the availability of team members, consultants, and key pieces of equipment, you can create a resource calendar for each that indicates which days are available and which are days off for a group, an individual, or a project asset such as a piece of important equipment. A calendar for team members from the same company could be the company calendar that shows working days, weekend days, and holidays. Individual team members can have individual calendars that show their vacation days or other days off, such as parental leave days. If major pieces of equipment are only available for certain periods of time, they can be given a resource calendar. Resource calendars become important tools when changes must be made to the schedule. When a resource calendar is applied to a duration estimate, the duration in days is distributed across the available calendar days. For example, if the duration is three days and the start date of the activity is Thursday, the activity would begin on Thursday and end on Monday of the following week, assuming the resource calendar shows that the person has the weekend off. If the weekend included an extra day off for a holiday like Labor Day, shown in the calendar in Figure 8.6, the completion day of the same three-day activity would be pushed to Tuesday. 


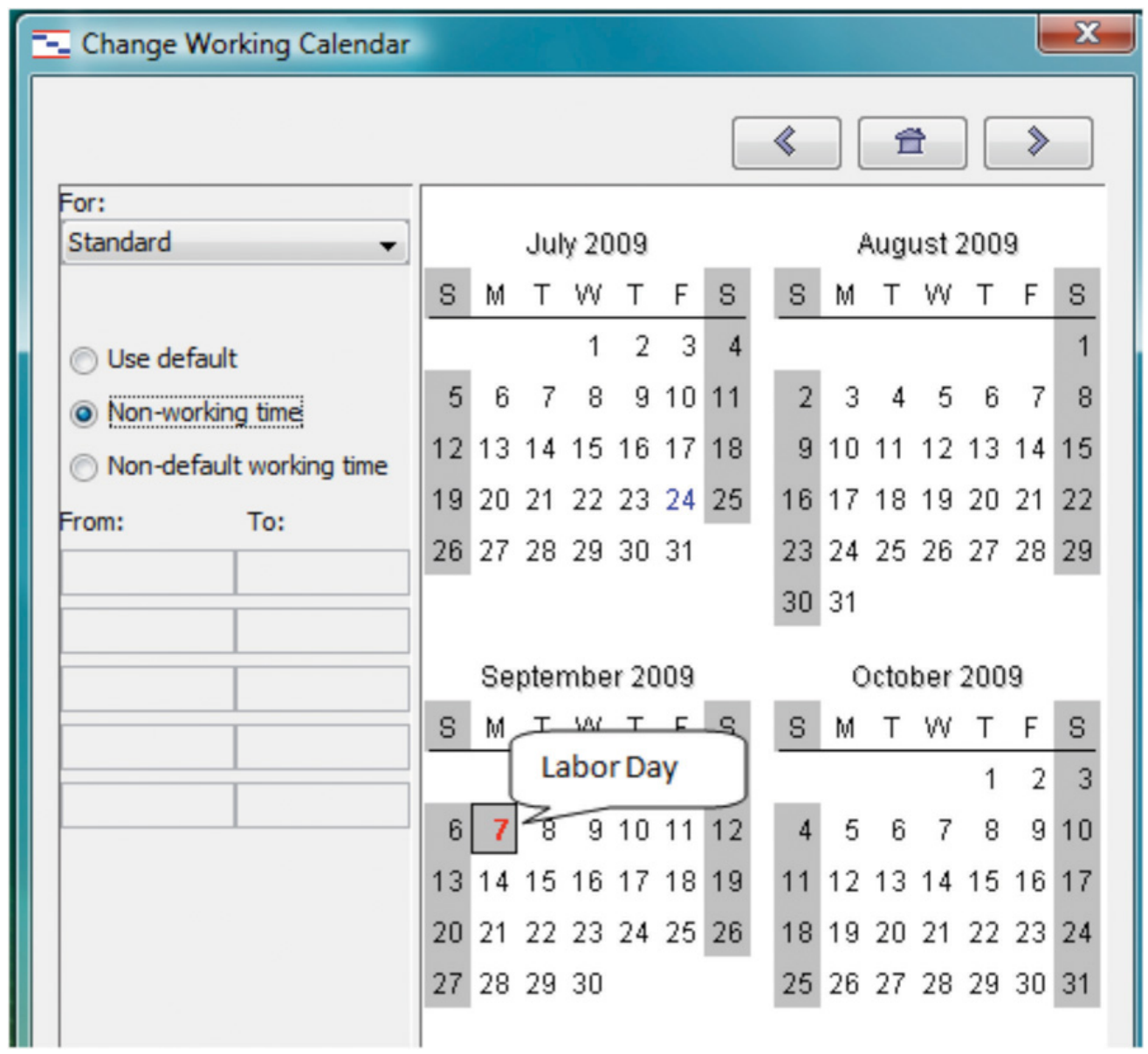

Nonworking days can be designated in a calendar.

\section{Activity Sequencing}

Determining the schedule of a project begins by examining each activity in the WBS to determine its relationship to the other activities.

\section{Project Logic}

The project logic is the development of the activity sequence or determining the order in which the activities will be completed. The process for developing the project logic involves identifying the predecessors - activities that come before-and successors - the activities that come after. 


\section{Project Logic for John's Move}

In our example of John's move, contacting Dion and Carlita—activity 1.1—comes before the lunch meeting is scheduled. You must logically contact Dion and Carlita before you schedule your Host Planning Lunch—activity 1.2. Your conversation with Dion and Carlita will provide you with dates they are available and establish their commitment to help you move. Therefore, the conversation with Dion and Carlita is a predecessor to the Host Planning Lunch Activity. This relationship is diagramed below.

Figure 8.7 Relationship between Two Activities

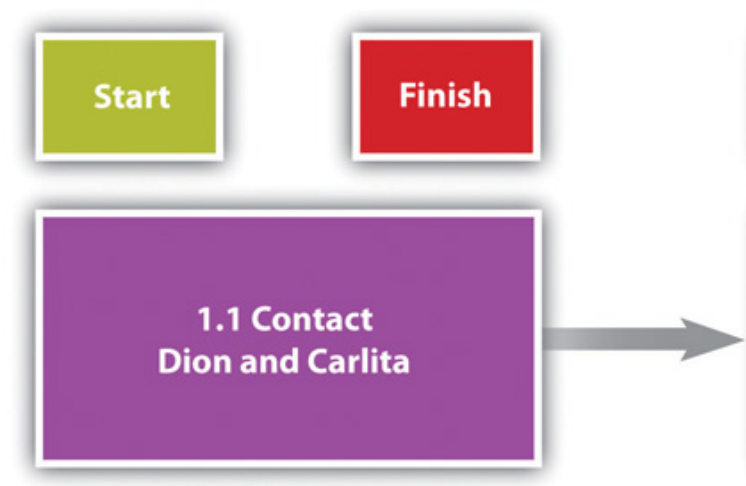

Predecessor

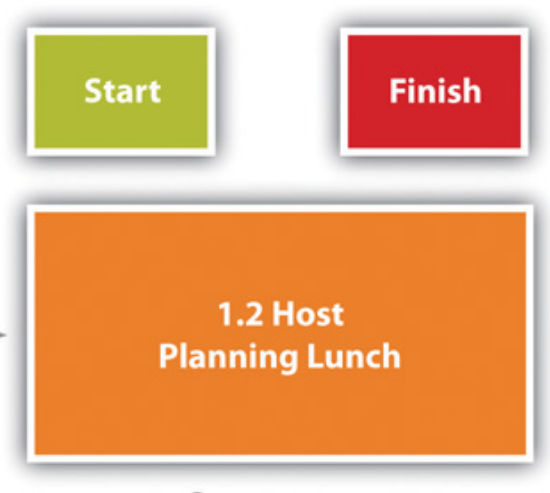

Successor

These terms define a relationship that is similar to a family relationship like father and son. The father exists in time before the son. Similarly, each element of the diagram can have predecessor-successor relationships with other elements, just like a father can be the son of someone else. Unlike the biological father-son relationship, activities can have more than one predecessor.

The relationship between a predecessor activity and a successor activity is called a dependency. The successor activity starts after and is dependent on the predecessor activity. Because the conversation with Dion and Carlita must take place before a planning meeting can be scheduled, this is called a natural dependency because the relationship can be inferred logically. Activities that have predecessor-successor relationships occur sequentially - one after the other. Another term for this type of relationship is finish-start, which means the first activity must finish before the next one can start. Refer to the figure above.

Some activities take place concurrently_at the same time. If they must begin at the same time, they have a start-start relationship. If the activities can start at different times but they must finish at the same time, they have a finish-finish relationship. Refer to Figure 8.8.

Figure 8.8 


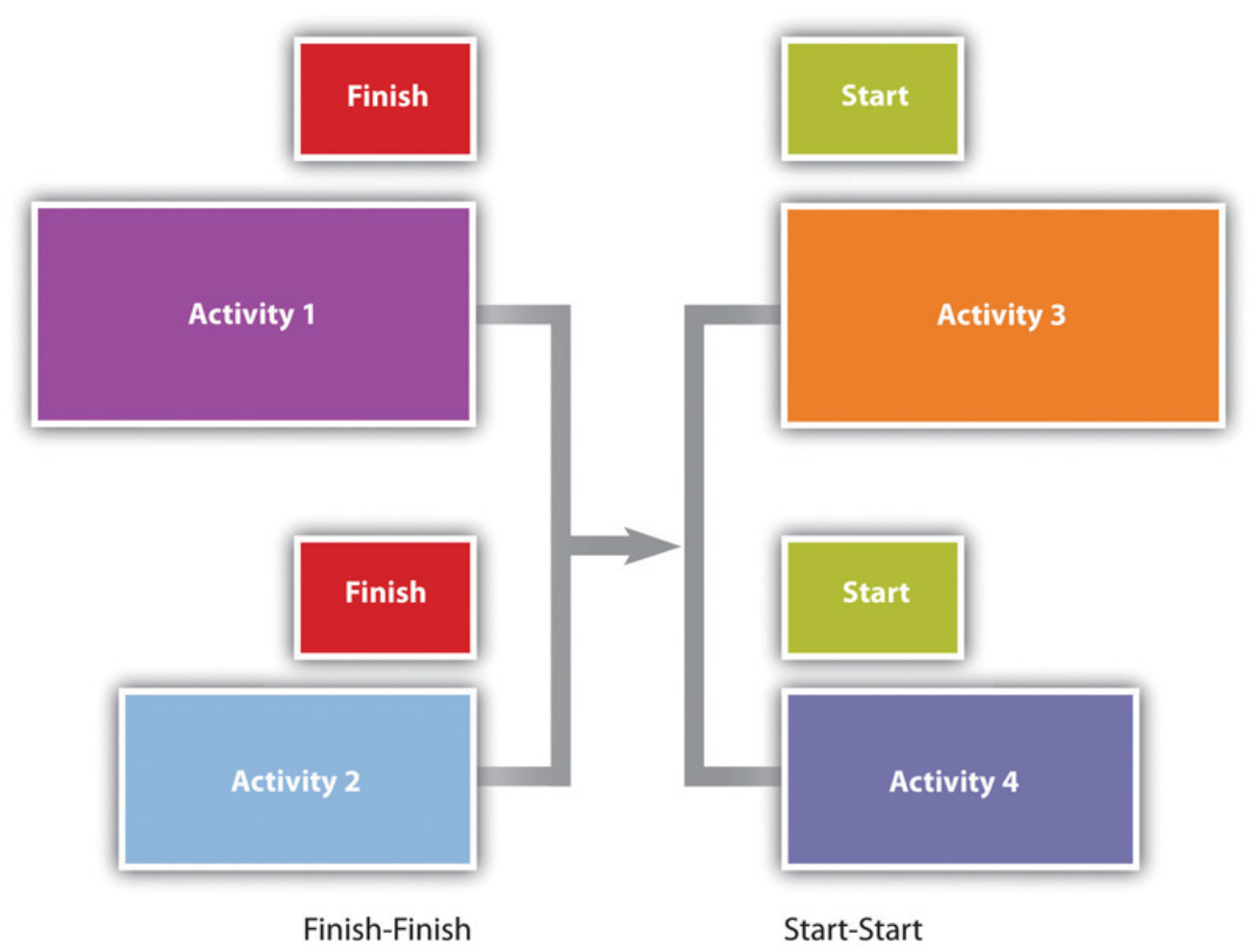

Concurrent activities can be constrained to finish at the same time or start at the same time.

\section{Predecessor Relationships in John's Move}

The figure below shows the activities in John's move with the predecessors identified for the Plan Move and Prepacking groups of activities. Because the finish-start relationship is by far the most common, the type of relationship is assumed to be finish-start unless otherwise mentioned.

Figure 8.9 Outline of Activities with Predecessors Identified

(Predecessors are in parentheses)

1. Plan Move/Project Start

1. Contact Dion and Carlita

2. Host planning lunch (1a)

3. Develop and distribute schedule (1b)

4. Make hotel arrangement in Atlanta (1a)

2. Prepacking

1. Gather packing material 
2. Select moving van company and sign contract

1. Contact 3 moving van companies and get bids (1c)

2. Select company and negotiate a final price (2bi)

3. Sign moving contract (2bii)

3. Pack small delicate items (1c, 2a)

\section{Lag and Lead Times}

Most activities in a network diagram have a finish-start relationship. If a certain amount of time must go by before a successor activity can begin, the required delay is called lag time. For example, concrete does not reach its full strength for several days after it is poured. Lag time is required between the end of the pouring process and the beginning of construction that puts stress on the concrete as diagrammed in Figure 8.10. Similarly, you must allow lag time for payment checks to be processed by the banking system before you can spend the money.

Figure 8.10

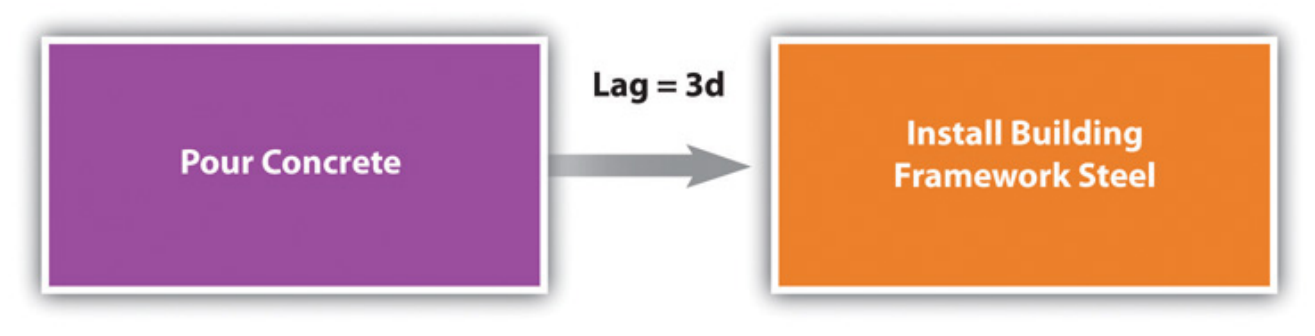

Required time between activities is lag time.

In some cases, the successor activity can overlap the end of its predecessor activity and begin before the predecessor is finished. This is called lead time.

\section{Lead Time in John's Move}

In John's move, you might begin separating the small and delicate items that will be packed in step 2.3 before you get the packing materials in step 2.1 so that when the materials are available, step 2.3 is already partially completed. If the preparing the small items for packing can overlap its predecessor and shortens the time it takes to accomplish both tasks by a day, it has a lead time of one day. 


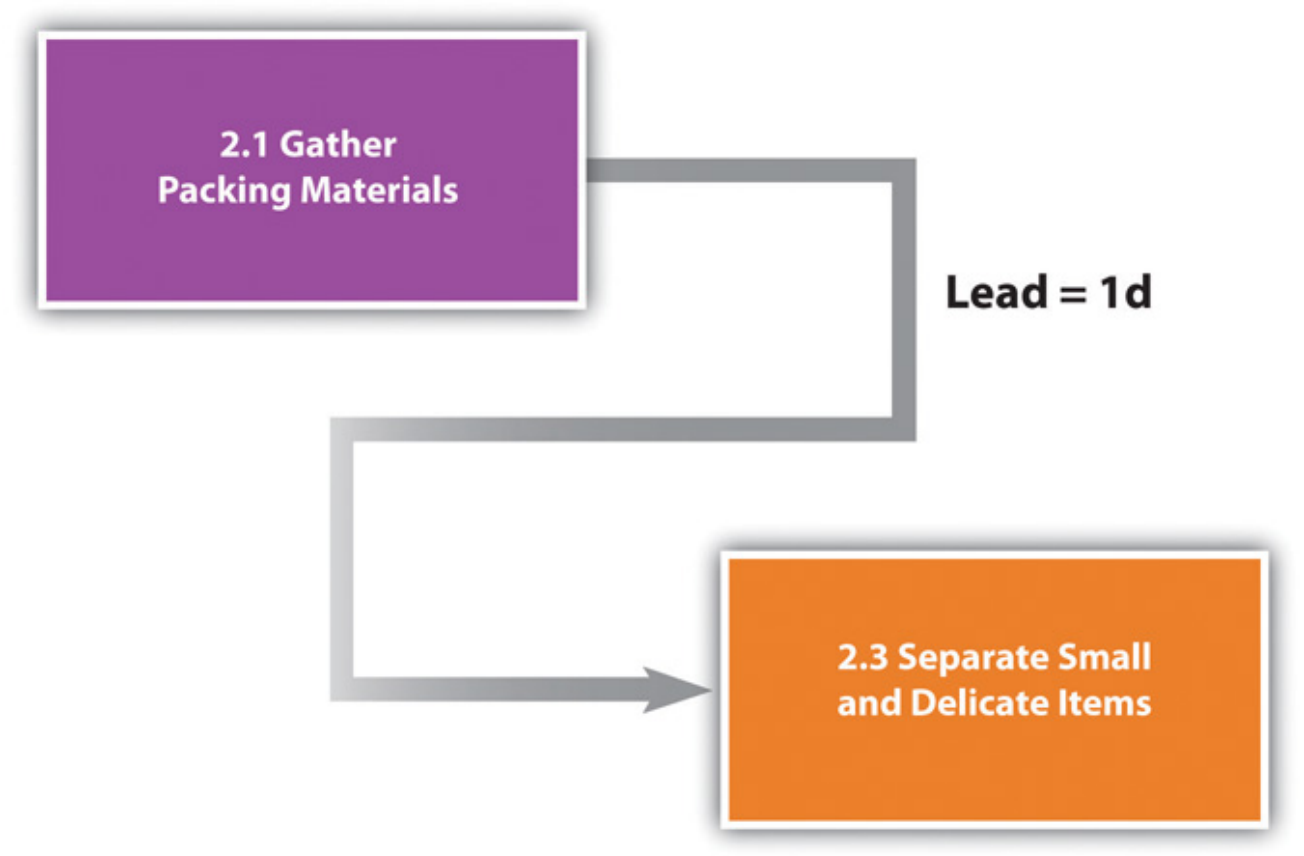

Overlap is called the lead time of the successor activity.

The characteristics and identifiers of an activity are its attributes.

At this point in the process of analyzing John's move, each activity has an identifying code, a short description, predecessors, and lead or lag times, as shown in a partial table of activities in Figure 8.12 "Table of Attributes".

Figure 8.12 Table of Attributes

\begin{tabular}{|l|l|l|l|l|}
\hline Code & Description & Predecessors & Relationships & Lead/Lag \\
\hline $\mathbf{1 a}$ & Contact Dion and Carlita & None & & 0 \\
\hline $\mathbf{1 b}$ & Host planning lunch & 1a & FS (Finish/Start) & 0 \\
\hline $\mathbf{1 c}$ & Develop and distribute schedule & 1b & FS & 0 \\
\hline $\mathbf{1 d}$ & Make hotel arrangement in Atlanta & 1a & FS & 0 \\
\hline $\mathbf{2 a}$ & Gather packing material & None & & 0 \\
\hline $\mathbf{2 b i}$ & Contact moving van companies and get three bids & 1c & FS & 0 \\
\hline 2bii & Select company and get final price & 2bi & FS & 0 \\
\hline 2biii & Sign moving contract & 2bii & FS & 0 \\
\hline 2c & Pac small and delicate items & 1c and 2a & FS and FS & 1 \\
\hline & & & \\
\hline
\end{tabular}

\section{Milestones}

Milestones are significant events in your project. An effective milestone schedule will capture the major 
constraints to the project schedule and provide a summary level overview of the project. Even though milestone events are significant to the project, they consume no resources and have no duration. Milestones are usually indicated on the project schedule with a diamond and often have a vertical line on a time-scaled graph to show the relationship of various schedule paths to the milestone.

In our John's move project, we might create a milestone called "all packing complete" to represent the date when everything is packed and ready for the moving van. Any delay in this date will mean a delay in the arrival of the moving van in Chicago, a delay in the arrival of the moving van in Atlanta, and a delay of all the unpacking and other downstream activities. See Figure 8.13 “Gantt Chart”.

\section{Graphic Representations}

Relationships between activities are easier to recognize if they are presented using graphics such as bar charts or a network of connected boxes.

\section{Bar Charts}

The type of bar chart used to illustrate activity relationships in a project is the Gantt chart. The Gantt chart was developed by Henry Gantt and used on major projects, including building the Hoover Dam and the U.S. interstate highway system (Reference.com, 2009). The Gantt chart, also called a bar chart, is a time-scaled graphic that represents each activity with a bar that reflects the duration, start, and finish time, as shown in Figure 8.13 “Gantt Chart”.

Figure 8.13 Gantt Chart

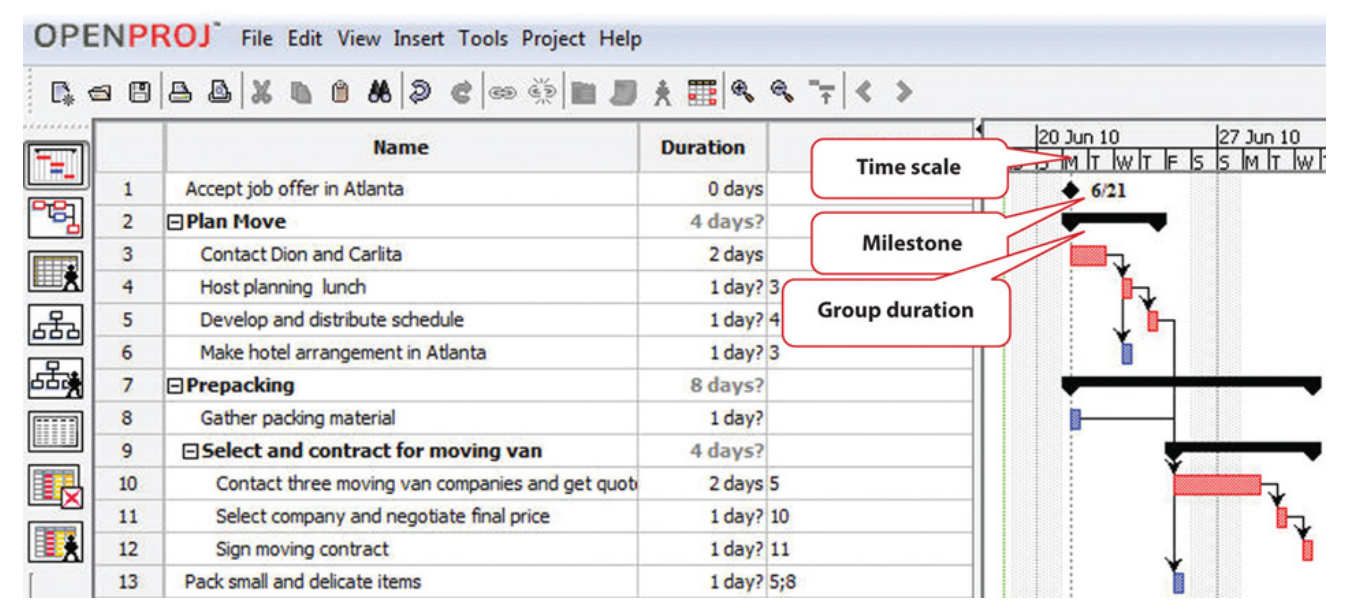

A Gantt chart is easy to read and provides sufficient information for project team members to plan activities within a short time frame. For many larger projects, a two-week bar chart, extracted from the larger master schedule, provides the information needed for team members and contractors to coordinate activity details. The Gantt chart provides information for simple planning but is limited because a Gantt chart does not illustrate complex relationships well. 


\section{Network Diagrams}

People recognize relationships and patterns more effectively when they look at diagrams like the one in Figure 8.14 "Project Network Diagram". The precedence diagram method (PDM) is a technique for graphically displaying the logic of the schedule by placing the activities in boxes with arrows between them to show the precedence-successor relationships. The boxes in this type of diagram are called nodes and the arrows indicate finish-start relationships. Compare the diagram in Figure 8.14 "Project Network Diagram” to the outline in Figure 8.9 "Outline of Activities with Predecessors Identified” to see how much easier it is to trace a sequential path from one activity to the next in the precedence diagram. This type of diagram is also called a project network diagram.

Figure 8.14 Project Network Diagram

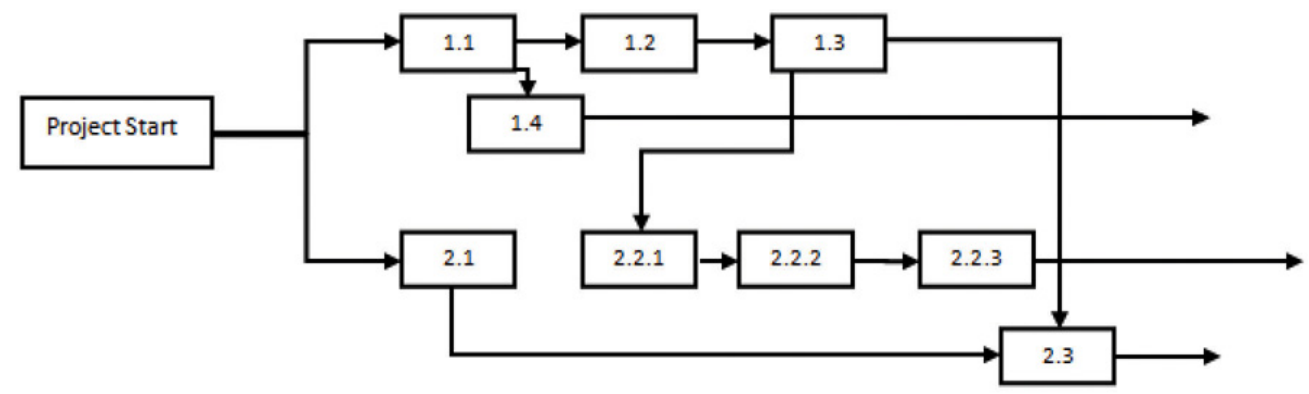

\section{Key Takeaways}

- The work breakdown structure is a list of activities, including estimates of their durations, their relationships with others, and the resources assigned to them.

- Bar charts are used to indicate durations and sequencing where the relationships are simple. Network diagrams are used to show complex relationships between activities.

\section{Exercises}

1. What is work breakdown structure?

2. If two activities are concurrent and they have the same completion date, they have a relationship.

3. A calendar that shows when a person, facility, or key piece of equipment is available is a calendar.

4. What is the advantage of a network diagram over a bar chart for illustrating the critical path? 


\section{Compare Charts}

Perceptions of graphic representations of data differ among individuals. Consider the bar chart and network diagram in this section. Describe which type of chart conveys the important aspects of the project best to you personally and why you think that is the case. Alternatively, describe which aspects of the project are conveyed to you best by which type of chart.

\section{References}

Project Management Institute, Inc., A Guide to the Project Management Body of Knowledge (PMBOK Guide), 4th ed. (Newtown Square, PA: Project Management Institute, Inc., 2008), 129.

Reference.com, “Henry Gantt,” http://www.reference.com/browse/wiki/Henry_Gantt (accessed July 27, 2009). 


\subsection{Critical Path and Float}

\section{Learning Objective}

1. Calculate critical path, project float, early start dates, and late start dates.

The critical path is the path through the network that results in the latest completion date of the project.

If any activity on the critical path is delayed, the completion of the project will be delayed by an equal amount. It is the path with the greatest total duration. To determine the critical path, add the amount of time estimated for the duration of each activity to the previous activity to determine which path through the network has the longest total duration, as shown in Figure 8.15 "Critical Path". Durations are indicated in days. The critical path through these tasks takes at least eight days. Activities on the critical path are shaded.

Figure 8.15 Critical Path

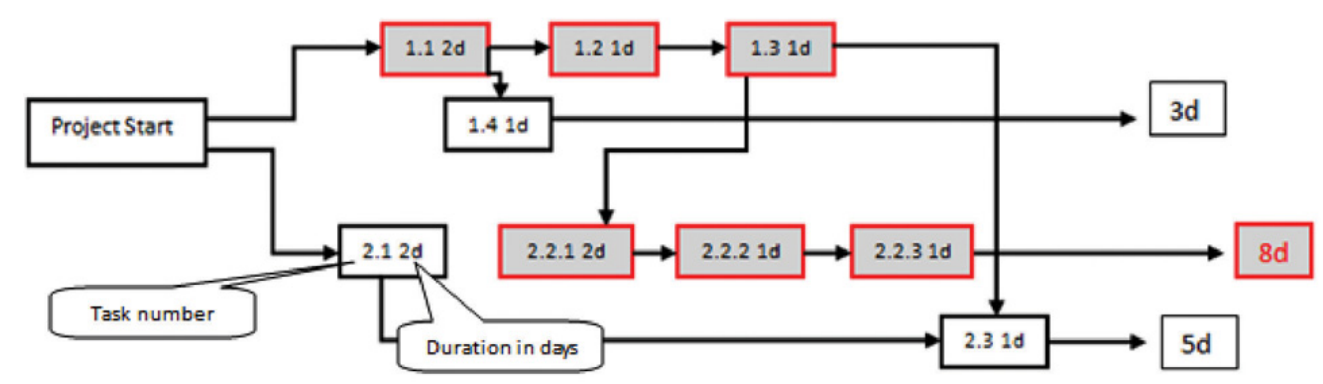

\section{Early Start Dates}

Starting dates can be assigned to each activity by doing a forward pass proceeding from left to right in the network diagram beginning with the project start date. The dates derived by this method are the early start (ES) dates. The early start date for an activity is the earliest date the activity can begin. The estimate considers durations and resource availability calendars. To calculate early start dates, begin with the project start date and assign that date as the start date of activities that have no predecessor activities. Follow these steps to calculate the early start dates of subsequent activities, assuming finish-start relationships:

- Add the predecessor activity's duration to its start date.

- Add the lag time or subtract the lead time. 
- Refer to the resource calendar (or calendars) that applies to the people and equipment necessary for the activity, and add the number of off-days that the activity would span on those calendars.

- Assign the calculated date as the early start date of the successor activity.

\section{Forward Pass for John's Move}

John begins planning his move to Atlanta the same day he accepts the job. The start date in this example is Monday, November 29, 2010. Tasks 1.1 and 2.1 can both start on that day, so the early start dates for tasks 1.1 and 2.1 are November 29. John calculates the early start date for the activities. A partial list is provided below. Compare the figure below and the figure in the next sidebar. Observe that John is willing to work on weekends, but activity 2.2.3 is delayed by two days because one of the moving companies did not provide bids on the weekend. Observe that activity 2.3 has a lead time of one day, but that relationship is between activity 2.1 and 2.3. The network path from activity 1.3 is longer, so the lead time with activity 2.1 is not considered in calculating the early start date of 2.3 .

Figure 8.16 Early Start Dates Determined by a Forward Pass

\begin{tabular}{|c|c|c|c|c|c|c|c|}
\hline Code & Description & Predecessors & Relationships & $\begin{array}{l}\text { Lead/ } \\
\text { Lag }\end{array}$ & Resources & Duration & $\begin{array}{l}\text { Early Start } \\
\text { Date }\end{array}$ \\
\hline $1 \mathbf{a}$ & Contact Dion and Carlita & None & & 0 & $\begin{array}{l}\text { J,D,C } \\
.25 \mathrm{hr} \\
\text { each }\end{array}$ & $2 \mathrm{~d}$ & $11 / 29$ \\
\hline $1 b$ & Host planning lunch & $1 \mathrm{a}$ & $\begin{array}{l}\text { FS } \\
\text { (Finish/Start) }\end{array}$ & 0 & $\begin{array}{l}\text { J,D,C } \\
2 \text { hr each }\end{array}$ & $1 \mathrm{~d}$ & $12 / 1$ \\
\hline 1c & $\begin{array}{l}\text { Develop and distribute } \\
\text { schedule }\end{array}$ & $1 b$ & FS & 0 & $\mathrm{~J} 2 \mathrm{hr}$ & $1 \mathrm{~d}$ & $12 / 2$ \\
\hline 1d & $\begin{array}{l}\text { Make hotel arrangement in } \\
\text { Atlanta }\end{array}$ & $1 \mathrm{a}$ & FS & 0 & $\mathrm{~J} .5 \mathrm{hr}$ & $1 \mathrm{~d}$ & $11 / 30$ \\
\hline $2 \mathbf{a}$ & Gather packing material & None & & 0 & D 2 hr & $1 \mathrm{~d}$ & $11 / 29$ \\
\hline $2 b \mathbf{b}$ & $\begin{array}{l}\text { Contact van companies } \\
\text { and get } 3 \text { bids }\end{array}$ & $1 \mathrm{c}$ & FS & & & $2 \mathrm{~d}$ & $12 / 3$ \\
\hline 2bii & 2bi & FS & 0 & $\mathrm{~J} .5 \mathrm{hr}$ & $1 \mathrm{~d}$ & $12 / 7$ & \\
\hline 2biii & Sign moving contract & 2bii & FS & & & $1 \mathrm{~d}$ & $12 / 8$ \\
\hline 2c & $\begin{array}{l}\text { Pack small and delicate } \\
\text { items }\end{array}$ & $\begin{array}{l}1 \mathrm{c} \\
2 \mathrm{a}\end{array}$ & $\begin{array}{l}\text { FS } \\
\text { FS }\end{array}$ & -1 & C 6 hr & $1 \mathrm{~d}$ & $12 / 3$ \\
\hline
\end{tabular}

Doing this process manually is error prone and time consuming. Fortunately, there are computer programs to assist in the process, but the project manager must understand the process well enough to recognize computer errors. Computer software must be combined with common sense or good judgment. 


\section{Float}

Float, sometimes called slack, is the amount of time an activity, network path, or project can be delayed from the early start without changing the completion date of the project.

\section{Total Float}

Total float is the difference between the finish date of the last activity on the critical path and the project completion date. Any delay in an activity on the critical path would reduce the amount of total float available on the project. A project can also have negative float, which means the calculated completion date of the last activity is later than the targeted completion date established at the beginning of the project.

\section{Float in John's Move}

The last activity in John's move has an early start date of December 28 and a duration of one day. John could start work on Wednesday, December 29. John's first day at work is Monday, January 3, so the project has a total float of five days.

Figure 8.17 Total Project Float

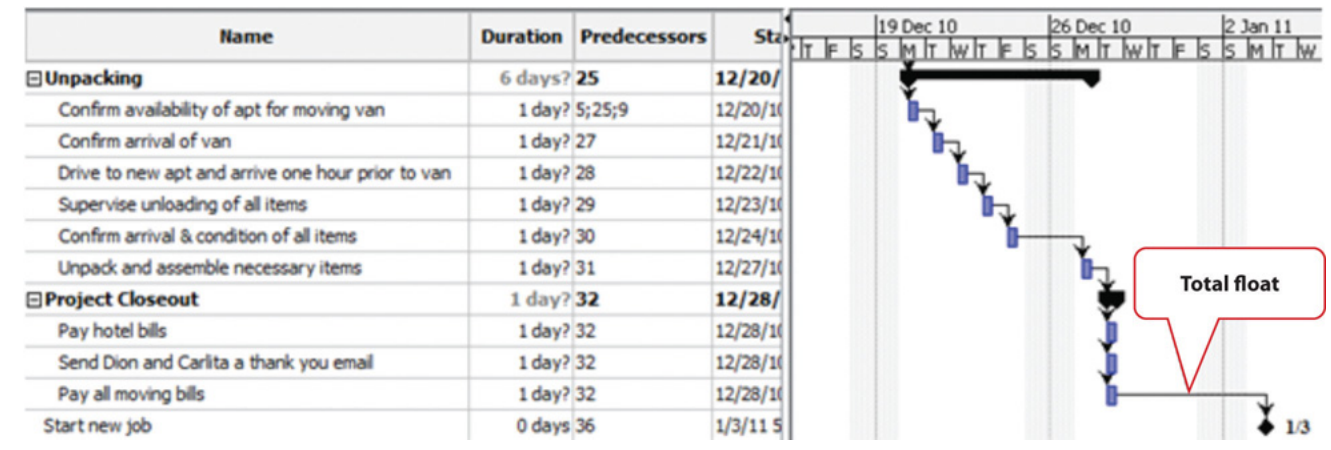

\section{Late Start Dates}

The next step is to work through the network diagram from right to left beginning with the mandated completion date, which is a milestone that is set in the project plan. Subtract the duration of each activity in each path to determine the latest date the activity could begin and still meet the project completion date. Resource calendars must be considered in the backward pass as well as the forward pass.

To calculate late start dates, begin with the project completion milestone and assign that date as the finish 
date of its predecessor activities. Follow these steps to calculate the late start dates of predecessor activities, assuming finish-start relationships:

- Subtract the predecessor activity's duration from its late finish date.

- Subtract the lag time or add the lead time to the late finish date.

- Refer to the resource calendar (or calendars) that applies to the people and equipment necessary for the activity, and subtract the number of off days that the activity would span on those calendars.

- Assign the calculated date as the late start date of the predecessor activity.

The difference between the early start date and the late start date for activities on the critical path is usually the same as the total float, unless the activities are affected by the resource calendars differently in the forward and backward pass. For example, if a piece of key equipment is only available for a few days, activities that depend on it have the same start and finish dates in the forward and backward passes.

\section{Free Float}

If activities that are not on the critical path have a difference between their early start date and their late start date, those activities can be delayed without affecting the project completion date. The float on those activities is called free float.

\section{Key Takeaway}

- To calculate total project float, begin at the start date and add the duration of each activity in each possible path through the network diagram, including nonworking days from the resource calendars, to determine the early project end date. The longest path through the network is the critical path. The difference between the early end date and the required completion date of the project is the total project float, and the start date of each activity is the early start date. To calculate the late start dates, begin with the required project completion date and work backward, subtracting the duration of each activity through each possible pathway.

\section{Exercises}

1. The path through the network diagram that has the longest total duration is the path.

2. The difference between the sum of the activity durations along the critical path and the project completion date is the project

3. If two sequential activities overlap and the successor activity can begin three days before the pre- 
decessor begins, those three days are called time.

4. If the last activity in the critical path has a completion date that is five days later than the project completion date, the project has a (two words) of five days.

5. What is the difference between free float and project float?

6. If an activity has a duration of three days, how do you calculate the finish date in a way that considers availability of the resources for that activity?

7. What would be an example of lag time between two activities?

\section{Project Float}

Consider a project in which you have been involved that experienced unexpected delays. Describe how the project's manager dealt with the delays. Specifically, consider if the delay was due to an activity that was on the project's critical path, if people or resources were diverted from other tasks, or if free float existed in the original schedule. Describe the ultimate effect on the project's completion date. 


\subsection{Managing the Schedule}

\section{Learning Objectives}

1. Describe methods of tracking and reporting progress.

2. Define resource leveling.

3. Describe methods of accelerating the schedule.

To manage a schedule, the project manager must know how the work is progressing compared to the master schedule and, if necessary, make changes to keep the project on time.

\section{Tracking and Reporting Progress}

Tracking the schedule performance involves measuring the work performed against the work expected to be performed with a given expenditure of resources. Periodic reporting on the progress of the project provides the project management team with information on how the project is performing against expectations and to make decisions and corrections. Accurate measurement of schedule performance requires planning during the early stages of the project to determine the unit of measure and process for tracking progress.

\section{Reporting Percentage Completed}

To determine the percentage of a project that has been completed, the project manager must determine what to measure. Some percentages are misleading. For example, a project that has completed 25 percent of the scheduled activities does not mean that the project is 25 percent complete. In our John's move example, four rooms were to be packed. After the bedroom was packed, packing was not 25 percent complete. The kitchen contained five times as many items and required more delicate, time-consuming packing. John estimated that 40 percent of the items to be packed were in the kitchen, 20 percent in the living room, 20 percent in the bedroom, and the remaining 20 percent in miscellaneous locations. If the unit of measure for these activities is items packed, the packing is only 20 percent complete instead of 25 percent if rooms are the unit of measure.

The unit of measure for tracking schedule progress is related to the estimate. If hours of labor are used as the unit of measure, the percentage of packing is even less because more time is estimated to pack each item in the kitchen. As the project management team estimates the duration for each activity, the 
amount of work to accomplish the tasks is captured in both resources expended and a unit of measure for tracking progress. The unit of measure is related to the type of project. On a software development project, the unit of measure may be lines of code written. The unit of measure that is chosen can affect the quality of the work.

\section{Units of Measure on a Programming Project}

Steve Ballmer of Microsoft recalls early clashes with IBM over the unit of measure used to determine how much Microsoft would get paid for its work.

In IBM there's a religion in software that says you have to count K-LOCs, and a K-LOC is a thousand lines of code. How big a project is it? Oh, it's sort of a $10 \mathrm{~K}$-LOC project. This is a $20 \mathrm{~K}-\mathrm{LOCer}$. And this is 50 K-LOCs. And IBM wanted to sort of make it the religion about how we got paid. How much money we made off OS/2, how much they did. How many K-LOCs did you do? And we kept trying to convince them-hey, if we have-a developer's got a good idea and he can get something done in 4 K-LOCs instead of 20 K-LOCs, should we make less money? Because he's made something smaller and faster, less KLOC. K-LOCs, K-LOCs, that's the methodology. Ugh anyway, that always makes my back just crinkle up at the thought of the whole thing (Cringely, 2009).

In this case, IBM's insistence on using thousands of lines of code as the unit of measure did not reward Microsoft for writing smaller code that would run faster. Microsoft and IBM cancelled their joint project for writing an operating system named OS/2. Microsoft wrote Windows, and IBM's OS/2 operating system was not able to compete with it successfully.

On a construction project, a unit of measure may be yards of concrete poured, and on a training project, the unit of measure may be the class curriculums developed or the students taught.

\section{Managing Schedules Using Milestones}

Milestones provide the opportunity for project management to focus on completing activities that will have the greatest impact on the schedule. On complex projects, focusing on the milestones is useful for communicating important dates to the entire project team. Project team members can then adjust their efforts to complete the activities connected to the milestone events.

Many project leaders believe that time lost on early activities can be made up toward the end of the project. Hard decisions about paying overtime and working weekends are often delayed until the end of the project when the pressure to complete the project on time becomes much stronger. Project managers who focus on milestone events create a sense of urgency to meet the milestone deadlines and spread the urgency to complete the project over the life of the project. Projects that meet milestone dates are more likely to meet project completion dates. 


\section{Informing Stakeholders}

A schedule update is distributed regularly to provide project stakeholders with an assessment of the progress of the project against the master schedule. This updated schedule is called the current schedule. The current schedule provides new start and end dates for all activities and the project. Calculations based on the current schedule may result in a new critical path and subsequent changes in the project execution plan.

The project team develops an understanding of the project productivity by comparing the current schedule to the original schedule. If the schedule is behind original estimates, the project team conducts an assessment of the causes of the schedule slippage and develops a plan to address the changes to the project. The project management team typically has several alternatives for addressing changes to the project situation. Selecting the right alternative requires good information.

\section{Resource Leveling}

The schedule of activities is constrained by the availability of resources. If you apply the resource calendar to each activity to be sure the people and equipment are available on those dates, you can still miss an important constraint. If there are several activities that use a particular person's time on the same days, that person could end up with too many activities scheduled for the same days and very little on other days. If key people are overloaded, the activities to which they are assigned might not be completed on time. Managing the schedule of activities to ensure that enough resources are available to complete each task by distributing the work load is called resource leveling. Activities to which that person is assigned and that have free float can be delayed to reduce work overload of key people.

\section{Accelerating the Schedule}

The project manager must know how to accelerate a schedule to compensate for unanticipated events that delay critical activities or to accommodate changes in the project completion date. Compressing or crashing the schedule are terms used to describe the various techniques used to shorten the project schedule. Project managers utilize several techniques to keep projects on schedule.

\section{Contingency Resources}

One method of accelerating the schedule is to add activities to the critical path that are empty or that are optional. If the project is behind schedule, the time can be made up by dropping these activities. This extra time that is built into the schedule is called contingency time, buffer, or reserve time. 


\section{Reassigning Resources}

Activities that are not on the critical path that have free float can be delayed without delaying the end date of the project if they start by the late start date. Project managers can divert some resources from activities with free float to activities on the critical path without delaying the completion of the project.

\section{Changing Scope}

The unit cost of work to be performed on a project is calculated at the beginning of the project based on the execution strategy of the project to meet the project completion date. If the project completion date is moved up, then the unit cost of work will likely increase. Conversely, a project team may be able to save money by extending the project end date. With more time, the project team may be able to schedule activities in such a way to reduce their costs. For example, an activity requiring overtime to be paid can now pay the labor at normal rates, saving the overtime premium. Changing elements of the master schedule means a change in scope. Scope changes often affect costs and require agreement by the parties who signed the original scope documents.

\section{Additional Resources}

Another option is to allocate funds that can be used to add resources if necessary. Available resources can be increased by adding overtime to existing resource calendars or by hiring additional contract workers or renting additional equipment.

\section{Adding Resources to the Dreamliner Project}

When Boeing sales of the new 878 Dreamliner Airplane exceeded expectations, contractors who were building the plane were asked to increase production while maintaining all quality and safety requirements. All contractors involved in the plane production were affected by this change.

One project team was responsible for developing and delivering training to the new employees who would be building the fuselage of the Dreamliner. Training for new employees had to be complete three months early and the project team developed an execution strategy to meet the new deadlines. The project had a month of float, so the project accelerated the schedule by two months. The team authorized overtime from forty to fifty hours a week for team members working activities on the critical path. The project team leased additional space and hired contractors to perform selected work packages on the critical path and delayed the production of library quality documents until after the critical dates on the project. Authorizing overtime and hiring contractors added a 15 percent cost to the project. Overtime and the procurement of additional contract help was authorized only for work packages on the critical path because work not on the critical path would not accelerate the schedule.

A concrete contractor on a construction project may be scheduled to lay one thousand yards of a building foun- 
dation by pouring one hundred yards a day for ten days. Foundations are on the critical path, and because of rain, the project is three days behind schedule. The project manager asked the concrete contractor to bring in a second crew and pour two hundred yards a day, and the work is complete in five days.

\section{Changing Quality}

Another option for accelerating the schedule is the changing of the quality specifications of the product. This is usually done as a scope change.

\section{Making Up Time by Reducing Quality}

At a midwestern university, a new building was being built, but it was behind schedule. To speed up the installation of the heating and cooling equipment, it was decided to make the zones of control larger, which meant that each floor would have fewer points where temperature was sensed and controlled and fewer air flow control boxes. The contract did not specify the zone size or how many control points were required on each floor of the building, so this change did not require a change in scope. As a result, when the sun is coming in on the south side of the building, those rooms get as much heat or cooling as the rooms on the north side, so they are often too hot. If the single temperature controller on each floor is set to a lower temperature, the rooms on the north side are too cold. The client for the building did not realize this change had been made until they were in the building for several months and the project was completed.

\section{Key Takeaways}

- Progress can be measured by determining the percentage of resources expended, completion of activities by scheduled dates, milestones achieved, or fraction of activities accomplished. Standards used to measure progress, particularly when partial payment to contractors is concerned, should be specified in contract documents.

- Resource leveling is reallocating people and equipment to remove periods of overuse or underuse.

- Unplanned delays and costs can be anticipated by including contingency time and budget amounts where needed to keep the schedule on time. Resource allocation and resource calendars should be examined to determine if a resource is overcommitted. Free float can be used to delay noncritical activities that use the same resource to allocate its time more evenly. If it is necessary to accelerate the schedule, activities that are not on the critical path can be delayed using their free float and their resources can be moved to activities on the critical path to complete them sooner. Contingency resources can be committed to speeding up the activities. If necessary, the scope can be changed to bring in additional resources or lower the quality. 


\section{Exercises}

1. Accelerating the project schedule is also known as the project.

2. Extra amounts of time and money that are built into the schedule to buffer against delays and extra costs are called time or funds.

3. What might be a drawback to a reporting method that stated project progress as a fraction of activities completed?

4. How does a manager accelerate a project by using free float?

Progress Reports

From the client's point of view, describe what you think would be the advantages of each type of progress measurement.

\section{References}

Cringely, R. X., Triumph of the Nerds, June 1996, http://www.pbs.org/nerds/part2.html (accessed July 27, 2009). 


\subsection{Project Scheduling Software}

\section{Learning Objectives}

1. Describe the relationship between the choice of software and project complexity.

2. Identify the features that should be considered when selecting software for project management.

Low-complexity projects can be managed with lists of activities on paper or by using an outline in word processing or spreadsheet software. This software is inadequate for tracking complex projects. Fortunately, there are several dedicated software programs that keep track of the complex relationships between activities and resources.

\section{Appropriate to Project Complexity}

Simple projects can be tracked using general purpose word processing and spreadsheet software like those available in Microsoft Office or OpenOffice. Medium-complexity projects benefit from dedicated project management software such as Microsoft Project and OpenProject. Complex projects require software that can track the interactions of thousands of tasks and produce sophisticated reports such as Oracle’s P6.

\section{Features}

There are dozens of computer software programs available with a wide range of prices. Some open source software programs are free, but others cost up to a thousand dollars. There are several considerations for selecting a project management software besides price.

\section{Currently Used Software}

Use software that is already in use and with which most team members are already familiar. If software that is used by most team members is appropriate to the complexity of your project, it is the default choice. It is also valuable to know what software is used by key vendors or project partners so files can be exchanged electronically in the same format. 


\section{Basic Features}

Any project management software that is selected must have the ability to track and display basic features such as the following:

- Durations

- Relationships

- Milestones

- Start and end dates

- Resource calendars

- Graphic displays using Gantt and network charts

\section{Collaboration}

Team members should be able to view the project schedule. Some software products require the use of expensive proprietary software that runs on the company's server and that will allow several different team members to use the same schedule and restricts the use of the software to team members who have access to the company's computer system. Other software products use a server on the Internet that is open to team members and vendors who have valid passwords.

\section{Advanced Features}

For more complex projects, look for advanced features, such as the following:

- Issue tracking that tracks problems, actions, and resolutions

- Project portfolio management that tracks and compares groups of related projects

- Automatic resource leveling and alerts when a resource is overscheduled

- Document management feature that tracks contracts, bids, scope changes, and incidents

\section{Key Takeaways}

- Medium- to high-complexity projects usually require the use of software that is designed specifically for managing projects.

- Features to look for when choosing project management software include (1) compatibility with existing software at the company or its vendors, (2) basic features for managing medium-com- 
plexity projects, (3) a method for collaboration between team members, and (4) if needed, advanced features for managing multiple projects.

\section{Exercises}

1. When choosing software, the new software should be with the software currently in use and with the software used by vendors and partners.

2. How does the complexity of the project affect the choice of software used to manage it?

3. What is an example of an advanced feature that is available for managing the most complex projects? Explain why this feature is needed for complex projects.

\section{Learning New Software}

Describe the methods that work best for you when you learn a new computer program, such as self-directed exploration, a textbook, self-paced tutorials, or organized classes with an instructor. If you wanted to require that all the members of your ten-person team use project management software that was new to all of them, how would you recommend that they learn the software? 


\subsection{Exercises}

Exercises at the end of the chapter are designed to strengthen your understanding and retention of the information recently acquired in the chapter.

\section{Essay Questions}

Write several paragraphs to provide more in-depth analysis and consideration when answering the following questions.

1. Compare the Gantt and Network charts. Describe the uses of each type of chart.

2. Choose a project with which you are familiar (it could be a simple project like John's move) and describe how the project could be crashed using each of the methods described in the text.

3. Describe what size project could be done using general purpose word processing and spreadsheet software and how you could structure the data in those documents to make it easier to transfer that data into a project management software, if necessary.

\section{Discussion}

The exercises in this section are designed to promote exchange of information among students in the classroom or in an online discussion. The exercises are more open ended, which means that what you find might be completely different from what your classmates find, and you can all benefit by sharing what you have learned.

1. Describe a personal experience where the average amount of work required of you was appropriate but the scheduling of that work was so uneven that there were periods when you could not get the work done on time and other periods when you did not have enough to do. Describe how you would have used resource leveling and free float to distribute your workload if you had been the manager. Consider the situations and solutions offered by classmates and suggest other ways they could have distributed their workloads more evenly.

2. Describe your experience working with a spreadsheet to manage data such as expenses or activities. How would the ability to treat them like data by sorting and filtering help you to prepare reports? 


\subsection{Software and Technology Exercises}

\section{Learning Objectives}

1. Use dedicated project management software to manage changes to the work breakdown structure (WBS).

2. Use the outline and subtotal features in a spreadsheet to create a low-complexity WBS.

3. Use the outline feature in a word processor to create a low-complexity WBS.

\section{Using Dedicated Project Management Software}

General purpose software such as word processing or spreadsheet programs are not capable of managing changes in relationships between activities or determining the critical path. They might suffice for the simplest projects, but more sophisticated interactive programs are needed for determining the effects of changes to interconnected activities. Small projects performed by groups with limited budgets can use open-source software such as OpenProj.

To complete this exercise, you must have permission to download and install software on your computer or use a computer that has OpenProj installed on it.

\section{Install OpenProj}

Complete the exercise by following these instructions:

1. Open a web browser and go to http://openproj.org. The program may be downloaded from this site, as shown in Figure 8.18 "Single User and Collaborative Versions".

Figure 8.18 Single User and Collaborative Versions 


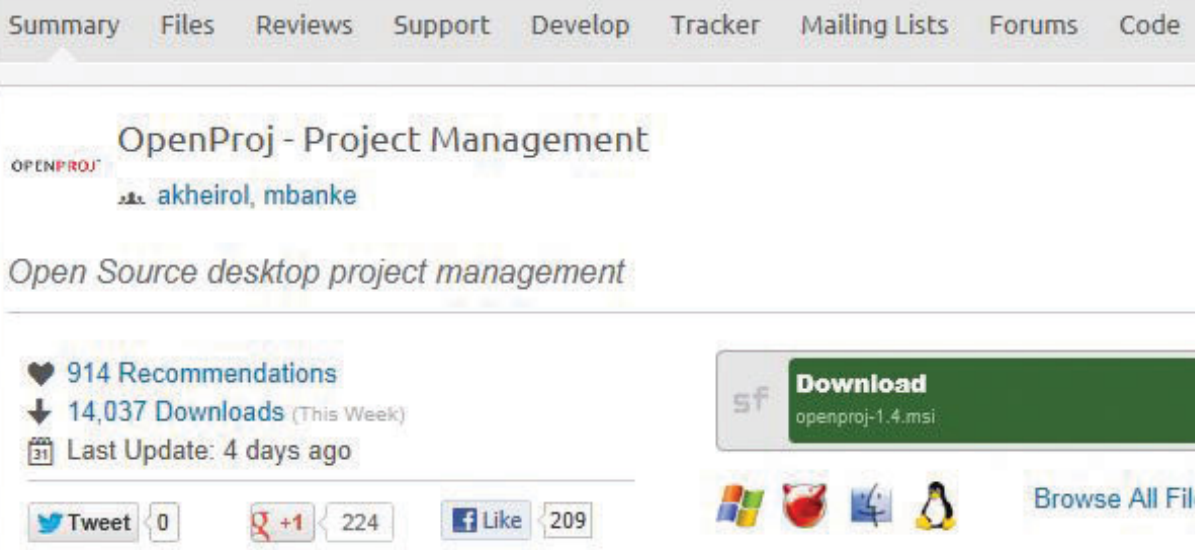

Source: Courtesy of Serena Software.

OpenProj is an open-source project management software that resembles Microsoft Project.

2. Click the Download now button. You must have administrative privileges to install software on the computer you are using.

3. Click the arrow next to the Save button, and then save this program to your computer in a location where you can find it again.

4. Open Windows explorer or your file finder program, locate the file you downloaded, and then double-click on it. Run the installation program and follow the directions on the screen.

Figure 8.19 Single User and Collaborative Versions

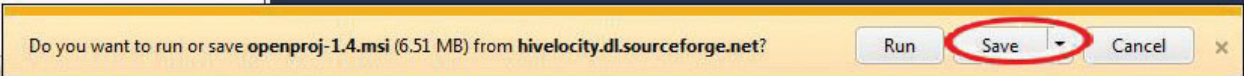

Source: Courtesy of Serena Software.

5. Open Windows explorer or your file finder program, locate the file you downloaded, and then double-click on it. Run the installation program and follow the directions on the screen.

6. After OpenProj is installed, start the program. Choose to create a new project. In the New Project dialog box, in the Project Name box, type Ch08StudentName replacing StudentName with your name without spaces.

7. In the Manager box, enter your name. The current date will display in the Start Date box by default. Your date will differ from the example shown in Figure 8.20 "Identify the Project and Its Manager”.

Figure 8.20 Identify the Project and Its Manager 
262 [Author removed at request of original publisher]

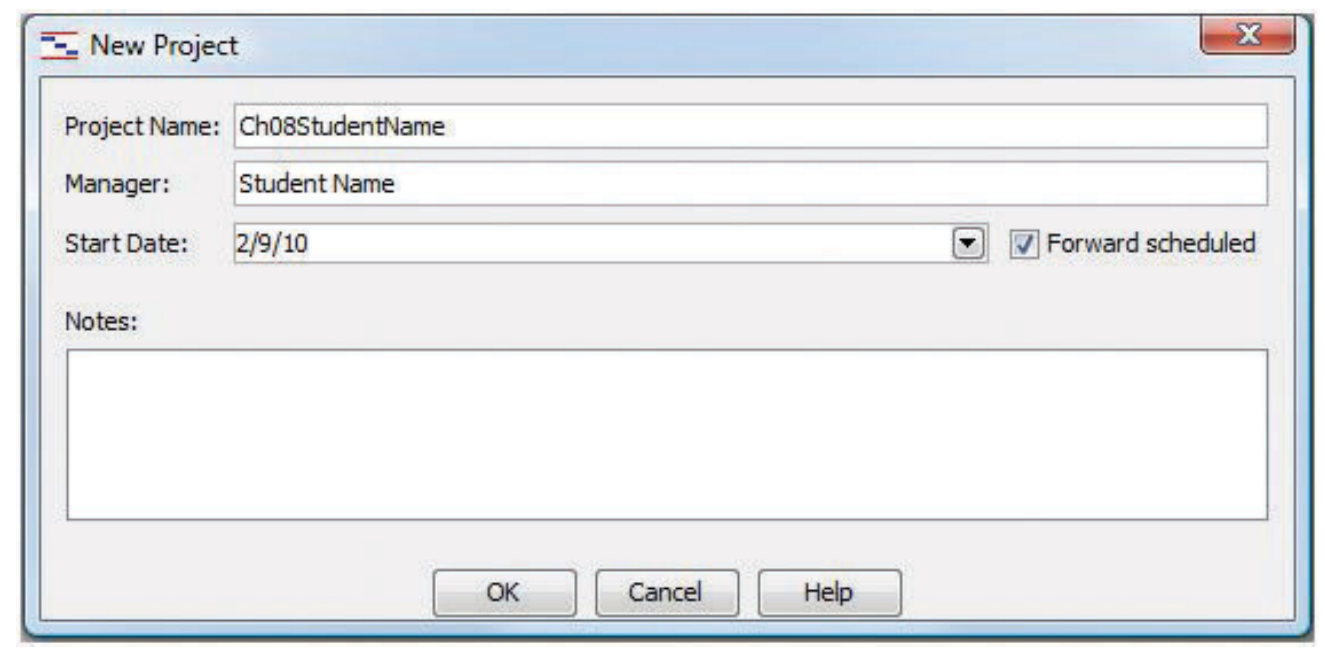

Source: Courtesy of Serena Software.

8. Capture this screen. Paste it into a blank word processing document named Ch08OpenProjStudentName and save the file using the Word 2003 .doc file format.

9. In OpenProj, click $O K$. Leave this program running for use in the next section.

\section{Import WBS from Excel}

1. Use Windows Explorer to navigate to the location where the supplemental files for this chapter are stored. Download the Excel spreadsheet Ch08JohnsMove.xls and then open it in Excel.

2. Select cells B3 through C36, as shown in Figure 8.21 "List of Activities and Their Durations Selected in a Spreadsheet”.

3. Copy this range of cells to the clipboard. (Use CTRL $+\mathrm{C}$ in Windows.)

4. Switch to the OpenProj window. In row 1, below Name, click the empty box. Paste the content. (Use CTRL+V in Windows.) The activities and their durations are placed in the project window, as shown in Figure 8.22 "List of Activities and Their Durations Pasted into OpenProj”.

Figure 8.22 List of Activities and Their Durations Pasted into OpenProj 


\begin{tabular}{|c|c|c|c|c|c|c|c|}
\hline \multicolumn{8}{|c|}{ OPENPROJ ${ }^{*}$ File Edit View Insert Tools Project Help } \\
\hline \multicolumn{8}{|l|}{$[*$} \\
\hline & & (1) & Name & Duration & Start & & 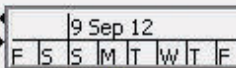 \\
\hline & 1 & \multicolumn{2}{|r|}{ Plan move } & \multicolumn{2}{|c|}{1 day? $9 / 10 / 128: 00 \mathrm{AM}$} & 9/10, & I \\
\hline & 2 & \multicolumn{2}{|r|}{ Contact Dion and Carlita } & \multicolumn{2}{|c|}{2 days $9 / 10 / 128: 00 \mathrm{AM}$} & 9/11, & 更 \\
\hline & 3 & \multicolumn{2}{|r|}{ Host planning lunch } & \multicolumn{2}{|c|}{1 day $9 / 10 / 128: 00 \mathrm{AM}$} & 9/10 & 图 \\
\hline & 4 & \multicolumn{2}{|r|}{ Develop and distribute schec } & \multicolumn{2}{|c|}{1 day $9 / 10 / 128: 00$ AM } & $9 / 10$ & 1 \\
\hline 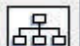 & 5 & & Make hotel arrangement in A & \multicolumn{2}{|c|}{1 day $9 / 10 / 128: 00 \mathrm{AM}$} & $9 / 10$ & 10 \\
\hline & 6 & & Prepacking & \multicolumn{2}{|c|}{1 day? $9 / 10 / 128: 00$ AM } & 9/10, & 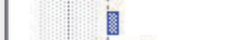 \\
\hline 品串 & 7 & & Gather packing material & \multicolumn{2}{|c|}{2 days $9 / 10 / 128: 00$ AM } & 9/11, & n \\
\hline & 8 & & Contact 3 moving companies & \multicolumn{2}{|c|}{5 days $9 / 10 / 128: 00 \mathrm{AM}$} & 9/14, & \\
\hline
\end{tabular}

Source: Courtesy of Serena Software.

5. Capture this screen and paste it into Ch08OpenProjStudentName.doc.

6. In OpenProj, move the pointer to the vertical line to the right of the Start column heading. Drag this line to the left to minimize the width of the Start column. Repeat this process to minimize the width of the End column to minimize both columns, as shown in Figure 8.23 "Reduce Size of Start and End Columns".

Figure 8.23 Reduce Size of Start and End Columns

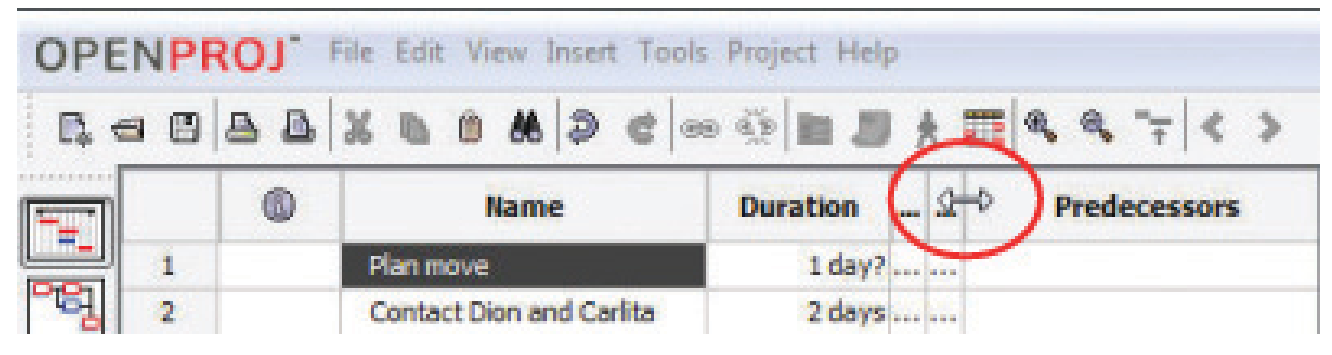

Source: Courtesy of Serena Software.

7. In the first column, click the cell with a 2 in it. Press and hold the Shift key. In the first column, click the cell with a 5 to select rows 2 through 5 .

8. On the toolbar, click the Indent button. The four selected activities are indented as subordinate activities, and the activity in the row above becomes the group name. A black group symbol spans the group in the chart at the right, as shown in Figure 8.24 "Group Defined".

Figure 8.24 Group Defined 


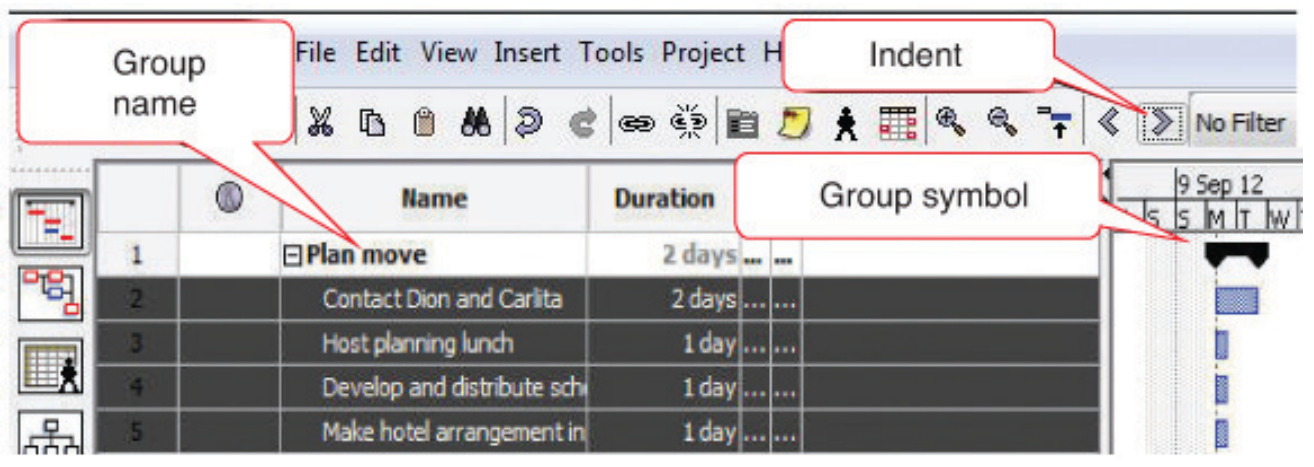

Source: Courtesy of Serena Software.

9. In the Predecessor column, in rows 3-5, type 2, 3, and 2.

The Gantt chart at the right adjusts the positions of the bars automatically and connects them with arrows to indicate their finish-start relationship, as shown in Figure 8.25 "List of Activities and Their Durations Selected in a Spreadsheet”. Notice that Saturdays and Sundays are gray. They are not included as workdays. This will be addressed in a later step.

Figure 8.25 List of Activities and Their Durations Selected in a Spreadsheet

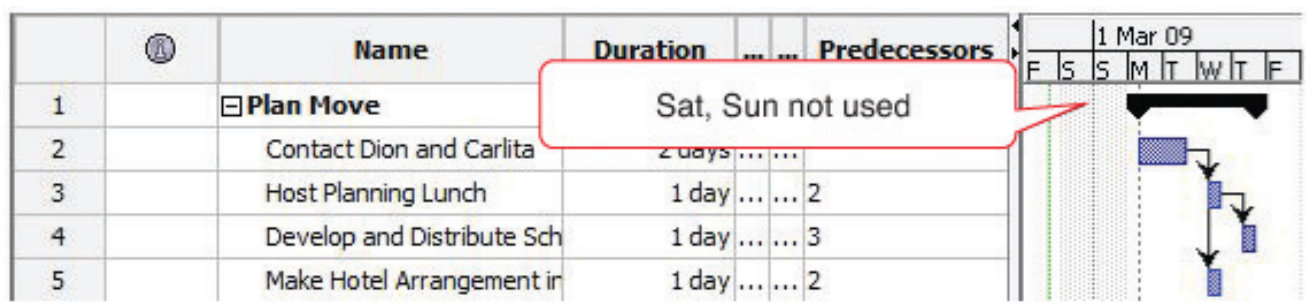

Source: Courtesy of Serena Software.

10. Repeat this process to indent the activities under the Prepacking, Packing, Moving, Unpacking, and Project Closeout headings.

11. Indent activities 16-19 another level to make them subactivities under Pack Apartment.

12. Fill in the remaining predecessors. Refer to the Predecessors column on the John's Move worksheet or Figure 8.25 "List of Activities and Their Durations Selected in a Spreadsheet" . Notice where two predecessors are indicated, they are separated by a semicolon. Notice that activities that span the weekend days are extended by two days, as shown in Figure 8.26 "Bar Chart Showing Durations and Relationships”.

Figure 8.26 Bar Chart Showing Durations and Relationships 


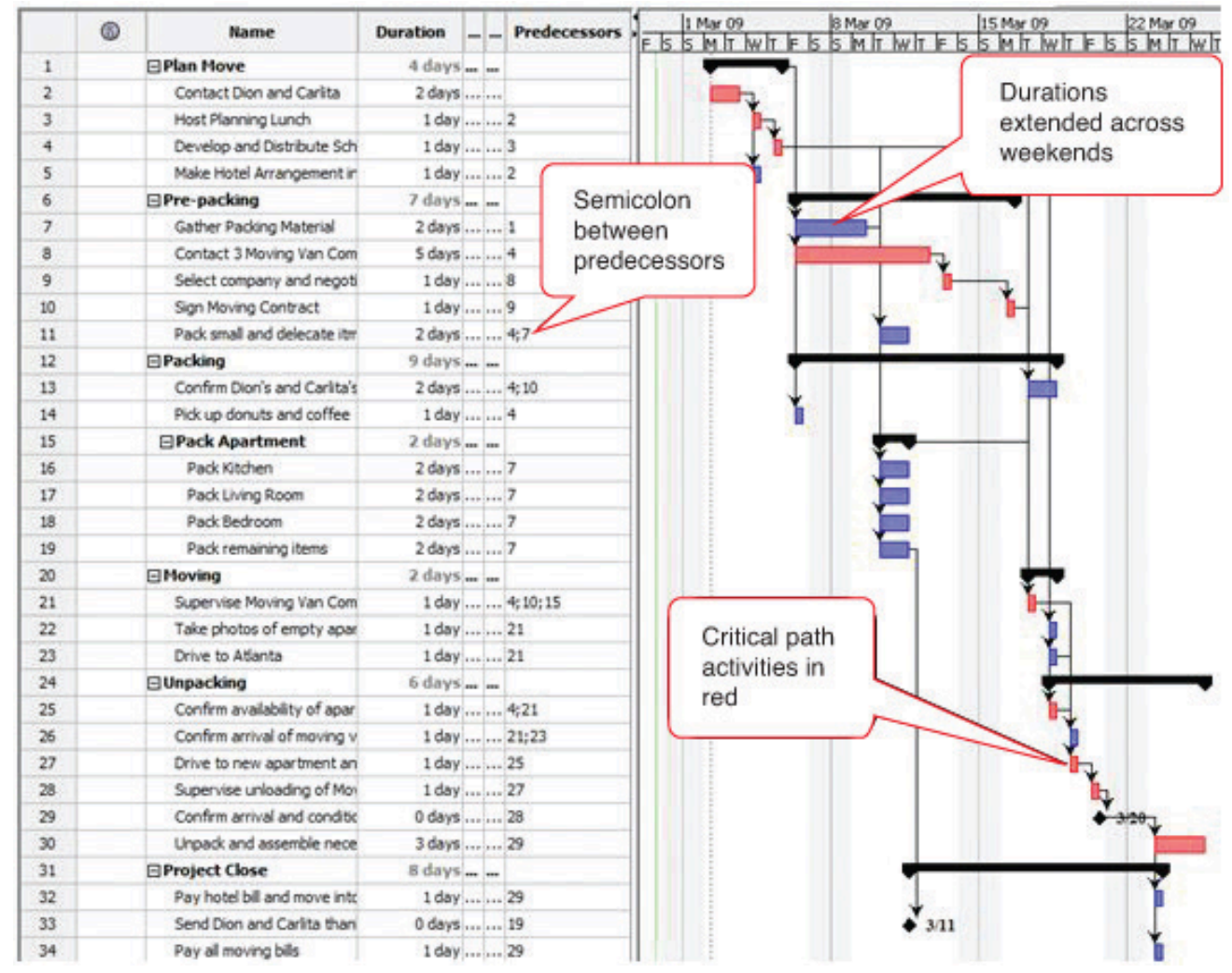

Source: Courtesy of Serena Software.

13. Capture this screen and paste it into Ch08OpenProjStudentName.doc.

14. In OpenProj, on the menu bar, click File and then click Save. Navigate to a folder where you save your files for this class and save the project file. Notice the project file name extension is .pod. Leave the project open.

15. Review your work in OpenProj and use the following rubric to determine its adequacy:

\begin{tabular}{|l|l|l|l|}
\hline Element & Best & Adequate & Poor \\
\hline File name & Ch08StudentName.pod & Ch08StudentName.pod & $\begin{array}{l}\text { Used a different } \\
\text { name }\end{array}$ \\
\hline $\begin{array}{l}\text { Use dedicated project } \\
\text { management software } \\
\text { to manage changes to } \\
\text { the WBS }\end{array}$ & $\begin{array}{l}\text { Activities imported from } \\
\text { Excel; correct groups; correct } \\
\text { predecessors; dates will differ } \\
\text { from figures }\end{array}$ & Same as Best & $\begin{array}{l}\text { Mistakes with } \\
\text { multiple } \\
\text { predecessors; } \\
\text { incorrect } \\
\text { groupings }\end{array}$ \\
\hline
\end{tabular}

16. Review your work in Ch08OpenProjStudentName.doc and use the following rubric to determine its adequacy: 


\begin{tabular}{|l|l|l|l|}
\hline Element & Best & Adequate & Poor \\
\hline File name & Ch08OpenProjStudentName.doc & $\begin{array}{l}\text { Same } \\
\text { name } \\
\text { saved as } \\
\text {.docx file }\end{array}$ & $\begin{array}{l}\text { Used a different } \\
\text { name }\end{array}$ \\
\hline $\begin{array}{l}\text { Use dedicated project } \\
\text { management software to } \\
\text { manage changes to the WBS }\end{array}$ & $\begin{array}{l}\text { Three screen captures that show } \\
\text { the development of the WBS in } \\
\text { OpenProj }\end{array}$ & $\begin{array}{l}\text { Same as } \\
\text { Best }\end{array}$ & $\begin{array}{l}\text { Missing screens or } \\
\text { lack of student name } \\
\text { in first screen }\end{array}$ \\
\hline
\end{tabular}

17. Save the files and submit them as directed by the instructor.

\section{Using the Subtotal and Outline Features in Excel 2007 for a Low-Complexity Work Breakdown Structure}

Some advanced spreadsheet programs such as Microsoft Excel can sort tables of text and data. If the text is used as category labels, the sorting feature can be used to bring all the same type of expenses together, after which they can be subtotaled by category. The individual rows in each category can be hidden, and the category text and a subtotal for each column that contains numeric data such as durations or costs are displayed. This feature may be used to manage the costs or durations associated with each item in a work breakdown structure for a low-complexity project.

Create a WBS using the subtotal and outline features of Microsoft Excel 2007:

1. Navigate to the folder where the student files for this chapter are located and then open Ch08JohnsMove.xls. Do not save the file-it will not be submitted.

2. Observe that a group name has been given to each row of the WBS in column E.

3. Click cell E1, and then type your name.

4. On the Data tab, in the Outline group, click Subtotal. The Subtotal dialog box displays.

5. Under At each change in click the arrow button. The program shows a list of column headings, as shown in Figure 8.27 "Subtotal Dialog Box".

6. On the list of column headings, click Group. A subtotal is calculated each time the label in this column changes.

7. In the Subtotal dialog box, under Use function, click the arrow button and then click Sum.

8. In the Subtotal dialog box, under Add subtotal to, next to Duration, click the check box. Click to remove any other check boxes under Add subtotal to if necessary. The durations will be summed for each group. Refer to Figure 8.28 "Subtotal Dialog Box Set to Sum the Durations for Each Type of Group”.

9. Capture this screen. Open a blank word processing document and save it as Ch08WBSExcel2007StudentName.doc using the Word 2003 file format. On the first line, type your name and the current date. Below the date, paste the screen capture. Leave the file open. 
10. In Ch08JohnsMove.xls, in the Subtotal dialog box, click OK. Subtotals are inserted below each type of group label, as shown in Figure 8.29 "Subtotal Dialog Box Set to Sum the Durations for Each Type of Group”.

11. Capture this screen and then paste it into Ch08WBSExcel2007StudentName.doc.

12. In Ch08JohnsMove.xls, at the upper left corner of the worksheet, click the number 2 . The detail of each type of group is hidden and the subtotals are displayed, as shown in Figure 8.30 "WBS Subtotaled and Collapsed”.

13. Capture this screen and then paste it into Ch08WBSExcel2007StudentName.doc.

14. At the upper left corner of the worksheet, click 3. The outline is expanded.

15. On the Data tab, in the Outline group, click Subtotal. In the Subtotal dialog box, click the Remove All button. The subtotals and outline are removed.

16. Close the spreadsheet. Do not save the changes.

17. Review your work and use the following rubric to determine its adequacy:

\begin{tabular}{|l|l|l|l|}
\hline Element & Best & Adequate & Poor \\
\hline File name & Ch08WBSExcel2007StudentName.doc & $\begin{array}{l}\text { Same as } \\
\text { Best }\end{array}$ & $\begin{array}{l}\text { Chapter } \\
\text { number or } \\
\text { student name } \\
\text { missing }\end{array}$ \\
\hline $\begin{array}{l}\text { Use the outline and subtotal } \\
\text { features in a spreadsheet to } \\
\text { create a low-complexity } \\
\text { work breakdown structure }\end{array}$ & $\begin{array}{l}\text { Name and date in first row; three } \\
\text { screen captures that show the use of } \\
\text { subtotal and outline }\end{array}$ & $\begin{array}{l}\text { Same as } \\
\text { Best }\end{array}$ & $\begin{array}{l}\text { Name not in } \\
\text { first line; name } \\
\text { not shown in } \\
\text { screen } \\
\text { captures }\end{array}$ \\
\hline
\end{tabular}

18. Save the file and submit it as directed by the instructor.

\section{Using the Outline Feature in Word 2007 for a Low-Complexity Work Breakdown Structure}

Advanced word processing software includes an outlining feature that allows the user to work in an outline format with collapsible headings. This feature may be used to define a work breakdown structure in a low-complexity project.

Create a WBS using an outline in Microsoft Word 2007:

1. Open MS Word 2007 and open a blank document. Save the file as Ch08WBSStudentName.docx using the Word 2007 document format that uses the .docx file extensions.

2. On the Home tab, in the Styles group, scroll to display the Title option, and then click Title.

3. Type John's Move and then press Enter. The text is formatted using the title style as shown in 
Figure 8.31 “Title Style”.

4. On the second line, type your name and then press Enter.

5. On the third line, type the date and then press Enter. Notice that the title style does not apply to the following lines. The program's default style is called the normal style.

6. On the Home tab, in the Styles group, scroll and click Heading 1. Type Plan Move and then press Enter. The Heading 1 style is applied.

7. On the Home tab, in the Styles group, click Heading 2. Type Contact Dion and Carlita and press Enter. Repeat this process to enter the following items formatted as Heading 2. Refer to Figure 8.32 “Title, Body Text, Heading 1, and Heading 2”.

- Host Planning Lunch

- Develop and Distribute Schedule

- Make Hotel Arrangement in Atlanta

- Prepacking

8. Open a new blank word processing document. On the first line, type your name and the date. Save the new document as Ch08OutlineWord2007StudentName.doc using the Word 2003 file format.

9. Switch to Ch08WBSStudentName.docx. Capture the screen that shows the outline at this point in the development of the exercise. Paste the screen into Ch08OutlineWord2007StudentName.doc. Save the file but leave it open.

10. In Ch08WBSStudentName.docx, at the end of the line that begins with Contact Dion and Carlita, click to place the insertion point and then press Enter.

11. Type Phone numbers are: Dion 555-0125, Carlita 555-0234. Observe that the additional text is formatted in normal style, similar to the name and date, as shown in Figure 8.33 "Screen Capture and Phone Numbers Added”.

12. Select the line that begins with Pre-packing. On the Home tab, in the Styles group, click Heading 1. The Heading 1 style is applied.

13. Use this process to fill in the remaining items in the WBS, as shown in Figure 8.34 "WBS with Three Levels”, using heading styles 1, 2, and 3.

14. On the View tab, in the Document Views group, click the Outline button. Change the zoom, if necessary, to display all the document text, as shown in Figure 8.35 "WBS in Outline View”. Each heading is also formatted with a corresponding outline level of the same number.

15. Capture this screen and paste it into Ch08OutlineWord2007StudentName.doc.

16. In Ch08WBSStudentName.docx, on the Outlining tab, in the Outline Tools group, click the Show Level button, and then click Level 2. Text that is formatted with Headings 1 and 2 are displayed while the title, normal text, and lower-level headings are not. Plus signs indicate the presence of hidden text, as shown in Figure 8.36 “Display of Levels 1 and 2".

17. Capture this screen and paste it into Ch08OutlineWord2007StudentName.doc. Save Ch08Out- 
lineWord2007StudentName.doc.

18. In Ch08WBSStudentName.docx, on the Outlining tab, in the Close group, click the Close Outline View button. Save the document.

19. Review your work and use the following rubric to determine its adequacy:

\begin{tabular}{|c|c|c|c|}
\hline Element & Best & Adequate & Poor \\
\hline File name & Ch08OutlineWord2007StudentName.doc & $\begin{array}{l}\text { Same as } \\
\text { Best but } \\
\text { in .docx } \\
\text { format }\end{array}$ & $\begin{array}{l}\text { Chapter } \\
\text { number or } \\
\text { student } \\
\text { name } \\
\text { missing }\end{array}$ \\
\hline $\begin{array}{l}\text { Use the outline } \\
\text { feature in a word } \\
\text { processor to create } \\
\text { a low-complexity } \\
\text { WBS }\end{array}$ & $\begin{array}{l}\text { Name and date on first line; three screen captures } \\
\text { that show the development and use of the WBS in } \\
\text { Word 2007's outline form using Heading styles } 1 \text {, } \\
2 \text {, and } 3\end{array}$ & $\begin{array}{l}\text { Same as } \\
\text { Best }\end{array}$ & $\begin{array}{l}\text { Missing } \\
\text { information } \\
\text { or screens }\end{array}$ \\
\hline File name & Ch08WBSStudentName.docx & $\begin{array}{l}\text { Same as } \\
\text { Best }\end{array}$ & $\begin{array}{l}\text { Chapter } \\
\text { number or } \\
\text { student } \\
\text { name } \\
\text { missing }\end{array}$ \\
\hline $\begin{array}{l}\text { Use the outline } \\
\text { feature in a word } \\
\text { processor to create } \\
\text { a low-complexity } \\
\text { WBS }\end{array}$ & $\begin{array}{l}\text { Title style applied to the first line; normal style } \\
\text { used for name, date, and phone numbers; heading } \\
\text { styles 1, 2, and } 3 \text { used as directed; can be collapsed } \\
\text { and expanded using the Outline view }\end{array}$ & $\begin{array}{l}\text { Same as } \\
\text { Best }\end{array}$ & $\begin{array}{l}\text { Incorrect } \\
\text { styles } \\
\text { applied to } \\
\text { some lines }\end{array}$ \\
\hline
\end{tabular}

20. Save the files and submit them as directed by the instructor. 


\section{Chapter 9: Estimating and Managing Costs}

An important part of a project manager's job is managing money. All types of organizations must manage their money well in order to fulfill their mission, including not-for-profit and government organizations. The tools and methods used to manage money on a project vary depending on the phase and complexity of the project. This chapter describes the methods used to estimate the cost of a project, create a budget, and manage the cost of activities while the project is being executed. 


\subsection{Estimating Costs}

\section{Learning Objectives}

1. Describe methods of estimating costs.

2. Identify the effects of project phase and complexity on the choice of estimating method.

3. Describe the method of combining cost estimates with a schedule to create a budget.

\section{Estimating Costs to Compare and Select Projects}

During the conceptual phase when project selection occurs, economic factors are an important consideration when choosing between competing projects. To compare the simple paybacks or internal rates of return between projects, an estimate of the cost of each project is made. The estimates must be accurate enough so that the comparisons are meaningful, but the amount of time and resources used to make the estimates should be appropriate to the size and complexity of the project. The methods used to estimate the cost of the project during the selection phase are generally faster and consume fewer resources than those used to create detailed estimates in later phases. They rely more on the expert judgment of experienced managers who can make accurate estimates with less detailed information. Estimates in the earliest stages of project selection are usually made using estimates based from previous projects that can be adjusted - scaled - to match the size and complexity of the current project or by applying standardized formulas.

\section{Analogous Estimate}

An estimate that is based on other project estimates is an analogous estimate. If a similar project cost a certain amount, then it is reasonable to assume that the current project will cost about the same. Few projects are exactly the same size and complexity, so the estimate must be adjusted upward or downward to account for the difference. The selection of projects that are similar and the amount of adjustment needed is up to the judgment of the person who makes the estimate. Normally, this judgment is based on many years of experience estimating projects, including incorrect estimates that were learning experiences for the expert. 


\section{Analogous Estimate for John's Move}

In the John's move example, John asked a friend for advice about the cost of his move. His friend replied, "I moved from an apartment a little smaller than yours last year and the distance was about the same. I did it with a fourteen-foot truck. It cost about \$575 for the truck rental, pads, hand truck, rope, boxes, and gas.” Because of the similarity of the projects, John's initial estimate of the cost of the move was less than $\$ 700$ and he decided that the cost would be affordable and the project could go forward.

Less experienced managers who are required to make analogous estimates can look through the documentation that is available from previous projects. If those projects were evaluated using the DarnallPreston Complexity Index (DPCI), the manager can quickly identify projects that have similar profiles to the project under consideration even if those projects were managed by other people. Comparing the original estimates with the final project costs on several previous projects with the same DPCI ratings gives a less experienced manager the perspective that it would take many years to acquire by trial and error. It also provides references the manager can use to justify the estimate.

\section{Parametric Estimate}

If the project consists of activities that are common to many other projects, average costs are available per unit. For example, if you ask a construction company how much it would cost to build a standard office building, they will ask for the size of the building in square feet and the city in which the building will be built. From these two factors - size and location - the company's estimator can predict the cost of the building. Factors like size and location are parameters-measurable factors that can be used in an equation to calculate a result. The estimator knows the average cost per square foot of a typical office building and adjustments for local labor costs. Other parameters such as quality of finishes are used to further refine the estimate. Estimates that are calculated by multiplying measured parameters by costper-unit values are parametric estimates.

\section{Parametric Estimate for John's Move}

To estimate the size of the truck needed for John's move, the parameter used by a truck rental company is the number of bedrooms, as shown below.

Figure 9.1 Number of Bedrooms Used for Parametric Cost Estimate 


\section{UHAUL Your moving and sforage resource Home Rates and reservations Moving supplies Locations}

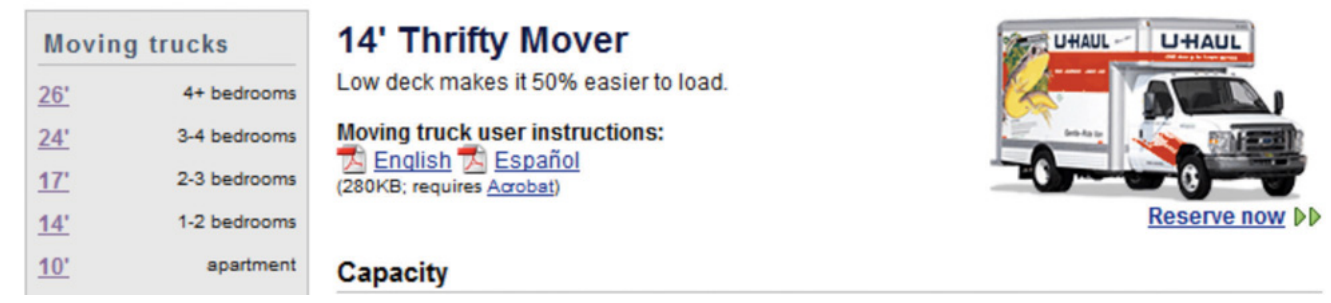

The moving company assumes that the number of bedrooms is the important parameter in determining how big a truck is needed for a move. For John's move, he has a one-bedroom apartment, so he chooses the fourteen-foot truck. Once the size is determined, other parameters, such as distance and days, are used to estimate the cost of the truck rental.

\section{Estimating Costs to Initiate Projects}

Once the project is selected, more accurate estimates are often needed to raise funds and agree on contracts with vendors in the initiation phase.

\section{Estimate During the Initiation Phase of John's Move}

John recalled that his friend also told him how tiring it was to do all the packing, loading, and driving himself, and some items were damaged when the load shifted inside the truck during the trip. John decides to call in favors from two friends, Dion and Carlita, to help him pack in Chicago and to hire some of the skilled labor like that needed to load the truck properly.

\section{Vendor Bid Analysis}

If services or products will be provided by vendors, the cost of those services can be determined by issuing a request for proposal (RFP). The RFP describes the work, service, or product to be provided by the vendor and the quality level required. The RFP is sent to a list of vendors who are qualified-meet standards of reliability and capability - to perform this type of work. They respond with a proposal for completing the work described in the RFP, including an estimate of the cost. Some government organizations are required to use the qualified vendor with the lowest bid. Other organizations are not bound to take the lowest bid but are usually required to justify their reasons for not doing so. 


\section{Using RFPs to Make Estimates on John's Move}

John wants to find out how much it would cost to hire a skilled crew to load and secure the furniture in the truck and then have another crew from the same company meet him in Atlanta to unload the truck and help him unpack. He is not sure if any companies offer this option, so he decides to ask three moving companies for bids. He also decides to ask for bids on a standard move that includes all phases of packing, loading, transportation, and unloading as a comparison to see if his cost-saving plan is worth the extra effort.

The project management team can review the responses by several vendors to the RFP to determine if their estimate of the cost of that aspect of the project is close to the estimate made during the project selection stage. If the estimates by the vendors are much higher than expected, and if the project cannot be completed for the cost that was used to select the project, the selection decision might have to be reconsidered. Reconsidering the selection of the project should take into consideration the economic ratings of the competing projects that were not chosen and who the project champions are for the projects that would be affected.

Some vendors may suggest an alternative way to meet the objective of the RFP in a more cost-effective manner that does not match the specifics of the RFP. Such alternatives can reduce costs if they are acceptable.

\section{Bottom-Up Estimating}

The most accurate and time-consuming estimating method is to identify the cost of each item in each activity of the schedule, including labor and materials. If you view the project schedule as a hierarchy where the general descriptions of tasks are at the top and the lower levels become more detailed, finding the price of each item at the lowest level and then summing them to determine the cost of higher levels is called bottom-up estimating.

\section{Bottom-Up Estimate for John's Move}

After evaluating the bids by the moving companies, John decides the savings are worth his time if he can get the packing done with the help of his friends. He decides to prepare a detailed estimate of costs for packing materials and use of a rental truck. He looks up the prices for packing materials and truck rental costs on company Web sites and prepares a detailed list of items, quantities, and costs, as shown below.

Figure 9.2 Detailed Cost Estimate 


\begin{tabular}{|c|c|c|c|c|}
\hline Category & Description & Quantity & Unit Price & Cost \\
\hline Packing Materials & Small Boxes & 10 & $\$ 1.70$ & $\$ 17.00$ \\
\hline Packing Materials & Medium Boxes & 15 & $\$ 2.35$ & $\$ 35.25$ \\
\hline Packing Materials & Large Boxes & 7 & $\$ 3.00$ & $\$ 21.00$ \\
\hline Packing Materials & Extra Large Boxes & 7 & $\$ 3.75$ & $\$ 26.25$ \\
\hline Packing Materials & Short Hanger Boxes & 3 & $\$ 7.95$ & $\$ 23.85$ \\
\hline Packing Materials & Box Tape & 2 & $\$ 3.85$ & $\$ 7.70$ \\
\hline Packing Materials & Markers & 2 & $\$ 1.50$ & $\$ 3.00$ \\
\hline Packing Materials & Mattress/Spring Bags & 2 & $\$ 2.95$ & $\$ 5.90$ \\
\hline Packing Materials & Lift Straps per Pair & 1 & $\$ 24.95$ & $\$ 24.95$ \\
\hline Packing Materials & Bubble Wrap & 1 & $\$ 19.95$ & $\$ 19.95$ \\
\hline Packing Materials & Furniture Pads & 4 & $\$ 7.95$ & $\$ 31.80$ \\
\hline Truck & Rental & & & $\$ 400.00$ \\
\hline Truck & Gas at $10 \mathrm{mpg}$ & 200 & $\$ 2.25$ & $\$ 45.00$ \\
\hline
\end{tabular}

This type of estimate is typically more accurate than an analogous or parametric estimate. In this example, the sum of packing materials and truck expenses is estimated to be $\$ 661.25$.

The detail can be rolled up - subtotaled - to display less detail. This process is made easier using computer software. On projects with low complexity, the cost estimates can be done on spreadsheet software.

\section{Rolling Up a Detailed Cost Estimate for John's Move}

For example, the subtotal feature could be used in Excel and collapsed to show the subtotals for the two categories of costs, as shown below.

Figure 9.3 Sum of Detailed Costs by Type

\begin{tabular}{|c|c|c|c|c|c|c|}
\hline \begin{tabular}{|l|l|l|}
1 & 2 & 3 \\
\end{tabular} & 4 & A & B & C & D & E \\
\hline \multirow{5}{*}{\begin{tabular}{|l|}
+ \\
+ \\
\end{tabular}} & 1 & Type & Description & Quantity & Unit Price & Cost \\
\hline & 13 & \multicolumn{2}{|c|}{ Packing Materials Total } & & & $\$ 216.65$ \\
\hline & 16 & Truck Total & & & & $\$ 445.00$ \\
\hline & 17 & Grand Total & & & & $\$ 661.65$ \\
\hline & 18 & & & & & \\
\hline
\end{tabular}

On larger projects, software that manages schedules can also manage costs and display costs by activity and by category. 


\section{Activity-Based Estimates}

An activity can have costs from more than one vendor plus costs for labor and materials from internal sources. Detailed estimates from all sources can be reorganized so those costs that are associated with a particular activity can be grouped by adding the activity code to the detailed estimate, as shown in Figure 9.4 "Detailed Costs Associated with Activities".

Figure 9.4 Detailed Costs Associated with Activities

\begin{tabular}{|c|c|c|c|c|c|}
\hline Category & Description & Activity & Quantity & Unit Price & Cost \\
\hline Packing Materials & Small Boxes & $2 a$ & 10 & $\$ 1.70$ & $\$ 17.00$ \\
\hline Packing Materials & Medium Boxes & $2 a$ & 15 & $\$ 2.35$ & $\$ 35.25$ \\
\hline Packing Materials & Large Boxes & $2 \mathrm{a}$ & 7 & $\$ 3.00$ & $\$ 21.00$ \\
\hline Packing Materials & Extra Large Boxes & $2 a$ & 7 & $\$ 3.75$ & $\$ 26.25$ \\
\hline Packing Materials & Short Hanger Boxes & $2 \mathrm{a}$ & 3 & $\$ 7.95$ & $\$ 23.85$ \\
\hline Packing Materials & Box Tape & $2 \mathrm{a}$ & 2 & $\$ 2.85$ & $\$ 7.70$ \\
\hline Packing Materials & Markers & $2 a$ & 2 & $\$ 1.50$ & $\$ 3.00$ \\
\hline Packing Materials & Mattress/Spring Bags & $2 a$ & 2 & $\$ 2.95$ & $\$ 5.90$ \\
\hline Packing Materials & Lift Straps per Pair & $2 a$ & 1 & $\$ 24.95$ & $\$ 24.95$ \\
\hline Packing Materials & Bubble Wrap & $2 a$ & 1 & $\$ 19.95$ & $\$ 19.95$ \\
\hline Packing Materials & Furniture Pads & $2 a$ & 4 & $\$ 7.95$ & $\$ 31.80$ \\
\hline Truck & Rental & $2 b$ & & & $\$ 400.00$ \\
\hline Truck & Gas at $10 \mathrm{mpg}$ & $2 b$ & 200 & $\$ 2.25$ & $\$ 45.00$ \\
\hline
\end{tabular}

The detailed cost estimates can be sorted by activity and then subtotaled by activity to determine the cost for each activity.

\section{Establishing a Budget}

Once the cost of each activity is estimated, it is possible to determine how much money is needed for each group of tasks and for the whole project.

\section{Cost of Tasks}

The cost of each group of activities of the project can be estimated by summing the costs of the components of each activity in the group. This process of subtotaling costs by category or activity is called cost aggregation. 


\section{Budget Timeline}

Because the costs are associated with activities and each activity has a start date and a duration, it is possible to calculate how much money needs to be spent by any particular date during the project. The money needed to pay for a project is usually transferred to the project account shortly before it is needed. These transfers must be timed so that the money is there to pay for each activity without causing a delay in the start of the activity. If the money is transferred too far in advance, the organization will lose the opportunity to use the money somewhere else, or they will have to pay unnecessary interest charges if the money is borrowed. A schedule of money transfers is created that should match the need to pay for the activities. The process of matching the schedule of transfers with the schedule of activity payments is called reconciliation. Refer to Figure 9.5 "Fund Transfers and Expenditures" that shows the costs of ten major activities in a project. Funds are transferred into the project account four times. Notice that during most of the project, there were more funds available than were spent except at activity 6 when all the available funds were spent.

Figure 9.5 Fund Transfers and Expenditures

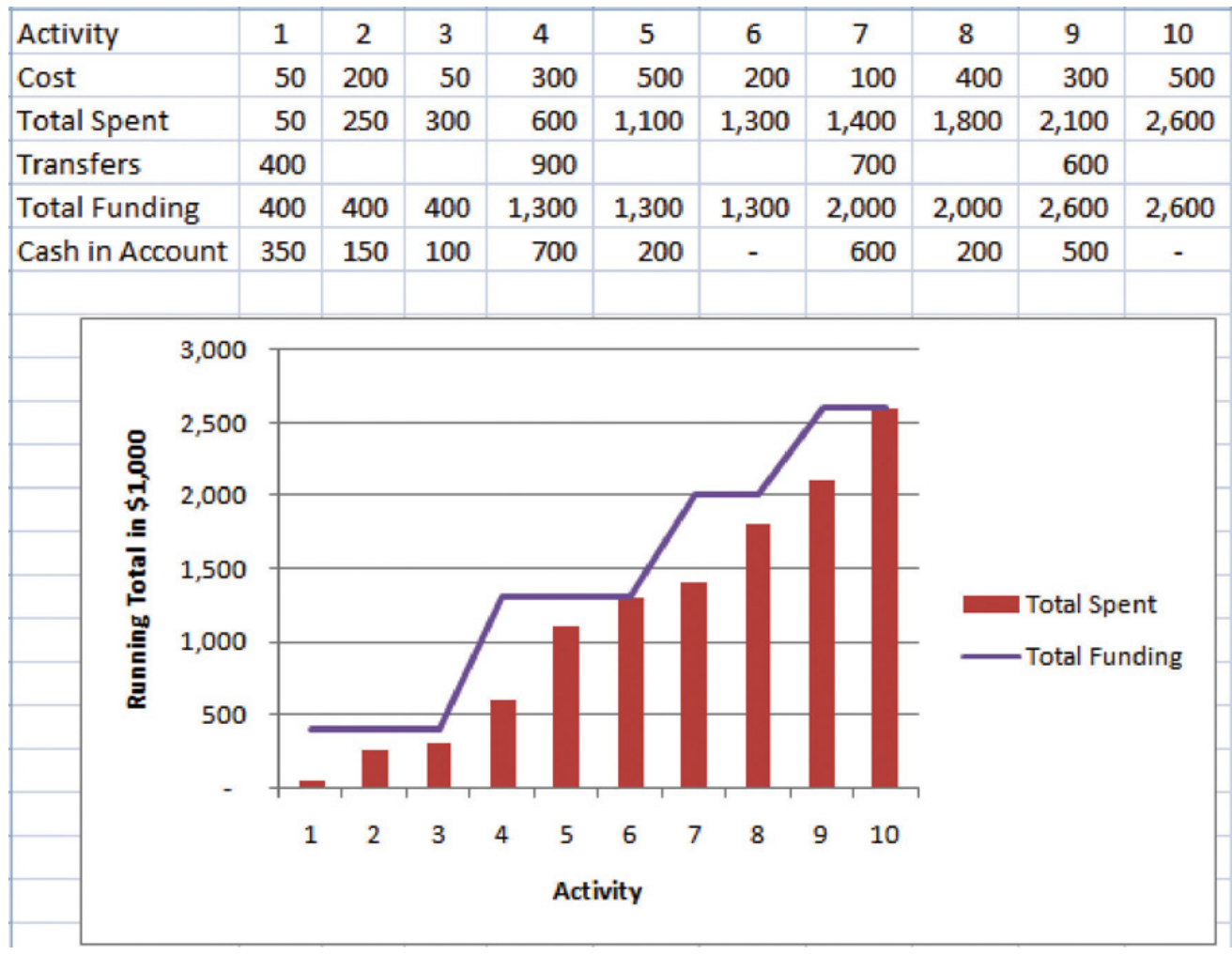

In the project budget profile shown in Figure 9.5 "Fund Transfers and Expenditures", there is no margin for error if the total of the first six activities exceeds the amount of funding at that point in the project.

Contractual agreements with vendors often require partial payment of their costs during the project. Those contracts can be managed more conveniently if the unit of measure for partial completion is the same as that used for cost budgeting. For example, if a contractor is pouring concrete for a large project, their contract may call for partial payment after 25 percent of the total volume of concrete is poured as determined by cubic yards of concrete. 


\section{Key Takeaways}

- Analogous estimating scales an estimate from a similar project to match the current project. Parametric estimating multiplies a standard cost-per-unit value by the number of units in the project. Bids from contractors can be compared to estimate costs. Bottom-up estimating determines the cost of each detail and aggregates them to determine activity cost estimates.

- During the project selection and approval stage, rough estimates are used that are usually obtained using analogous and parametric methods. Vendor bid analysis and detailed bottom-up estimates are used in the initiation phase to estimate project costs.

- Detailed estimates are associated with activities and aggregated during the planning phase to create an activity-based budget. Funding transfers are arranged to reconcile money spent to money from funding sources in a timely manner.

\section{Exercises}

1. An estimate that is obtained by scaling up an estimate from a similar project is a(n) estimate.

2. An estimate that uses standard costs per unit such as price per square foot or price per cubic yard is a estimate.

3. Matching the transfer of funds into the project account with the money spent is called

\section{Estimates}

Consider a project in which you have been involved that used an estimating technique to provide numbers for the conceptual plan. Briefly describe the type of project and identify the estimating method used. 


\subsection{Managing the Budget}

\section{Learning Objectives}

1. Describe methods to manage cash flow.

2. Describe the terms and relationships of budget factors used in earned value analysis.

3. Calculate and interpret budget and schedule variances.

4. Calculate and interpret the schedule performance index and the cost performance index.

5. Calculate and interpret estimates to complete the project.

6. Calculate the revised final budget.

Projects seldom go according to plan in every detail. It is necessary for the project manager to be able to identify when costs are varying from the budget and to manage those variations.

\section{Managing Cash Flow}

If the total amount spent on a project is equal to or less than the amount budgeted, the project can still be in trouble if the funding for the project is not available when it is needed. There is a natural tension between the financial people in an organization, who do not want to pay for the use of money that is just sitting in a checking account, and the project manager, who wants to be sure that there is enough money available to pay for project expenses. The financial people prefer to keep the company's money working in other investments until the last moment before transferring it to the project account. The contractors and vendors have similar concerns, and they want to get paid as soon as possible so they can put the money to work in their own organizations. The project manager would like to have as much cash available as possible to use if activities exceed budget expectations.

\section{Contingency Reserves}

Most projects have something unexpected occur that increases costs above the original estimates. If estimates are rarely exceeded, the estimating method should be reviewed because the estimates are too high. It is not possible to predict which activities cost more than expected, but it is reasonable to assume that some of them will be. Estimating the likelihood of such events is part of risk analysis, which is discussed in more detail in a later chapter. 
Instead of overestimating each cost, money is budgeted for dealing with unplanned but statistically predictable cost increases. Funds allocated for this purpose are called contingency reserves (Project Management Institute, Inc., 2008). Because it is likely that this money will be spent, it is part of the total budget for the project. If this fund is adequate to meet the unplanned expenses, then the project will complete within the budget.

\section{Management Reserves}

If something occurs during the project that requires a change in the project scope, money may be needed to deal with the situation before a change in scope can be negotiated with the project sponsor or client. It could be an opportunity as well as a challenge. Money can be made available to the project to be used at the discretion of the manager to meet needs that would change the scope of the project. These funds are called management reserves. Unlike contingency reserves, they are not likely to be spent and are not part of the project's budget baseline, but they can be included in the total project budget (Project Management Institute, Inc., 2008).

\section{Evaluating the Budget During the Project}

A project manager must regularly compare the amount of money spent with the budgeted amount and report this information to managers and stakeholders. It is necessary to establish an understanding of how this progress will be measured and reported.

\section{Reporting Budget Progress on John's Move}

In the John's move example, he estimated that the move would cost about $\$ 1,500$ and take about sixteen days. Eight days into the project, John has spent $\$ 300$. John tells his friends that the project is going well because he is halfway through the project but has only spent a fifth of his budget. John's friend Carlita points out that his report is not sufficient because he did not compare the amount spent to the budgeted amount for the activities that should be done by the eighth day.

As John's friend points out, a budget report must compare the amount spent with the amount that is expected to be spent by that point in the project. Basic measures such as percentage of activities completed, percentage of measurement units completed, and percentage of budget spent are adequate for less complex projects, but more sophisticated techniques are used for projects with higher complexity.

\section{Earned Value Management}

A method that is widely used for medium- and high-complexity projects is the earned value manage- 
ment (EVM) method. EVM is a method of comparing the budgeted and actual costs of a project periodically during the project. It combines the scheduled activities with detailed cost estimates of each activity. It allows for partial completion of an activity if some of the detailed costs associated with the activity have been paid but others have not. The earned value analysis method compares the anticipated cost of work that is scheduled to be done at a given point in time against what has been done and how much it actually cost.

\section{The Budgeted Cost of Work and Planned Value}

The budgeted cost of work scheduled (BCWS) comprises the detailed cost estimates for each activity in the project. The amount of work that should have been done by a particular date is the planned value (PV). These terms are used interchangeably by some sources, but the planned value term is used in formulas to refer to the sum of the budgeted cost of work up to a particular point in the project, so we will make that distinction in the definitions in this text for clarity.

\section{Planned Value on Day Six of John's Move}

On day six of the project, John should have taken his friends to lunch and purchased the packing materials. The portion of the BCWS that should have been done by that date (the planned value) is listed in Figure 9.6 "Planned Value for Lunch and Packing Materials". This is the planned value for day six of the project.

Figure 9.6 Planned Value for Lunch and Packing Materials

\begin{tabular}{|l|l|l|}
\hline Description & Quantity & Cost \\
\hline Lunch & 3 & $\$ 45.00$ \\
\hline Small Boxes & 10 & $\$ 17.00$ \\
\hline Medium Boxes & 15 & $\$ 35.25$ \\
\hline Large Boxes & 7 & $\$ 21.00$ \\
\hline Extra Large Boxes & 7 & $\$ 26.25$ \\
\hline Short Hanger Boxes & 3 & $\$ 23.85$ \\
\hline Box Tape & 2 & $\$ 7.70$ \\
\hline Markers & 2 & $\$ 3.00$ \\
\hline Mattress/Spring Bags & 2 & $\$ 5.90$ \\
\hline Lift Straps per Pair & 1 & $\$ 24.95$ \\
\hline Bubble Wrap & 1 & $\$ 19.95$ \\
\hline Furniture Pads & 4 & $\$ 31.80$ \\
\hline & Total & $\$ 261.65$ \\
\hline
\end{tabular}




\section{Budgeted Cost of Work Performed and Earned Value}

The budgeted cost of work performed (BCWP) is the budgeted cost of work scheduled that has been done. If you sum the BCWP values up to that point in the project schedule, you have the earned value (EV).

\section{Actual Cost}

The amount spent on an item is often more or less than the estimated amount that was budgeted for that item. The actual cost (AC) is the sum of the amounts actually spent on the items.

\section{Comparing PV, EV, and AC in John's Move on Day Six}

Dion and Carlita were both trying to lose weight and just wanted a nice salad. Consequently, the lunch cost less than expected. John makes a stop at a store that sells moving supplies at discount rates. They do not have all the items he needs, but the prices are lower than those quoted by the moving company. They have a very good price on lifting straps so he decides to buy an extra pair. He returns with some of the items on his list, but this phase of the job is not complete by the end of day six. John bought half of the small boxes, all of five other items, twice as many lifting straps, and none of four other items. John is only six days into his project, and his costs and performance are starting to vary from the plan. Earned value analysis gives us a method for reporting that progress. Refer to the figure below.

Figure 9.7 Planned Value, Earned Value, and Actual Cost 


\begin{tabular}{|c|c|c|c|c|c|c|}
\hline \multirow[b]{3}{*}{ Description } & \multicolumn{6}{|c|}{ Project Earned Value Analysis-Day 6} \\
\hline & \multicolumn{2}{|c|}{ Budgeted Cost of Work Scheduled (BCWS) } & \multicolumn{2}{|c|}{ Budgeted Cost of Work Performed (BCWP) } & \multicolumn{2}{|c|}{ Actual Cost (AC) } \\
\hline & Quantity & Cost & Quantity & Cost & Quantity & Cost \\
\hline Lunch & 3 & $\$ 45.00$ & 3 & $\$ 45.00$ & 3 & $\$ 35.00$ \\
\hline Small Boxes & 10 & $\$ 7.00$ & 5 & $\$ 8.50$ & 5 & $\$ 9.50$ \\
\hline Medium Boxes & 15 & $\$ 35.25$ & 15 & $\$ 35.25$ & 15 & $\$ 28.00$ \\
\hline Large Boxes & 7 & $\$ 21.00$ & & & & \\
\hline Extra Large Boxes & 7 & $\$ 26.25$ & & & & \\
\hline Short Hanger Boxes & 3 & $\$ 23.85$ & & & & \\
\hline Box Tape & 2 & $\$ 7.70$ & 2 & $\$ 7.70$ & 2 & $\$ 5.50$ \\
\hline Markers & 2 & $\$ 3.00$ & 2 & $\$ 3.00$ & 2 & $\$ 2.00$ \\
\hline Mattress/Spring Bags & 2 & $\$ 5.90$ & 2 & $\$ 5.90$ & 2 & $\$ 7.50$ \\
\hline Lift Straps per Pair & 1 & $\$ 24.95$ & 1 & $\$ 24.95$ & 2 & $\$ 38.50$ \\
\hline Bubble Wrap & 1 & $\$ 19.95$ & & & & \\
\hline \multirow[t]{2}{*}{ Furniture Pads } & 4 & $\$ 31.80$ & 4 & $\$ 31.80$ & 4 & $\$ 28.50$ \\
\hline & PV & $\$ 261.65$ & $\mathbf{E V}$ & $\$ 162.10$ & AC & $\$ 154.50$ \\
\hline
\end{tabular}

The original schedule called for spending \$261.65 (PV) by day six. The amount of work done was worth $\$ 162.10$ (EV) according to the estimates, but the actual cost was only \$154.50 (AC).

\section{Schedule Variance}

The project manager must know if the project is on schedule and within the budget. The difference between planned and actual progress is the variance. The schedule variance (SV) is the difference between the earned value (EV) and the planned value (PV). Expressed as a formula, SV = EV - PV. If less value has been earned than was planned, the schedule variance is negative, which means the project is behind schedule.

\section{Schedule Variance on John's Move}

Planning for John’s move calls for spending $\$ 261.65$ by day six, which is the planned value (PV). The difference between the planned value and the earned value is the scheduled variance (SV). The formula is SV = EV - PV. In this example, SV $=\$ 162.10-\$ 261.65=\$(99.55)$ A negative SV indicates the project is behind schedule.

The difference between the earned value (EV) and the actual cost (AC) is the cost variance (CV). Expressed as a formula, $\mathrm{CV}=\mathrm{EV}-\mathrm{AC}$ 


\section{Cost Variance on John's Move}

The difference between the earned value of $\$ 162.10$ and the actual cost of $\$ 154.50$ is the cost variance (CV).

The formula is CV $=\mathrm{EV}-\mathrm{AC}$. In this example, $\mathrm{CV}=\$ 162.10-\$ 154.50=\$ 7.60$.

A positive CV indicates the project is under budget.

\section{Variance Indexes for Schedule and Cost}

The schedule variance and the cost variance provide the amount by which the spending is behind (or ahead of) schedule and the amount by which a project is exceeding (or less than) its budget. They do not give an idea of how these amounts compare with the total budget.

The ratio of earned value to planned value gives an indication of how much of the project is completed. This ratio is the schedule performance index (SPI). The formula is SPI = EV/PV. In the John's move example, the SPI equals 0.62 (SPI $=\$ 162.10 / \$ 261.65=0.62)$ A SPI value less than one indicates the project is behind schedule.

The ratio of the earned value to the actual cost is the cost performance index (CPI). The formula is CPI $=\mathrm{EV} / \mathrm{AC}$.

\section{Cost Performance Index of John's Move}

In the John's move example, CPI $=\$ 162.10 / \$ 154.50=1.05 \mathrm{~A}$ value greater than 1 indicates the project is under budget.

Figure 9.8 Schedule Variance and Cost Variance on Day Six of the John’s Move Project 


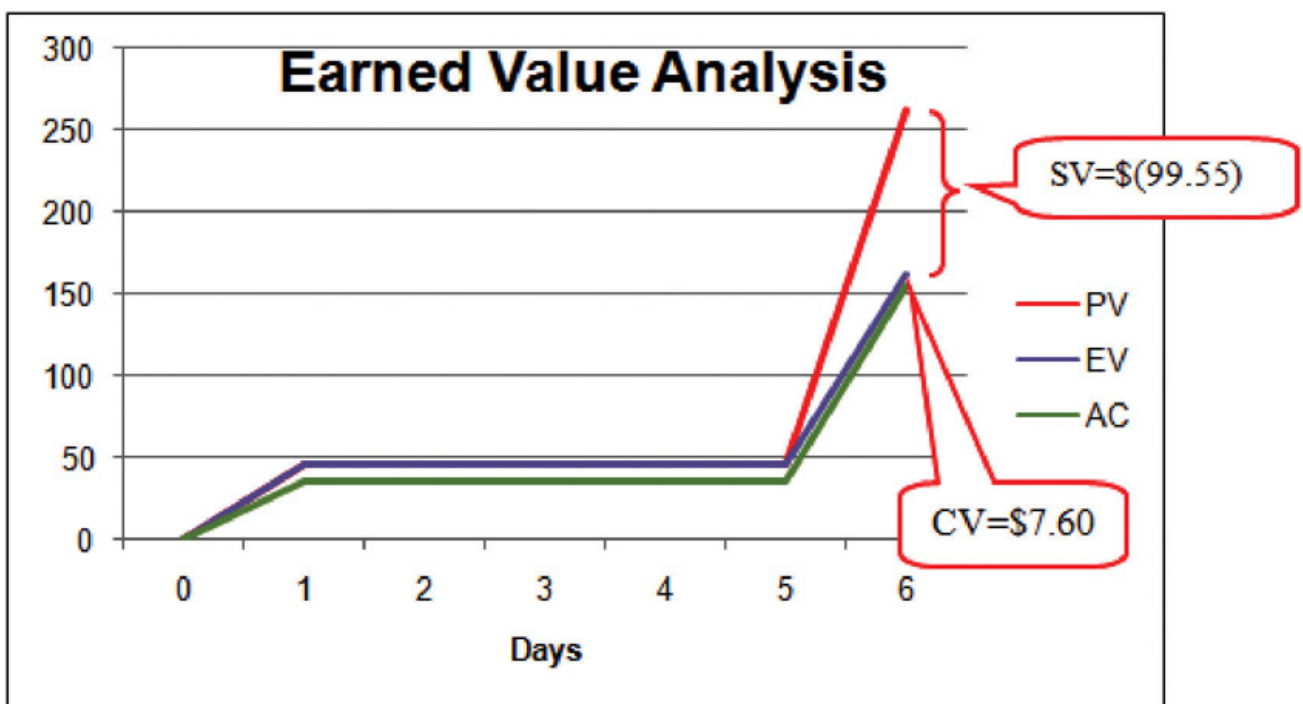

The cost variance of positive $\$ 7.60$ and the CPI value of 1.05 tell John that he is getting more value for his money than planned for the tasks scheduled by day six. The schedule variance (SV) of negative $\$ 99.55$ and the schedule performance index (SPI) of 0.62 tell him that he is behind schedule in adding value to the project.

During the project, the manager can evaluate the schedule using the schedule variance (SV) and the schedule performance index (SPI) and the budget using the cost variance (CV) and the cost performance index (CPI).

\section{Estimated Cost to Complete the Project}

Partway through the project, the manager evaluates the accuracy of the cost estimates for the activities that have taken place and uses that experience to predict how much money it will take to complete the unfinished activities of the project - the estimate to complete (ETC).

\section{Atypical Cost Variance}

To calculate the ETC, the manager must decide if the cost variance observed in the estimates to that point are representative of the future. For example, if unusually bad weather causes increased cost during the first part of the project, it is not likely to have the same effect on the rest of the project. If the manager decides that the cost variance up to this point in the project is atypical-not typical-then the estimate to complete is the difference between the original budget for the entire project - the budget at completion (BAC) — and the earned value (EV) up to that point. Expressed as a formula, ETC = BAC EV 


\section{Estimate to Complete John's Move}

In John's move, John was able to buy most of the items at a discount house that did not have a complete inventory and, he chose to buy an extra pair of lift straps. He knows that the planned values for packing materials were obtained from the price list at the moving company where he will have to buy the rest of the items, so those two factors are not likely to be typical of the remaining purchases. The reduced cost of lunch is unrelated to the future costs of packing materials, truck rentals, and hotel fees. John decides that the factors that caused the variances are atypical. He calculates that the estimate to complete (ETC) is the budget at completion $(\$ 1,534)$ minus the earned value at that point $(\$ 162.10)$, which equals $\$ 1,371.90$. Expressed as a formula, ETC $=\$ 1,534-\$ 162.10=\$ 1,371.90$.

\section{Typical Cost Variance}

If the manager decides that the cost variance is caused by factors that will affect the remaining activities, such as higher labor and material costs, then the estimate to complete (ETC) needs to be adjusted by dividing it by the cost performance index (CPI). For example, if labor costs on the first part of a project are estimated at $\$ 80,000$ (EV) and they actually cost $\$ 85,000$ (AC), the cost variance will be 0.94. (Recall that the cost variance $=\mathrm{EV}-\mathrm{AC})$.

To calculate the estimate to complete (ETC) assuming the cost variance on known activities is typical of future cost, the formula is $\mathrm{ETC}=(\mathrm{BAC}-\mathrm{EV}) / \mathrm{CPI}$. If the budget at completion (BAC) of the project is $\$ 800,000$, the estimate to complete is $(\$ 800,000-\$ 80,000) / 0.94=\$ 766,000$.

\section{Estimate Final Project Cost}

If the costs of the activities up to the present vary from the original estimates, it will affect the total estimate for the project cost. The new estimate of the project cost is the estimate at completion (EAC). To calculate the EAC, the estimate to complete (ETC) is added to the actual cost (AC) of the activities already performed. Expressed as a formula, EAC = AC + ETC.

\section{Estimate at Completion for John's Move}

The revised estimate at completion (EAC) for John's move at this point in the process is EAC $=\$ 154.50+$ $\$ 1,371.90=\$ 1,526.40$.

Refer to Figure 9.9 "Summary of Terms and Formulas for Earned Value Analysis" for a summary of terms and formulas. 
Figure 9.9 Summary of Terms and Formulas for Earned Value Analysis

\begin{tabular}{|c|c|c|c|c|}
\hline Term & Acronym & Description & Formula & $\begin{array}{l}\text { John's } \\
\text { Move }\end{array}$ \\
\hline Actual Cost & $\mathrm{AC}$ & The money actually spent on projects up to the present & & $\$ 154.50$ \\
\hline Budget at Completion & BAC & Original budget for the project (same as BCWS) & & $\$ 1,534.00$ \\
\hline Cost Performance Index & CPI & Ratio of earned value to actual cost & $\mathrm{CPI}=\mathrm{EV} / \mathrm{AC}$ & 1.05 \\
\hline Cost Variance & $\mathrm{CV}$ & Difference between earned value and actual cost & $\mathrm{CV}=\mathrm{EV}-\mathrm{AC}$ & $\$ 7.60$ \\
\hline Earned Value & $\mathrm{EV}$ & Sum of estimates for work actually done up to the present & & $\$ 162.10$ \\
\hline Estimate at Completion & EAC & Revised estimate of total project cost & $\mathrm{EAC}=\mathrm{AC}+\mathrm{ETC}$ & $\$ 1,526.40$ \\
\hline Estimate to Complete & ETC & $\begin{array}{l}\text { Money to complete the project if early cost variance is } \\
\text { atypical }\end{array}$ & $\mathrm{ETC}=\mathrm{BAC}-\mathrm{EV}$ & $\$ 1,371.90$ \\
\hline Estimate to Complete & ETC & $\begin{array}{l}\text { Money to complete the project if early cost variance is } \\
\text { typical }\end{array}$ & $\begin{array}{l}\mathrm{ETC}-(\mathrm{BAC}-\mathrm{EV}) / \\
\mathrm{CPI}\end{array}$ & N/A \\
\hline Planned Value & PV & Sum of the estimates for work done up to the present & & $\$ 261.65$ \\
\hline $\begin{array}{l}\text { Schedule Performance } \\
\text { Index }\end{array}$ & SPI & Ratio of earned value to planned value & $\mathrm{SPI}=\mathrm{EV} / \mathrm{PV}$ & .62 \\
\hline Schedule Variance & SV & Difference between earned value and planned value & $\mathrm{SV}=\mathrm{EV}-\mathrm{PV}$ & $\$(99.55)$ \\
\hline
\end{tabular}

\section{Key Takeaways}

- Extra money is allocated in a contingency fund to deal with activities where costs exceed estimates. Funds are allocated in a management reserves in case a significant opportunity or challenge occurs that requires change of scope but funds are needed immediately before a scope change can typically be negotiated.

- Schedule variance is the difference between the part of the budget that has been done so far (EV) versus the part that was planned to be completed by now (PV). Similarly, the cost variance is the difference between the EV and the actual cost (AC).

- The schedule performance index (SPI) is the ratio of the earned value and the planned value. The cost performance index (CPI) is the ratio of the earned value (EV) to the actual cost (AC).

- The formula used to calculate the amount of money needed to complete the project (ETC) depends on whether or not the cost variance to this point is expected to continue (typical) or not (atypical). If the cost variance is atypical, the ETC is simply the original total budget (BAC) minus the earned value (EV). If they are typical of future cost variances, the ETC is adjusted by dividing the difference between BAC and EV by the CPI.

- The final budget is the actual cost (AC) to this point plus the estimate to complete (ETC). 


\section{Exercises}

1. Money that is allocated for dealing with unplanned but predictable expenses is reserve.

2. The formula used to calculate the cost performance index is

3. The formula used to calculate the estimate to complete for atypical cost variances is

4. The sum of the budgeted amounts for the tasks that have been performed is the (two words).

5. Schedule variance is the minus the and cost variance is the minus the (use acronyms).

6. Schedule performance index is I__ and the cost performance index is (use acronyms).

7. The revised final budget is the plus the (use acronyms).

Estimating Earned Value

Consider a project you are familiar with in which the contractor or service provider who was performing the work needed to be replaced before the job was completed. Describe how the value of the contractor's efforts up to that point was determined and how that evaluation compared to an earned value analysis.

\section{References}

Project Management Institute, Inc., A Guide to the Project Management Body of Knowledge (PMBOK Guide), 4th ed. (Newtown Square, PA: Project Management Institute, Inc., 2008), 173. 


\subsection{Exercises}

Exercises at the end of the chapter are designed to strengthen your understanding and retention of the information recently acquired in the chapter.

\section{Short Answer Questions}

The questions in this section refer to the project budget shown below.

Figure 9.10 Example for Short Answer Questions

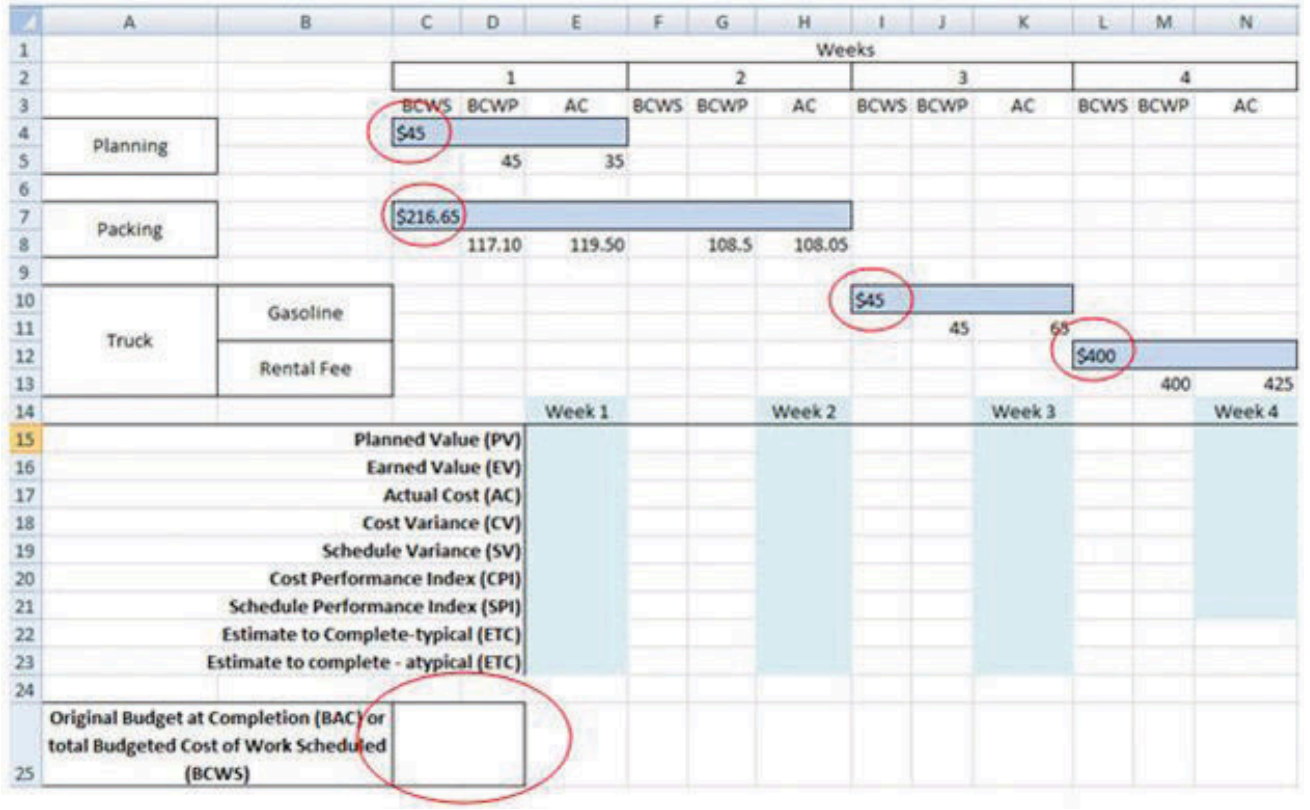

This project has three completed activities whose durations are indicated by the blue bars in row 2. The budgeted cost of work scheduled for each task is shown on the bar in row 2 . The budgeted cost of work scheduled for each week is shown on row 3 . Notice that the amounts in row 3 add up to the amounts shown on the bars. Rows 4 and 5 indicate the budgeted cost of work performed and actual cost. Notice that the second task started a week late.

1. What is the planned value (PV) at the end of week three?

2. What is the earned value (EV) at the end of week three?

3. What is the actual cost (AC) at the end of week three?

4. What is the cost variance (CV) at the end of week three?

5. What is the schedule variance (SV) at the end of week three?

6. What is the planned value (PV) at the end of week seven?

7. What is the earned value (EV) at the end of week seven? 
8. What is the actual cost (AC) at the end of week seven?

9. What is the cost variance (CV) at the end of week seven?

10. What is the schedule variance (SV) at the end of week seven?

11. What is the cost performance index (CPI) at the end of week seven?

12. What is the schedule performance Index at the end of week seven?

13. If the budget at completion (BAC) for this project is $\$ 500,000$, what is the Estimate to Complete (ETC) at the end of week seven if the cost and schedule variances experienced are typical of the remainder of the activities?

14. Based on your answer to the previous question, what is the estimate at completion (EAC) for this project?

\section{Essay Questions}

Write several paragraphs to provide more in-depth analysis and consideration when answering the following questions.

1. A project is about a third of the way through its scheduled activities, and an earned value management report has been prepared. The summary indicates that it has a CPI of 0.9 and an SPI of 0.8 . What do these two values tell you about the project?

2. A project is about half done with a CV of $\$(4,000)$ due to atypical costs in the first half of the project. Its project manager provides an ETC of \$50,000. Interpret this statement in your own words.

3. Give an example of an analogous estimate and a parametric estimate that are different from those described in the text.

\section{Discussion}

The exercises in this section are designed to promote exchange of information among students in the classroom or in an online discussion. The exercises are more open ended, which means that what you find might be completely different from what your classmates find, and you can all benefit by sharing what you have learned.

1. Describe an experience of your own that involved a parametric estimate. Describe the parameter and how it was used. Compare the estimate with the actual cost.

2. As an inexperienced project manager, how do you develop expert knowledge? Interview someone who would qualify as an expert in estimating costs and ask them to describe the process they went through. Ask them for advice on how to become an acknowledged expert in estimating and then share what you learn with your classmates. 


\subsection{Software and Technology Exercise}

\section{Learning Objective}

1. Create a spreadsheet to perform an earned value analysis.

\section{Earned Value Analysis}

In this exercise, you apply the formulas of earned value (EV) analysis to the John's Move project. Complete the exercise by following these instructions:

1. Navigate to the location where the student supplement files are stored and open Ch09EV.xls in a spreadsheet program such as MS Excel. Save the file on your computer as Ch09EVStudentName.xls. Four tasks span four weeks. The budgeted cost of work scheduled (BCWS) is shown at the beginning of each bar, as shown in Figure 9.11 "EV Analysis for John's Move”.

2. In cell C25, type $=\mathrm{C} 4+\mathrm{C} 7+\mathrm{I} 10+\mathrm{L} 12$ and then press Enter. The sum of the budgeted amounts for each task is the budget at completion (BAC).

3. Click cell C25 to select it. In the Number group, click the Increase Decimal button two times, if necessary, to display two decimal places. See Figure 9.12 "BAC Calculation”.

4. Click cell E15. Type $=C 4+C 7 / 2$. The planned value (PV) for the first week is the BCWS for the week. In this example, that is all the BCWS for planning and half of the BCWS for packing. The packing task is scheduled to take two weeks. Without further instructions, the budgeted amount is divided equally between the two weeks.

5. Move the mouse pointer to the Enter button on the Formula bar. See Figure 9.13 "PV Calculation for Week 1”. Entering formulas by using this button keeps the selection on the current cell.

6. On the Formula bar, click the Enter button. The PV is calculated and displayed in cell E15.

7. Capture this screen and paste it into a blank word processing document. Save the word processing document as Ch9EVStudentName using the Word 2003 .doc file format.

8. In the spreadsheet, click cell E16. Type $=D 5+D 8$ and then, on the Formula bar, click the Enter button. The EV is the sum of the budgeted work that has been performed up to that point in the project. See Figure 9.14 "EV Calculation for Week 1".

9. Click cell E17. Type $=E 5+E 8$ and then, on the Formula bar, click the Enter button. The actual cost (AC) for week 1 is the sum of the AC for planning and packing that occurred in 
week 1.

10. Click cell E18. Type $=E 16-E 17$ and then, on the Formula bar, click the Enter button. The cost variance $(\mathrm{CV})$ for week 1 is the $\mathrm{EV}$ minus the AC.

11. Click cell E19. Type $=E 16-E 15$ and then, on the Formula bar, click the Enter button. The schedule variance (SV) for week 1 is EV minus the PV. See Figure 9.15 “AC, CV, and SV Calculations for Week 1".

12. Refer to the definitions of CPI and SPI. Enter formulas in cells E20 and E21 to calculate the CPI and SPI. Recall that formulas begin with an equal sign and use cell names instead of the numbers in those cells. Use the Decrease Decimal or Increase Decimal buttons as needed to display two decimal places. See Figure 9.16 “CPI and SPI Calculations for Week 1”.

13. Refer to the definitions of estimate to complete (ETC) for typical and atypical variances in AC. Enter formulas in cells E22 and E23 to calculate the ETC for typical and atypical CV. Recall that the BAC value is in cell C25. Compare your results to Figure 9.17 "ETC at the End of Week 1 for Typical and Atypical AC”.

14. Click cell H15. Type $=E 15+C 7 / 2$ and then, on the Formula bar, click the Enter button. The $\mathrm{PV}$ at the end of week 2 is the sum of PV from the previous week plus the PV for the current week. In this case, the PV for week 2 is the second half of the packing task.

15. Click cell H16. Type $=E 16+G 8$ and then, on the Formula bar, click the Enter button. The EV at the end of week 2 is the sum of $E V$ from the previous week plus the budgeted cost of work performed (BCWP) for the current week.

16. Click cell H17. Type $=E 17+H 8$ and then, on the Formula bar, click the Enter button. The AC at the end of week 2 is the sum of AC from the previous week plus the AC for the current week.

17. Refer to the definitions for CV, SV, CPI, SPI, and ETC and write formulas in cells H18 through H23 to calculate those values at the end of week 2. See Figure 9.18 "Calculations for Week 2".

18. Capture the screen and paste it into Ch09EVStudentName.doc.

19. In the spreadsheet, apply what you have learned to perform similar calculations for weeks 3 and 4. See Figure 9.19 “Calculations for Weeks 3 and 4”.

20. Click cell E5. Type 30 and then, on the Formula bar, click the Enter button. Notice that all the calculations that depend on the AC in this cell are recalculated. See Figure 9.20 "Values That Depend on the AC in Cell E5 Change”.

21. Capture the screen and paste it into Ch09EVStudentName.doc.

Prepare the worksheet for printing:

1. In the spreadsheet, on the menu bar, click Page Layout. In the Page Setup group, at the lower right corner, click the Expand button.

2. In the Page Setup dialog box, on the Page tab, click the Landscape button and the Fit To button. See Figure 9.21 "Printout Oriented Horizontally and Forced to Fit on One Page”.

3. In the Page Setup dialog box, on the Header/Footer tab, click the In the Header dialog box, 
click the Left section, and then type your name. Click the Center section and then type John's Move. Click the Right section box and type For InstructorName, substituting your instructor's name. See Figure 9.22 “Your Name and Your Instructor’s Name in the Header”.

4. Click $O K$ to close both dialog boxes. Close the print preview, if necessary.

5. Review your work in Ch09EVStudentName.xls and use the following rubric to determine its adequacy:

\begin{tabular}{|c|c|c|c|}
\hline Element & Best & Adequate & Poor \\
\hline File name & Ch09EVStudentName.xls & Ch09EVStudentName.xlsx & $\begin{array}{l}\text { Did not include } \\
\text { student name }\end{array}$ \\
\hline $\begin{array}{l}\text { Create a } \\
\text { spreadsheet } \\
\text { to perform } \\
\text { an EV } \\
\text { analysis }\end{array}$ & $\begin{array}{l}\text { Formulas that produce the values } \\
\text { shown in Figure } 9.16 \text { "CPI and SPI } \\
\text { Calculations for Week } 1 \text { ” and Figure } \\
9.17 \text { "ETC at the End of Week } 1 \text { for } \\
\text { Typical and Atypical AC”, } \\
\text { depending on the value in cell E5; } \\
\text { names in header for printout }\end{array}$ & Same as Best & $\begin{array}{l}\text { Could do } \\
\text { formulas for } \\
\text { weeks } 1 \text { and } 2 \text { but } \\
\text { could not apply } \\
\text { knowledge to } \\
\text { weeks } 3 \text { and } 4 \text {; } \\
\text { errors in } \\
\text { formulas; missing } \\
\text { header }\end{array}$ \\
\hline
\end{tabular}

6. Review your work in Ch09EVStudentName.doc and use the following rubric to determine its adequacy:

\begin{tabular}{|l|l|l|l|}
\hline Element & Best & Adequate & Poor \\
\hline File name & Ch09EVStudentName.doc & $\begin{array}{l}\text { Same name } \\
\text { saved as } \\
\text { docx file }\end{array}$ & $\begin{array}{l}\text { Used a } \\
\text { different } \\
\text { name }\end{array}$ \\
\hline $\begin{array}{l}\text { Use dedicated project management } \\
\text { software to manage changes to the } \\
\text { WBS }\end{array}$ & $\begin{array}{l}\text { Three screen captures that show } \\
\text { the development of the } \\
\text { spreadsheet }\end{array}$ & Same as Best & $\begin{array}{l}\text { Missing } \\
\text { screens }\end{array}$ \\
\hline
\end{tabular}

7. Save the file and submit it as directed by the instructor. 


\section{Chapter 10: Managing Project Quality}

Project managers have two different interests in quality. Some projects are performed to provide a significant improvement in the quality of an existing process, and the project activities themselves must reflect high-quality standards. A basic knowledge of the statistics and procedures used in quality control will help the project manager understand the objectives of step projects and perform projects in companies that are committed to high-quality standards. 


\subsection{Quality and Statistics}

\section{Learning Objectives}

1. Define quality.

2. Define and explain statistics terms used in quality control.

3. Estimate the likelihood of samples falling within one, two, or three standard deviations of the mean given a normal distribution caused by random factors.

\section{Definitions of Quality and Grade}

Quality is a relative term, which means that something is of high or low quality compared to what it is required to be. According to the International Organization for Standardization (ISO), quality is "the degree to which a set of inherent characteristics fulfill requirements" (International Organization for Standardization, 2005; Project Management Institute, 2008). The requirements of a product or process can be categorized or given a grade. The quality is determined by how well something meets the requirements of its grade. Consider the following examples.

\section{Quality of Gasoline Grades}

Petroleum refiners provide gasoline in several different grades based on the octane rating because higher octane ratings are suitable for higher compression engines. Gasoline must not be contaminated with dirt or water, and the actual performance of the fuel must be close to its octane rating. A shipment of low-grade gasoline graded as 87 octane that is free of water or other contaminants would be of high quality, while a shipment of high grade 93 octane gas that is contaminated with dirt would be of low quality.

\section{Quality of Furniture Packing in John's Move}

John has antique furniture that is in excellent condition that was left to him by his grandmother. The pieces are important to John for sentimental reasons and they are also valuable. John decides to hire movers (high-grade professionals) to load his furniture into the truck using appropriate padding and restraints to prevent dents and scratches during the long trip to Atlanta and then to unload the truck in Atlanta. John's standard for high qual- 
ity is that no observable damage occurs to his large pieces of furniture, especially the antiques. If the furniture arrives in his new apartment without a single dent, scratch, or other damage, the activity will be of high quality.

John's standard for packing his kitchen is lower. His dishes are old and cheap, so he decides to trust his inexperienced friends (low-grade amateurs) to help him pack his kitchen. If a few of the dishes or glassware are chipped or broken in the process, the savings in labor cost will more than make up for the loss, and the dishes can be easily replaced. If John has a few chipped dishes and a broken glass or two by the time he is unpacked in Atlanta, he will consider the kitchen packing to be of high quality.

For most people, the term quality also implies good value-getting your money's worth. For example, even low-grade products should still work as expected, be safe to use, and last a reasonable amount of time.

\section{Statistics Terminology}

Determining how well products meet grade requirements is done by taking measurements and then interpreting those measurements. Statistics - the mathematical interpretation of numerical data - is useful when interpreting large numbers of measurements and is used to determine how well the product meets a specification when the same product is made repeatedly. Measurements made on samples of the product must be between control limits - the upper and lower extremes of allowable variation - and it is up to management to design a process that will consistently produce products between those limits.

\section{Setting Control Limits in Gasoline Production}

A petroleum refinery produces large quantities of fuel in several grades. Samples of the fuels are extracted and measured at regular intervals. If a fuel is supposed to have an 87 octane performance, samples of the fuel should produce test results that are close to that value. Many of the samples will have scores that are different from 87. The differences are due to random factors that are difficult or expensive to control. Most of the samples should be close to the 87 rating and none of them should be too far off. The manufacturer has grades of 85 and 89 , so they decide that none of the samples of the 87 octane fuel should be less than 86 or higher than 88 .

If a process is designed to produce a product of a certain size or other measured characteristic, it is impossible to control all the small factors that can cause the product to differ slightly from the desired measurement. Some of these factors will produce products that have measurements that are larger than desired and some will have the opposite effect. If several random factors are affecting the process, they tend to offset each other most of the time, and the most common results are near the middle of the range. This idea is called the central limit theorem.

If the range of possible measurement values is divided equally into subdivisions called bins, the measurements can be sorted, and the number of measurements that fall into each bin can be counted. The result is a frequency distribution that shows how many measurements fall into each bin. If the effects that are causing the differences are random and tend to offset each other, the frequency distribution is 
called a normal distribution, which resembles the shape of a bell with edges that flare out. The edges of a theoretical normal distribution curve get very close to zero but do not reach zero.

\section{Normal Distribution of Gasoline Samples}

A refinery's quality control manager measures many samples of 87 octane gasoline, sorts the measurements by their octane rating into bins that are 0.1 octane wide, and then counts the number of measurements in each bin. Then she creates a frequency distribution chart of the data, as shown in Figure 10.1 "Normal Distribution of Measurements of Gasoline Samples”.

If the measurements of product samples are distributed equally above and below the center of the distribution as they are in Figure 10.1 "Normal Distribution of Measurements of Gasoline Samples", the average of those measurements is also the center value that is called the mean and is represented in formulas by the lowercase Greek letter $\mu$ (pronounced mu). The amount of difference of the measurements from the central value is called the sample standard deviation or just the standard deviation. The first step in calculating the standard deviation is subtracting each measurement from the central value and then squaring that difference. (Recall from your mathematics courses that squaring a number is multiplying it by itself and that the result is always positive.) The next step is to sum these squared values and divide by the number of values minus one. The last step is to take the square root. The result can be thought of as an average difference. (If you had used the usual method of taking an average, the positive and negative numbers would have summed to zero.) Mathematicians represent the standard deviation with the lowercase Greek letter $\sigma$ (pronounced sigma). If all the elements of a group are measured, it is called the standard deviation of the population and the second step does not use a minus one.

Figure 10.1 Normal Distribution of Measurements of Gasoline Samples

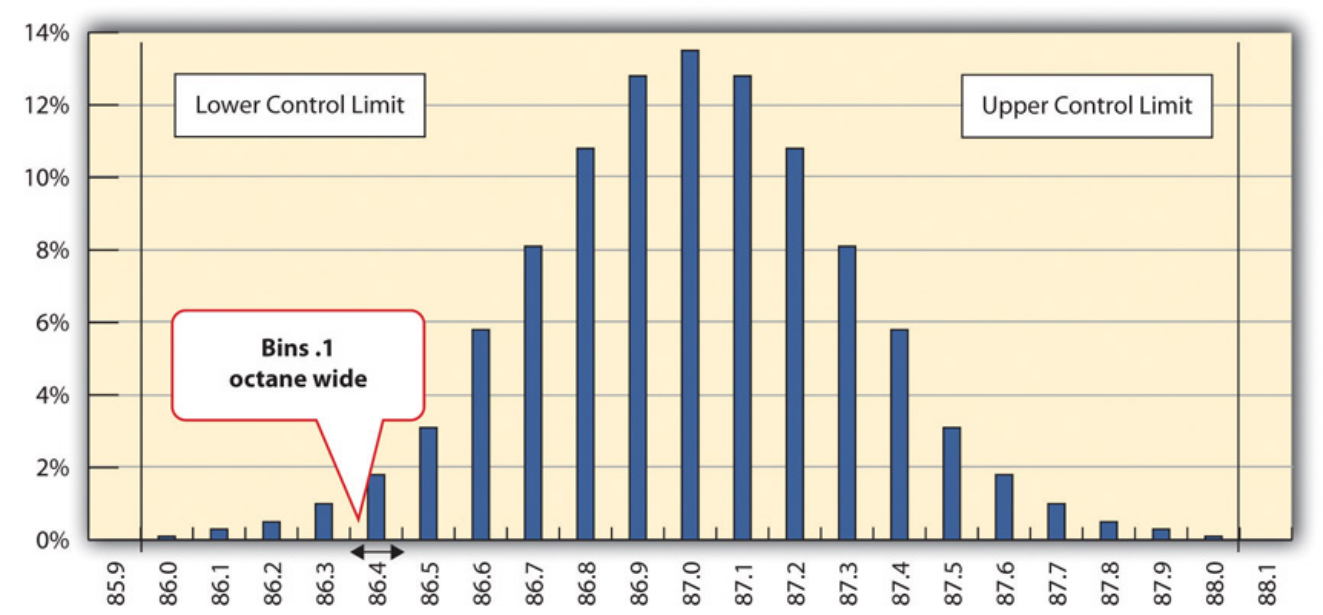

The chart shows that the most common measurements of octane rating are close to 87 and that the other measurements are distributed equally above and below 87. The shape of the distribution chart supports the central limit theorem's assumption that the factors that are affecting the octane rating are random and tend to offset each other, which is indicated by the symmetric shape. This distribution is a classic example of a normal distribution. The quality control manager notices that none of the measurements are above 88 or below 86 so they are within control limits and concludes that the process is working satisfactorily. 


\section{Standard Deviation of Gasoline Samples}

The refinery's quality control manager uses the standard deviation function in his spreadsheet program to find the standard deviation of the sample measurements and finds that for his data, the standard deviation is 0.3 octane. She marks the range on the frequency distribution chart to show the values that fall within one sigma (standard deviation) on either side of the mean. See the figure below.

Figure 10.2

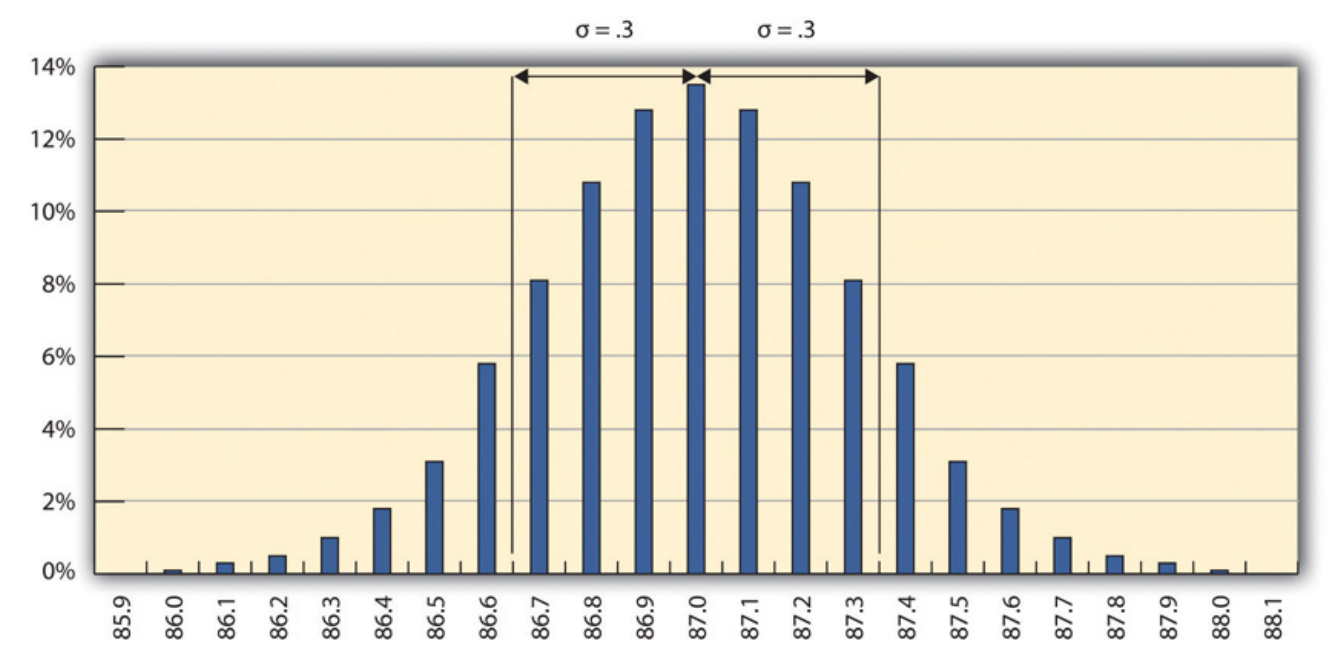

Most of the measurements are within 0.3 octane of 87.

For normal distributions, about 68.3 percent of the measurements fall within one standard deviation on either side of the mean. This is a useful rule of thumb for analyzing some types of data. If the variation between measurements is caused by random factors that result in a normal distribution and someone tells you the mean and the standard deviation, you know that a little over two-thirds of the measurements are within a standard deviation on either side of the mean. Because of the shape of the curve, the number of measurements within two standard deviations is 95.4 percent, and the number of measurements within three standard deviations is 99.7 percent. For example, if someone said the average (mean) height for adult men in the United States is 5 feet 10 inches (70 inches) and the standard deviation is about 3 inches, you would know that 68 percent of the men in the United States are between five feet seven inches (67 inches) and six feet one inch (73 inches) in height. You would also know that about 95 percent of the adult men in the United States were between five feet four inches and six feet four inches tall, and that almost all of them (99.7 percent) are between five feet one inches and six feet seven inches tall. These figures are referred to as the 68-95-99.7 rule.

\section{Almost All Samples of Gasoline are Within Three STD}

The refinery's quality control manager marks the ranges included within two and three standard deviations, as shown below. 


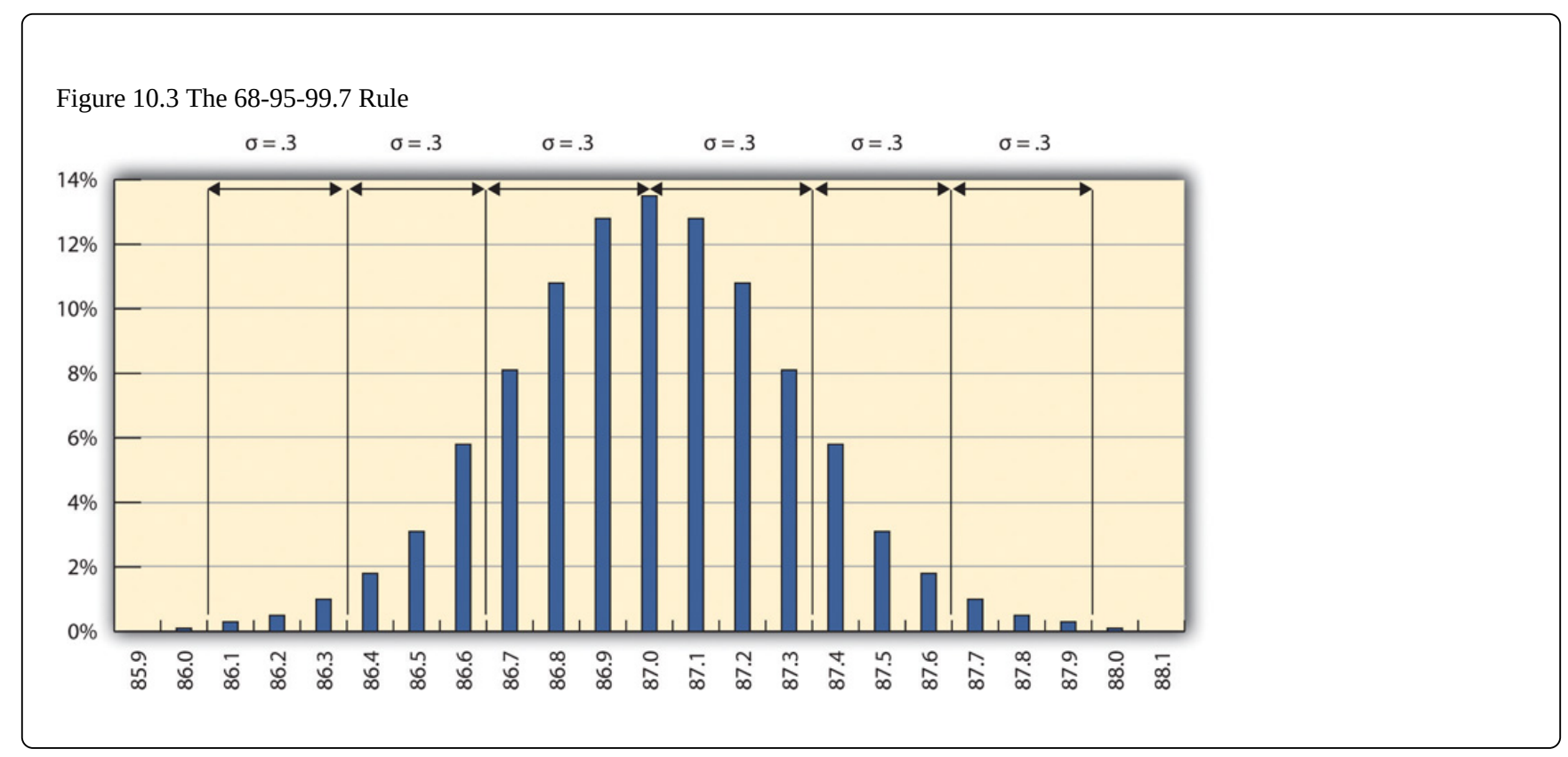

Some products must have less variability than others to meet their purpose. For example, if one machine drills a hole and another machine shapes a rod that will slide through the hole, it might be very important to be sure that if the smallest hole was ever matched with the widest rod, that the rod would still fit. Three standard deviations from the control limits might be fine for some products but not for others. In general, if the mean is six standard deviations from both control limits, the likelihood of a part exceeding the control limits from random variation is practically zero (2 in 1,000,000,000). Refer to Figure 10.4 "Meaning of Sigma Levels".

Figure 10.4 Meaning of Sigma Levels

\begin{tabular}{|l|l|l|l|l|}
\hline $\begin{array}{l}\text { Standard Deviations between Mean and } \\
\text { Either Control Limit }\end{array}$ & $\begin{array}{l}\text { Sigma } \\
\text { Level }\end{array}$ & $\begin{array}{l}\text { Percentage Inside } \\
\text { Control Limits }\end{array}$ & $\begin{array}{l}\text { Percentage Outside } \\
\text { Control Limits }\end{array}$ & $\begin{array}{l}\text { Parts Outside Control Limits } \\
\text { (approximate) }\end{array}$ \\
\hline 1 & 1 & $68.3 \%$ & $31.7 \%$ & 32 per 100 \\
\hline 2 & 2 & $95.4 \%$ & $4.6 \%$ & 5 per 100 \\
\hline 3 & 3 & $99.7 \%$ & $.3 \%$ & 3 per 1,000 \\
\hline 4 & 4 & $99.9937 \%$ & $.0063 \%$ & 4 per 100,000 \\
\hline 5 & 5 & $99.99994 \%$ & $.00006 \%$ & 6 per 10 million \\
\hline 6 & 6 & $99.9999998 \%$ & $.0000002 \%$ & 2 per billion \\
\hline
\end{tabular}

\section{A Step Project Improves Quality of Gasoline}

A new refinery process is installed that produces fuels with less variability. The refinery's quality control manager takes a new set of samples and charts a new frequency distribution diagram, as shown below. 


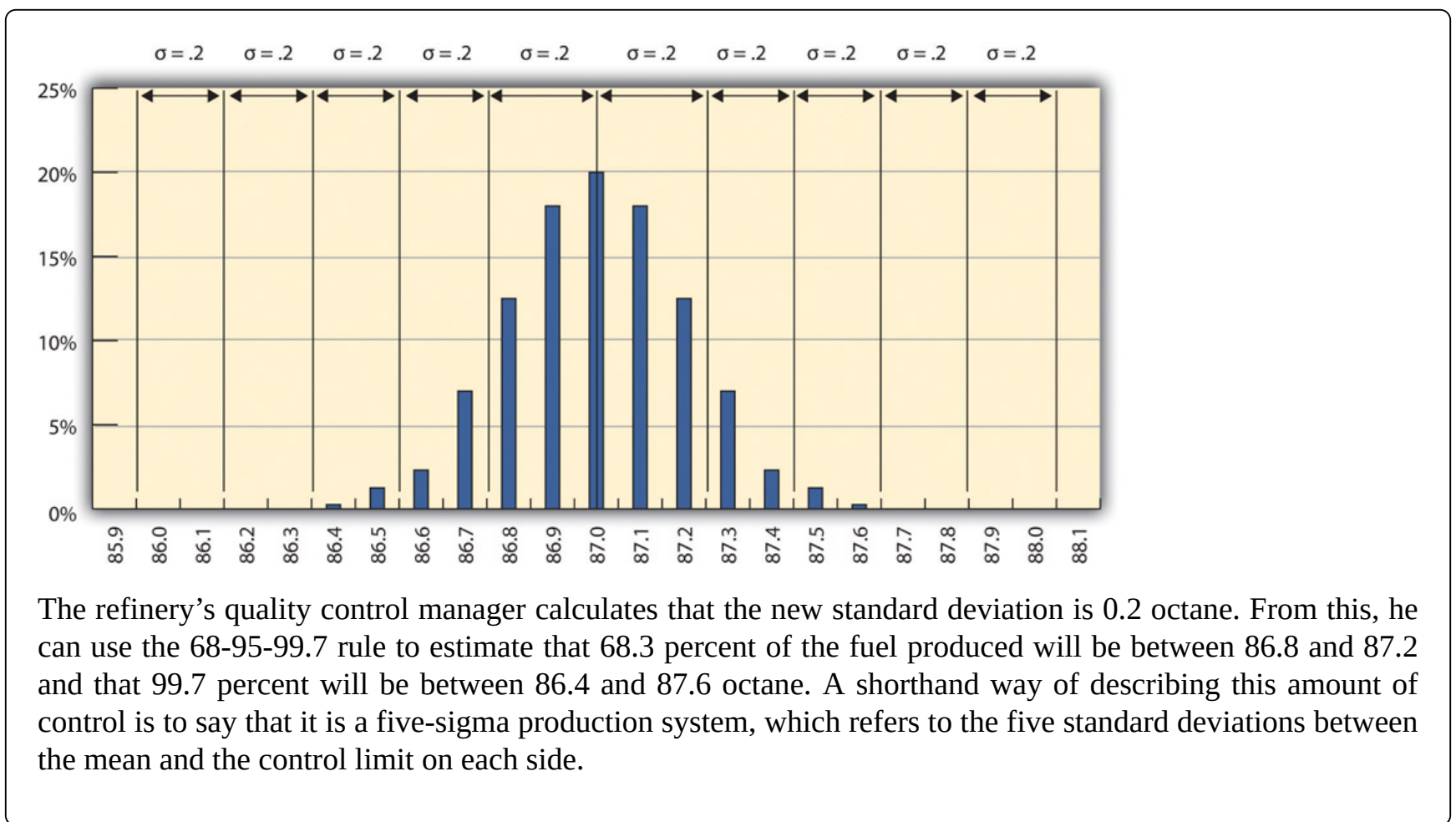

\section{Key Takeaways}

- Quality is the degree to which a product or service fulfills requirements and provides value for its price.

- Statistics is the mathematical interpretation of numerical data, and several statistical terms are used in quality control. Control limits are the boundaries of acceptable variation.

- If random factors cause variation, they will tend to cancel each other out-the central limit theorem. The central point in the distribution is the mean, which is represented by the Greek letter mu, $\mu$. If you choose intervals called bins and count the number of samples that fall into each interval, the result is a frequency distribution. If you chart the distribution and the factors that cause variation are random, the frequency distribution is a normal distribution, which looks bell shaped.

- The center of the normal distribution is called the mean, and the average variation is calculated in a special way that finds the average of the squares of the differences between samples and the mean and then takes the square root. This average difference is called the standard deviation, which is represented by the Greek letter sigma, $\sigma$.

- About 68 percent of the samples are within one standard deviation, 95.4 percent are within two, and 99.7 percent are within three. 


\section{Exercises}

1. According to the ISO, quality is the degree to which a set of inherent characteristics fulfill

2. The upper and lower extremes of acceptable variation from the mean are called the limits.

3. The odds that a sample's measurement will be within one standard deviation of the mean is percent.

4. How is quality related to grade?

5. If the measurements in a frequency distribution chart are grouped near the mean in normal distribution, what does that imply about the causes of the variation?

6. If you have a set of sample data and you had to calculate the standard deviation, what are the steps?

7. If a set of sample measurements has a mean of 100 , a normal distribution, a standard deviation of 2, and control limits of 94 and 106, what percentage of the samples are expected to be between 94 and 106? Explain your answer.

Using Statistical Measures

Choose two groups of people or items that have a measurable characteristic that can be compared, such as the height of adult males and females. Describe the distribution of the measurements by stating whether you think the groups have a relatively small or large standard deviation and whether the distributions overlap (e.g., some women are taller than some men even though the mean height for men is greater than the mean height for women). Demonstrate that you know how to use the following terms correctly in context:

- Normal distribution

- Standard deviation

- Mean

\section{References}

International Organization for Standardization, Quality Management Systems-Fundamentals and Vocabulary (Geneva: ISO Press, 2005).

Project Management Institute, Inc., A Guide to the Project Management Body of Knowledge (PMBOK Guide), 4th ed. (Newtown Square, PA: Project Management Institute, Inc., 2008), 190. 


\subsection{Development of Quality as a Competitive Advantage}

\section{Learning Objectives}

1. Describe the historical events and forces that led up to today's emphasis on quality as a competitive requirement.

2. Describe quality awards in Japan and the United States.

3. Describe quality programs and standards such as TQM, Six Sigma, and ISO 9000.

4. Describe and calculate the cost of quality.

Quality management is an approach to work that has become increasingly important as global cooperation and competition have increased. A review of the history of quality management explains why it is so important to companies and why clients often require projects to document their processes to satisfy quality standards.

\section{Statistical Control Before World War II}

Prior to the late 1700s, products such as firearms and clocks were made as individual works where the parts were adjusted to each other so they could work together. If a part broke, a new one had to be made by hand to fit. In 1790 in France, Honoré Blanc demonstrated that he could make musket parts so nearly identical that a musket could be assembled from bins of parts chosen at random (Alder, 1997). The practice of making parts to a high level of accuracy in their dimensions and finishes made the parts interchangeable. The use of interchangeable parts became the founding principle of assembly line manufacturing to produce all manner of goods from sewing machines to automobiles. The manufacturers of firearms and weapons were often the leaders in improving quality because reliable and safe operation of weapons and their rapid repair is a matter of life and death.

\section{Statistical Control in the United States During World War II}

During World War II, factories were converted from manufacturing consumer goods to weapons. War plants had to make large numbers of parts as fast as possible while doing it safely for the workers and for the service members who used them. Important improvements in quality control (QC) - the management of production standards through statistical interpretation of random product measurements, which emphasizes consistency and accuracy-were made during this period. A key figure in the history of quality management who was an important person in the war effort was Walter Shewhart at Bell 
Telephone Laboratories. Shewhart recognized that real processes seldom behaved like theoretical random distributions and tended to change with time. He separated causes of variation into two categories: chance cause and assignable cause. Chance causes could be ignored if they did not cause too much variation, and trying to eliminate them often made the problem worse, but assignable causes could be fixed. To help distinguish between variations caused by random events and trends that indicated assignable causes, Shewhart introduced the control chart, which is also known as a type of run chart because data are collected while the process is running. A control chart has time on the bottom axis and a plot of sample measurements. The mean, upper control limit, lower control limit, and warning lines that are two sigma from the mean are indicated by horizontal lines.

\section{Control Chart Shows Production Variation of Gasoline}

The refinery quality control manager takes samples each day of the 87 octane gasoline for twenty days and charts the data on a control chart, as shown below.

Figure 10.6 Control Chart Displaying Variations Due to Chance Causes

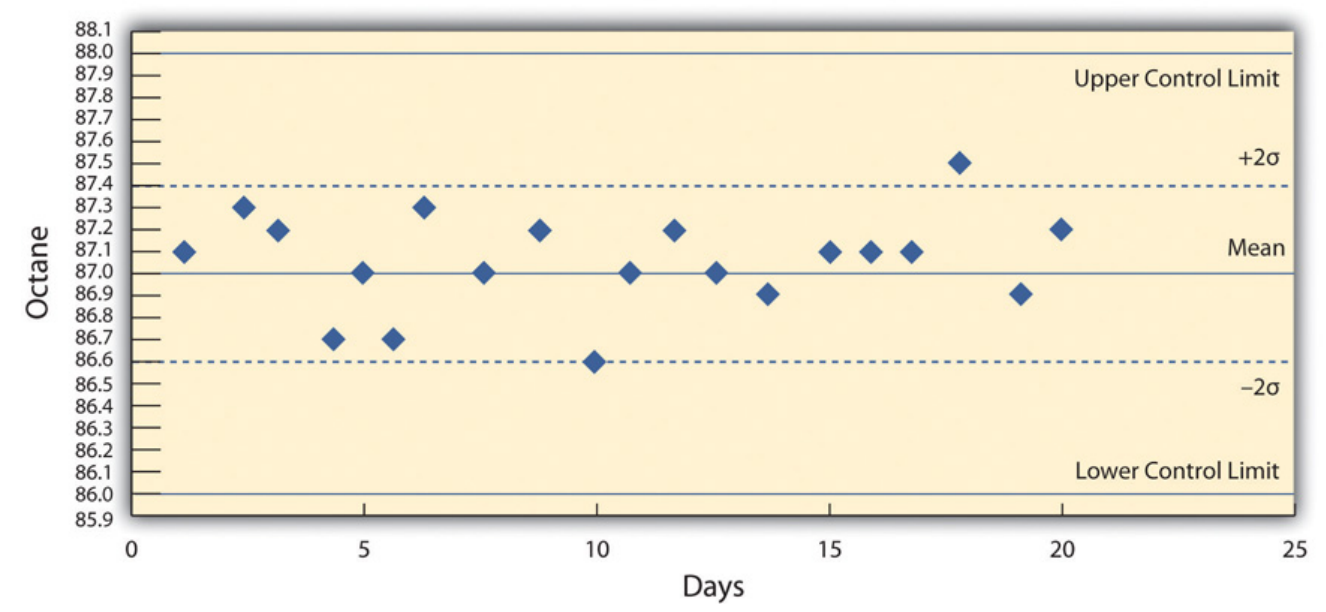

She recognizes that the highest and lowest measurements are not part of a trend and are probably due to chance causes. However, the control chart from the next twenty days, as shown below, indicates an upward trend that might be due to an assignable cause. She alerts the process manager to let him know that there is a problem that needs to be fixed before the product exceeds the upper control limit. This might indicate the need to initiate a project to fix the problem.

Figure 10.7 Control Chart Displaying Variations That Might Be Due to an Assignable Cause 


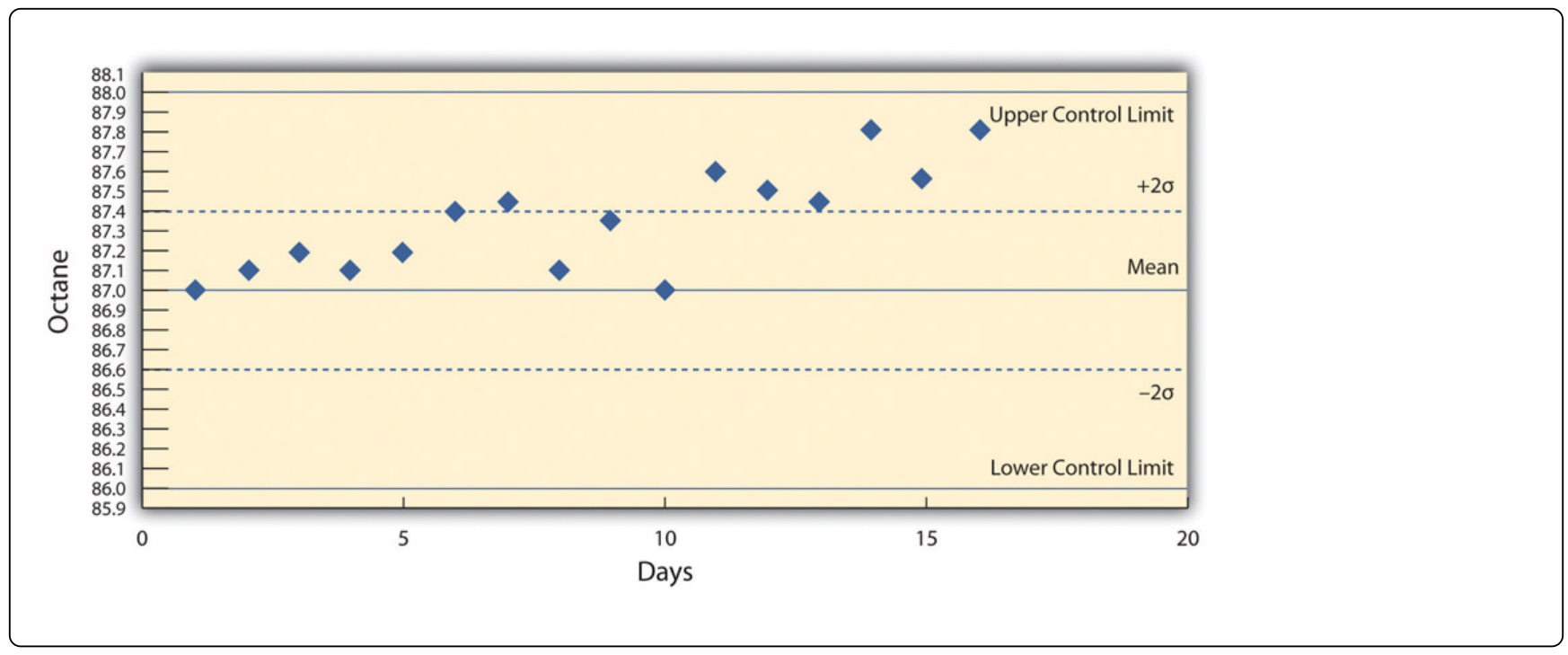

\section{Deming and Postwar Japan}

The most influential person in modern quality control was an American who was a hero in Japan but virtually unknown in the United States. W. Edwards Deming worked with Shewhart at Bell Labs and helped apply Shewhart's ideas to American manufacturing processes during World War II. Following the war, American factories returned to the production of consumer goods. Many of the other major manufacturing centers in the world had been damaged by bombing during the war and took time to recover. Without the safety needs of wartime and with little competition, quality control was not a high priority for American companies (Dowd, 2006). Management in the United States focused on increasing production to meet demand and lowering costs to increase profits.

After the war, while the United States occupied Japan, Deming was asked by the U.S. Department of the Army to assist with the statistics of the 1950 census in Japan. Kenichi Koyanagi, the managing director of the Union of Japanese Scientists and Engineers and a very influential industrialist, asked Deming to speak to twenty-one top industrial leaders on the topic of global strategy for Japanese industry. Deming went beyond Shewhart's work and talked about his philosophy of quality manufacturing and how the responsibility for quality begins with management. He explained that a corporate culture devoted to producing high-quality products would result in less waste, lower costs, greater client loyalty, and greater market share. With Koyanagi's support, Deming's ideas were widely adopted by these influential leaders.

Deming described his philosophy as a system of profound knowledge, which has four parts:

1. Appreciation of a system. Understanding how suppliers, producers, and clients interact

2. Knowledge of variation. Understanding statistical variation

3. Theory of knowledge. Understanding what can be known and what cannot

4. Knowledge of psychology. Understanding human nature

In 1950, the Japanese created the Deming prize in Deming's honor, which is awarded to an individual 
and a company for major advances in quality improvements. In 1960, Deming was awarded the Order of the Sacred Treasure, Second Class by the Prime Minister on behalf of Emperor Hirohito.

\section{Quality Management in America}

By the 1970s, Japanese companies had a reputation for high quality and were taking market share from American companies, but Deming's teachings were virtually unknown in his own country. It was not until 1980 that America became aware of Deming when his work was described in an NBC documentary titled If Japan Can, Why Can't We? (Dowd, 2006) By then, Deming was eighty years old and the producer of the show originally assumed he was dead (Boardman, 1994).

In 1982, Deming's book was published and later retitled Out of Crisis, in 1986 (Deming, 1982). It was aimed at explaining his system to American manufacturers and the American public. In the book, Deming described fourteen principles of management to guide the implementation of his philosophy. Some of them were challenges to Western managers and very different from the thinking that was prevalent at the time. In brief, they are as follows:

1. Create constancy of purpose toward improvement of product and service.

2. Adopt a new philosophy. We are in a new economic age. Western management must awaken to the challenge, learn their responsibilities, and take on leadership for a change.

3. Cease dependence on inspection to achieve quality. Eliminate the need for inspection on a mass basis by building quality into the product in the first place.

4. End the practice of awarding business on the basis of price tag. Instead, minimize cost. Move toward a single supplier for any one item, on a long-term relationship of loyalty and trust.

5. Improve constantly and forever the system of production and service to improve quality and productivity and thus constantly decrease costs.

6. Institute training on the job.

7. Institute leadership. The aim of supervision should be to help people and machines and gadgets to do a better job. Supervision of management is in need of overhaul, as well as supervision of production workers.

8. Drive out fear, so that everyone may work effectively for the company.

9. Break down barriers between departments.

10. Eliminate slogans, exhortations, and targets for the workforce asking for zero defects and new levels of productivity.

11. Eliminate work standards (quotas) on the factory floor. Substitute leadership.

12. Remove barriers that rob the hourly worker of his right to pride of workmanship.

13. Institute a vigorous program of education and self-improvement.

14. Put everybody in the company to work to accomplish the transformation. The transformation is everybody's job. 
Between 1979 and 1982, Ford Motor Company lost \$3 billion, and they were looking for solutions to their problems. They chose to apply Deming's approach to develop the new Taurus-Sable model and by 1986 had become the most profitable American auto company (Gabor, 2001).

Ford adopted a Japanese approach to quality known in America as total quality management (TQM). TQM in Japan has four major components:

1. Kaizen. Improvement must involve all members of a company (Encyclopedia Britannica, 2009).

2. Atarimae hinshitsu. Make things work the way they are supposed to work (NationMaster.com, 2009).

3. Kansei. Learn from the way a user applies the product to make improvements (WASEDA University, 2010).

4. Miryokuteki hinshitsu. Things should have an aesthetic quality and be pleasing to use (NationMaster.com, 2009).

According to Peter B. Petersen (Petersen, 1999), TQM differs from the Deming approach in four fundamental ways:

1. The Deming approach represents one philosophy that is used in its entirety or not at all. In contrast, TQM can be tailored to a particular environment.

2. Both agree that a long-term commitment is required by top management. However, Deming would drop clients if they started to wane, while TQM consultants were less demanding.

3. Deming insists on constancy of purpose, while TQM adapts to the situation, which results in lack of constancy.

4. Deming requires adoption of his principles of profound knowledge, while TQM lacks this unified philosophy.

Many poorly qualified consulting firms provided training in TQM to American companies. The approach worked in some cases but not in others where it was applied superficially, and the movement's credibility was diminished.

Another approach to quality management in the United States was formulated at Motorola in 1986 and was named Six Sigma (6б). The Six Sigma practices were based on Deming's work, TQM, and others and had similarities regarding continuous efforts at improvement involving everyone at the company. It emphasized a clear focus on achieving quantifiable financial returns from any Six Sigma project. To determine the financial return on a quality initiative, the cost of quality (COQ) must be determined. The cost of quality has two parts: the cost of prevention and the cost of failure (or nonconformance). The cost of quality is the sum of the cost of prevention and the cost of failure. If spending more on prevention reduces the cost of failure by an even greater amount, the total cost of quality is reduced.

- Cost of prevention

1. Cost of conformance. Cost to improve quality

2. Cost of appraisal. Cost to measure and evaluate quality 
- Cost of failure

1. Internal costs. Repairing bad parts before shipment or retooling a manufacturing line to reduce failures

2. External costs. Managing returns, lawsuits, product recalls

Six Sigma identified individuals as experts in quality and awarded titles like Champion and Master Black Belt. The name Six Sigma refers to a process that has six standard deviations from the mean to either control limit that would ensure virtually zero defects. (In practice, the Six Sigma approach allows for a 1.5 sigma drift, so it is really a 4.5 sigma standard that allows approximately 3.4 defects per million products.) This approach was adopted by Jack Welch at General Electric with great success. By the late 1990s, about two-thirds of the top five hundred companies in the United States had begun Six Sigma projects, including Ford, which had allowed its quality programs to slip. To provide encouragement and a consistent standard, the U.S. government created the Malcolm Baldrige National Quality Award in 1987 to encourage companies to improve quality; the award was named for Malcolm Baldrige who was the U.S. secretary of commerce from 1981 to 1987 (National Institute of Standards and Technology, 2008). The criteria used to determine award winners are as follows:

1. Leadership of senior executives

2. Strategic planning

3. Customer and market focus

4. Measurement, analysis, and knowledge management

5. Workforce focus

6. Process management

7. Results

\section{Trade and International Standards}

Trade between countries increased as countries recovered from WWII and began producing consumer goods. In 1948, the General Agreement on Tariffs and Trade (GATT) established the rules for international trade in the postwar world. Through years of negotiations based on GATT, the World Trade Organization (WTO) was created in 1995. The WTO is a negotiating forum where governments can discuss ways to help trade flow as freely as possible (World Trade Organization, 2009).

Increases in trade forced companies to improve the quality of their products to compete for clients and to exchange parts reliably between companies that used parts suppliers. To assist in developing standards for quality that would be the same between countries, an organization of 158 national standards groups formed the International Organization for Standardization (ISO), which is headquartered in Switzerland. For example, a company might require a parts supplier to meet certain ISO standards if it wants to bid on contracts. There are thousands of ISO standards, and they are grouped by their numbers. The ISO 9000 group of standards relate to quality: 
- ISO 9000. Fundamentals and vocabulary for this group of quality standards.

- ISO 9001. Standards for evaluating the quality management processes in an organization. It has five parts:

1. Overall requirements for the quality management system and documentation

2. Management responsibility, focus, policy, planning and objectives

3. Resource management and allocation

4. Product realization and process management

5. Measurement, monitoring, analysis, and improvement

- ISO 9004. Ways to extend benefits of ISO 9001 to employees, owners, suppliers, partners, and society in general. It is a guide for top management for overall quality improvement.

- ISO 9011. Guidance for auditing a quality system.

Recommended steps for implementing a quality management system (QMS) are as follows:

1. Fully engage top management.

2. Identify key processes and the interactions needed to meet quality objectives.

3. Implement and manage the QMS and its processes.

4. Build your ISO 9001-based QMS.

5. Implement the system, train company staff, and verify effective operation of your processes.

6. Manage your QMS - focus on client satisfaction, strive for continual improvement.

7. If necessary, seek third-party certification and registration of the QMS, or alternatively, issue a self-declaration of conformity (International Organization for Standardization, 2005).

\section{Key Takeaways}

- The need for production of safe, reliable weapons that could be mass produced led to use of methods to assure that parts were manufactured within controlled limits. An early example is the interchangeable musket parts produced in France in 1790 and, later, the quality control methods introduced by Shewhart in the United States during World War II.

- Following World War II, Japanese companies followed advice from Deming and others to make quality a top priority for management. Higher-quality products gave Japan a competitive advantage with U.S. consumers that forced U.S. firms to respond with similar quality programs.

- The Deming award is given by Japan to companies doing business in Japan for high-quality standards. Similarly, the Baldrige National Quality Award is given to U.S. companies and individuals for their contribution to quality.

- Total quality management is a flexible program that is adapted from Japanese practices that emphasize kaizen, participation by all; atarimaie hinshitsu, making things work the way they 
should; kansei, learning from the way the client uses the product to make improvements; and miryokuteki hinshitsu, giving products an aesthetic quality to make them pleasing to use. Six Sigma identifies specialists within the organization and assigns titles like Master Black Belt. Each quality project must evaluate the cost of quality to gain approval.

- The International Standards Institute devises guidelines for establishing practices. The ISO 9000 group are guidelines for establishing practices that are likely to create quality products.

- The cost of quality has two parts: the cost of prevention and the cost of failure. The cost of prevention includes costs to establish quality practices and the costs to verify them. The cost of failure includes internal costs before the product is sold, such as waste and fixing products, while external costs include those that occur after the product is sold, such as returns and lawsuits.

\section{Exercises}

1. Quality control is very important in the manufacturing of because the safe and reliable operation of those products is a matter of life and death.

2. The prize for quality in Japan is named after (last name).

3. The quality program created at Motorola and adopted by Jack Welch at General Electric is

4. The cost of quality considers the cost of prevention and the cost of

5. What is the purpose of having an international quality standard like ISO?

6. Describe benchmarking.

7. If a quality program costs $\$ 10,000$ to plan and $\$ 50,000$ to administer, what is the COQ if the program reduces waste by $\$ 30,000$ and returns of bad products by $\$ 40,000$ ? Explain how you calculated the answer.

Balancing Cost of Prevention to Cost of Failure

Describe a project activity where the cost of prevention might be much higher than the cost of failure and unlikely enough to accept the risk of its failure rather than pay the cost of prevention. Similarly, describe a project activity where the cost of prevention is smaller than the cost of failure.

\section{References}

Alder, K., "Innovation and Amnesia: Engineering Rationality and the Fate of Interchangeable Parts Manufacturing in France,” Technology and Culture 38, no 2 (April 1997): 273-311.

Boardman, T. J., “The Statistician Who Changed the World: W. Edwards Deming, 1900-1993," The American Statistician 48 (August 1994): 179-87. 
Deming, W. E., Out of the Crisis (Boston: MIT Press, 1982).

Dowd, J., "How the Japanese Learned to Compete," Asia Times, October 27, 2006, http://www.atimes.com/atimes/Japan/HJ27Dh01.html (accessed August 11, 2009).

Encyclopedia Britannica, s.v. “Total Quality Control,” http://www.britannica.com/EBchecked/topic/ 1387304/Total-Quality-Control (accessed August 13, 2009).

Gabor, A. (2001, June 13). Quality revival, Part 2: Ford embraces Six Sigma. New York Times (Late Edition (east Coast)), p. C.5. Retrieved October 24, 2010, from ProQuest National Newspapers Core. (Document ID: 74042886).

International Organization for Standardization, Quality Management Systems-Fundamentals and Vocabulary (Geneva: ISO Press, 2005), in Project Management Institute, Inc., A Guide to the Project Management Body of Knowledge (PMBOK Guide), 4th ed. (Newtown Square, PA: Project Management Institute, Inc., 2008).

National Institute of Standards and Technology, "Frequently Asked Questions about the Malcolm Baldrige National Quality Award,” November 25, 2008, http://www.nist.gov/baldrige/index.cfm (accessed August 14, 2009).

NationMaster.com, “Miryokuteki Hinshitsu,” 2005, http://www.statemaster.com/encyclopedia/ Miryokuteki-Hinshitsu (accessed August 14, 2009).

Petersen, P. B., “Total Quality Management and the Deming Approach to Quality Management,” Journal of Management History 5, no. 8 (1999): 468-88.

WASEDA University, “Kansei Quality” (accessed June 20, 2010).

World Trade Organization, "Understanding the WTO: Basics," http://www.wto.org/english/thewto_e/ whatis_e/tif_e/fact1_e.htm (accessed August 14, 2009). 


\subsection{Relevance of Quality Programs to Project Quality}

\section{Learning Objectives}

1. Identify the similarities between process quality management and project quality management.

2. Identify the differences between process quality management and project quality management.

Project quality refers to two distinct aspects of the project. Project quality can refer to the quality of the product or service delivered by the project. Does the end product meet client specifications? For example, does a software development project develop a program that performs to the client's requirements? A software program that performs the basic work functions but does not integrate with existing software would not be considered a quality product, as long as the client specified that the software must interface with existing software.

Project quality can also refer to managing the project efficiently and effectively. Almost any client specification can be met if the project manager has unlimited time and resources. Recall that high quality means meeting the requirements for a particular grade while providing value. Meeting project deliverables within the time and resource constraints is also a measure of project quality. Developing a project execution plan that matches the complexity level of the project is the most critical aspect in developing a project plan that meets project specifications within the time frame and at the lowest costs. These two aspects of project quality have similarities and differences to quality as applied to parent organizations.

\section{Similarities}

All successful quality programs have (1) a requirement for commitment to quality by all the employees and their partners and (2) an emphasis on error prevention and client satisfaction. To comply with TQM, Six Sigma, ISO, or other quality standards required by the client or by the project management firm, the project manager must engage in quality programs and provide documents that specifically comply with the quality standards in use. For example, a project is typically required to follow the parent organization's work processes related to procurement and document management. Any project processes that interface with the organization's quality processes will be required to meet the quality standards of the organization.

If a large project involves repetitive processes such as welding or pouring concrete, statistical processes control methods can be used to maintain the quality of the product. These processes control methods are similar to those used by process managers in the manufacturing environment. The intent is for the work of the project to meet design specifications. The welding tools and equipment must be sufficient to perform the welds established in the welding specifications, and the welds must be tested, usually by an 
independent tester, to assure the end product meets the design specifications. The civil engineers design a concrete pour to meet certain criteria that will support a structure. The criteria, detailed in the design specifications, provide the parameters that the construction crew must meet when pouring the concrete. On large projects, which sometimes have thousands of welds and hundreds of yards of concrete to pour, the use of quality control tools and methods are critical to meeting design specifications

\section{Differences}

Because projects are temporary, spotting trends in samples produced by repetitive processes is not as important as considering quality in the planning of the project. Instead, the project manager must be able to provide documentation that demonstrates that the correct processes are in place to prevent quality failures.

The cost of quality (COQ) must be considered in the scope document and the project budget. If the group or company that is providing the project management is separate from the client, the project budget will bear the cost of prevention while the client will reap the rewards of avoiding the costs of failure. If senior management does not recognize the benefit to the organization of reducing cost of failure by spending more on prevention during the project, the project manager can be placed in the position of producing a product or service that he or she knows could be of higher quality.

If the cost of quality is not specifically considered and approved by senior management in the scope of the project, quality might be sacrificed during the project to meet budget goals.

\section{Cost of Quality in an Energy Management System}

At a midwestern university, a new building was being built, but it was over budget. To reduce the cost of the energy management system and avoid a late penalty, the project manager installed a cheaper energy management system. The less expensive system could not reduce power to the air circulation fans during peak electrical price periods, and it was not compatible with other campus systems. Five years after the building was built, when a central control unit was installed to coordinate building energy consumption, the incompatible system was replaced because it could not communicate with the central campus energy control system or save as much in electrical costs. The university did not take the time to specify the quality of the building control system in the scope statement and was not aware of the implication of the substitution at the time it was made. As a result, the cost of quality was lower in the prevention category but much higher in the cost of failure category. Because the parties acted in their own interests instead of the interest of the total university and quality was not a team effort, waste occurred and total cost increased.

Some separation of responsibility for quality is necessary. For example, if a project is undertaken to build a facility that makes something, it is important to distinguish between the quality of the work done by the project team and the quality of the items produced after the project is over. The client provides specifications for the facility that should result in production of quality products. It is the client's responsibility to provide appropriate project requirements that will result in a facility that can produce quality products. It is the project manager's responsibility to meet the project requirements. The project manager 
must focus on meeting requirements for project activities, but as part of the quality team, opportunities to improve the quality of the final product should be discussed with the client. If the final products fail to meet quality standards, someone will be blamed for the failure. It could be the project manager, even if he or she met all the requirements of the project specified by the client.

\section{Cost of Prevention in Safety Training}

An electronic parts manufacturer chooses to expand operations and needs to hire and train fifty employees. It uses its own human resources department to handle the selection and hiring of the employees, but it contracts with a nearby technical college to provide some of the training. The technical college is responsible for designing and delivering training on the topic of plant safety practices. The objective of the training project is to reduce the number of workplace accidents, but that is not the characteristic by which the quality of the training program is determined because the rate of accidents for employees who go through the training will not be known until after they have been employed for months or years. The criteria for determining the quality of the training must be something that can be controlled and measured by the project manager during the project.

Because projects are time sensitive, meeting activity finish dates is a common characteristic of quality work on a project that is not typical of a requirement of a process manager.

\section{Timely Delivery Part of Quality}

At a remote mining site in South America, the gasoline and diesel fuel must be brought in by truck over poorly maintained roads to run the trucks and heavy equipment used to set up an ore processing facility. The vendor for supplying fuel is required to provide fuel in the right grades for the various vehicles, in the appropriate quantities, and in a timely manner. If fuel of the right type and grade, with acceptable levels of impurities, is delivered a week after the vehicles have run out of fuel, the work on the fuel-delivery activity is of low quality.

\section{Key Takeaways}

- Both project and process quality management require commitment from all employees, including top management. They are both client oriented and prevention oriented.

- Projects are temporary and allow fewer opportunities to improve repetitive processes. Cost of prevention is often part of the project budget, but the cost of failure usually happens after the project is completed. This separation of costs and benefits can lead to taking short-term savings on the project at the expense of higher cost of failure after the project is complete. 


\section{Exercises}

1. How is quality control of a project different from quality control of a manufacturing process?

Cost of Failure after the Project

Consider a project you have been involved in, in which the cost of prevention would be part of the project budget but the cost of failure would be incurred after the project was completed. Describe why you think top management would have to be involved to make the best decision for the company. 


\subsection{Planning and Controlling Project Quality}

\section{Learning Objectives}

1. Define statistical measurement terminology.

2. Identify sources of information for the planning process.

3. Identify and describe the techniques for controlling project quality.

4. Describe the results of planning and controlling quality.

High quality is achieved by planning for it rather than by reacting to problems after they are identified. Standards are chosen and processes are put in place to achieve those standards.

\section{Measurement Terminology}

During the execution phase of the project, services and products are sampled and measured to determine if the quality is within control limits for the requirements and to analyze causes for variations. This evaluation is often done by a separate quality control group, and knowledge of a few process measurement terms is necessary to understand their reports. Several of these terms are similar, and it is valuable to know the distinction between them.

The quality plan specifies the control limits of the product or process; the size of the range between those limits is the tolerance. Tolerances are often written as the mean value, plus or minus the tolerance. The plus and minus signs are written together, \pm .

\section{Tolerance in Gasoline Production}

The petroleum refinery chose to set its control limits for 87 octane gasoline at 86 and 88 octane. The tolerance is $87 \pm 1$.

Tools are selected that can measure the samples closely enough to determine if the measurements are within control limits and if they are showing a trend. Each measurement tool has its own tolerances. For example, if a machine is making rods whose diameters should be $10 \mathrm{~mm} \pm 0.01 \mathrm{~mm}$, you need a measuring device that can accommodate a rod that is $10 \mathrm{~mm}$ wide but can measure that width to a much smaller tolerance than $0.01 \mathrm{~mm}$, such as $0.001 \mathrm{~mm}$. 
The choice of tolerance directly affects the cost of quality (COQ). In general, it costs more to produce and measure products that have small tolerances. The costs associated with making products with small tolerances for variation can be very high and not proportional to the gains. For example, it might double the manufacturing cost to improve a process from a $4 \sigma$ to a $5 \sigma$ (lower tolerances from 25 percent of control limits to 20 percent), which might only reduce the number of parts that are out of control from 4 per 100,000 to 6 per 10 million (see Figure 10.4 "Meaning of Sigma Levels"). The cost of failure of only 4 parts per 100,000 might be much less than the cost of prevention.

\section{Defining and Meeting Client Expectations}

Clients provide specifications for the project that must be met for the project to be successful. Meeting project specifications is one definition of a project success. Clients often have expectations that are more difficult to capture in a written specification. For example, one client will want to be invited to every meeting of the project and will then select the ones that seem most relevant. Another client will want to only be invited to project meetings that need client input. Inviting this client to every meeting will cause unnecessary frustration. Listening to the client and developing an understanding of the expectations that are not easily captured in specifications is important to meeting the client's expectations.

Project surveys that capture how the client perceives the project performance provide the project team with data that is useful in meeting client expectation. If the results of the surveys indicate that the client is not pleased with some aspect of the project, the project team has the opportunity to explore the reasons for this perception with the client and develop recovery plans. The survey can also help define what is going well and what needs improved.

\section{Sources of Planning Information}

Planning for quality is part of the initial planning process. The early scope, budget, and schedule estimates are used to identify processes, services, or products where the expected grade and quality should be specified. Risk analysis is used to determine which of the risks the project faces could affect quality.

\section{Techniques}

Several different tools and techniques are available for planning and controlling the quality of a project. The extent to which these tools are used is determined by the project complexity and the quality management program in use by the client. 


\section{Quality Management Methodology}

The quality management methodology required by the client is used. The project manager must provide the documentation the client needs to prove compliance with their methodology. There are several different quality management methodologies, but they usually have characteristics that are similar to the ones described previously in the text.

\section{Flowcharting}

Many processes are more complicated than a simple sequence of related events that include several different paths. A flowchart uses standard symbols to diagram a process that has branches or loops. Diamonds indicate decisions, and arrows indicate the direction of the flow of the process, as shown in Figure 10.8 "Flowchart of a Quality Control Process".

Figure 10.8 Flowchart of a Quality Control Process 


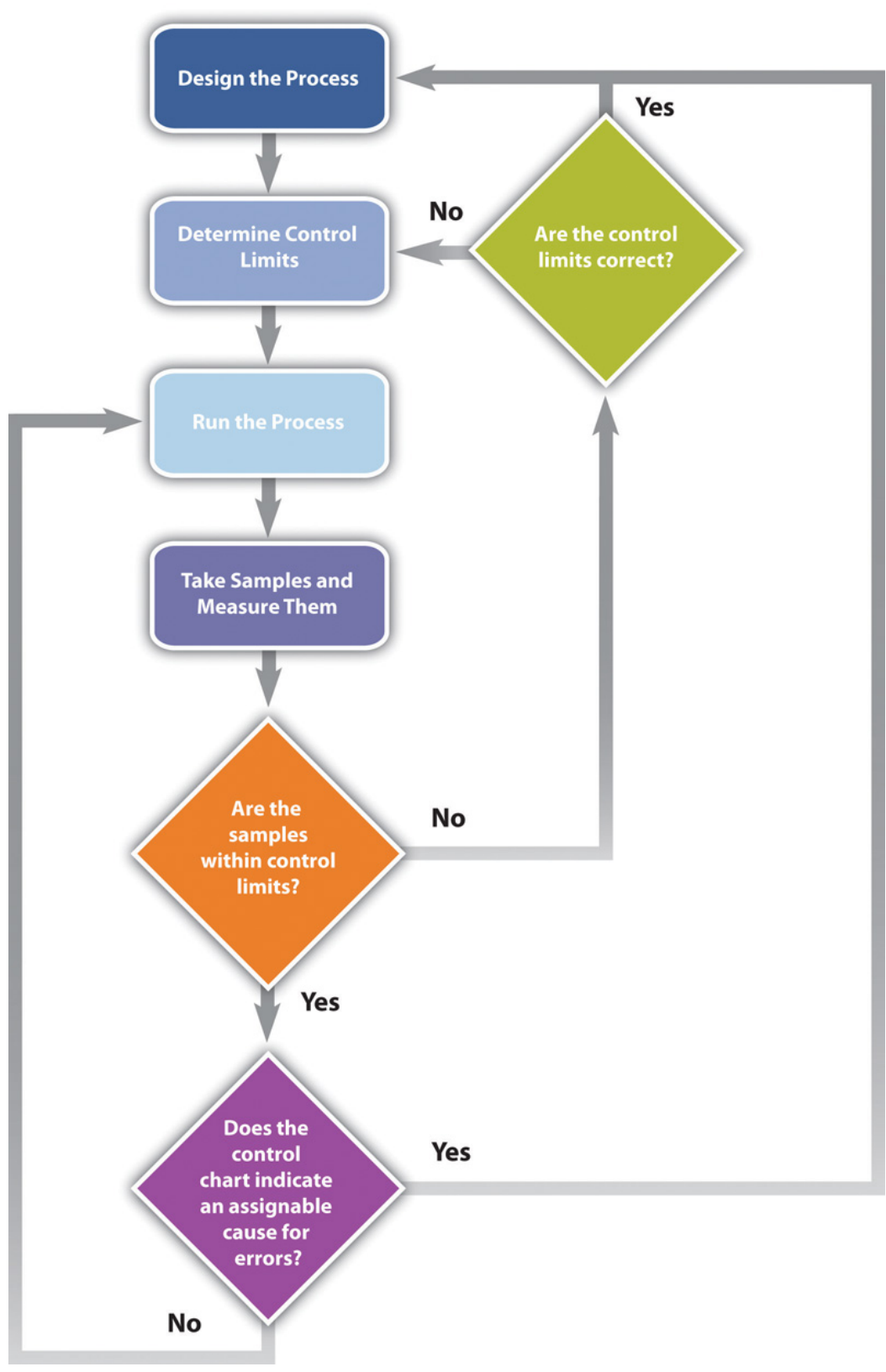

The process used to plan and assess quality can be described using flowcharts. They are useful for communicating processes that have logical branches that can be determined by simple yes or no questions. Flowcharting is also useful for discovering misunderstanding in project roles and responsibilities and communicating responsibility for work processes.

\section{Benchmarking}

When products like shoes were made by hand, artisans would seek some degree of standardization by marking standard lengths for different parts of the product on their workbench. In modern management practice, if a particular method or product is a standard of quality, comparing your organization's quality plan to it is called benchmarking. If a product or service is similar to something that is done in another 
industry or by a competitor, the project planners can look at the best practices that are used by others and use them as a comparison.

\section{Cost-to-Benefit Analysis}

Because the cost of prevention is more often part of the project budget, the case must be made for increasing the project budget to raise quality. Some quality management programs, like Six Sigma, require that expenditures for quality are justified using a cost-to-benefit analysis that is similar to calculating the cost of quality, except that it is a ratio of cost of increasing quality to the resulting benefit. A cost-benefit analysis in some quality programs can take into account nonfinancial factors such as client loyalty and improvements to corporate image and the cost-to-benefit analysis takes the form of a written analysis rather than a simple numeric ratio. It is similar to determining the cost of quality (COQ).

\section{Design of Experiments}

Measuring for quality of manufactured products or use of repetitive processes requires taking samples. Specialists in quality control design a test regimen that complies with statistical requirements to be sure that enough samples are taken to be reasonably confident that the analysis is reliable. In project management, the testing experiments are designed as part of the planning phase and then used to collect data during the execution phase.

\section{Control Charts}

If some of the functions of a project are repetitive, statistical process controls can be used to identify trends and keep the processes within control limits. Part of the planning for controlling the quality of repetitive processes is to determine what the control limits are and how the process will be sampled.

\section{Cause and Effect Diagrams}

When control charts indicate an assignable cause for a variation, it is not always easy to identify the cause of a problem. Discussions that are intended to discover the cause can be facilitated using a causeand-effect or fishbone diagram where participants are encouraged to identify possible causes of a defect. 


\section{Diagramming Quality Problems}

For example, a small manufacturing firm tries to identify the assignable causes to variations in its manufacturing line. They assemble a team that identifies six possibilities, as shown in the fishbone diagram below.

Figure 10.9 Cause and Effect Diagram

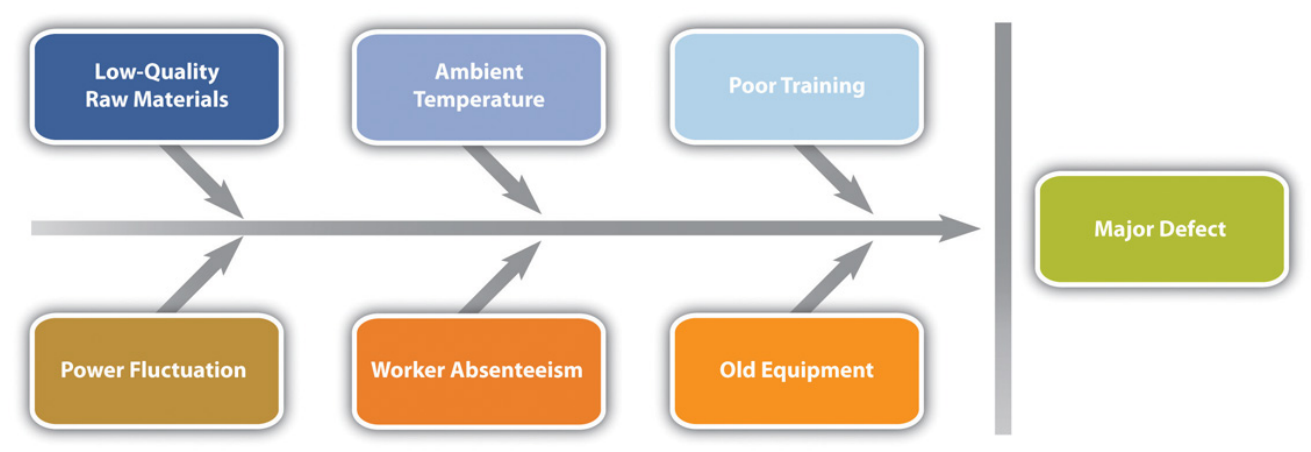

Each branch of the diagram can be expanded to break down a category into more specific items.

An engineer and the electrician work on one of the branches to consider possible causes of power fluctuation and add detail to their part of the fishbone diagram, as shown below.

Figure 10.10 Possible Causes of Power Fluctuation

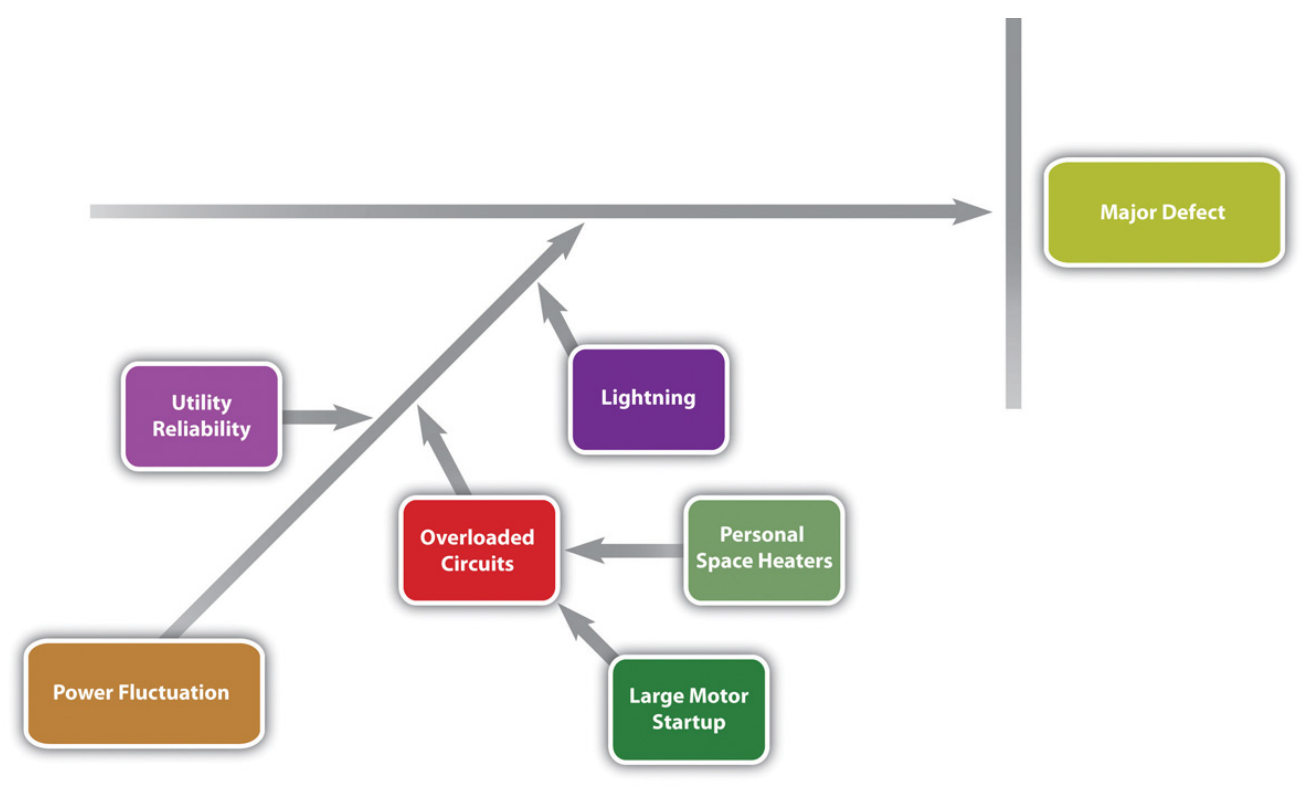

\section{Check Sheets, Histograms, and Pareto Charts}

When several quality problems need to be solved, a project manager must choose which ones to address first. One way to prioritize quality problems is to determine which ones occur most frequently. This data can be collected using a check sheet, which is a basic form on which the user can make a check 
in the appropriate box each time a problem occurs or by automating the data collection process using the appropriate technology. Once the data are collected, they can be analyzed by creating a type of frequency distribution chart called a histogram. A true histogram is a column chart where the width of the columns fill the available space on the horizontal axis and are proportional to the category values displayed on the $x$ axis, while the height of the columns is proportional to the frequency of occurrences. Most histograms use one width of column to represent a category, while the vertical axis represents the frequency of occurrence.

\section{Charting Electrical Problems}

The engineer and electrician place a recording meter on the electrical supply to the manufacturing area and instruct the building automation system to keep a log of voltage coming into the plant from the local utility and when it starts and stops large electrical fan motors. They create a check sheet to track the number of times that power dips or spikes due to lighting strikes or electric space heater malfunctions. They collect the data, count the number of occurrences in each category, and then chart the number of occurrences in a histogram, as shown below.

Figure 10.11 Histogram Showing Frequency of Power Problems by Likely Cause

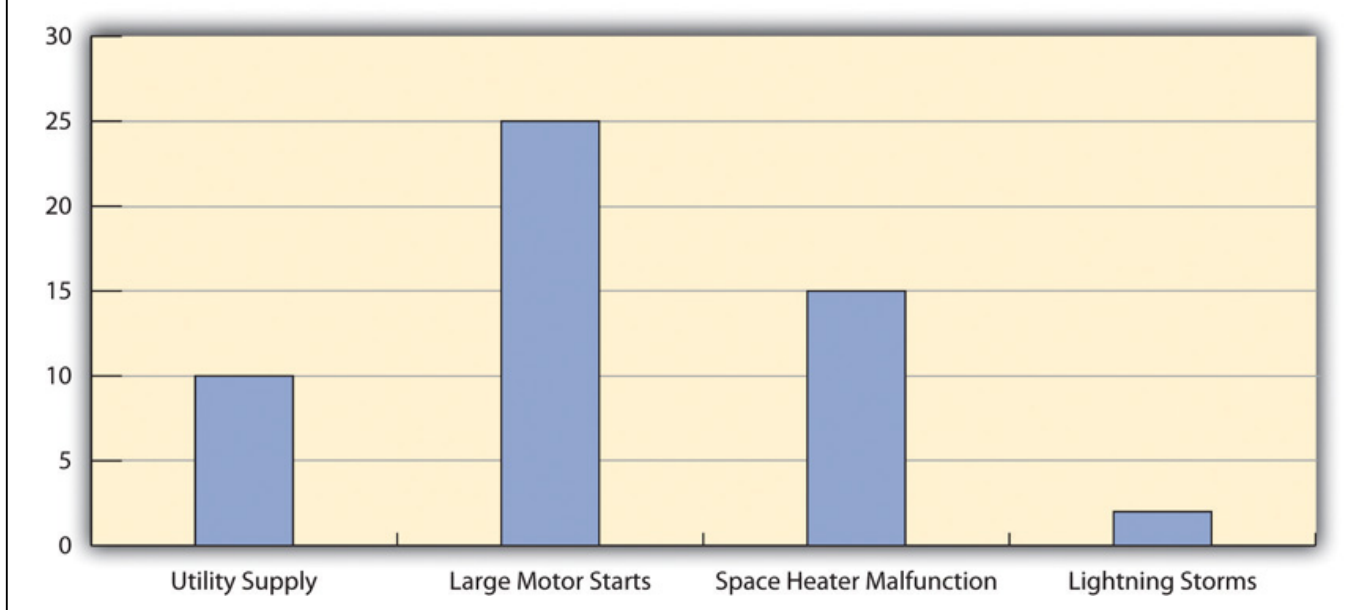

A variation on the histogram is a frequency distribution chart invented by economist Vilfredo Pareto known as a Pareto chart, in which the columns are arranged in decreasing order with the most common on the left and a line added that shows the cumulative total. The combination of columns and a line allows the user to tell at a glance which problems are most frequent and what fraction of the total they represent.

\section{Using Pareto Chart to Analyze Voltage Problem}

The engineer creates a Pareto chart by sorting the data and adds a line to show total problems, as shown below. He concludes that about half of the electrical voltage problems are caused when one of the large electrical fan 
motors on the same circuit as the manufacturing line is shut down to conserve electricity by the energy management system and then restarted.

Figure 10.12 Pareto Chart with Problems in Decreasing Order and a Line Showing a Cumulative Total

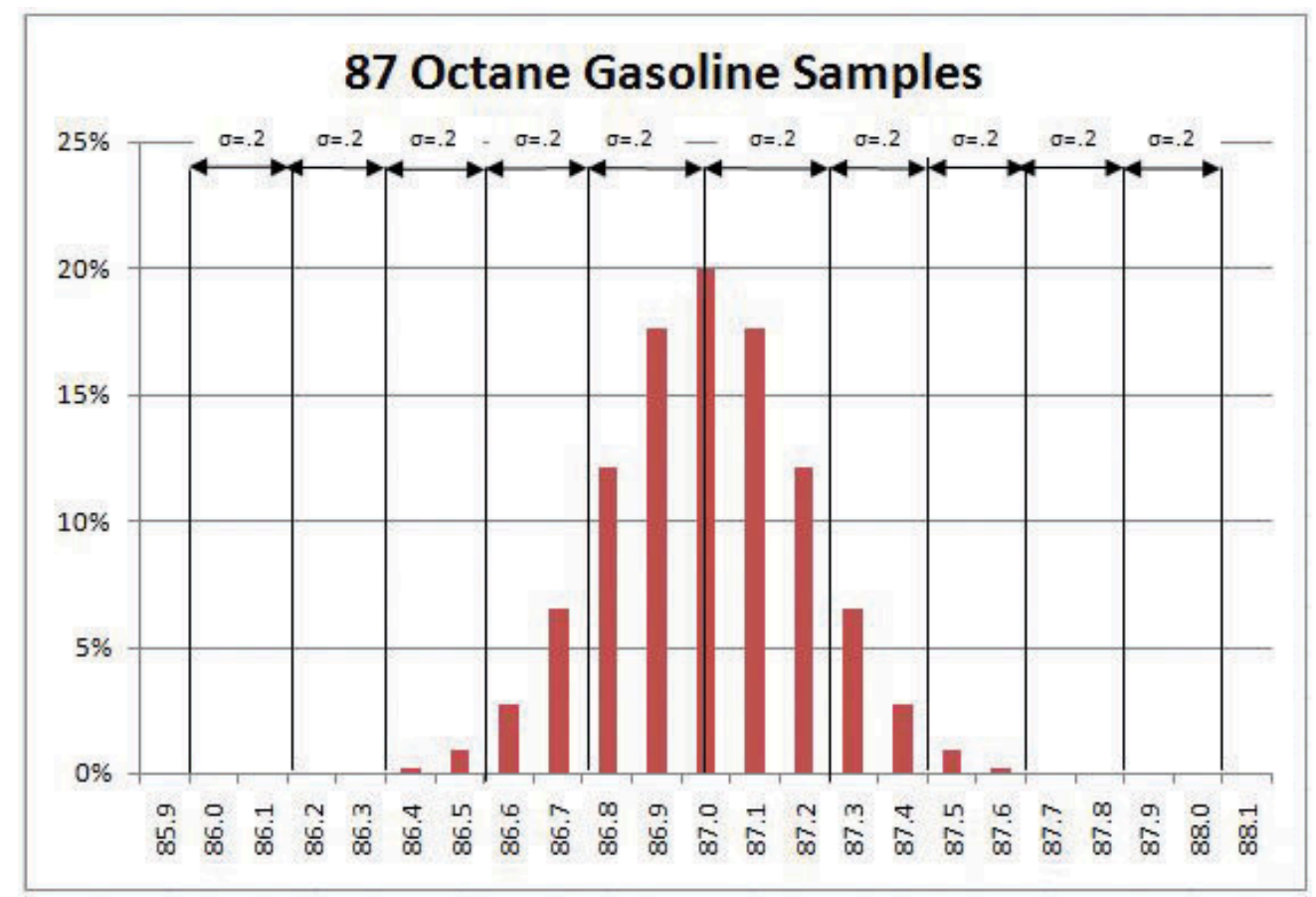

\section{Planning and Control Results}

The quality plan is produced during the initiation phase. The methods, procedures, and logic are described to demonstrate a commitment to a project of high quality. The plan identifies the products or services that will be measured and how they will be measured and compared to benchmarks. A flowchart demonstrates the logic and pathways to improve the plan.

During the execution phase, data are collected by measuring samples according to the design specified in the plan. The data are charted and analyzed. If variations are due to assignable causes, change requests are created.

\section{Key Takeaways}

- Statistical control terms that are commonly used are tolerance (the range between control limits), flowchart (a diagram showing decision branches and loops), benchmarking (comparison to best practices), fishbone diagram (shows possible causes of quality problems), check sheet (form used to record frequency of problem occurrences), histogram (column chart that shows frequency of 
problems), and Pareto chart (histogram sorted by frequency from highest to smallest with a line that shows total cumulative problems).

- The quality planning process uses initial scope, budget, and schedule estimates to identify areas that need quality management.

- Control of quality in repetitive processes use statistical control methods that involve designing testing while considering the cost of quality, taking measurements, and then analyzing the data using run charts that show control limits and trends. Methodologies are compared to the best practices by competitors, which is called benchmarking. Errors are documented using check sheets and analyzed using fishbone diagrams, histograms, or Pareto charts.

- The products of planning and controlling quality are a quality management plan, data, analysis documents, and proposals for improvement

\section{Exercises}

1. The range from the mean to either control limit is the

2. A diagram that shows branches and loops based on decisions is a (two words)

3. The best practices in an industry to which a company can compare its practices are called

4. What is the difference between a histogram and a Pareto chart?

Quality Management Plan

Consider a project in which you have been involved where there was a quality management plan or where such a plan was missing. Describe the effect of having or not having such a plan. 


\subsection{Assuring Quality}

\section{Learning Objective}

1. Describe the purpose and methods of quality assurance.

The purpose of quality assurance is to create confidence that the quality plan and controls are working properly. To assure quality, time must be allocated to review the original quality plan and compare that plan to how quality is being created during the execution of the project.

\section{Process Analysis}

The flowcharts of quality processes are compared to the processes followed during actual operations. If the plan was not followed, the process is analyzed and corrective action taken. The corrective action could be to educate the people involved on how to follow the quality plan or to revise the plan.

The experiments that sample products and processes and collect data are examined to see if they are following statistically valid sampling techniques and that the measurement methods have small enough tolerances to detect variation within control limits.

Because projects are temporary, there are fewer opportunities to learn and improve within one project if it has a short duration, but even in short projects, the quality manager should have a way to learn from experience and change the process for the next project of a similar complexity profile.

\section{Analyzing Quality Processes in Safety Training}

The technical college responsible for training employees in safe plant practices evaluates its instructor selection process at the end of the training to see if it had the best criteria for selection. For example, it required the instructors to have Masters degrees in manufacturing to qualify as college instructors. The college used an exit survey of the students to ask what they thought would improve the instruction of future classes on this topic. Some students felt that it would be more important to require that the instructors have more years of training experience, while others recommended that the college seek certification as a training center by the Occupational Safety and Health Administration (OSHA) (Occupational Safety and Health Administration, 2007). The college considered these suggestions and decided to retain its requirement of a Masters degree but add a requirement that the instructor be certified by OSHA in plant safety. 


\section{Quality Audit}

For additional confidence and assurance, an outside group can come in and review the quality procedures and accuracy of the data. This process is similar to a financial audit and is called a quality audit. The purpose of a quality audit is to compare the stated quality goals of the project against the actual practice and procedures that are used. It is not a certification of the quality of the products themselves.

\section{Key Takeaway}

- The purpose of quality assurance is to build confidence in the client that quality standards and procedures are being followed. This is done by an internal review of the plan, testing, and revisions policies or by an audit of the same items performed by an external group or agency.

\section{Exercises}

1. How is a quality audit different from a quality plan?

Customer Confidence

Consider a product that has suffered from a failure in its quality. Describe how the company handled the problem and its effect on your personal perception of the company and your confidence in buying its products.

\section{References}

Occupational Safety and Health Administration, OSHA Training Institute Education Center Fact Sheet, July 3, 2007, http://www.osha.gov/dte/oti/index.html (accessed August 7, 2009). 


\subsection{Exercises}

Exercises at the end of the chapter are designed to strengthen your understanding and retention of the information recently acquired in the chapter.

\section{Essay Questions}

Write several paragraphs to provide more in-depth analysis and consideration when answering the following questions.

1. Describe the difference between chance cause and assignable cause. How do these terms relate to Deming's system of profound knowledge?

2. According to the text, why did the quality of manufactured goods decline in the United States after World War II, and how did Japan take advantage of that situation?

3. Describe the four Japanese terms used in TQM and give an example of how they might apply to a particular product.

\section{Discussion}

The exercises in this section are designed to promote exchange of information among students in the classroom or in an online discussion. The exercises are more open ended, which means that what you find might be completely different from what your classmates find, and you can all benefit by sharing what you have learned.

1. The auto industry has been a highly visible battleground for international competition in which quality and the public's perception of a company's quality have played an important role. Deming stresses that management is 85 percent of the problem and the solution to a company's quality. What are specific examples with which you are familiar from the news or personal experience that demonstrate management leadership (or lack of leadership) toward improving quality.

2. Consider how the four Japanese concepts of quality included in TQM are applied in your educational institution. Based on your experience with the management of your school, does the management use the principles of kaizen, atarimae hinshitsu, kansei, and miryokuteki hinshitsu? Provide an example (or counter example) of each. 


\subsection{Software and Technology Exercises}

\section{Learning Objectives}

1. Predict likely range of values in a normal distribution.

2. Recognize assignable and unassignable causes of statistical variation.

\section{Predicting Value Ranges Using Standard Deviation}

Real production processes are never perfect. In some cases, a few products that are too small or that do not work will just cause inconvenience, but in other cases they might be life threatening. Samples of the production process will show how much variation occurs. If it appears that the variations are distributed equally above and below the mean (average), it might be assumed that the statistics of a normal distribution can be used to predict the percentage of products that will be defective when many of them are produced even if none of the samples are defective.

Some projects are initiated to increase the quality by reducing the variation in production. To understand the language of statistics and how it is used to justify a project, it is useful to gain a "feel" for how the distribution of samples is described by the standard deviation. A spreadsheet can be used to simulate samples of production runs where the mean and standard deviation can be chosen to show their relationship in a normal distribution. By trying different values for the standard deviation and observing the effect on the distribution of estimated samples in a chart, you can develop a sense of how the two are related.

Recall that a standard deviation is called a sigma and represented by the Greek letter $\sigma$ and the 68-95-99.7 rule refers to the percentage of samples that will be within one, two, and three standard deviations of the mean.

\section{Examine a Normal Distribution}

Complete the exercise by following these instructions:

1. Navigate to the directory location where the exercise files for this unit are located and open Ch10STD.xls in a spreadsheet program such as MS Excel.

2. In cell A2, replace StudentName with your name. 
3. This worksheet is designed to simulate a set of sample values that vary from the mean for random reasons and form a normal distribution. The data and calculations in columns A through $\mathrm{F}$ are hidden. They are used to calculate the values in column $\mathrm{G}$ on which the chart is based.

4. Notice the following features of the spreadsheet:

- Column A has bins. In this example, the bins are .1 units wide. The size of the bin and the horizontal scale of the chart are determined by the value in cell L5.

- This simulation uses forty-two bins that are distributed equally above and below the mean. The mean value can be specified in cell L4.

- The usual method is to sample a sequence of products, count the number that fall into each bin, and then calculate the standard deviation. In this simulation, you can specify the standard deviation in cell L3, and the percentage of samples that are likely to occur in each bin is calculated and displayed in column G. The display is rounded to a whole percent. The display of decimal places can be increased using the spreadsheet's controls.

- The percentage of estimated samples that occur in each bin is charted using a column chart. The scale at the left side of the chart indicates the percent of the samples in each bin.

5. Compare the chart in the spreadsheet to the chart in Figure 10.13 "Normal Distribution of Gasoline Samples" that was used in the text. Observe that the standard deviation, $\sigma$, is .2 and that almost all the sample values occur between 86.4 and 87.6- three $\sigma$ on either side of the mean.

6. Open a word processing document and then save it as Ch10STDStudentName.doc. Switch back to the spreadsheet and capture the screen. Switch to the word processing document and paste the screen into the document.

7. Switch back to the spreadsheet. To see the effect of a better production process that would have a $\sigma$ of .1 instead of .2, click cell L3. Type .1 and then, on the Formula bar, click the Enter button. The distribution narrows so that almost all the estimated samples are within .3 on either side of the mean (87.0), as shown in Figure 10.14 "Normal Distribution with Smaller Standard Deviation”.

8. Capture the screen showing in the narrow distribution and paste it into the word processing document.

9. In the spreadsheet, in cell L3, type .4 and then, on the Formula bar, click the Enter button. Notice that a larger standard deviation means the distribution is more spread out. Three standard deviations is $1.2(3 \times .4)$, so almost all the samples will be within 1.2 on either side of the mean, as shown in Figure 10.15 “Normal Distribution with Larger Standard Deviation”.

10. Capture this screen and paste it into the word processing document.

11. Change the value in cell L3 to 1 . Almost all the samples will be above 84 (87-3) and below $90(87+3)$, but the horizontal scale is too small to show all the values.

12. Change the value in cell L5 to .3. 
13. Capture the screen and paste it into the word processing document.

\section{Use the Spreadsheet for a Different Example}

The effects of a lower-than-expected octane rating in a passenger car might be engine knock during acceleration and less power climbing a hill, but the effect of lower-than-expected octane fuel in a military aircraft might mean that the plane could not achieve the desired altitude or speed in a critical situation. Aviation gasoline is designed for use in high-performance engines that require 100 octane fuel. Use the spreadsheet to examine the estimated distribution of gasoline samples with a different mean and $\sigma$.

\section{Examine a Normal Distribution}

Complete the exercise by following these instructions:

1. Change the value in cell L4 to 100 and the standard deviation in cell L3 to .1. Notice that a standard deviation of .1 means that 99.7 percent of the gasoline samples will be between 99.7 and 100.3 octane.

2. Practice changing the mean and standard deviation values in the spreadsheet. Each time you do so, predict the high and low values that represent three $\sigma$ above and below the mean and use the spreadsheet to check your prediction. If the values extend beyond the sides of the chart, increase the increment value in cell L5.

3. Capture the screen that shows one of your estimates that is different from the examples shown in the previous steps and paste it into the word processing document.

4. In the word processing document, below the last screen, write between one hundred and two hundred words to describe what you learned about the relationship between the standard deviation and the distribution of likely values. Specifically describe how you predict the upper and lower limits of the range.

5. Close the spreadsheet. Do not save the changes.

6. Save the word processing document as Ch10STDStudentName.doc.

7. Review your work and use the following rubric to determine its adequacy:

\begin{tabular}{|l|l|l|l|}
\hline Element & Best & Adequate & Poor \\
\hline File name & Ch10STDStudentName.doc & $\begin{array}{l}\text { Same or } \\
\text { docx file } \\
\text { format }\end{array}$ & Student name missing \\
\hline $\begin{array}{l}\text { Predict likely } \\
\text { range of values } \\
\text { in a normal } \\
\text { distribution }\end{array}$ & $\begin{array}{l}\text { Five screen captures plus a reflective } \\
\text { essay on what you learned about } \\
\text { predicting the upper and lower limits } \\
\text { defined by 3 } \sigma\end{array}$ & $\begin{array}{l}\text { Same as } \\
\text { Best }\end{array}$ & $\begin{array}{l}\text { Missing pictures; essay does } \\
\text { not describe how the upper } \\
\text { and lower limits of 3 } \sigma \text { are } \\
\text { calculated }\end{array}$ \\
\hline
\end{tabular}


8. Revise the document, if necessary. Save the document and submit it as directed by the instructor.

\section{Recognizing Variations Due to Unassignable and Assignable Causes}

W. Edwards Deming teaches that some variation is inevitable due to chance cause. A manager needs to recognize the difference between variations that are due to chance and those that indicate the presence of an assignable cause or a trend. If it appears that there is an assignable cause for variation in quality, a project manager might be required to identify and fix the problem. To communicate with process managers who are monitoring and sampling production, it is useful to understand the use of control charts.

A run chart is a type of chart that shows variations from the mean as a function of time. The value of each sample is plotted to show the day it was taken and how it differs from the mean. If the variation is random, there will be roughly the same number of points above and below the mean.

A spreadsheet can be used to simulate random variations in production. In this exercise, the spreadsheet uses its random number function to pick two numbers that are positive and two that are negative and adds them to the mean. Each number represents a variation that is between the control limits. Most of the time the positive and negative numbers cancel each other out and result in a sum that is close to the mean, but occasionally the four random factors add up to values that are far from the mean.

In this part of the exercise, you observe variations in a run chart and frequency distribution chart that are due to random effects. You generate the random numbers several times to see what production runs with random (unassignable) variations look like.

\section{Examine a Run Chart with Random Effects}

Complete the exercise by following these instructions:

1. Navigate to the directory location where the exercise files for this unit are located and open Ch10ControlChart.xls in a spreadsheet program such as MS Excel.

2. Observe that in cells B4 through B23 the RAND function is used to simulate the effects of four random influences on each day of production for a twenty-day period.

3. Scroll the screen or adjust the zoom so that you can see both charts. See Figure 10.16 "Screen Adjusted to Show Both Charts".

4. On your keyboard, near the top, press the F9 key. The random functions pick new numbers. Observe how the samples on the run chart change and how the frequency distribution changes.

5. Press the F9 key several more times until you get a set of samples that are grouped close to the mean like the example shown in Figure 10.17 “Most Samples near the Mean”. 
6. Open a word processing document and then save it as Ch10RunChartStudentName.doc. Switch back to the spreadsheet and capture the screen. Switch to the word processing document and paste the screen into the document. Your values will differ from those in the figure.

7. According to Deming, it is not productive to hold employees to quality standards that they do not control. Consider the effect on employee moral if this set of samples was taken as the standard by which the next run would be judged.

8. Press the F9 key again and stop at a set of samples that has a greater variation, such as the example shown in Figure 10.15 “Normal Distribution with Larger Standard Deviation”.

9. Capture this screen and paste it into Ch10RunChartStudentName.doc. Because of the chancecause random factors, this set of data has more variation. If employee performance were punished or rewarded based on this data, they would become discouraged because they do not control the quality. Leave both files open.

\section{Examine a Run Chart with Assignable Cause}

Complete the exercise by following these instructions:

An assignable cause can be mixed in with the chance-cause random effects. In this part, you introduce a factor that causes the samples to display a trend. You run the simulation several times to learn how to recognize a set of data that is a mix of random (chance-cause) factors and a trend that is probably from an assignable cause.

1. In the spreadsheet, click cell B2. Type .03 and then, on the Formula bar, click the Enter button. The random functions are recalculated, but each value is increased by .03 over its predecessor.

2. Press the F9 key several times and observe how this trend appears within the samples such as the example in Figure 10.19 “Trend That Is Probably Due to an Assignable Cause”.

3. It is clear that action must be taken soon to prevent the next batch of samples from exceeding the control limit. The process manager might create a project to identify the assignable cause and take the necessary action, such as replacing a worn-out piece of equipment. Choose an example where the upward trend is most apparent. Capture the screen and paste it into the word processing document.

4. Close the spreadsheet without saving the changes.

5. In the word processing document, below the last picture, write a reflective essay of between one hundred and two hundred words that describes how you would recognize the difference between run charts that show assignable and unassignable causes. Discuss the effect on morale if one of the runs with random values that are close to the mean is chosen as the standard of performance by which workers would be measured.

6. Leave the word processing document open.

7. Review your work and use the following rubric to determine its adequacy: 
332 [Author removed at request of original publisher]

\begin{tabular}{|l|l|l|l|}
\hline Element & Best & Adequate & \multicolumn{1}{|c|}{ Poor } \\
\hline File name & Ch10RunChartStudentName.doc & Ch10RunChartStudentName.docx & $\begin{array}{l}\text { Did not } \\
\text { include } \\
\text { name in file } \\
\text { name }\end{array}$ \\
\hline $\begin{array}{l}\text { Recognize } \\
\text { assignable } \\
\text { and } \\
\text { unassignable } \\
\text { causes of } \\
\text { statistical } \\
\text { variation }\end{array}$ & $\begin{array}{l}\text { Three screen captures that show } \\
\text { two random causes and one } \\
\text { assignable cause; an essay that } \\
\text { describes how to recognize the } \\
\text { difference and the effect on } \\
\text { worker morale if a run with low } \\
\text { random variation is chosen as a } \\
\text { standard }\end{array}$ & Same as Best & $\begin{array}{l}\text { Missing } \\
\text { screen; } \\
\text { essay does } \\
\text { not address } \\
\text { both } \\
\text { requirements }\end{array}$ \\
\hline
\end{tabular}

8. Save the file and submit it as directed by the instructor. 


\section{Chapter 11: Managing Project Risk}

Project managers must be prepared to deal with adversity. Planning for events that can delay a project, decrease its quality, or increase its budget is a necessary part of project planning. 


\subsection{Defining Risk}

\section{Learning Objectives}

1. Define project risk.

2. Define the difference between known and unknown risks.

3. Describe the difference between the business risk of the organization and project risk.

Risk is the possibility of loss or injury (Merriam-Webster Online, 2009).Project risk is an uncertain event or condition that, if it occurs, has an effect on at least one project objective (Project Management Institute, Inc., 2008).Risk management focuses on identifying and assessing the risks to the project and managing those risks to minimize the impact on the project. There are no risk-free projects because there is an infinite number of events that can have a negative effect on the project. Risk management is not about eliminating risk but about identifying, assessing, and managing risk.

Tzvi Raz, Aaron Shenhar, and Dov Dvir (Raz, Shenhar, \& Dvir, 2002). studied the risk management practices on one hundred projects in a variety of industries. The results of this study suggested the following about risk management practices:

- Risk management is not widely used.

- The projects that were most likely to have a risk management plan were those that were perceived to be high risk.

- When risk management practices were applied to projects, they appeared to be positively related to the success of the project.

- The risk management approach influenced the meeting of project schedules and cost goals but exerted less influence on project product quality.

- Good risk management increases the likelihood of a successful project.

Risk deals with the uncertainty of events that could affect the project. Some potential negative project events have a high likelihood of occurring on specific projects. Examples are as follows:

- Safety risks are common on construction projects.

- Changes in the value of local currency during a project affect purchasing power and budgets on projects with large international components.

- Projects that depend on good weather, such as road construction or coastal projects, face risk of delays due to exceptionally wet or windy weather. 
These are examples of known risks. Known risks are events that have been identified and analyzed for which advanced planning is possible. Other risks are unknown or unforeseen.

\section{Terrorist Attack}

On September 11, 2001, project team members were flying from various locations to a project review meeting in South Carolina when all flights were cancelled because of the attacks on the World Trade Center. Members of the leadership team could not make the meeting or return to their home base, and progress on the project, like many projects that day, was delayed.

\section{Sudden Family Death}

Just before a project meeting in Texas, the engineering lead received word that his father had died in the middle of the night. The team delayed making decisions on some critical engineering events without the knowledge and judgment of the engineering manager.

\section{Whole Crew Fails Drug Test}

On a project in Texas, the entire twelve-member masonry crew failed the drug screening test even though they had been told that drug screening was required on the project.

These events were unforeseen by the project team, and in all three cases the projects experienced schedule delays and additional costs.

Project risks are separate from the organizational risks that are associated with the business purpose of the project.

A project was chartered to design and construct a copper mine at a cost not to exceed $\$ 1.2$ billion. If a project is completed on time, within budget, and meets all quality specifications, the project is successful. If the price of copper drops below the profit threshold for the company, the organizational goals of the project may not be achieved. The price of copper is an organizational or business risk. The copper mining company authorized the project based on assumptions about the future price of copper. The price of copper is not a project risk on this project. 


\section{Key Takeaways}

- Project risk is the possible outcome that planned events on the project will not occur as planned or that unplanned events will occur that will have a negative impact on the project.

- Known risks can be identified before they occur, while unknown risks are unforeseen.

- Organizational risks are associated with the business purpose of the project and assumed by the client when deciding to do the project.

\section{Exercises}

1. According to PMI, project risk is a(n) event or condition that, if it occurs, has an effect on at least one project objective.

2. A risk such as the future market price of a commodity is an example of a(n) risk.

3. Define risk in your own words.

4. Give an example of a known risk and an unknown risk that are different from those in the text.

5. Describe the difference between organizational risk and project risk in your own words and give an example of each that is not used in the text.

Planning for Known and Unknown Risks

Consider a trip that you might be planning. Describe at least five risks that are associated with taking the trip.

\section{References}

Merriam-Webster Online, s.v. “risk,” http://www.merriam-webster.com/dictionary/Risk (accessed August 21, 2009).

Project Management Institute, Inc., A Guide to the Project Management Body of Knowledge (PMBOK Guide), 4th ed. (Newtown Square, PA: Project Management Institute, Inc., 2008), 273.

Raz, T., Aaron J. Shenhar, and Dov Dvir, "Risk Management, Project Success, and Technological Uncertainty,” R\&D Management 32 (2002): 101-12. 


\subsection{Risk Management Process}

\section{Learning Objectives}

1. Identify the major elements in managing project risk.

2. Describe the processes for identifying project risk.

3. Describe the processes for evaluating risk.

4. Describe the processes for mitigating risk.

Managing risks on projects is a process that includes risk assessment and a mitigation strategy for those risks. Risk assessment includes both the identification of potential risk and the evaluation of the potential impact of the risk. A risk mitigation plan is designed to eliminate or minimize the impact of the risk events - occurrences that have a negative impact on the project. Identifying risk is both a creative and a disciplined process. The creative process includes brainstorming sessions where the team is asked to create a list of everything that could go wrong. All ideas are welcome at this stage with the evaluation of the ideas coming later.

\section{Risk Identification}

A more disciplined process involves using checklists of potential risks and evaluating the likelihood that those events might happen on the project. Some companies and industries developed risk checklists based on experience from past projects. The Construction Industry Institute (Construction Indistry Institute Cost/ Schedule Task Force, 1989) developed a detailed checklist of potential risks based on the experience of several large construction companies executing major construction projects. These checklists can be helpful to the project manager and project team in identifying both specific risks on the checklist and expanding the thinking of the team. The past experience of the project team, project experience within the company, and experts in the industry can be valuable sources for identifying potential risk on a project.

Identifying the sources of risk by category is another method for exploring potential risk on a project. Some examples of categories for potential risks include the following:

- Technical

- Cost

- Schedule

- Client 
- Contractual

- Weather

- Financial

- Political

- Environmental

- People

The people category can be subdivided into risks associated with the people. Examples of people risks include the risk of not finding the skills needed to execute the project or the sudden unavailability of key people on the project. David Hillson (Hillson, 2003) uses the same framework as the work breakdown structure (WBS) for developing a risk breakdown structure (RBS). A risk breakdown structure organizes the risks that have been identified into categories using a table with increasing levels of detail to the right.

\section{Risks in John's Move}

In John's move, John makes a list of things that might go wrong with his project and uses his work breakdown structure as a guide. A partial list for the planning portion of the RBS is shown below.

Figure 11.1 Risk Breakdown Structure (RBS)

\begin{tabular}{|c|c|c|}
\hline Level 1 & Level 2 & Level 3 \\
\hline \multirow{10}{*}{ Plan Move } & \multirow{3}{*}{ Contact Dion and Carlita } & Dion backs out \\
\hline & & Carlita backs out \\
\hline & & No common date available \\
\hline & \multirow{3}{*}{ Host planning lunch } & Restaurant full or closed \\
\hline & & Wrong choice of ethnic food \\
\hline & & Dion or Carlita have special food allergies or preferences \\
\hline & \multirow{2}{*}{ Develop and distribute schedule } & Printer out of toner \\
\hline & & Out of paper \\
\hline & \multirow{2}{*}{ Make hotel arrangements in Atlanta } & City hotels full due to major event \\
\hline & & Lost reservation \\
\hline
\end{tabular}

The result is a more obvious understanding of where risks are most concentrated. Hillson's approach helps the project team identify known risks but can be restrictive and less creative in identifying unknown risks and risks not easily found inside the work breakdown structure. 


\section{Risk Evaluation}

After the potential risks have been identified, the project team then evaluates the risk based on the probability that the risk event will occur and the potential loss associated with the event. Not all risks are equal. Some risk events are more likely to happen than others, and the cost of a risk event can vary greatly. Evaluating the risk for probability of occurrence and the severity or the potential loss to the project is the next step in the risk management process.

The Construction Industry Institute conducted a study of large construction project risk evaluation and categorized risk according to the potential impact of project costs. High-impact risk consisted of risks that could increase the project costs by 5 percent of the conceptual budget or 2 percent of the detailed budget. Only thirty potential risk events met these criteria. These were the critical few potential risk events that the project management team focused on when developing a project risk mitigation or management plan. Risk evaluation is about developing an understanding of which potential risks have the greatest possibility of occurring and can have the greatest negative impact on the project. These become the critical few.

Figure 11.2 Risk and Impact

\section{Impact}

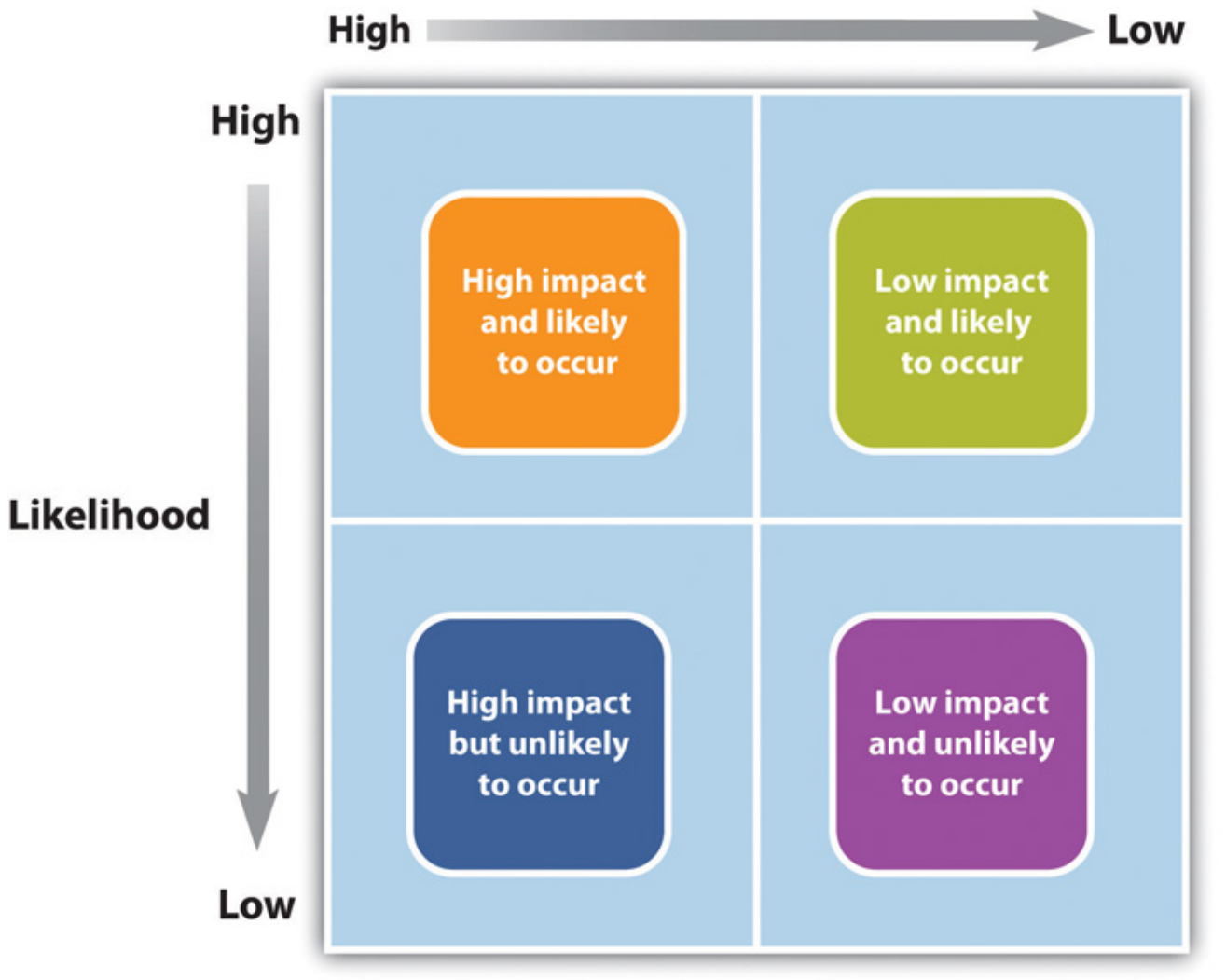

There is a positive correlation - both increase or decrease together-between project risk and project complexity. A project with new and emerging technology will have a high-complexity rating and a correspondingly high risk. The project management team will assign the appropriate resources to the tech- 
nology managers to assure the accomplishment of project goals. The more complex the technology, the more resources the technology manager typically needs to meet project goals, and each of those resources could face unexpected problems.

Risk evaluation often occurs in a workshop setting. Building on the identification of the risks, each risk event is analyzed to determine the likelihood of occurring and the potential cost if it did occur. The likelihood and impact are both rated as high, medium, or low. A risk mitigation plan addresses the items that have high ratings on both factors-likelihood and impact.

\section{Risk Analysis of Equipment Delivery}

For example, a project team analyzed the risk of some important equipment not arriving to the project on time. The team identified three pieces of equipment that were critical to the project and would significantly increase the costs of the project if they were late in arriving. One of the vendors, who was selected to deliver an important piece of equipment, had a history of being late on other projects. The vendor was good and often took on more work than it could deliver on time. This risk event (the identified equipment arriving late) was rated as high likelihood with a high impact. The other two pieces of equipment were potentially a high impact on the project but with a low probably of occurring.

Not all project mangers conduct a formal risk assessment on the project. There are barriers to identifying risks. David Parker and Alison Mobey (Parker \& Mobey, 2004) found in a phenomenological study of project managers that there was a low understanding of the tools and benefits of a structured analysis of project risks. The lack of formal risk management tools was seen as a barrier to implementing a risk management program. The level of investment in formal risk management was also associated with managerial psychological dimensions.

Some project managers are more proactive and will develop elaborate risk management programs for their projects. Other managers are reactive and are more confident in their ability to handle unexpected events without prior planning, while some managers are risk averse and prefer to be optimistic and not consider risks or to avoid taking risks whenever possible.

On projects with a low complexity profile, the project manager may informally track items that may be considered risk items. On more complex projects, the project management team may develop a list of items perceived to be higher risk and track them during project reviews. On projects with greater complexity, the process for evaluating risk is more formal with a risk assessment meeting or series of meetings during the life of the project to assess risks at different phases of the project. On highly complex projects, an outside expert may be included in the risk assessment process, and the risk assessment plan may take a more prominent place in the project execution plan.

On complex projects, statistical models are sometimes used to evaluate risk because there are too many different possible combinations of risks to calculate them one at a time. One example of the statistical model used on projects is the Monte Carlo simulation, which simulates a possible range of outcomes by trying many different combinations of risks based on their likelihood. The output from a Monte Carlo simulation provides the project team with the probability of an event occurring within a range and for combinations of events. For example, the typical output from a Monte Carol simulation may reflect that 
there is a 10 percent chance that one of the three important pieces of equipment will be late and that the weather will also be unusually bad after the equipment arrives.

\section{Risk Mitigation}

After the risk has been identified and evaluated, the project team develops a risk mitigation plan, which is a plan to reduce the impact of an unexpected event. The project team mitigates risks in the following ways:

- Risk avoidance

- Risk sharing

- Risk reduction

- Risk transfer

Each of these mitigation techniques can be an effective tool in reducing individual risks and the risk profile of the project. The risk mitigation plan captures the risk mitigation approach for each identified risk event and the actions the project management team will take to reduce or eliminate the risk.

\section{Risk Avoidance}

Risk avoidance usually involves developing an alternative strategy that has a higher probability of success but usually at a higher cost associated with accomplishing a project task. A common risk avoidance technique is to use proven and existing technologies rather than adopt new techniques, even though the new techniques may show promise of better performance or lower costs. A project team may choose a vendor with a proven track record over a new vendor that is providing significant price incentives to avoid the risk of working with a new vendor. The project team that requires drug testing for team members is practicing risk avoidance by avoiding damage done by someone under the influence of drugs.

\section{Risk Sharing}

Risk sharing involves partnering with others to share responsibility for the risk activities. Many organizations that work on international projects will reduce political, legal, labor, and others risk types associated with international projects by developing a joint venture with a company located in that country. Partnering with another company to share the risk associated with a portion of the project is advantageous when the other company has expertise and experience the project team does not have. If the risk event does occur, then the partnering company absorbs some or all of the negative impact of the event. The company will also derive some of the profit or benefit gained by a successful project. 


\section{Risk Sharing on Pipeline in Peru}

One example of risk sharing is a large United States construction firm that won a contract to build a pipeline in Peru. The company partnered with a construction company in Peru with a reputation for performing on time. The Peruvian company brought local expertise and the U.S. company contributed the latest construction methods. If the project had not successfully completed on time, both companies would have received less profit, but the project was successful and both companies met profit targets.

\section{Risk Reduction}

Risk reduction is an investment of funds to reduce the risk on a project. On international projects, companies will often purchase the guarantee of a currency rate to reduce the risk associated with fluctuations in the currency exchange rate. A project manager may hire an expert to review the technical plans or the cost estimate on a project to increase the confidence in that plan and reduce the project risk. Assigning highly skilled project personnel to manage the high-risk activities is another risk reduction method. Experts managing a high-risk activity can often predict problems and find solutions that prevent the activities from having a negative impact on the project. Some companies reduce risk by forbidding key executives or technology experts to ride on the same airplane.

\section{Risk Transfer}

Risk transfer is a risk reduction method that shifts the risk from the project to another party. The purchase of insurance on certain items is a risk transfer method. The risk is transferred from the project to the insurance company. A construction project in the Caribbean may purchase hurricane insurance that would cover the cost of a hurricane damaging the construction site. The purchase of insurance is usually in areas outside the control of the project team. Weather, political unrest, and labor strikes are examples of events that can significantly impact the project and that are outside the control of the project team.

\section{Contingency Plan}

The project risk plan balances the investment of the mitigation against the benefit for the project. The project team often develops an alternative method for accomplishing a project goal when a risk event has been identified that may frustrate the accomplishment of that goal. These plans are called contingency plans. The risk of a truck drivers strike may be mitigated with a contingency plan that uses a train to transport the needed equipment for the project. If a critical piece of equipment is late, the impact on the schedule can be mitigated by making changes to the schedule to accommodate a late equipment delivery. 


\section{Roof Left Unfinished for Late Equipment}

On one project, the project team left a section of a roof unfinished to allow the installation of equipment after the building was done and the roof installed. The equipment was late, and the project would have been delayed if the building was not completed. The project team left a section of the roof unfinished to allow the equipment to be placed in the building with the use of a crane. The roof was then completed, and the project finished on time.

In this example, the equipment arriving on time to meet the project schedule was considered a high risk. One option was to delay the end of the project. The team developed a contingency plan to install the roof in two phases to allow the installation of the equipment, if it was late. The contingency plan was more expensive and contingency funds were placed in the budget to cover the possibility that the equipment would be late.

Contingency funds are funds set aside by the project team to address unforeseen events that cause the project costs to increase. Projects with a high-risk profile will typically have a large contingency budget. Although the amount of contingency allocated in the project budget is a function of the risks identified in the risk analysis process, contingency is typically managed as one line item in the project budget.

Some project managers allocate the contingency budget to the items in the budget that have high risk rather than developing one line item in the budget for contingencies. This approach allows the project team to track the use of contingency against the risk plan. This approach also allocates the responsibility to manage the risk budget to the managers responsible for those line items. The availability of contingency funds in the line item budget may also increase the use of contingency funds to solve problems rather than finding alternative, less costly solutions. Most project managers, especially on more complex projects, will manage contingency funds at the project level, with approval of the project manager required before contingency funds can be used.

\section{Key Takeaways}

- Risk management is a creative process that involves identifying, evaluating, and mitigating the impact of the risk event.

- Risk management can be very formal, with defined work processes, or informal, with no defined processes or methods. Formal risk evaluation includes the use of checklists, brainstorming, and expert input. A risk breakdown structure (RBS) can follow the work breakdown structure (WBS) to identify risk by activity.

- Risk evaluation prioritizes the identified risks by the likelihood and the potential impact if the event happens.

- Risk mitigation is the development and deployment of a plan to avoid, transfer, share, and reduce project risk. Contingency planning is the development of alternative plans to respond to the occurrence of a risk event. 


\section{Exercises}

1. A risk plans eliminates or minimizes the impact of risk events.

2. Risk management is a creative process that involves identifying, evaluating, and the impact of risk events

3. A process for risk assessment that is parallel to the WBS is a (three words).

4. Choose a project risk that could be related to the John's move example that is not described in the text and describe a mitigation plan for that risk. You may choose from any part of the John's move example that has been described in previous chapters.

5. If you are planning a party at your residence, list three project risks and rate each of them for their potential impact and likelihood. Use high, medium, and low.

6. Describe the similarities and differences between risk transfer and risk sharing.

Risk Management

Assume that you are involved in planning a wedding. What are three risks that might affect the ceremony or reception, and how would you mitigate the impact of those risks? For example, if you are planning an outdoor wedding, describe the backup plan in case of rain.

\section{References}

Construction Industry Institute Cost/Schedule Task Force, Management of Project Risks and Uncertainties (Austin, TX: Construction Industry Institute, 1989).

Hillson, D., “Using a Risk Breakdown Structure in Project Management,” Journal of Facilities Management 2, no. 1 (2003): 85-97.

Parker, D. and Alison Mobey, “Action Research to Explore Perceptions of Risk in Project Management,” International Journal of Productivity and Performance Management 53, no. 1 (2004): 18-32. 


\subsection{Project Risk by Phases}

\section{Learning Objectives}

1. Describe the elements of risk management during the initiation phase.

2. Describe the elements of risk management during the planning phase.

3. Describe the elements of risk management during the execution phase.

4. Describe the elements of risk management during the closeout phase.

Project risk is dealt with in different ways depending on the phase of the project.

\section{Initiation Phase}

Risk is associated with things that are unknown. More things are unknown the beginning of a project, but risk must be considered in the initiation phase and weighed against the potential benefit of the project's success in order to decide if the project should be chosen.

\section{Risks by Phase in John's Move}

In the initiation phase of John's move, John considers the risk of events that could affect the whole project. He identifies the following risks during the initiation phase that might have a high impact and rates the likelihood of their happening from low to high.

1. His new employer might change his mind and take back the job offer after he's given notice at his old job: Low.

2. The current tenants of his apartment might not move out in time for him to move in by the first day of work at the new job: Medium.

3. The movers might lose his furniture: Low.

4. The movers might be more than a week late delivering his furniture: Medium.

5. He might get in an accident driving from Chicago to Atlanta and miss starting his job: Low. John considers how to mitigate each of the risks.

1. During his job hunt, John had more than one offer, and he is confident that he could get another job, but he might lose deposit money on the apartment and the mover. He would also lose wages 
during the time it took to find the other job. To mitigate the risk of his new employer changing his mind, John makes sure that he keeps his relationships with his alternate employers cordial and writes to each of them thanking for their consideration in his recent interviews.

2. John checks the market in Atlanta to determine the weekly cost and availability of extended-stay motels.

3. John checks the mover's contract to confirm that they carry insurance against lost items, but they require the owner to provide a detailed list with value estimates and they limit the maximum total value. John decides to go through his apartment with his digital camera and take pictures of all of his possessions that will be shipped by truck and to keep the camera with him during the move so he has a visual record and won't have to rely on his memory to make a list. He seals and numbers the boxes so he can tell if a box is missing.

4. If the movers are late, John can use his research on extended-stay motels to calculate how much it would cost. He checks the moving company's contract to see if they compensate the owner for late delivery, and he finds that they do not.

5. John checks the estimated driving time from Chicago to Atlanta using an Internet mapping service and gets an estimate of eleven hours of driving time. He decides that it would be too risky to attempt to make the drive by himself in one day, especially if he didn't leave until after the truck was packed. John plans to spend one night on the road in a motel to reduce the risk of an accident caused by driving while too tired.

John concludes that the high-impact risks can be mitigated and the costs from the mitigation would be acceptable in order to get a new job.

\section{Planning Phase}

Once the project is approved and it moves into the planning stage, risks are identified with each major group of activities. A risk breakdown structure (RBS) can be used to identify increasing levels of detailed risk analysis.

\section{Risk Breakdown Structure for John's Move}

John decides to ask Dion and Carlita for their help during their first planning meeting to identify risks, rate their impact and likelihood, and suggest mitigation plans. They concentrate on the packing phase of the move. They fill out a table of risks, as shown below.

Figure 11.5 Risk Breakdown Structure (RBS) for Packing John’s Apartment 


\section{Legend:}

RA: Risk Avoidance; RS: Risk Sharing; RR: Risk Reduction; RT: Risk Transfer

\begin{tabular}{|c|c|c|c|}
\hline Level 1 & Level 2 & Level 3 - Risks & Mitigation \\
\hline \multirow{10}{*}{ Packing } & \multirow{3}{*}{ Pack Kitchen } & Cuts from handling sharp knives & Buy small boxes for packing knives (RR) \\
\hline & & $\begin{array}{l}\text { Cuts from cracked glasses that break while } \\
\text { being packed }\end{array}$ & Discard cracked glasses (RA) \\
\hline & & Transporting alcoholic beverages & Give opened bottles to Dion or Carlita (RA) \\
\hline & \multirow{3}{*}{$\begin{array}{l}\text { Pack Living } \\
\text { Room }\end{array}$} & Damage to antique furniture & $\begin{array}{l}\text { Supervise wrapping and loading personally (RR) and require movers to } \\
\text { insure against damage (RT) }\end{array}$ \\
\hline & & $\begin{array}{l}\text { Lose parts while taking apart the entertainment } \\
\text { center }\end{array}$ & Buy box of large freezer bags with a marker to bag and label parts (RR) \\
\hline & & $\begin{array}{l}\text { Break most valuable electronics — TV, DVD, } \\
\text { Tuner, Speakers }\end{array}$ & Buy boxes of the right size with sufficient bubble wrap (RR) \\
\hline & \multirow{2}{*}{$\begin{array}{l}\text { Pack } \\
\text { Bedroom }\end{array}$} & Break large mirror & Buy or rent a mirror-box with Styrofoam blocks at each corner (RR) \\
\hline & & $\begin{array}{l}\text { Lose prescription drugs or pack them where } \\
\text { they cannot be found quickly }\end{array}$ & Separate prescription drugs for transportation in the car (RA) \\
\hline & \multirow{2}{*}{$\begin{array}{l}\text { Pack } \\
\text { Remaining } \\
\text { Items }\end{array}$} & Damage to house plants & $\begin{array}{l}\text { Ask Carlita to care for them and bring them with her in her van when } \\
\text { she visits in exchange for half of them (RS) }\end{array}$ \\
\hline & & $\begin{array}{l}\text { Transportation of flammable liquids from } \\
\text { charcoal grill }\end{array}$ & Give to Dion or Carlita and buy replacements in Atlanta (RA) \\
\hline
\end{tabular}

\section{Execution Phase}

As the project progresses and more information becomes available to the project team, the total risk on the project typically reduces, as activities are performed without loss. The risk plan needs to be updated with new information and risks checked off that are related to activities that have been performed.

Understanding where the risks occur on the project is important information for managing the contingency budget and managing cash reserves. Most organizations develop a plan for financing the project from existing organizational resources, including financing the project through a variety of financial instruments. In most cases, there is a cost to the organization to keep these funds available to the project, including the contingency budget. As the risks decrease over the length of the project, if the contingency is not used, then the funds set aside by the organization can be used for other purposes.

To determine the amount of contingency that can be released, the project team will conduct another risk evaluation and determine the amount of risk remaining on the project. If the risk profile is lower, the project team may release contingency funds back to the parent organization. If additional risks are uncovered, a new mitigation plan is developed including the possible addition of contingency funds. 


\section{Closeout Phase}

During the closeout phase, agreements for risk sharing and risk transfer need to be concluded and the risk breakdown structure examined to be sure all the risk events have been avoided or mitigated. The final estimate of loss due to risk can be made and recorded as part of the project documentation. If a Monte Carlo simulation was done, the result can be compared to the predicted result.

\section{Risk Closeout on John's Move}

To close out the risk mitigation plan for John's move, John examines the risk breakdown structure and risk mitigation plan for items that need to be finalized. He makes a checklist to be sure all the risk mitigation plans are completed, as shown below.

Figure 11.6 Closeout of Risk Mitigation Plan for John’s Move

\begin{tabular}{|l|l|l|}
\hline Risk & Mitigation & Closeout \\
\hline $\begin{array}{l}\text { Items lost by } \\
\text { movers }\end{array}$ & $\begin{array}{l}\text { Mover's insurance plus digital image } \\
\text { inventory }\end{array}$ & $\begin{array}{l}\text { Confirm all of the numbered boxes are present } \\
\text { and still sealed }\end{array}$ \\
\hline $\begin{array}{l}\text { Antique } \\
\text { furniture } \\
\text { damaged }\end{array}$ & $\begin{array}{l}\text { Mover's insurance plus personal supervision } \\
\text { of wrapping and loading }\end{array}$ & $\begin{array}{l}\text { Supervise unloading and unwrapping; visually } \\
\text { inspect each piece }\end{array}$ \\
\hline House plants & $\begin{array}{l}\text { Ask Carlita to bring half of them in her van } \\
\text { when she visits }\end{array}$ & $\begin{array}{l}\text { Confirm that the plants are healthy and that } \\
\text { Carlita brought about half of them }\end{array}$ \\
\hline
\end{tabular}

Risk is not allocated evenly over the life of the project. On projects with a high degree of new technology, the majority of the risks may be in the early phases of the project. On projects with a large equipment budget, the largest amount of risk may be during the procurement of the equipment. On global projects with a large amount of political risk, the highest portion of risk may be toward the end of the project.

\section{Key Takeaways}

- During the initiation phase, risks are identified that could threaten the viability of the project. Mitigation options are considered to see if they would be sufficient to protect the project.

- During the planning phase, risks are identified and analyzed for each activity group in a risk breakdown structure, and mitigation is planned for each risk

- During the execution phase, risks are checked off as activities are completed or mitigation is performed if loss does occur. New risks are identified and added to the plan.

- During the closeout phase, insurance contracts are cancelled and partnerships terminated. A summary of actual costs associated with risks are compared with initial estimates to refine estimating capabilities. The successes and failures of the risk management plan are summarized and saved 
with the project documentation to add to the company’s corporate knowledge.

\section{Exercises}

1. High-risk events that require expensive mitigation options threaten the choice of the project during the phase.

2. A risk breakdown structure is developed during the phase.

3. Risk transfers and risk sharing arrangements are terminated during the phase.

4. If you plan an outdoor wedding, what is a risk that would threaten the project in the initiation phase and a mitigation plan that would allow the project to proceed?

5. In your own words, describe risk management during the planning phase.

6. In your own words, describe risk management during the closeout phase?

\section{Risk Assessment}

Recall a project that you considered at one time but decided against during the initiation phase because the risks were too great or the mitigation plan was insufficient to proceed. Describe the project, the risks, the mitigation plan, and why you chose not to go forward. 


\subsection{Project Risk and the Project Complexity Profile}

\section{Learning Objective}

1. Identify the relationship between project risk and external, internal, technical, and environmental complexity.

Risk seems to have a positive correlation to complexity. High-risk projects are in most cases highly complex. The process of conducting a risk analysis focuses on understanding what can go wrong and the likelihood that it will go wrong. The project team then develops a project mitigation plan that addresses the items that were identified as high risk. The complexity analysis explores the project from the perspective of what elements on the project add to project complexity. The result of this analysis is the information needed by the project leadership to develop an appropriate execution plan. This execution plan also contains the risk management plan.

Although increased complexity on a project increases the project risk profile, risk is only one component of the complexity profile, and the manageability of the risk is also reflected in the complexity level of the project. For example, the organizational component of the project may be extremely complex with decision making shared among several independent clients. The project management team will develop an execution plan that includes developing and maintaining alignment among the various clients. Although the organizational risk of the project decreases with the development of the execution plan, the organizational approach of the client did not change the complexity level of the project. If the Darnall-Preston Complexity Index (DPCI) is used to rate the project, high ratings in each category carry their own types of increased risks.

\section{External Complexity}

Projects that have a high score in the external complexity category in the DPCI are larger and longer than usual for the project management group and the project manager and the available resources are lacking. Due to lack of experience on this size project, unknown risks are significant. The inadequacy of resources will cause risks that are more predictable.

\section{Internal Complexity}

Projects with high scores for internal complexity have risks to the budget, schedule, and quality due to organizational complexity and changes of scope due to lack of clarity in project and scope statements. 


\section{Technological Complexity}

High scores in technological complexity are associated with high levels of risk due to unknown flaws in the technology and lack of familiarity with it. These problems result in risks to the schedule, budget, and quality.

\section{Environmental Complexity}

Environmental complexity includes legal, cultural, political, and ecological factors. High scores for complexity in this category imply high risks for delay and expensive resolution to lawsuits, public opposition, changes for political considerations, and unforeseen ecological impacts.

\section{Key Takeaways}

- There is a positive correlation between the complexity of a project and the risk. Increased levels of complexity imply more people, newer technologies, and increased internal and external unknown factors.

- High scores for external complexity imply high risks to the schedule, budget, and quality due to unknown factors and limited resources.

- High scores for internal complexity imply high risks to the budget, schedule, and quality due to organizational complexity and changes of scope due to lack of clarity in project and scope statements.

- High scores for technological complexity imply high risks to the budget, schedule, and quality due to unknown flaws in the technology and lack of familiarity with it.

- Environmental complexity includes legal, cultural, political, and ecological issues. High scores for complexity in this category imply high risks for delay and expensive resolution to lawsuits, public opposition, changes for political considerations, and unforeseen ecological impacts.

\section{Exercises}

1. There seems to be a correlation between project complexity and risk.

2. One complexity category that is likely to have high risks due to unknown causes is due to lack of experience with the size of project.

3. How does a high degree of complexity in a project's environment affect the level of risk?

Environmental Risks

Identify a project with which you are familiar or one that has been in the news recently where the external 
environmental complexity caused increased costs or delays. Describe the impact of the risk, and the mitigation and its effectiveness. If the mitigation was ineffective, describe how you might have prepared a different mitigation plan. 


\subsection{Exercises}

Exercises at the end of the chapter are designed to strengthen your understanding and retention of the information recently acquired in the chapter.

\section{Essay Questions}

Write several paragraphs to provide more in-depth analysis and consideration when answering the following questions.

1. Choose a simple project with which you are familiar and describe a risk that is typical of each phase of the project and a mitigation plan for those four risks.

2. Assume that you are considering the purchase of a house. What are examples of each of the four types of risk mitigation that are associated with buying a house? Explain your choice of each example and relate it to the definition of each type of risk mitigation.

3. Assume that you are working on a complex project to add a wing to a hospital that is next to a natural wetland. Using the four categories of the Darnall-Preston Complexity Index, identify a high-impact risk and explain your choice.

\section{Discussion}

The exercises in this section are designed to promote exchange of information among students in the classroom or in an online discussion. The exercises are more open ended, which means that what you find might be completely different from what your classmates find, and you can all benefit by sharing what you have learned.

1. Choose a situation with which you are familiar where a risk event occurred that had a high impact on a project causing it to exceed the contingency allowances in the schedule or budget. Do you think this event was an unknown or known risk? What additional mitigation efforts (if any) should be used on a similar project in the future? Consider situations described by your classmates and contribute ideas for mitigation of events in their projects.

2. Consider your personal health. What are two examples of known risks and a mitigation plan for those two risks? Describe your mitigation plan for unknown risks. Consider the risks and plans described by your classmates and make suggestions for other mitigation options. 


\subsection{Web Exercise}

\section{Learning Objective}

1. Describe the benefits of estimating risk using a Monte Carlo simulation.

\section{Monte Carlo Risk Simulations}

Planning for risks is a form of betting on the future. An accomplished gambler knows the odds of drawing a certain combination of cards in a poker hand or of a ball landing on a number at a roulette wheel. If a project has several risk factors, they are not likely to all occur on the same project, but it is important to know the odds of that happening and to compare them to the potential profit of the project. If several risks do materialize on the same project, it might cause the company to lose money on the project, and senior management must decide if the benefit is worth the risk.

Computers can generate random numbers that can be used to simulate the likelihood of combinations of risk factors occurring and the impact on the project's profitability. These simulations calculate odds like those a gambler would use before placing a bet, and the process is named after a famous gambling center in Europe.

To use a Monte Carlo simulation, you have to decide how the frequency of occurrences is distributed. Three types of distributions are most common: normal, skewed, and equal. If they are governed by the central limits principle, the occurrences will have a normal distribution.

Figure 11.7 Normal Distribution

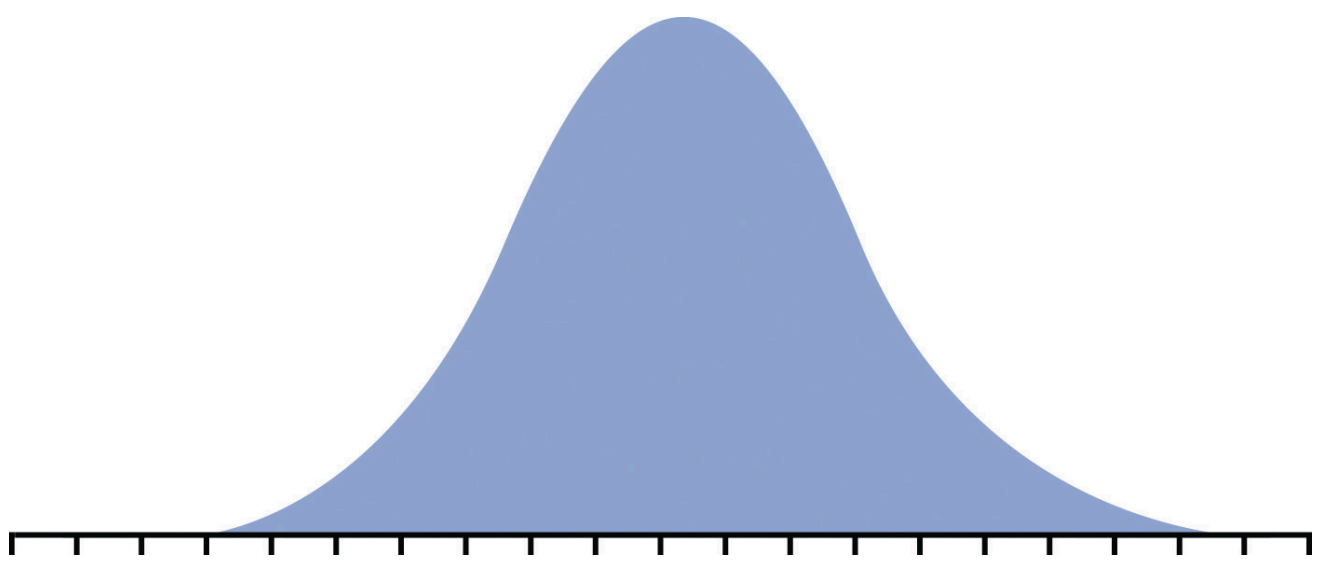


If the likely frequency of occurrences of a risk factor is more likely to be distributed to either side of the middle of the range, it is a skewed distribution.

Figure 11.8 Skewed Distribution

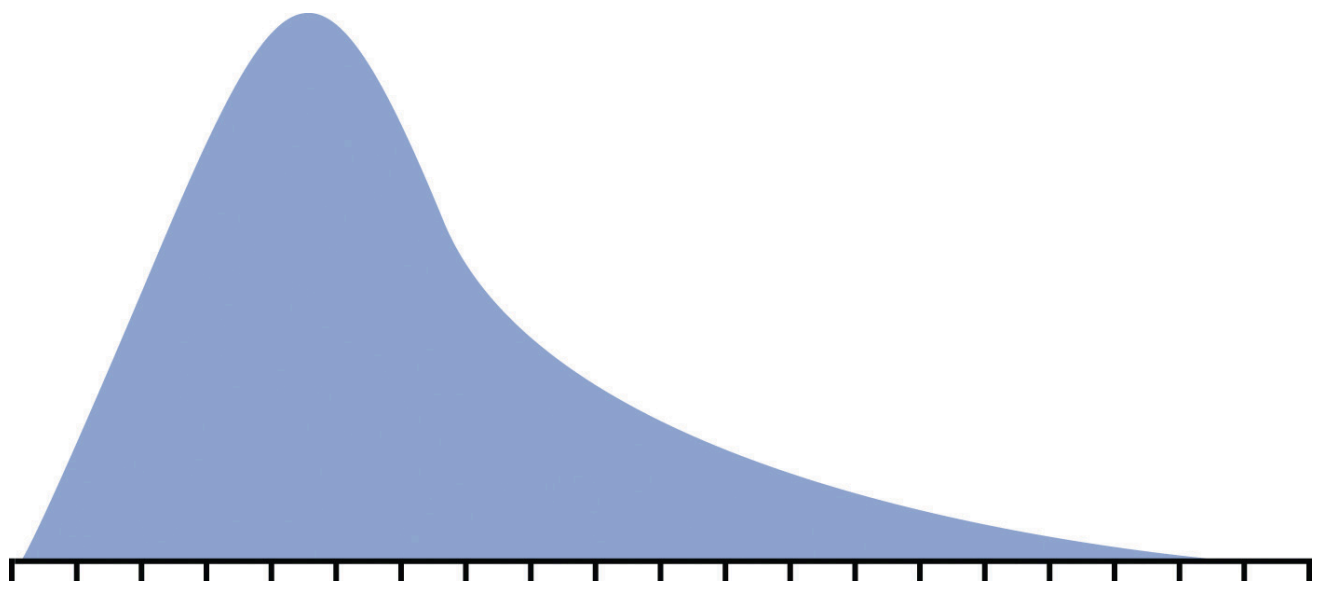

If the likelihood of occurrence is evenly distributed across the range where each possibility has the same odds of occurring, it is an equal distribution.

Figure 11.9 Equal Distribution

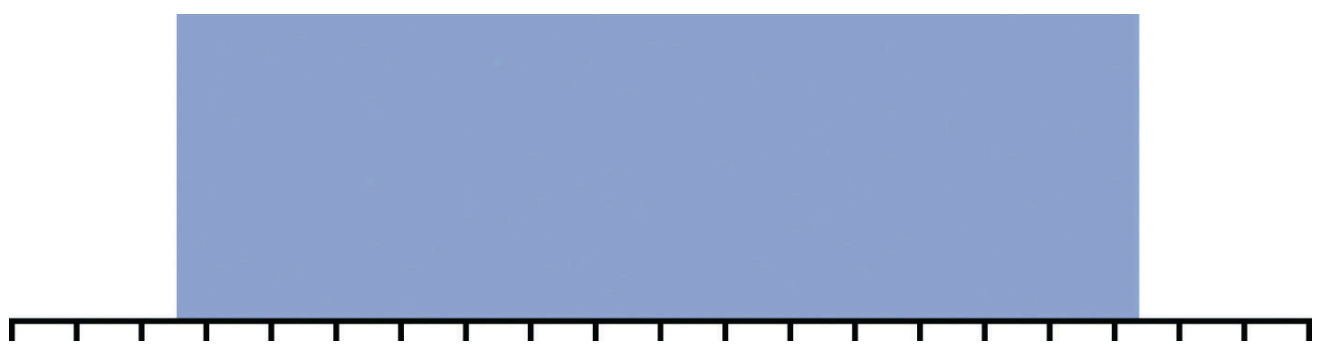

A computer can choose numbers for each risk factor that represent a possible outcome for that risk on the project according to its distribution. Those numbers are fed into a spreadsheet that determines the effect on the project and its costs. This process is repeated thousands of times, and the result of each iteration - repeated process — is stored in a table of possible outcomes. This table is summarized in a histogram that shows how many of the iterations produced profit (or loss) in each range (bin).

The outcome of a Monte Carlo simulation gives managers an idea of how much the project could make or lose and the odds of that happening. Monte Carlo simulations are often used to predict the likelihood of a new product making a profit or loss. The same methods can be applied to predicting the profit or loss on a project.

\section{Learn More about Monte Carlo Simulations}

Complete the exercise by following these instructions: 
1. Open a blank document in a word processing program and then save the document as Ch11MonteCarloStudentName.doc. Leave the document open.

2. Start a web browser and then to go to A Practical Guide to Monte Carlo Simulations at http://www.vertex42.com/ExcelArticles/mc/MonteCarloSimulation.html.

3. Read the first screen to review the concepts.

4. Near the bottom of the first screen, click the arrow labeled Sales Forecast Example, as shown in Figure 11.10 "Next Page Button”.

Figure 11.10 Next Page Button

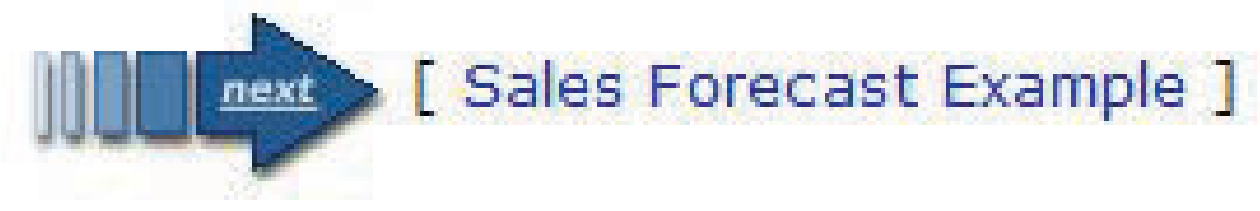

Source: Courtesy of www.vertex42.com.

5. Scroll down past the advertisements and begin reading at Step 1. Capture a screen that shows Step 1 and paste it into Ch11MonteCarloStudentName.doc.

6. Read the explanation of how to create a model.

7. Use the Next button at the bottom of the screen to go to step 2, Generating Random Inputs.

8. Read steps 2, 3, and 4 on this screen.

9. Continue reading and advancing screens until you get to the histogram as shown in Figure 11.11 “Estimated Loss or Profit”.

Figure 11.11 Estimated Loss or Profit

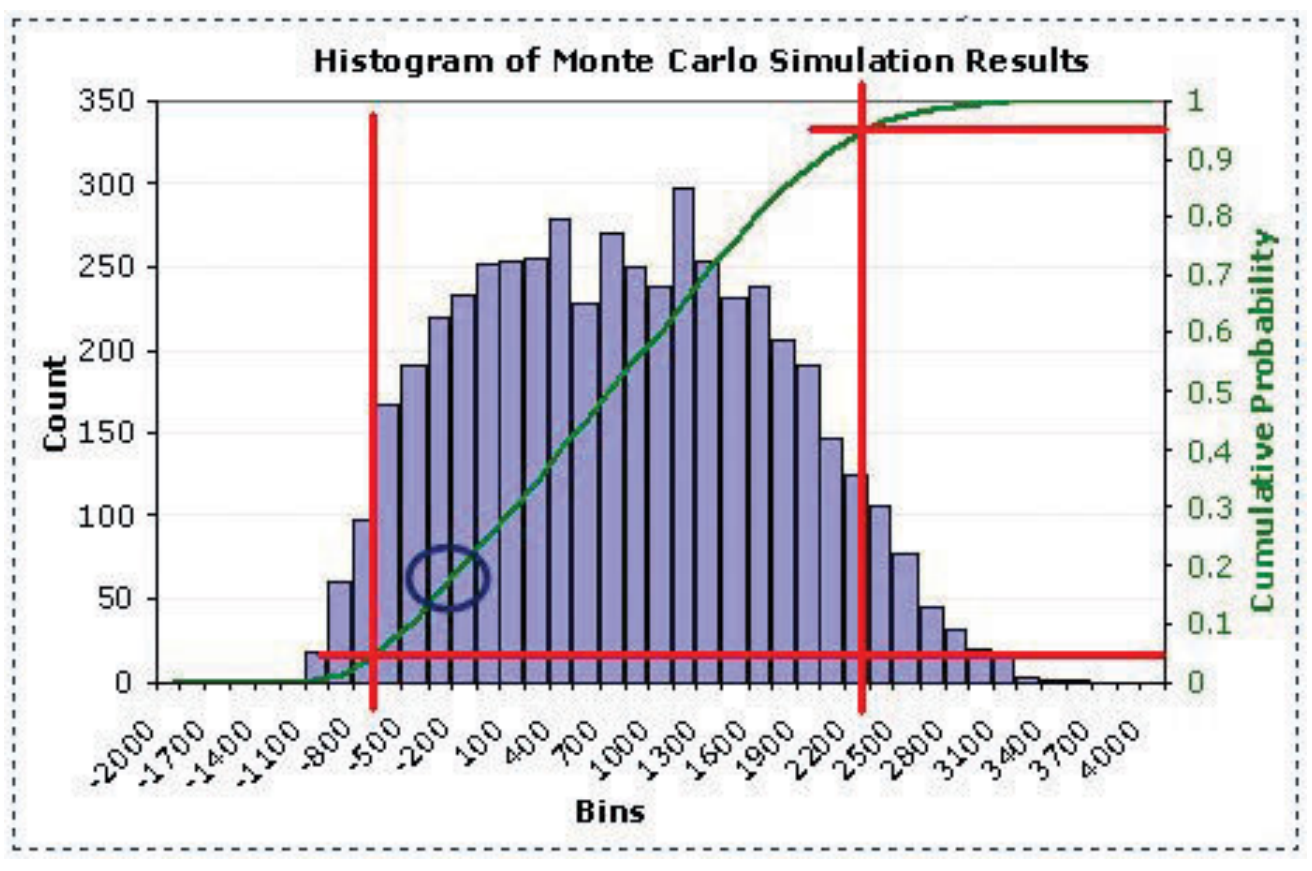


Source: Adapted from Wittwer, J.W., “Creating a Histogram In Excel” from www.vertex42.com, June 1, 2004, http://vertex42.com/ExcelArticles/mc/Histogram.html.

10. The green line is the cumulative probability. The red lines are intended to help you find the 5 percent and 95 percent probability points on the green line.

11. Capture this screen and paste it into Ch11MonteCarloStudentName.doc.

12. Refer to Figure 11.11 "Estimated Loss or Profit”. Notice a spot on the green line is circled. According to the horizontal scale, this is the spot on the cumulative percentage line that marks the difference between negative and positive income for the project. In the word processing document, below the last screen capture, describe how you would use this chart to predict the percentage chance that this project will lose money. Leave the document open.

\section{Learn about Using Dedicated Monte Carlo Simulation Software}

Complete the exercise by following these instructions:

1. Use your web browser to go to Monte Carlo Simulation Tutorial at http://www.solver.com/ simulation/monte-carlo-simulation/tutorial.htm.

2. Read each of the first seven screens. Capture screens where indicated in the following list and paste them into Ch11MonteCarloStudentName.doc:

- Introduction (Capture the section titled The Flawed Average Model.)

- Introducing Uncertainty

- Introducing Uncertainty (cont.)

- Uncertain Functions and Statistics

- Using Interactive Simulation (Capture the table near the bottom.)

- Viewing the Full Range of Profit Outcomes

- Focusing on Profitable Outcomes (Capture the simulation results histogram at the bottom of the screen.)

3. The authors make the case that a simple average of the risks produces an estimate that is too high. If they run a thousand combinations of risk outcomes, they predict a lower profit and a certain likelihood of losing money. In the word processing document, below the last screen capture, review the screens and answer the following questions:

- What does a simple average model predict for a net profit?

-What does the simulation predict is the "True Average" profit?

- If most of the risk factors occur, how much money could the project lose? 


\section{Analysis}

1. At the bottom of Ch11MonteCarloStudentName.doc, write between one hundred and two hundred words to describe the benefits of estimating risk using a Monte Carlo simulation versus a simple average of the risks. Use specific references to the assigned reading in the text and in the web pages in the previous two parts of this exercise.

2. Review your work and use the following rubric to determine its adequacy:

\begin{tabular}{|c|c|c|c|}
\hline Element & Best & Adequate & Poor \\
\hline File name & Ch11MonteCarloStudentName.doc & $\begin{array}{l}\text {.docx } \\
\text { version }\end{array}$ & $\begin{array}{l}\text { Student name not } \\
\text { included }\end{array}$ \\
\hline $\begin{array}{l}\text { Describe the } \\
\text { benefits of } \\
\text { estimating } \\
\text { risk using a } \\
\text { Monte Carlo } \\
\text { simulation }\end{array}$ & $\begin{array}{l}\text { Two screen captures plus a description of how } \\
\text { the chart is used to estimate the percentage } \\
\text { chance of losing money; three screen captures } \\
\text { and answers to the three questions; description } \\
\text { of the benefits of a Monte Carlo simulation }\end{array}$ & $\begin{array}{l}\text { Same as } \\
\text { Best }\end{array}$ & $\begin{array}{l}\text { Missing screens; } \\
\text { inaccurate estimates; } \\
\text { incorrect answers to } \\
\text { the three questions; } \\
\text { description without } \\
\text { specific references }\end{array}$ \\
\hline
\end{tabular}

3. Save the file and submit it as directed by the instructor. 


\section{Chapter 12: Project Procurement and Closure}

To achieve the objectives of the project, the management team will purchase goods and some services. The process of obtaining goods and services from providers who are outside of the organization is procurement. This chapter discusses the process for selecting the work that will be procured and the different methods and processes for procuring the equipment, materials, and services for the project. 


\subsection{Identifying the Need for Resources Outside the Organization}

\section{Learning Objectives}

1. Identify the factors that are considered when deciding whether to buy goods from within the organization or to obtain them from outsiders.

2. Identify what factors are considered when deciding to outsource or perform the work within the organization.

The project team decides the work that will be self-performed-performed by members of the project team-and the work that will be outsourced to others. The procurement strategy focuses on the work that will be outsourced-performed by outsiders.

Luu, Ng, and Chen (Luu, Ng, \& Chen, 2003) studied project procurement selection priorities and identified budget and schedule as the most important considerations in the decision to outsource activities. This study of construction projects also identified other items that project managers must consider in developing a procurement strategy, including quality, risk, complexity, and flexibility. Some outsourcing decisions are easy.

\section{Outsourcing Steel and Concrete in New York}

A construction company has a contract to build a large building in downtown New York. Most, if not all, the construction materials, such as steel and concrete, will be purchased from companies that specialize in steel and concrete. Existing companies that produce and sell steel can provide the steel the project needs at a much lower cost and faster than if the project manager's organization attempted to build the capacity itself.

Some outsourcing decisions — sometimes called make or buy decisions — are more difficult. On the same building construction project, new construction materials and methods are required that will make the building more energy efficient. The project manager can outsource this portion of the project to companies that have this expertise or develop this expertise on the project and self-perform the work. The costs of developing this expertise within the project will be more expensive and may take more time than outsourcing this work.

Self-performing this work also has benefits. The project team would develop this expertise and the additional expertise would add value to the parent company and save money on future projects. The project management team would have greater control over the work because the work would be performed by members of the project team instead of outsiders. Self-performing and outsourcing the work have both benefits and risks. 
This decision is primarily influenced by the following:

- Cost (budget)

- Schedule

The following factors also influence outsourcing decisions:

- Risk

- Quality

- Flexibility

\section{Outsourcing Versus Self-Performing}

On the New York building construction project, the project manager decided to outsource the portion of the work that required new methods and materials. The project team assigned engineers from the project team to evaluate the work during the project and to assess the appropriate methods and costs for the parent company to develop this capacity within the company. The additional costs of developing the capacity and the additional risks of implementing a new method with existing resources outweighed the benefits of developing the capacity within the organization.

The project procurement strategy begins with these self-perform or buy decisions.

\section{New York Construction Project}

On the New York building construction project, the basic engineering and construction activities are core expertise of the parent company, and the project team had access to the qualified resources to perform the work. The decision to self-perform this portion of the work was easy because the company had a cost and schedule advantage by using the existing resources. The purchase of the steel, concrete, and other commodities was also easy because the costs of developing those resources far outweighed the benefit of purchasing them.

Some of the procurement decisions are not so obvious and the project team evaluates the cost, schedule, quality, flexibility, and risk implication of self-performing versus outsourcing the work.

\section{Key Takeaways}

- The factors that influence procurement are primarily cost and schedule but also include risk, quality, and flexibility.

- To determine whether to outsource or do the work within the organization, consider which option 
is less costly and which option can deliver the work on time.

\section{Exercises}

1. The primary factors that influence procurement are cost and

2. In addition to the two primary factors that influence procurement, what are three other important factors?

3. What is one advantage of doing the work within the organization instead of outsourcing it?

Internalize your learning experience by preparing to discuss the following.

Choose a situation with which you are familiar where you or your organization chose to hire someone outside your organization instead of developing the skill yourselves. What factors were most important in making the choice and how do they relate to the factors described in this section?

\section{References}

Luu, D. T., S. Thomas Ng, and Swee Eng Chen, "Parameters Governing the Selection of Procurement System," Journal of Engineering, Construction, and Architectural Management 10, no. 3 (2003): 209-18. 


\subsection{Procurement Plan}

\section{Learning Objectives}

1. Describe the role of suppliers.

2. Describe the role of vendors.

3. Describe the role of partners.

After the outsourcing versus self-performing decisions are made, the procurement team develops the purchasing plan.

The method of purchasing products or services depends on the uniqueness and importance of the product or service. One way to organize the procurement plan is by the type of relationship with the providers of the outsourced goods or services.

\section{Suppliers}

Some of the goods or services are commonly available with little variation in quality or availability. Such goods and services are called commodities. The providers of commodities are suppliers and there are usually several from which to choose. Purchasing commodities from suppliers focuses on achieving the lowest cost. Cost of commodities can often be found in the supplier's catalog. On smaller, less complex projects, supplies can be purchased as needed from the supplier's catalog.

Additional cost savings are often available if large quantities of a commodity are purchased from the same supplier. On larger, more complex projects, a list of materials and supplies is developed from the project cost estimate. This list is provided to suppliers as a request for quote (RFQ), and the suppliers respond with their lowest price. To avoid choosing a bid from a company that will make a promise it cannot keep, many organizations will maintain a list of suppliers that meet the organization's requirements. These requirements usually include the proven ability to meet the quality and schedule specifications.

The project management team develops a procedure for requesting a quote. On smaller projects, the parent purchasing organization may process all RFQs. On larger projects, a procurement organization is established with expertise in purchasing. The purchasing team will develop a list of all procurement requirements for the project and develop a procurement schedule that assures the materials will be available to the project when needed.

The project team develops an RFQ based on the quantity and schedule needs of the project and sends 
the RFQ to the identified qualified suppliers. The suppliers then develop a quote that lists the specific materials to be provided, the price for each, and a schedule for delivery. The project team evaluates each quote from suppliers and determines that the supplier bid meets all the requirements, and in most cases, the supplier with the lowest price will be awarded the bid.

\section{RFQ for Housing Contractor}

A housing contractor who is building ten identical houses develops a materials list that includes all the carpentry, plumbing, and electrical supplies needed to build all ten houses. The housing contractor develops an RFQ for all these materials, including the construction schedule, and submits the RFQ to the four largest building supply companies in the region. Each of the supply companies decides to bid on the project and provides a bid for the materials in the RFQ. One of the bidders has the lowest price but is unable to deliver the materials to the job site. The project team calculates the cost of transporting the materials to the job site. After the cost of transportation is added to the bid, it is no longer the lowest total cost. The bidder with the total lowest total cost is awarded the contract.

Some organizations that do a large number of projects will develop a relationship with one or two suppliers based on developing cost savings for both organizations. This relationship is commonly called a key supplier relationship.

\section{Key Supplier for Housing Supplies}

The housing contractor develops a key supplier relationship with one or two of the building supply companies. The building supply company would guarantee a 10 percent discount on all materials and the contractor would promise to purchase exclusively from the key supplier. Both organizations save the cost and time associated with preparing the bid. The building supply company plans on a consistent volume of business from the contractor and the contractor can expect priority treatment when supplies are scarce.

\section{Vendors}

Vendors often provide a unique product or service that cannot be readily purchased in the marketplace. The vendor typically provides a product or service that is designed for the project. The following are examples of products or services provided by vendors:

- A large military contract to design and build a new fighter aircraft

- A new software program design to improve the efficiency of a hospital emergency room

- The design and construction of a blast furnace for a new steel mill

Products and services from vendors need input and insight from the vendor. Instead of issuing a request for quote (RFQ) for a list of commodities, the project team issues a request for proposal (RFP). Com- 
panies responding to an RFP are invited to provide creative approaches to adding value to the project. Bidders are encouraged to offer design alternatives, alternative uses of materials, and scheduling alternatives that meet all the project requirements and also reduce the total project cost. The bids are evaluated on the total value to the project, including the contribution to the project goals.

\section{RFP for Mining Operation}

A copper mining project in Argentina included the design and construction of the mine site, the extraction of copper from the raw materials, the building of a pipeline to transport the copper ore to the Atlantic coast, and the construction of a port to enable the loading of the copper ore into various size ships. The construction materials, such as lumber, steel, and concrete, were purchased through suppliers, including key suppliers.

Some of the equipment used to extract the copper ore from the raw materials costs several million dollars and is only fabricated by a few companies. The project team designs the equipment to meet characteristics of the mining environment in Argentina: size, hardness, and composition of the raw material. The bid documents sent to the mining equipment vendors included the design specification and performance specification of the equipment, the project schedule, and the mining process. A request for proposal (RFP) was issued to each of the vendors.

Because vendor performance is critical to the success of the project, the management of the vendor relationship is a project management priority. Project management will often implement processes that encourage the vendors to submit suggestions that will reduce total project cost, shorten the schedule, or improve the performance. The project management team will often assign someone from the team to monitor the relationship and provide support from project resources to help assure vendor success.

\section{Partners}

If the parent organization lacks key skills or relationships, it might work with other organizations as partners-especially on international projects.

\section{Partnership on Mining Project}

In the Argentina mining project example, the United States parent organization had project management, engineering, procurement, construction, and mining technology expertise. The company also had relationships with major mining equipment vendors. The U.S. construction company partnered with an Argentinean company that had expertise and relationships important to the success of the project.

The Argentinean company contributed local knowledge of the construction workforce; local engineering and construction practices, knowledge, and expertise in the government permitting processes; and an existing relationship with potential key suppliers and local vendors.

A partnership is a formal arrangement to execute the project with each party contributing resources. 
In most partnerships, both parties benefit from the success of the project and share the costs associated with a less successful project. Critical to the success of a partnership is the clear definition of roles and responsibilities on the project, a common understanding of the project goals, and a scope of work for each partner.

Building the relationship between major partners on the project is similar to building relationships with clients. On a large, complex project, a partnership alignment session is often required to build the trust required for open communication channels. Maintaining the relationship permits more effective problem solving and coordinated action on the project. A well-managed partnering relationship can contribute to the achievement of project goals, reduce overall costs, and shorten the project schedule. In most cases, the parent organization is aware of weaknesses in the project resources or skills and searches for a potential partner that has the needed resources or skills. In our Argentinean example, the parent company knew that construction experience in Argentina would be important to a successful project. Both companies will research the capability of the other company to assure that the partnership is appropriate for both companies.

\section{Biotech Plant Partnership in Puerto Rico}

On a project to build a new biotech plant in Puerto Rico, a large engineering and construction company selected a Puerto Rican civil engineering company to design the site work on the project. Because the plant was needed quickly, the project schedule was an important component of every discussion and meeting the project end date was a major goal. The Puerto Rican Company was asked to begin developing the civil drawings early, before much of the needed information had been developed. This was a situation where a partnering relationship would benefit the project. Both companies would mutually support each other to achieve project goals and both would benefit from project success.

In this situation, the project procurement plan specified the development of a subcontract for the civil engineering, and a contract was developed with a clear scope of work and a cost based on completing the work in the contract on time and according to specification. Because the aggressive project schedule required the civil engineering company to begin work before all the needed information was available, change orders were required when new information became available. The contract allowed several days to evaluate the impact of the change on cost and schedule, and the time evaluation process began to cause delays in the project.

Eventually, a new contract was developed to make the Puerto Rican company a partner. These new partnering arrangements allowed the engineers to get early information and contribute ideas that would shorten the schedule. This case is an example of the need to evaluate the project goals and environment and develop a procurement strategy that matches the conditions of the project.

\section{Key Takeaways}

- Commodities are purchased through suppliers using a request for quote (RFQ) and selected on the basis of price. An exception is the key supplier relationship where the supplier-organization relationship is long term and the supplier passes along some of the savings of avoiding the bidding process. 
- Vendors provide products and services that are designed for the project based on a request for proposal (RFP) that invites the vendors to meet the goals of the request using their products and skills.

- If the organization lacks key skills or relationships, it might form a partnership arrangement with another company to share the benefits and risks of the project.

\section{Exercises}

1. Commodities are described in an (three-letter acronym).

2. The objectives of the work are described in an details of how to accomplish those objectives is proposed by the vendor.

3. If a project takes place in a different country, the project team might seek a with a local company to provide local contacts and expertise in local issues.

4. What is different about a key supplier relationship?

5. What is the difference between an RFP and an RFQ?

6. How is a partnership different from a vendor relationship?

Internalize your learning experience by preparing to discuss the following.

If you were building your own house, what would be an example of something that would be procured using an RFQ and something that would be procured with an RFP? Describe how your choices meet the descriptions of products or services procured from suppliers or vendors. 


\subsection{Selecting the Type of Contract}

\section{Learning Objectives}

1. Identify factors that determine which type of contract to select.

2. Describe the types of fixed cost contracts.

3. Describe the types of cost reimbursable contracts.

An agreement between the organization and an outside provider of a service or materials is a legal contract. To limit misunderstandings and make them more enforceable, contracts are usually written documents that describe the obligations of both parties.

Because legal agreements often create risk for the parent organization, procurement activities are often guided by the policies and procedures of the parent organization. After the project management team develops an understanding of what portions of the project work will be outsourced and defines the type of relationships that are needed to support the project execution plan, the procurement team begins to develop the contracting plan. On smaller, less complex projects, the contract development and execution is typically managed through the parent company or by a part-time person assigned to the project. On larger, more complex projects, the procurement team can consist of work teams within the procurement function with special expertise in contracting. The contract plan defines the relationship between the project and the subcontractors (supplier, vendor, or partner) and also defines a process for making changes in the agreement to accommodate changes that will occur on the project. This change management process is similar to the change management process used with the project agreement with the project client.

The contracting plan of the project supports the procurement approach of the project. The following are some factors to consider when selecting the type of contract:

- The uncertainty of the scope of work needed

- The party assuming the risk of unexpected cost increases

- The importance of meeting the scheduled milestone dates

- The need for predictable project costs

There are several types of contracting approaches and each supports different project environments and project approaches. The legal contracts that support the procurement plan consist of two general types of contract: the fixed price and the cost reimbursable contracts, with variations on each main type. 


\section{Fixed Price Contracts}

The fixed price contract is a legal agreement between the project organization and an entity (person or company) to provide goods or services to the project at an agreed-on price. The contract usually details the quality of the goods or services, the timing needed to support the project, and the price for delivering goods or services. There are several variations of the fixed price contract. For commodities and goods and services where the scope of work is very clear and not likely to change, the fixed price contract offers a predictable cost. The responsibility for managing the work to meet the needs of the project is focused on the contractor. The project team tracks the quality and schedule progress to assure the contractors will meet the project needs. The risks associated with fixed price contracts are the costs associated with project change. If a change occurs on the project that requires a change order from the contractor, the price of the change is typically very high. Even when the price for changes is included in the original contract, changes on a fixed price contract will create higher total project costs than other forms of contracts because the majority of the cost risk is transferred to the contractor, and most contractors will add a contingency to the contract to cover their additional risk.

Fixed price contracts require the availability of at least two or more suppliers that have the qualifications and performance histories that assure the needs of the project can be met. The other requirement is a scope of work that is most likely not going to change. Developing a clear scope of work based on good information, creating a list of highly qualified bidders, and developing a clear contract that reflects that scope of work are critical aspects of a good fixed priced contract.

\section{Fixed Total Cost Contract}

If the service provider is responsible for incorporating all costs, including profit, into the agreed-on price, it is a fixed total cost contract. The contractor assumes the risks for unexpected increases in labor and materials that are needed to provide the service or materials and in the quantity of time and materials needed.

\section{Fixed Price with Price Adjustment}

The fixed price contract with price adjustment is used for unusually long projects that span years. The most common use of this type of contract is the inflation-adjusted price. In some countries, the value of its local currency can vary greatly in a few months, which affects the cost of local materials and labor. In periods of high inflation, the client assumes risk of higher costs due to inflation, and the contract price is adjusted based on an inflation index. The volatility of certain commodities can also be accounted for in a price adjustment contract. For example, if the price of oil significantly affects the costs of the project, the client can accept the oil price volatility risk and include a provision in the contract that would allow the contract price adjustment based on a change in the price of oil. 


\section{Fixed Price with Incentive Fee Contract}

Fixed price with incentive fee is a contract type that provides an incentive for performing on the project above the established baseline in the contract. The contract might include an incentive for completing the work on an important milestone for the project. Often contracts have a penalty clause if the work is not performed according to the contract. For example, if the new software is not completed in time to support the start-up of a new plant, the contract might penalize the software company a daily amount of money for every day the software is late. This type of penalty is often used when the software is critical to the project and the delay will cost the project significant money.

\section{Incentive Fee on Copper Mine Project}

A project in South America to design and construct a copper mine would supply copper to several companies throughout the world. The copper that would be produced by the mine was sold before the mine was complete and ships were scheduled to make the delivery dates to processing plants.

Any delay in the project would mean a delay in shipping and significant loss to the mine, the shipping company, and the plants that were expecting the copper. Including an incentive fee for completing the project on time and including the important subcontracts increased the likelihood that the mine would make copper deliveries on time.

\section{Fixed Unit Price}

If the service or materials can be measured in standard units, but the amount needed is not known accurately, the price per unit can be fixed - a fixed unit price contract. The project team assumes the responsibility of estimating the number of units used. If the estimate is not accurate, the contract does not need to be changed, but the project will exceed the budgeted cost.

\section{Fixed Unit Price Contract for Concrete}

An example of a fixed price contract is a contract for the concrete needed for the foundation of a building. The project contracted for the concrete company to supply 1,000 cubic yards (CY) at 5,000 PSI (hardness standard) of concrete at the project site according to, and in support of, the project schedule for $\$ 70$ per square yard. This is an example of a unit price contract. If the project only uses $970 \mathrm{CY}$, then the total costs will be lower. If the project uses 1,050 CY, then the costs will be higher.

An alternative pricing would be to establish a fixed price of $\$ 70,000(1,000 \mathrm{CY} \times \$ 70.00)$. Both the unit price approach and the total costs approach are fixed price contracts. 


\begin{tabular}{|l|l|l|l|l|}
\hline Type & $\begin{array}{l}\text { Known } \\
\text { Scope }\end{array}$ & $\begin{array}{l}\text { Share of } \\
\text { Risk }\end{array}$ & $\begin{array}{l}\text { Incentive for Meeting } \\
\text { Milestones }\end{array}$ & $\begin{array}{l}\text { Predictability of } \\
\text { Cost }\end{array}$ \\
\hline Fixed Total Cost & Very High & $\begin{array}{l}\text { All } \\
\text { Contractor }\end{array}$ & Low $>$ & Very High \\
\hline Fixed Unit Price & High & $\begin{array}{l}\text { Mostly } \\
\text { Project }\end{array}$ & Low & High \\
\hline $\begin{array}{l}\text { Fixed price with Incentive } \\
\text { Fee }\end{array}$ & High & $\begin{array}{l}\text { Mostly } \\
\text { Project }\end{array}$ & High & Medium-high \\
\hline $\begin{array}{l}\text { Fixed Fee with Price } \\
\text { Adjustment }\end{array}$ & High & $\begin{array}{l}\text { Mostly } \\
\text { Project }\end{array}$ & Low & Medium \\
\hline
\end{tabular}

\section{Cost Reimbursable Contracts}

In a cost reimbursable contract, the organization agrees to pay the contractor for the cost of performing the service or providing the goods. Cost reimbursable contracts are also known as cost plus contracts. Cost reimbursable contracts are most often used when the scope of work or the costs for performing the work are not well known. The project uses a cost reimbursable contract to pay the contractor for allowable expenses related to performing the work. Since the cost of the project is reimbursable, the contractor has much less risk associated with cost increases. When the costs of the work are not well known, a cost reimbursable contract reduces the amount of money the bidders place in the bid to account for the risk associated with potential increases in costs.

The contractor is also less motivated to find ways to reduce the cost of the project unless there are incentives for supporting the accomplishment of project goals. Cost reimbursable contracts also require good documentation of the costs that occurred on the project to assure that the contractor gets paid for all the work performed and to assure that the organization is not paying for something that was not completed.

\section{Cost Reimbursable Contract to Drill Wells}

A project to build a new plant in an area that did not have sufficient water included the drilling of water wells to produce several thousand gallons of water a day for the new plant. Although geological surveys indicated there was sufficient water to meet the plant's requirements, the number of wells needed was unknown. The project developed a cost reimbursable contract that paid the well drilling contractor for allowable costs associated with drilling the wells.

Allowable costs included the costs associated with locating all the equipment and materials to the project site, the labor and materials used to drill the wells, daily costs for the use of the drilling rigs, routine maintenance of the drilling equipment, the room and board for the workers, and administrative fees and profit. The contractor collected the costs associated with drilling the wells each month and submitted a bill to the project accountant.

The contractor is paid an additional amount above the costs. There are several ways to compensate the contractor. 


\section{Cost Reimbursable Contract with Fixed Fee}

A cost reimbursable contract with a fixed fee provides the contractor with a fee or profit amount that is determined at the beginning of the contract and does not change.

Fixed Fee for Providing Water

On the new water plant project, the project accountant reviewed each bill, including time cards for labor, invoices for materials, and other documents that supported the invoice. The contractor was then reimbursed for the allowable costs plus the administrative fee and a fixed amount for his profit.

\section{Cost Reimbursable Contract with Percentage Fee}

A cost reimbursable contract with a percentage fee pays the contractor for costs plus a percentage of the costs, such as 5 percent of total allowable costs. The contractor is reimbursed for allowable costs and is paid a fee.

\section{Percentage Fee to Evaluate Dam in West Virginia}

A small community in West Virginia was worried about the structural integrity of a dam above the town. The county council was worried the dam would break and cause loss of life and property. They contracted with a civil engineering firm to evaluate the dam structure and attest to the structural soundness. The firm hired an expert from outside the area and paid the expert $\$ 1,000.00$ per day plus expenses such as meals, travel, and lodging. The civil engineering firm billed the community for the expert's fees and expenses plus 10 percent of the total.

\section{Cost Reimbursable Contract with an Incentive Fee}

A is used to encourage performance in areas critical to the project. Often the contract attempts to motivate contractors to save or reduce project costs. The use of the cost reimbursable contract with an incentive fee is one way to motivate cost reduction behaviors. 


\section{Incentive Fee for Road Project}

A road construction company won a contract to build a small road to the new county courthouse. The estimate to complete the road was $\$ 10$ million. The contract received a cost reimbursable contract that would pay all costs plus a 3 percent fee. The contactor could also earn an incentive by performing the work for less than $\$ 10$ million. The contract might include a fee that would pay the contract 20 percent of all savings below the estimated \$10 million. In this case, the county got the road at a lower cost, and the contractor made more money.

The contract could have focused on schedule and paid a bonus for completing ahead of schedule. This type of contract requires that the project management team has the capability to assure the quality of work performed meets project specifications and the savings was not generated through reducing the quality of the work.

\section{Cost plus Contract with Award Fee}

A cost plus contract with award fee reimburses the contractor for all allowable costs plus a fee that is based on performance criteria. The fee is typically based on goals or objectives that are more subjective. An amount of money is set aside for the contractor to earn through excellent performance, and the decision on how much to pay the contractor is left to the judgment of the project team. The amount is sufficient to motivate excellent performance.

The following Reuters story is about the use of an award fee to incentivize the contractor's performance in maintaining the ship’s performance during transfer to other owners.

VSE Corporation (NASDAQ GS: VSEC) reported today that it has been awarded a \$249 million cost-plus award fee contract option modification by the Naval Sea Systems Command that can be exercised by the Navy to provide one additional year of continued support to NAVSEA PMS 326 and 333 for ex-U.S. Navy ships that are sold, leased or otherwise transferred through the Foreign Military Sales (FMS) program to FMS clients.

This contract provides for services supporting U.S. ships that are sold, leased or otherwise transferred to FMS clients by providing engineering, technical, procurement, logistics, test, inspection, calibration, repair, maintenance and overhaul support services, including reactivation and modernization.

Since 1995, VSE’s International Group, GLOBAL Division (formerly BAV Division) has transferred 42 ships to foreign governments. VSE is currently reactivating EX-USNS Andrew J. Higgins (TAO-190) for transfer to Chile. Additionally, VSE actively supports various countries through the follow-on technical support requirements of the contract, providing training, maintenance, repair, and in-country infrastructure improvement assistance in support of transferred ships. Countries currently supported by VSE include Bahrain, Egypt, Japan, Mexico, Taiwan, Turkey, Poland, Philippines, Italy and Romania.

"We are extremely pleased to have won this award. It is a testament to the confidence and trust we have earned from the U.S. Navy and their foreign clients for the past 14 years," said VSE CEO/COO/President Maurice "Mo" Gauthier. "We look forward to continuing to deliver excellence and innovative technology solutions to the world's navies for years to come” (VSE Corporation, 2009). 


\section{Time and Materials Contracts}

On small activities that have a high uncertainty, the contractor might charge an hourly rate for labor, plus the cost of materials, plus a percentage of the total costs. This type of contract is called time and materials (T\&M). Time is usually contracted on an hourly rate basis and the contractor usually submits time sheets and receipts for items purchased on the project. The project reimburses the contractor for the time spent based on an agreed-on rate and the actual cost of the materials. The fee is typically a percent of the total cost.

Time and materials contracts are used on projects for work that is smaller in scope and has uncertainty or risk, and the project rather than the contractor assumes the risk. Since the contractor will most likely include contingency in the price of other types of contracts to cover the high risk, T\&M contracts provide lower total cost to the project.

Figure 12.9 Table of Contract Types and Characteristics

\begin{tabular}{|l|l|l|l|l|}
\hline $\begin{array}{l}\text { Cost Reimbursable } \\
\text { (CR) }\end{array}$ & $\begin{array}{l}\text { Known } \\
\text { Scope }\end{array}$ & $\begin{array}{l}\text { Share of } \\
\text { Risk }\end{array}$ & $\begin{array}{l}\text { Incentive for Meeting } \\
\text { Milestones }\end{array}$ & $\begin{array}{l}\text { Predictability of } \\
\text { Cost }\end{array}$ \\
\hline CR with Fixed Fee & Medium & $\begin{array}{l}\text { Mostly } \\
\text { Project }\end{array}$ & Low & Medium-high \\
\hline $\begin{array}{l}\text { CR with Percentage } \\
\text { Fee }\end{array}$ & Medium & $\begin{array}{l}\text { Mostly } \\
\text { Project }\end{array}$ & Low $>$ & Medium-high \\
\hline $\begin{array}{l}\text { CR with Incentive } \\
\text { Fee }\end{array}$ & Medium & $\begin{array}{l}\text { Mostly } \\
\text { Project }\end{array}$ & High & Medium \\
\hline CR with Award Fee & Medium & $\begin{array}{l}\text { Mostly } \\
\text { Project }\end{array}$ & High & Medium \\
\hline Time and Materials & Low & All Project & Low & Low \\
\hline
\end{tabular}

To minimize the risk to the project, the contract typically includes a not-to-exceed amount, which means the contract can only charge up to the agree amount. The T\&M contract allows the project to make adjustments as more information is available. The final cost of the work is not known until sufficient information is available to complete a more accurate estimate.

\section{Archeological Site Evaluation}

On a road construction project, the survey team discovers an archeological site. Contractors are required to preserve archeological sites and the project team explores ways to advance the schedule while a decision is made on how to handle the site. The project issues a T\&M contract to an archeologist to determine the nature of the site and develop a plan to preserve the integrity of the site. A T\&M contract is awarded because the size and character of the site is unknown and the amount of time and the type of equipment needed to explore the site is also unknown.

An archeologist from the local university was issued a T\&M contract to cover the labor and expenses to explore the site and develop a plan. An hourly rate was established for each member of the five-person arche- 
ological team. Equipment rental fees plus 15 percent was paid on all equipment rented and supplies used. The archeological team's profit was incorporated into the labor rates.

A not-to-exceed amount was also included in the contract to capture the team's estimate of the amount of work. A contract change order would increase the not-to-exceed number when more information was available.

\section{Progress Payments and Change Management}

Vendors and suppliers usually require payments during the life of the contract. On contracts that last several months, the contractor will incur significant cost and will want the project to pay for these costs as early as possible. Rather than wait until the end of the contract, a schedule of payments is typically developed as part of the contract and is connected to the completion of a defined amount of work or project milestones. These payments made before the end of the project and based on the progress of the work are called progress payments. For example, a concrete supplier on a construction project may bill the contract for the amount of concrete poured the previous month plus the profit earned during that period. On a training project, the contract might develop a payment schedule that pays for the development of the curriculum, and payment is made when the curriculum is completed and accepted. In each case, there is a defined amount of work to be accomplished, a time frame for accomplishing that work, and a quality standard the work must achieve before the contractor is paid for the work.

Just as the project has a scope of work that defines what is included in the project and what work is outside the project, vendors and suppliers have a scope of work that defines what they will produce or supply to the company. (Partners typically share the project scope of work and may not have a separate scope of work.) Often changes occur on the project that require changes in the contractor's scope of work. How these changes will be managed during the life of the project is typically documented in the contract. Capturing these changes early, documenting what changed and how the change impacted the contract, and developing a change order (a change to the contract) are important to maintaining the progress of the project. Conflict among team members will often arise when changes are not documented or when the team cannot agree on the change. Developing and implementing an effective change management process for contractors and key suppliers will minimize this conflict and the potential negative effect on the project.

\section{Key Takeaways}

- Contract selection is based on uncertainty of scope, assignment of risk, need for predictable costs, and the importance of meeting milestone dates.

- Total fixed cost is a single price where the scope is well defined. A fixed price with incentive contract offers a reward for finishing early or under budget or a penalty for being late. A fixed price with adjustment allows for increases in cost of materials or changes in currency values. A fixed unit price contract sets a price per unit, but the exact number of units is not known.

- In a cost reimbursable contract, the project pays for costs. A cost plus fixed fee contract assures 
the contractor of a known fee. A cost plus percentage fee calculates the fee as a percentage of the costs. A cost plus incentive fee sets goals for the contractor to achieve that would result in a bonus. A cost plus award fee is similar, but the goals are more subjective. Time and materials contracts pay for costs plus an hourly rate for the contractor's time.

\section{Exercises}

1. A key factor in choosing the type of contract is the uncertainty of the , risk, cost, or schedule of the activity.

2. A contract with an fee might reward the contractor for finishing early.

3. Contracts that pay the contractor's costs are contracts.

4. Which type of contract is most appropriate to use if the scope is extremely well known, and which type is most appropriate if the scope is very uncertain? Explain your choices.

5. Why would a water well drilling company prefer a cost reimbursable contract versus a fixed cost contract?

Internalize your learning experience by preparing to discuss the following.

If you were a contractor, which type of contract would you prefer most and which would you like least? Explain your choices. Your explanation should demonstrate that you are familiar with the definitions of the contracts you chose and at least one similar type of contract.

\section{References}

VSE Corporation, "VSE Awarded \$249 Million Cost-Plus Award Fee Contract Option Modification by Navy,” Business Wire, August 24, 2009, http://www.businesswire.com/portal/site/home/permalink/?ndmViewId=news_view\&newsId=20090824006017\&newsLang=en (accessed October 5, 2009). 


\subsection{Procurement Process}

\section{Learning Objectives}

1. Describe the components of the procurement plan.

2. Identify the decisions made when selecting the type of contract.

3. Describe how bidders are qualified, solicited, and chosen.

4. Identify the methods used to manage the contracts.

The project procurement cycle reflects the procurement activities from the decision to purchase the material or service through the payment of the bills and closing of procurement contracts.

\section{Procurement Plan}

After the decision has been made to purchase goods or outsource services, the procurement team develops a plan that includes the following:

- Selecting the appropriate relationships and contract approaches for each type of purchased goods or outsourced service

- Preparing RFQs and RFPs and evaluating partnership opportunities

- Evaluating RFQs, RFPs, and partnerships

- Awarding and signing contracts

- Managing quality, timely performance, and contract changes

- Closing contracts

Depending on the complexity level of the project, each of these steps can take either hours or sometimes weeks of work to complete. Each of these steps is also included in the project master schedule. The time involved in the procurement cycle can influence the scheduling of critical activities, including the decision to self-perform the work or contract the work to others. The equipment and materials deliveries and completion of contracted work dates are placed on the project schedule and any procurement activities that create a project delay or fall on the project critical path may require special attention. 


\section{Selecting the Contract Approach}

The technical teams typically develop a description of the work that will be outsourced. From this information, the project management team answers the following questions:

- Is the required work or materials a commodity, customized product or service, or unique skill or relationship?

- What type of relationship is needed: supplier, vendor, or partnership?

- How should the supplier, vendor, or potential partner be approached: RFQ, RFP, or personal contact?

- How well known is the scope of work?

- What are the risks and which party should assume which types of risk?

- Does the procurement of the service or goods affect activities on the project schedule's critical path and how much float is there on those activities?

- How important is it to be sure of the cost in advance?

The procurement team uses the answers to the first three questions listed above to determine the approach to obtaining the goods or services and the remaining questions to determine what type of contract is most appropriate.

A key factor in selecting the contract approach is determining which party will take the most risk. The team determines the level of risk that will be managed by the project and what risks will be transferred to the contractor. Typically, the project management team wants to manage the project risk, but in some cases, contractors have more expertise or control that enable them to be better positioned to manage the risk associated with the contracted work.

\section{Weather Risk on Concrete Contract}

On a construction contract, the concrete supplier will not be penalized for schedule delays caused by weather because the project team has more options for making up weather delays than the concrete supplier. The risk associated with weather remains with the project and not transferred through the contract.

The contractor knows more about the risks associated with obtaining the raw materials used to make concrete and assumes the risk of delays caused by shortages of those materials.

\section{Soliciting Bids}

A solicitation is the process of requesting a price and supporting information from bidders. The solici- 
tation usually takes the form of either a request for quote (RFQ) or a request for proposal (RFP). Partnerships are pursued and established on a case-by-case basis by senior management.

\section{Qualifying Bidders}

Potential bidders are people or organizations capable of providing the materials or performing the work required for the project. On smaller, less complex projects, the parent company typically has a list of suppliers and vendors that have successfully provided goods and services in the past, and the project has access to the performance record of companies on that list. On unique projects, where no suppliers lists exist, the project team develops a list of potential suppliers and then qualifies them to become eligible to bid on project work. Eligible bidders are placed on the bidders list and provided with a schedule of when work on the project will be bid.

The eligibility of a supplier is determined by the ability to perform the work in a way that meets project requirements and demonstrates financial stability. Ability to perform the work includes the ability to meet quality specifications and meet the project schedule. During times when economic activity is high in a region, many suppliers become busy and stretch their resources. The project team investigates the potential suppliers to assure they have the capacity and the track record of meeting deadlines before they are included on the bidder's list.

The potential supplier must also be financially stable to be included on the bidders list. A credit check or a financial report from Dun and Bradstreet $(\mathbf{D \& B})$ — a provider of financial information about individual companies — will provide the project with information about the potential bidder's financial status. D\&B services include the following:

- D\&B proprietary rankings and predictive creditworthiness scores

- Public filings, including suits, liens, judgments, and UCC filings—standardized financial disclosure documents that conform to the uniform commercial code

- Comprehensive payment history, including D\&B’s Paydex Scores

- Company financial statements and history

\section{Request for Quote}

A request for quote focuses on price. The type of materials or service is well defined and can be obtained from several sources. The bidder that can meet the project quality and schedule requirements usually wins the contract by quoting the lowest price. 


\section{Request for Proposal}

A request for a proposal accounts for price but focuses on meeting the project quality or schedule requirements. The process of developing a proposal in response to an RFP can be very expensive for the bidder, and the project team should not issue an RFP to a company that is not eligible to win the bid.

\section{Evaluating Bids}

Evaluation of bids in response to RFQs for commodity items and services is heavily graded for price. In most cases, the lowest total price will win the contract. The total price will include the costs of the goods or services, any shipping or delivery costs, the value of any warranties, and any additional service that adds value to the project.

The evaluation of bids based on RFPs is more complex. The evaluation of proposals includes the price and also an evaluation of the technical approach chosen by the bidder. The project team evaluating the proposal must include people with the expertise to understand the technical aspects of the various proposal options and the value of each proposal to the project. On more complex projects, the administrative part of the proposal is evaluated and scored by one team, and the technical aspect of the proposal is evaluated by another team. The project team combines the two scores to determine the best proposal for the project.

\section{Awarding the Contract}

After the project team has selected the bidder that provides the best value to the project, a project representative validates all conditions of the bid and the contract with the potential contractor. Less complex awards, like contracts for building materials, require a reading and signing of the contract to assure the building materials supplier understands the contract terms and requirements of the project schedule. More complex projects require a detailed discussion of the goals, the potential barriers to accomplishing those goals, the project schedule and critical dates for the contract to make, and the processes for resolving conflicts and improving work processes.

\section{Planning Session Follows Contract Award}

On a design and construction project to build a major industrial plant in the Chicago area, the project invited two critical partners to a three-day planning session after the project contracts were awarded.

The project manager began the session by stating that the project leadership intended to create an environment that enabled each of the partners to exceed profit expectations on the project and that the only way to accomplish this goal was through a mutually supportive team where everyone contributed to improve project performance and everyone benefited from better performance. The session then focused on developing ways to 
resolve problems and increase performance. Although this may appear to be a simple process of focusing contractors on project success, the process took several days of lengthy discussion and conflict resolution. The effort invested in developing alignment between the project team and contractors can significantly improve project performance.

\section{Managing the Contracts}

The contract type determines the level of effort and the skills needed to manage the contract. The manager of supplier contracts develops detailed specifications and assures compliance to these specifications. The manager of vendor contracts assures the contractors that bid the work have the skills and capacity to accomplish the work according to the project schedule and tracks the vendor's performance against the project needs, supplying support and direction when needed. The manager of partnering arrangements develops alignment around common goals and work processes. Each of these approaches requires different skills and various degrees of effort.

Items that take a long time to acquire-long lead items-receive early attention by the project leadership. Examples of long lead items are equipment that is designed and built specifically for the project, curriculum that is created for training a new workforce, and a customized bioreactor for a biotech project. These items might require weeks, months, and sometimes years to develop and deliver to the project site. Long lead items that are procured through the normal procurement cycle may cause delays in the project, and the project team identifies these items early to begin the procurement activities as soon as possible.

After the contract is awarded, the project team tracks the performance of the contractor against performance criteria in the contract and his contribution to the performance of the project. Typically, the contractors deliver the product or service that meets the quality expectations and supports the project schedule. Typically, there are also one or two contractors that do not perform to project expectations. Some project managers will then pull out the contract and attempt to persuade the contractor to improve performance or be penalized. Other project managers will explore with the contractor creative ways to improve performance and meet project requirements. The contract management allows for both approaches to deal with nonperforming contractors and the project team must assess what method is most likely to work in each situation.

\section{Building Support with Vendor on Chemical Plant Project}

Eastman Chemical was building a new plant at their Kingsport, Tennessee location when a critical vendor began falling behind schedule. The project team analyzed the situation and determined the vendor had taken on more work than it was capable of completing by the project's required due dates. This was an important vendor to the project and any delay in delivery from the vendor meant a delay in the completion of the project.

The project manager and Eastman executives flew to the vendor's plant in New Jersey and brought a large bar graph of the project schedule. The discussion focused on the critical project dates and the importance of 
the equipment delivery dates. Eastman offered technical support to the team and resources from the project to expedite the delivery. During lunch, Eastman executives and managers from the project walked with the plant manager around the plant floor, talking with the skilled labor working on the equipment. Eastman managers left Eastman hats and other small gifts as tokens of appreciation for their effort in supporting the Eastman project.

The effort by the Eastman project team to improve the vendor's schedule performance was successful. The vendor was able to make critical dates and the project completed on time.

Managing contractor performance on a project is as important to the overall project outcomes as the work performed by the project team.

\section{Logistics and Expediting}

Equipment and materials that are purchased for use on the project must be transported, inventoried, warehoused, and often secured. This area of expertise is called logistics. The logistics for the project can be managed by the project team or can be included in the RFP or RFQ. On international projects, materials may be imported, and the procurement team manages the customs process. On smaller projects, the logistical function is often provided by the parent company. On larger projects, these activities are typically contracted to companies that specialize in logistical services. On larger, more complex projects, that procurement team will include logistical expertise.

The project work often depends on materials procured for the project. The delivery of these materials influences the scheduling of the project, and often some materials are needed earlier than normal procurement practices would deliver. On long lead items, the project schedule is included in the contracting plans and contractors must explain how they will support the project schedule.

On large, complex projects, critical items might be scheduled for delivery after they are needed on the project. The procurement team then explores ideas with the contractor to expedite — speed up - the manufacturing or transportation of the equipment or materials. The contract can often place a priority on the fabrication of the equipment and delivery of the equipment to meet the project schedule. The project logistics team can also explore ways of shortening the transportation time. For example, a project in Argentina flew some critical equipment from Sweden rather than transport the equipment by ship to save several weeks in transit. The logistics costs were higher, but the overall value to the project was greater.

\section{Key Takeaways}

- The procurement plan includes determining the category of materials or services, choosing the type of contractual relationship, soliciting bids, selecting bidders, managing the work, and closing the contracts. 
- The decisions made when selecting the type of contract are based on whether the materials can be provided by suppliers, vendors, or partners; how well defined the work is; how the risk will be shared; the importance of the task to the schedule; and the need for certainty of the cost.

- Companies that bid on contracts are evaluated on past performance and current financial status. RFQs and RFPs are sent to those companies. RFQs are evaluated on price and RFPs are evaluated on price and method.

- Long lead time items are identified and monitored. Items that are critical to the schedule or delayed are assigned to an expediter. The logistics of handling delivery, storage, and transportation are determined. Work and materials are inspected for quality.

\section{Exercises}

1. Materials that are widely available with standardized quality are which are provided by

2. The financial soundness of a vendor can be measured by the ratings provided by (company name).

3. If an item takes a long time to deliver or if it is an important item, an might be assigned to be sure it is delivered on time.

Internalize your learning experience by preparing to discuss the following.

Assume that you are managing a project to replace the heating and cooling system in an old building and you would like to consider alternatives that are more environmentally sustainable in addition to the typical systems. How would you go about it? Describe what type of relationship you think you need, what type of contract you would choose, and how you would identify and select a provider. 


\subsection{Project Closure}

\section{Learning Objectives}

1. Describe the procedures for closing out contracts.

2. Describe the elements and purpose of the postproject review process.

3. Identify the types of documents that should be archived.

4. Identify the objectives of the project closeout celebration.

Team members who were excited by the project in its early stages may find it difficult to maintain their focus to complete the project. They might already be looking forward to the next project. Bringing a project to an end requires a different management style that focuses on details as well as an analysis of the decisions that were made.

\section{Closeout Procurement Contracts}

The last stage of the project procurement cycle includes the payment of the bills and closing of procurement contracts.

\section{Contracts with Suppliers}

Suppliers provide commodities that should meet standards of quality. The project team must check the records of deliveries made and determine that they were acceptable quality. If any items were rejected for poor quality or not delivered, the final payment is adjusted accordingly.

\section{Punch Lists and Performance Tests}

If a vendor is providing a service or building something for the project, there are usually items that must be fixed or mistakes that must be corrected before the contract is complete. On a software project, performance tests are run on the software, usually by the people who will be using the software, and any performance expectations not met are noted. Sometimes the expectations were not captured in the project scope of work and sometimes the performance did not meet the expectations established in the scope. If 
the items were not in the scope of work and the owner wants the work done, then the owner typically issues a change order. If the expectations were in the scope of work, the contractor is still responsible for completing the work.

On a project to build a new house, the owner might go through the house looking for minor items not completed by the contractor. Before the contract is closed, any minor items that need to be repaired or completed are placed on a punch list, which is a list of all the items found by the owner that still remain to be done. The project team will then work on all of the items on the list, building a small schedule to complete the remaining work.

If the number of items on the punch list is too large or the amount of work is significant, the project team continues to work the project. Once the punch list becomes smaller, the project manager begins closing down the project, maintaining only enough staff and equipment to support the team that is working the punch list.

\section{Transfer to Customer or Sponsor}

If the product of the project is a building, software system, or something that must be operated and maintained by someone else, it must be turned over to the people who will be responsible for it after the project is complete. They might perform their own inspection to determine if the project team has met its goals for quality and that all elements of the project are complete. These performance tests are typically identified in the original project contract.

\section{Final Payments}

The final payment is usually more than a simple percentage of the work that remains to be completed. Completing the project might involve fixing the most difficult problems that are disproportionately expensive to solve, so the final payment should be large enough to motivate the vendor to give the project a high priority so that the project can be completed on time.

If the supplier has met all the contractual obligations, including fixing problems and making repairs as noted on a punch list, the project team signs off on the contract and submits it to the accounting department for final payment. The supplier is notified that the last payment is final and completes the contractual agreement between the supplier and the project.

\section{Overtime Needed to Complete Project and Earn Final Payment}

The building automation vendor devoted additional personnel and paid them overtime wages to troubleshoot the problems and get them resolved so the building could open on time. When the project team was satisfied, they approved the system and the final payment. 


\section{Postproject Evaluations}

Before the team is dissolved and begins to focus on the next project, a review is conducted to capture the lessons that can be learned from this project, often called a lessons learned meeting or document. The team explores what went well and captures the processes to understand why they went well. The team asks if the process is transferable to other projects. The team also explores what did not go well and what people learned from the experience. The process is not to find blame but to learn.

Quality management is a process of continuous improvement that includes learning from past projects and making changes to improve the next project. This process is documented as evidence that quality management practices are in use. Some organizations have formal processes for changing work processes and integrating the lessons learned from the project so other projects can benefit. Some organizations are less formal in the approach and expect individuals to learn from the experience and take the experience to their next project and share what they learned with others in a very informal way.

\section{Project Profile Evaluation}

One of the first activities was to create a project profile to determine where the challenges were most likely to occur. If the Darnall-Preston Complexity Index (DPCI) was used, each of the complexity evaluations is reviewed and compared to actual events that occurred during the project. The team explores the changes in the complexity level during the life of the project and how the team managed the complexity during the life of the project. Learning from this exercise develops expertise that is useful in making the next project profile. The DPCI rating is adjusted, if necessary, for reference purposes on future projects.

\section{Trust and Alignment Effectiveness}

The project leadership reviews the effect of trust—or lack of trust—on the project and the effectiveness of alignment meetings at building trust. The team determines which problems might have been foreseen and mitigated and which ones could not have been reasonably predicted. What were the cues that were missed by the team that indicated a problem was emerging? What could the team have done to better predict and prevent trust issues?

\section{Schedule Management}

The original schedule of activities and the network diagram are compared to the actual schedule of events. Events that caused changes to the schedule are reviewed to see how the use of contingency reserves and float mitigated the disruption caused by those events. The original estimates of contingency time are reviewed to determine if they were adequate and the estimates of duration and float were accu- 
rate. These activities are necessary for the project team to develop expertise in estimating schedule elements in future projects - they are not used to place blame.

\section{Budget Management}

A review of budget estimates for the cost of work scheduled is compared to the actual costs. If the estimates are frequently different from the actual costs, the choice of estimating method is reviewed.

\section{Risk Mitigation}

After the project is finished, the estimates of risk can be reviewed and compared to the events that actually took place. Did events take place on the project that were unforeseen? What cues existed that may have allowed the team to predict these events? Was the project contingency sufficient to cover unforeseen risks? Even if nothing went wrong on this project, it is not proof that risk mitigation was a waste of money, but it is useful to compare the cost of avoiding risk versus the cost of unexpected events to understand how much it cost to avoid risk.

\section{Procurement Contracts}

The performance of suppliers and vendors is reviewed to determine if they should still be included in the list of qualified suppliers or vendors. The choice of contract for each is reviewed to determine if the decision to share risk was justified and if the choice of incentives worked.

\section{Customer Satisfaction}

Relationships with the client are reviewed and decisions about including the client in project decisions and alignment meetings are discussed. The client is given the opportunity to express satisfaction and identify areas in which to improve. Often a senior manager from the organization interviews the client to develop feedback on the project team performance.

\section{Reports}

The results of the postproject evaluations are summarized in reports for external and internal use. 


\section{Stakeholders}

A general report that provides an overview of the project is created to provide stakeholders with a summary of the project. The report includes the original goals and objectives and statements that show how the project met those goals and objectives. Performance on the schedule and budget are summarized and an assessment of client satisfaction is provided. A version of this report can be provided to the client as a stakeholder and as another means for deriving feedback.

\section{Senior Management}

The report to senior management contains all the information provided to the stakeholders in a short executive summary. The report identifies practices and processes that could be improved or lessons that were learned that could be useful on future projects.

\section{Document Archival}

The documents associated with the project must be stored in a safe location where they can be retrieved for future reference. Signed contracts or other documents that might be used in tax reviews or lawsuits must be stored. Organizations will have legal document storage and retrieval policies that apply to project documents and must be followed. Some project documents can be stored electronically.

Care should be taken to store documents in a form that can be recovered easily. If the documents are stored electronically, standard naming conventions should be used so documents can be sorted and grouped by name. If documents are stored in paper form, the expiration date of the documents should be determined so they can be destroyed at some point in the future. The following are documents that are typically archived:

- Charter documents

- Scope statement

- Original budget

- Change documents

- DPCI ratings

- Manager's summary-lessons learned

- Final DPCI rating 


\section{Project Celebration}

A symbolic ending of a project can be a final celebration to mark the end of the project and perhaps the dissolution of the team. The end of a major project is often a time to reflect. Project team members and stakeholders have typically invested a great deal of time and emotional energy into the success of the project. Because of this investment and because of the close relationships that develop during a project, project closure in often sad. Project managers stay tuned into the project team environment and use celebrations and team recognition to ameliorate the effects of project closure.

This is an opportunity to improve client satisfaction and team member satisfaction. Awards or recognition plaques might be given out to individuals who made an outstanding contribution to the project. Celebrating and reviewing the challenges and successes of the project creates a positive memory of the project and reinforces the learning that can be transferred to future projects. Groups or teams can be recognized and instances where trust between team members made a positive difference can be rewarded.

The client can be praised for contributions during planning and execution of the project.

\section{Key Takeaways}

- To close contracts, systems are tested, materials are inspected, and punch lists of work to be completed are made.

- The purpose of the postproject review is to examine decisions that were made with partial knowledge with the way the project actually developed to learn from the experience and to improve future decisions. It is also used to identify processes that can be improved.

- Original project documents, such as the charter, scope statement, and budget, are stored. Documents developed during the project, such as change agreements, are stored. Postproject reviews, including a summary of lessons learned and a final project profile description—DPCI rating — are saved.

- At the project closeout celebration, positive behavior is awarded for individuals, and groups and the client or sponsor is invited to speak to enforce a sense of satisfaction.

\section{Exercises}

1. Why is a postproject review valuable to future projects?

2. Which documents should be archived?

3. Why should the project have a closeout celebration?

Internalize your learning experience by preparing to discuss the following.

Consider why it would be important to withhold a significant amount for the final payment. If you are familiar 
390 [Author removed at request of original publisher]

with a situation where a contractor had to spend extra to fix or finish items to complete a job, describe why they might need a financial incentive to get those jobs done. 


\subsection{Exercises}

Exercises at the end of the chapter are designed to strengthen your understanding and retention of the information recently acquired in the chapter.

\section{Essay Questions}

Write several paragraphs to provide more in-depth analysis and consideration when answering the following questions.

1. Describe an activity that would require an RFP and why it should be handled with an RFP instead of a RFQ or a partnership.

2. Describe a procurement task. Rate it for the amount of uncertainty of the scope, cost, schedule, and risk. Choose a contract type and explain why that contract type would be an appropriate choice for that set of uncertainties.

3. Describe requirements of a particular quality method, and describe how a postproject review would meet that standard.

\section{Discussion}

The exercises in this section are designed to promote exchange of information among students in the classroom or in an online discussion. The exercises are more open ended, which means that what you find might be completely different from what your classmates find, and you can all benefit by sharing what you have learned.

1. Research the document retention standards at an organization of your choice that apply to normal business records. Describe how those standards would or would not meet the needs of project document archival. Be prepared to compare the standards of the organization you described with those described by your classmates.

2. Describe a situation with which you are familiar where conflicts arose over completion of punch list items or fixing items to complete a project. 


\subsection{Web Exercises}

\section{Learning Objectives}

1. Locate commodities in online catalogs.

2. Use an RFQ template obtained online.

3. Use an RFP template obtained online.

4. Describe and interpret $\mathrm{D} \& \mathrm{~B}$ financial reports using definitions from the $\mathrm{D} \& \mathrm{~B}$ website.

\section{Locate Commodities in Online Catalogs}

Commodities can be purchased from online catalogs if the buyer knows exactly what is needed for the task.

\section{Learn More about Using an Online Catalog to Buy Commodities}

Complete the exercise by following these instructions:

1. Open a blank document in a word processing program and then save the document as Ch12CommoditiesStudentName.doc. Leave the document open.

2. Use your web browser and go to http://www.eastmfg.com. The catalog is provided in PDF format. This format is not easily changed by the viewer.

3. Click the Parts menu and then click the link to the Hardware Catalog shown in Figure 12.11 "Parts Catalog”.

Figure 12.11 Parts Catalog

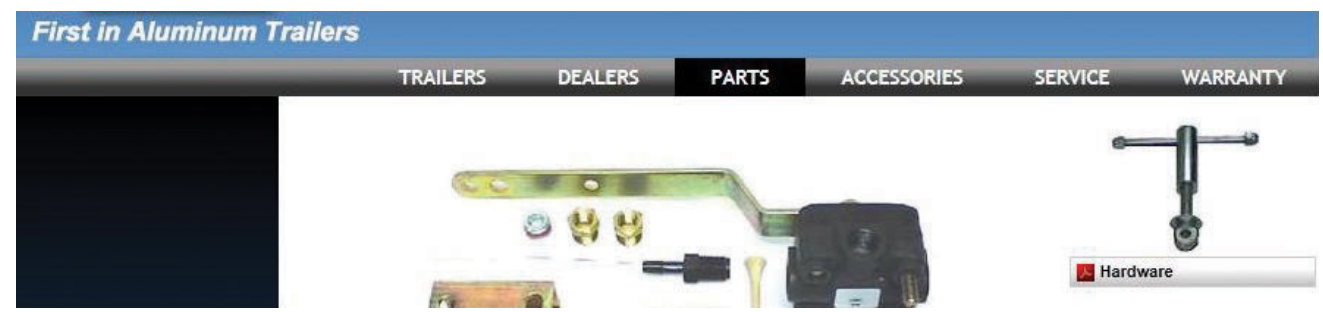


Source: Courtesy of http://www.eastmfg.com.

4. In the Search box, type Lynch Pin and then press Enter. Refer to Figure 12.12 "Searching for a Part”.

Figure 12.12 Searching for a Part

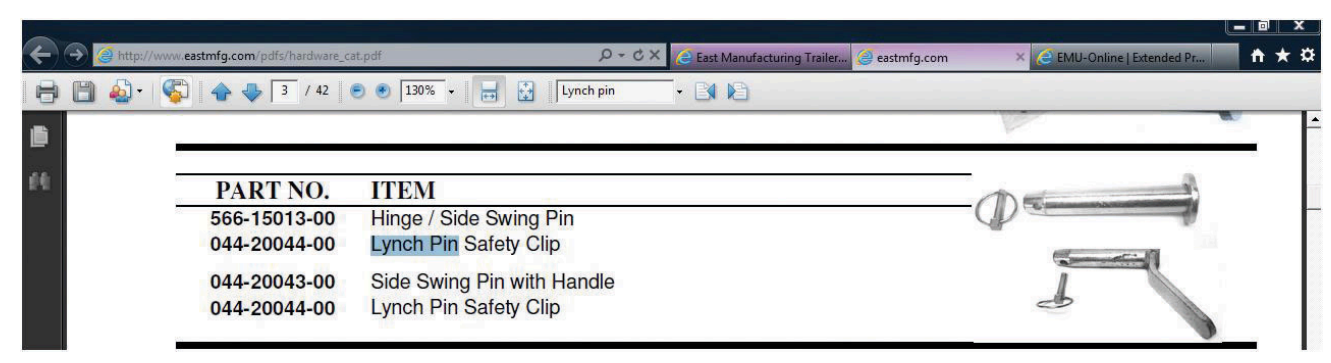

Source: Courtesy of http://www.eastmfg.com.

5. Notice the following characteristics:

- The price is not listed. Separate price lists are often maintained for different classes of customer, and discounts are usually available for large orders.

- There is a unique catalog number for each type of anchor. This number is used for placing orders.

- The part's capacity, size, and weight are provided.

- Some labels require knowledge of the product to understand; for example, Side Swing Pin.

6. Capture this screen and paste it into Ch12CommoditiesStudentName.doc.

\section{Analysis}

1. At the bottom of Ch12CommoditiesStudentName.doc, write between one hundred and two hundred words to describe how to navigate and interpret an online catalog that is provided in PDF format.

2. Review your work and use the following rubric to determine its adequacy:

\begin{tabular}{|l|l|l|l|}
\hline Element & Best & Adequate & Poor \\
\hline File name & Ch12CommoditiesStudentName.doc & $\begin{array}{l}\text {.docx } \\
\text { version }\end{array}$ & $\begin{array}{l}\text { Student name not } \\
\text { included }\end{array}$ \\
\hline $\begin{array}{l}\text { Locate } \\
\text { commodities in } \\
\text { online catalogs }\end{array}$ & $\begin{array}{l}\text { Two screen captures; a description of how to } \\
\text { navigate an online catalog in PDF format }\end{array}$ & $\begin{array}{l}\text { Same as } \\
\text { Best }\end{array}$ & $\begin{array}{l}\text { Missing screens; } \\
\text { inaccurate } \\
\text { description }\end{array}$ \\
\hline
\end{tabular}


3. Save the file and submit it as directed by the instructor.

\section{Use an Online RFQ Template}

Commodities can be services that are specifically defined and common enough to have standardized descriptions and quality. In this exercise, you download a template for writing an RFQ from the state of Massachusetts for requesting quotes on testing software for accessibility compliance.

\section{Locate and Download an RFQ Template}

Complete the exercise by following these instructions:

1. Open a blank document in a word processing program and then save the document as Ch12RFQStudentName.doc Leave the document open.

2. Use your web browser to type http://www.mass.gov/dep/recycle/reduce/rmrfq.pdf.

3. Scroll to the Preface page, as shown in Figure 12.13 "Description of RFQ Template".

4. Add this web address to your browser's bookmarks or favorites list in the Project Management folder.

5. Capture a screen that shows the address in the Project Management folder in the favorites or bookmarks and then paste it into Ch12RFQStudentName.doc.

6. Scroll through appendices at the end of the document. Capture a screen from one of these appendices pages and then paste it into Ch12RFQStudentName.doc.

\section{Analysis}

1. At the bottom of Ch12RFQStudentName.doc, write between one hundred and two hundred words to describe the advantages of using a template. Make specific reference to at least two sections of the RFQ template used in the first part of this exercise, including page references.

2. Review your work and use the following rubric to determine its adequacy: 


\begin{tabular}{|l|l|l|l|}
\hline Element & Best & Adequate & \multicolumn{1}{|l|}{ Poor } \\
\hline $\begin{array}{l}\text { File } \\
\text { name }\end{array}$ & Ch12RFQStudentName.doc & $\begin{array}{l}\text { Student } \\
\text { name not } \\
\text { included }\end{array}$ \\
\hline $\begin{array}{l}\text { Use an } \\
\text { RFQ } \\
\text { template } \\
\text { obtained } \\
\text { online }\end{array}$ & $\begin{array}{l}\text { A screen capture that shows a link to the template in the } \\
\text { Project Management folder in the bookmarks or } \\
\text { favorites; screen capture of one of the first eight pages; } \\
\text { reflective essay between one hundred and two hundred } \\
\text { words on use of a RFQ template }\end{array}$ & $\begin{array}{l}\text { Project } \\
\text { Management } \\
\text { folder does not } \\
\text { show links } \\
\text { from previous } \\
\text { exercises }\end{array}$ & $\begin{array}{l}\text { Missing } \\
\text { screens; only } \\
\text { one feature } \\
\text { discussed; } \\
\text { no page } \\
\text { references }\end{array}$ \\
\hline
\end{tabular}

3. Save the file and submit it as directed by the instructor.

\section{Use an Online RFP Template}

If you need to rely on the vendor's experience and expertise to solve a problem, you can request companies to submit proposals on how they would go about it. The state of Maryland provides a template for RFPs.

\section{Locate and Download an RFP Template}

Complete the exercise by following these instructions:

1. Open a blank document in a word processing program and then save the document as Ch12RFPStudentName.doc. Leave the document open.

2. In a browser, type http://energy.maryland.gov/documents/ProcurementConsultingServicesRFPFINAL.pdf. An RFP template used by the Maryland Energy Administration displays as a PDF file, as shown in Figure 12.14 "Source of RFQ Template".

Figure 12.14 Source of RFQ Template 


\section{Request for Proposals}

\section{Procurement Consulting Services for \\ The Maryland Energy Administration}

\section{PROJECT NO. DEXR1400001}

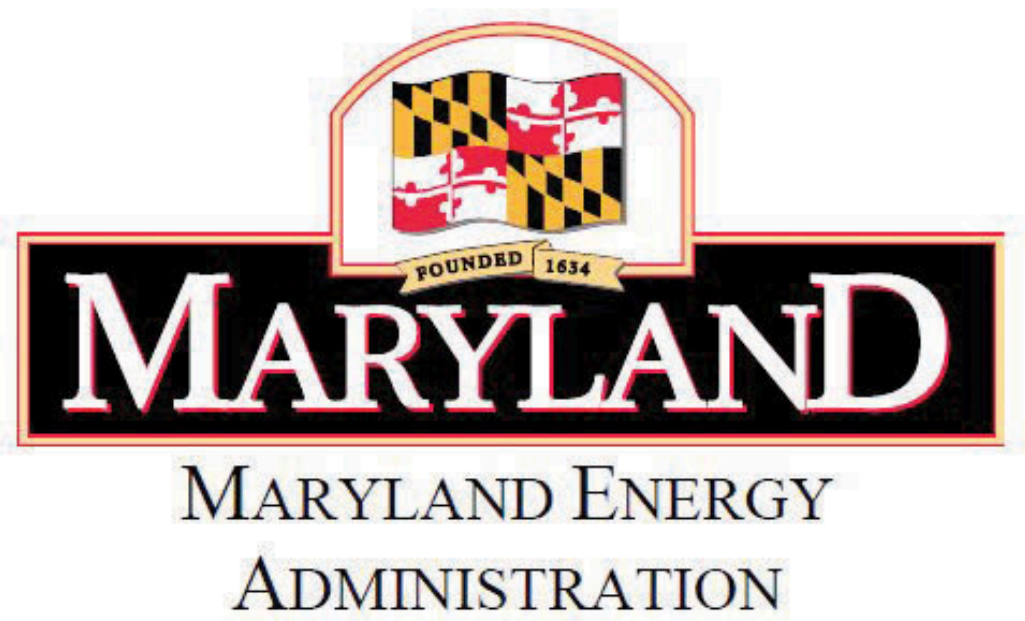

Source: Courtesy of Maryland Energy Administration.

3. Add this web address to your browser's bookmarks or favorites in the Project Management folder.

4. Capture a screen that shows the address in the Project Management folder in the favorites or bookmarks and then paste it into Ch12RFPStudentName.doc.

5. Scroll to section 1.7 Pre-Proposal Conference. Observe that many organizations give contractors an opportunity to meet and ask questions before they prepare a proposal.

6. Scroll back to page ii, Project No. Observe that the state asks the contractors who decide not to bid to explain why.

7. Capture the screen that shows the list of reasons why the contractor chose not to bid, and then paste it into Ch12RFPStudentName.doc.

8. Explore the other sections of this RFP template and choose one that is new to you or that you find most interesting.

\section{Analysis}

1. At the bottom of Ch12RFPStudentName.doc, write between one hundred and two hundred 
words to describe what you learned from each of the three sections: the pre-proposal conference, the refusal to bid, and the third section of your choice. Make specific reference to each of the three sections of the RFP template used in Part I including page references.

2. Review your work and use the following rubric to determine its adequacy:

\begin{tabular}{|l|l|l|l|}
\hline Element & Best & Adequate & Poor \\
\hline $\begin{array}{l}\text { File } \\
\text { name }\end{array}$ & Ch12RFPStudentName.doc & $\begin{array}{l}\text { docx } \\
\text { version }\end{array}$ & $\begin{array}{l}\text { Student } \\
\text { name not } \\
\text { included }\end{array}$ \\
\hline $\begin{array}{l}\text { Use an } \\
\text { RFP } \\
\text { template } \\
\text { obtained } \\
\text { online }\end{array}$ & $\begin{array}{l}\text { A screen capture that shows a link to the template in the } \\
\text { Project Management folder in the bookmarks or favorites; } \\
\text { screen capture of the preproposal conference; reflective } \\
\text { essay between one hundred and two hundred words on the } \\
\text { conference, refusal, and one other section with specific } \\
\text { page references }\end{array}$ & $\begin{array}{l}\text { Project } \\
\text { Management } \\
\text { folder does } \\
\text { not show } \\
\text { links from } \\
\text { previous } \\
\text { exercises }\end{array}$ & $\begin{array}{l}\text { Missing } \\
\text { screens; four } \\
\text { sections not } \\
\text { discussed } \\
\text { individually; } \\
\text { no page } \\
\text { references }\end{array}$ \\
\hline
\end{tabular}

3. Save the file and submit it as directed by the instructor.

\section{Interpret D\&B Financial Ratings}

The relationship between the project and its suppliers and vendors involves trust that both parties will keep their financial commitments. This trust may be based on past experience, but it can also be based on a third party's rating of the financial health of the organization and its past behavior. For example, organizations with better credit ratings can negotiate lower prices with suppliers and vendors because there is less risk. One of the most popular rating agencies is D\&B. In this exercise, you locate and review the types of financial reports that are available from D\&B.

\section{Locate and Review the Financial Reports Available from D\&B}

Complete the exercise by following these instructions:

1. Open a blank document in a word processing program and then save the document as Ch12DBStudentName.doc. Leave the document open.

2. In a browser, type http://www.dnb.com/us/customer_service/scores.html. The D\&B web page displays, as shown in Figure 12.15 "D\&B Ratings".

3. Add this web address to your browser's bookmarks or favorites in the Project Management folder.

4. Capture a screen that shows the address in the Project Management folder in the favorites or bookmarks and then paste it into Ch12DBStudentName.doc. 
5. Scroll down the page to the D\&B Rating Interpretation table. The rating in the first column indicates the worth of the company, and the numbers 1 through 4 indicate its general credit worthiness, where 1 is high and 4 is low. For example, a rating of 1A-4 indicates a company with a worth between $\$ 500,000$ and $\$ 749,999$ with a low credit worthiness rating.

6. Capture this screen and paste it into Ch12DBStudentName.doc.

7. Scroll down to the US Employee Range Designation table. Notice this rating indicates the number of employees, where ER1 is more than 1,000.

8. Capture this screen and paste it into Ch12DBStudentName.doc.

9. Scroll down to the D\&B PAYDEX Value table. Observe that the PAYDEX score indicates when the company pays its debts. Notice that paying off debts sooner than is contractually required earns a PAYDEX score above 80.

10. Capture this screen and paste it into Ch12DBStudentName.doc.

11. Scroll down to the Financial Stress Score table. Notice that companies with a score of 1 are estimated to have a probability of failure of .03 percent (3 per 10,000) of failing in the next twelve months, while a rating of 5 means a probability of failure of 4.7 percent (almost 1 in 20).

12. Capture this screen and paste it into Ch12DBStudentName.doc.

\section{Analysis}

1. At the bottom of Ch12DBStudentName.doc, write between one hundred and two hundred words to describe the function of these four tables.

2. Explain what it would mean if a company had the following D\&B ratings:

- BB-1

- ER3

- PAYDEX 80

- Financial stress: 4

3. Review your work and use the following rubric to determine its adequacy: 


\begin{tabular}{|l|l|l|l|}
\hline Element & Best & Adequate & Poor \\
\hline File name & Ch12DBStudentName.doc & $\begin{array}{l}\text {.docx } \\
\text { version }\end{array}$ & $\begin{array}{l}\text { Student name } \\
\text { not included }\end{array}$ \\
\hline $\begin{array}{l}\text { Describe } \\
\text { and interpret } \\
\begin{array}{l}\text { D\&B } \\
\text { financial } \\
\text { reports } \\
\text { using } \\
\text { definitions } \\
\text { online }\end{array}\end{array}$ & $\begin{array}{l}\text { A screen capture that shows a link to the template in } \\
\text { the Project Management folder in the bookmarks or } \\
\text { favorites; four screens that show the four tables; } \\
\text { reflective essay between one hundred and two hundred } \\
\text { words on use of D\&B ratings; interpretation of } \\
\text { example scores }\end{array}$ & $\begin{array}{l}\text { Same as } \\
\text { Best }\end{array}$ & $\begin{array}{l}\text { Missing } \\
\text { screens; } \\
\text { incorrect } \\
\text { interpretation } \\
\text { of table; } \\
\text { incorrect } \\
\text { interpretation } \\
\text { of ratings }\end{array}$ \\
\hline
\end{tabular}

4. Save the file and submit it as directed by the instructor. 


\section{Project Management from Simple to Complex}

Have you created any supplementary materials for use with Project Management from Simple to Complex such as test items, a question bank, or presentation slides? If so, please consider sharing your materials through this online textbook!

The University of Minnesota Libraries have begun to share supplementary materials through our online textbooks, using Google Drive to provide access to faculty and staff that may need to use those materials. Please see Understanding Media and Culture as an example:

https://umn.pressbooks.network/mediaandculture/

If you have created any supplementary material for Project Management from Simple to Complex, please contact the University of Minnesota Libraries eLearning Support Initiative at learnlib@umn.edu for more information on how you can share your materials and make them available to faculty and students worldwide. 